\title{
Local health policy development processes : health promotion and network perspectives on local health policy-making in the Netherlands
}

Citation for published version (APA):

Hoeijmakers, M. J. A. (2005). Local health policy development processes : health promotion and network perspectives on local health policy-making in the Netherlands. [Doctoral Thesis, Maastricht University]. Universiteit Maastricht. https://doi.org/10.26481/dis.20050526mh

Document status and date:

Published: 01/01/2005

DOI:

10.26481/dis.20050526mh

Document Version:

Publisher's PDF, also known as Version of record

Please check the document version of this publication:

- A submitted manuscript is the version of the article upon submission and before peer-review. There can be important differences between the submitted version and the official published version of record.

People interested in the research are advised to contact the author for the final version of the publication, or visit the DOI to the publisher's website.

- The final author version and the galley proof are versions of the publication after peer review.

- The final published version features the final layout of the paper including the volume, issue and page numbers.

Link to publication

\footnotetext{
General rights rights.

- You may freely distribute the URL identifying the publication in the public portal. please follow below link for the End User Agreement:

www.umlib.nl/taverne-license

Take down policy

If you believe that this document breaches copyright please contact us at:

repository@maastrichtuniversity.nl

providing details and we will investigate your claim.
}

Copyright and moral rights for the publications made accessible in the public portal are retained by the authors and/or other copyright owners and it is a condition of accessing publications that users recognise and abide by the legal requirements associated with these

- Users may download and print one copy of any publication from the public portal for the purpose of private study or research.

- You may not further distribute the material or use it for any profit-making activity or commercial gain

If the publication is distributed under the terms of Article $25 f a$ of the Dutch Copyright Act, indicated by the "Taverne" license above, 


\title{
LOCAL HEALTH POLICY DEVELOPMENT PROCESSES
}

\author{
Health promotion and network perspectives on \\ local health policy-making in the Netherlands
}

\section{PROEFSCHRIFT}

ter verkrijging van de graad van doctor aan de Universiteit Maastricht,

op gezag van de Rector Magnificus, Prof. mr. G.P.M.F. Mols volgens het besluit van het College van Decanen,

in het openbaar te verdedigen op donderdag 26 mei 2005 om 16.00 uur

door

Marjan Hoeijmakers 


\section{Promotores:}

Prof. Dr. N.K. de Vries

Prof. Dr. E. De Leeuw (Deakin University, Melbourne, Australia)

Prof. Dr. P. Kenis (Universiteit van Tilburg)

\section{Beoordelingscommissie:}

Prof. Dr. J.A.M. Maarse (voorzitter)

Dr. P. van Assema

Prof. Dr. H.FL. Garretsen (Universiteit van Tilburg)

Prof. Dr. K. Horstman

Prof. Dr. G.J. Kok

\section{Colofon}

Cover design: D\&L graphics

Layout: D\&L graphics: John Derwall \& Eric Lemmens

www.dlgraphics.n!

Printed by: Ponsen \& Loojen bv

ISBN: $\quad 90-8590-001-8$

The study presented in this thesis was conducted at the Maastricht Care and Public Health Research Institute (CAPHRI) in the Faculty of Health Sciences of Maastricht University. Caphri Is part of the Netherlands School of Primary Care Research (CaRe), acknowledged in 1995 by the Royal Netherlands Academy of Art and Science (KNAW).

The study on local health policy development processes described in this thesis was financially supported by the Netherlands Organisation for Health Research and Development (ZON-MW, project number 98-4-52). 
I dedicate this thesis to my former colleagues and friends in Burkina Faso, Uganda and the Democratic Republic of the Congo, who are working to realise their dreams and ideas in far more difficult circumstances than I am. 
$\therefore \quad-\quad$ 


\section{TABLE OF CONTENTS}

List of abbreviations

List of tables and figures

PART I. SETTING THE STAGE TO INVESTIGATE LOCAL HEALTH

POLICY-MAKING: RESEARCH DESIGN AND THEORETICAL FRAMEWORK 1

Chapter 1. Introduction to the research project

$1.1 \quad$ Background

1.1.1 An overview of the history of public health

1.1.2 Public health and governance in the Netherlands

1.2 Why study local health policy-making?

1.2.1 Local health policy in Central Limburg, the Netherlands

1.2.2 Objective and research questions

1.3 Research design and methods

1.3.1 Multiple case study

1.3.2 Methods

1.3.3 Quailty of the research

1.4 Outline of the thesis

Chapter 2. Theoretical perspectives on the evaluation of health policy-making at the local level

2.1 Health promotion theory and practice

2.1.1 Introduction

2.1.2 Theory of health promotion

2.1.3 Health promotion practice

2.1.4 Conclusion

2.2 Health policy

2.2.1 Introduction

2.2.2 Defining policy and health policy

2.2.3 The policy-making process

2.2.4 "Theory of Streams"

2.3 Stakeholder and network analysis

2.3.1 Stakeholder analysis

2.3.2 Network analysis

2.4 An evaluative framework for local health policy-making

2.4.1 Criteria and indicators 
Chapter 9. The development of local health policy: discussion

9.1 Reflections on methodology and the quality of the research

9.1.1 Strengths and limitations of the inquiry into local health policy-making

9.2 Reflections on the findings on local health policy-making

9.2.1 Stakeholders' ideas and activities

9.2.2. Interrelatedness of stakeholders and policy networks

9.2.3 The presence of a policy entrepreneur

9.2.4 Effective components of the local health policy-making processes

9.2.5 The 'Theory of Streams'

Chapter 10. Policy processes: conclusions

10.1 Introduction

10.2 Involvement of the stakeholders in the policy process

10.3 The development of local health policy

10.3.1 Contributions of actors and factors to the development of health policy at the local level

10.3.2 Differences between municipalities in policy development and its outcome

10.3.3 Contributions by the community-based project Hartslag (Midden) Limburg to policy development and its integration in locall health policy

10.4 The use of new tools in health promotion research

10.5 Final comments

References

Summary

Samenvatting

Appendices

Dank je well 


\section{LIST OF ABBREVIATIONS}

\section{General}

CVD

CBS

GES

KPA

MHWS

NSPOH

OGZ

PHS

RCT

RIVM

RPHS

RVZ

STIVORO

VNG

WCPV

WHO

ZON-MW

\section{Cardiovascular Disease}

Statistics Netherlands

Health Impact Assessment

Diversified products provision model (KPA Model, Keuze Producten Aanbod)

Ministry of Heallth, Welfare and Sports

National Institute for Public and Occupational Health

Public Health Care

Public Health Service

Randomised Controlled Trial

National Institute for Public Health and the Environment

Regional Public Health Service

Council for Public Health and Health Care

National Organisation for Tobacco Control

Association of Netherlands Municipalities

Law on collective prevention in public health

World Health Organisation

Netherlands Organisation for Health Research and Development

\section{Names of organisations, groups and individuals relating to the four cases in the study}

ACS

$\mathrm{AE}$

$\mathrm{CAD}$

$\mathrm{CC}$

$\mathrm{CDC}$

$\mathrm{CE}$

GP

$\mathrm{H}$

$\mathrm{HC}$

$\mathrm{HCO}$

$\mathrm{HE}$

HN

$\mathrm{JH}$

J.I

$\mathrm{M}$

MHC

$\mathrm{NC}$

$\mathrm{NH}$

PC

PD

PHS

Pro

RIA

SC
Regional Administrative Body for the Allocation of Care Services (RIO]

Local Association for the elderly

CAD, Agency for care and treatment of addicts

District Care Coordinator for the elderly

Child Day Care

Council for the Elderly

General Practitioner

Hospital

Housing Corporation

Home Care Organisation (Thuiszorg)

Home for the Elderly

Association for home nursing (lokale kruisvereniging)

Day Care Centre for the elderly (Jozef Huis)

Local Health Initiatives

Municipal administration

Regional Centre for Mental Health Care

Neighbourhood Council

Nursing Home

Coordinating Platform for Health Care Consumers

Platform for the Disabled

(Regional) Public Health Service (GGD)

Proteion, umbrella organisation of homes for the elderly and nursing homes

Regional Institute for Outpatient Mental Health Care (Riagg)

Local Sports Council 
SMH Social Services for the Mentally Handicapped (SPD)

Sp Sports club

SW Social Work (AMW)

VWS Voluntary Welfare Services (Algemene Hulpdienst)

WS Welfare Service (Welzijnswerk)

YCS Youth Care Coordination Service (Bureau Jeugdzorg) 


\section{LIST OF TABLES and FIGURES}

Table 1.1 Methods and types of data in investigating local health policy

Table 2.1 Three paradigms for public health

Table 2.2 Evaluation criteria for local health policy

Table 4.1 Activities of the Hartslag (Midden) Limburg project.

Table 5.1 Advantages and disadvantages of having an external evaluator

Table 5.2 Advantages and disadvantages of evaluators as co-participants

Table 7.1 Response to 2001 stakeholder identification

Table 7.2 Classifications of respondents in 2001

Table 7.3 Interests of stakeholders

Table 7.4 Involvement in policy-making in the past

Table 7.5 Stakeholders" expectations about their influence

Table 7.6 Interdependency of stakeholders

Table 7.7 Network densities

Table 8.1 Health issues on the municipal agenda

Table 8.2 Response to 2003 stakeholder identification

Table 8.3 Classification of respondents in 2003

Figure 1.1 Development of a network of public health services in the Netherlands

Figure 1.2 Case study method and qualitative measures

Figure 2.1 Graphic Representation of the Ottawa Charter

Figure 2.2 Representation of the 'Theory of Streams'

Figure 2.3 Triangulation of methods

Figure 4.1 Continuum of health interwentions

Figure 4.2 An outcome model for health promotion

Figure 4.3 The position of the Hartslag project on the health interventions continuum

Figure 6.1 The development of the operationalisation of the inquiry

Figure 7.1 Networks at the policy level (2001)

Figure 8.1 Networks in Weert (2003)

Figure 8.2 Networks in Roermond (2003)

Figure 8.3 Networks in Roggel \& Neer (2003)

Figure 8.4 Networks in Roerdalen (2003) 


\section{SETTING THE STAGE TO INVESTIGATE LOCAL HEALTH POLICY-MAKING: RESEARCH DESIGN AND THEORETICAL FRAMEWORK}

Making health policy is not a new task for municipal authorities in the Netherlands; they have successfully intervened in public health for more than a century. Their autonomy in this and other domains has, however, gradually changed into an executive role, l.e., the implementation of national health policy. However, as of 1 January 2003, all municipal authorities have been obliged by the Minister of Health, Welfare and Sports to develop their own local health policy, covering a period of four years. The Dutch government has formulated a policy that requires municipal authorities to be explicitly responsible for the promotion of health. The Minister, as well as national and regional public health organisations, have stimulated and supported the municipal authorities to reinforce public health at the local level.

The Regional Public Health Service [RPHS) in the central part of Limburg (the most southern province of the Netherlands\}, the University of Maastricht and the Netherlands Organisation for Health Research and Development (ZON-MW) have joined forces to examine the initial establishment of local health policy. The region of Central Limburg covers the geographical area south of the town of Venlo and north of the town of Sittard. It is a rural area, which includes two towns, Weert and Roermond. The region is divided into fourteen municipalities, which are relatively small in size (2,500 to 15,000 inhabitants), except for three larger ones, with 32,000 to 50,000 inhabitants. The Regional Public Health Service, located in Roermond, is a public health organisation financed jointly by the fourteen municipal authorities. It provides public health care for the population of these municipalities $(234,074$ inhabitants). After a merger in 2002 with the RPHS in the northern part of the province, the area they catered for grew by a further thirteen municipalities (which meant an increase of 269,737 inhabitants).

Part $I$ of this thesis sets the stage for our study of local health policy. The first chapter introduces the research project. After giving an overview of the history of public health in general and in the Netherlands in particular, it presents the research questions and research design. The theoretical framework is presented in the second chapter, and elaborates on concepts from health promotion theory and policy science. The chapter also presents an evaluation instrument that combines the various theoretical concepts in a comprehensive, multilevel framework. Chapter 2 ends with the description of the research methods and the operationalisation of this inquiry. 


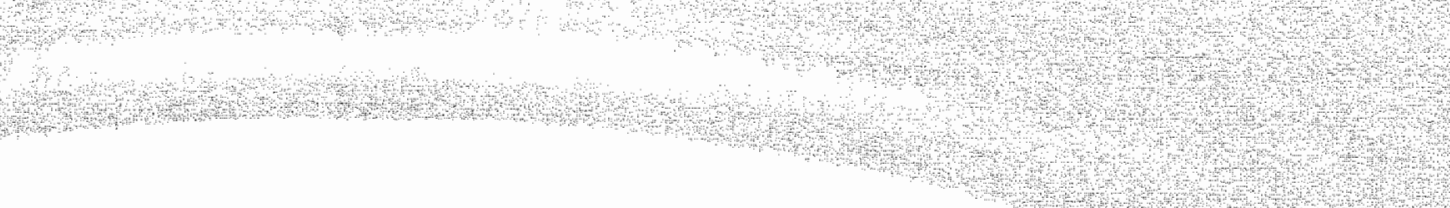

SPl

erte a

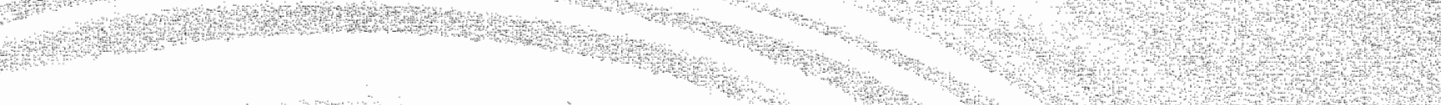

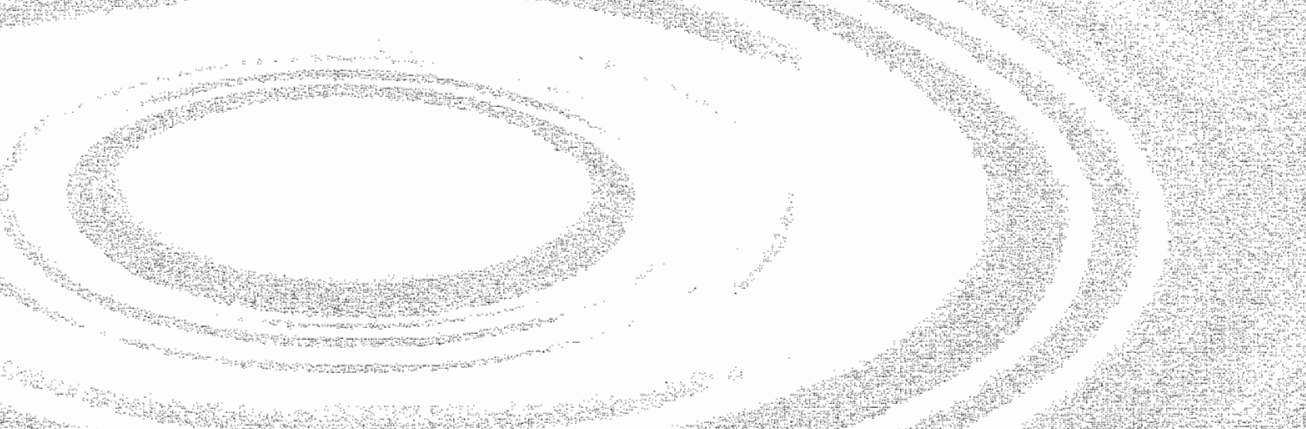

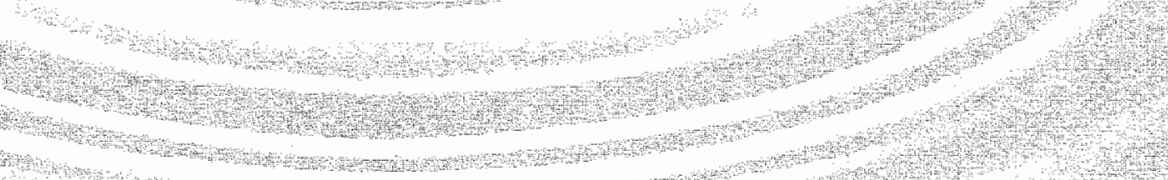

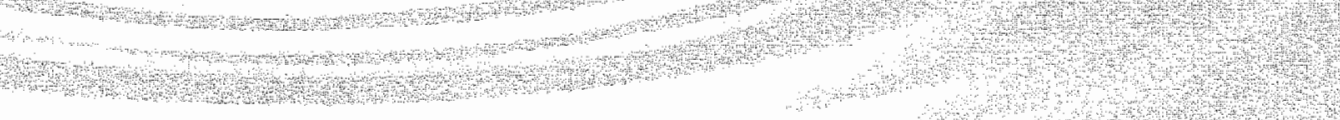

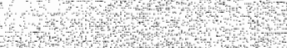

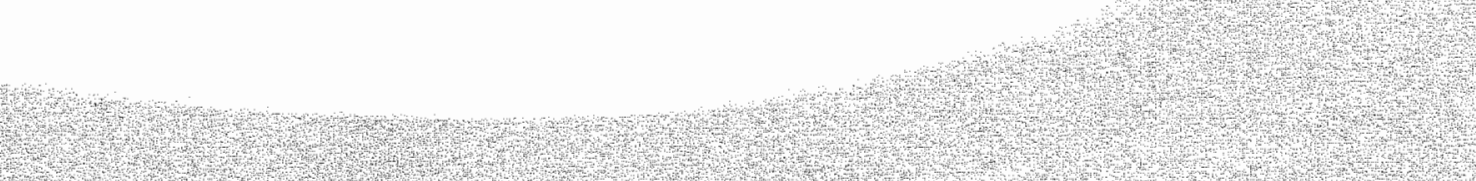

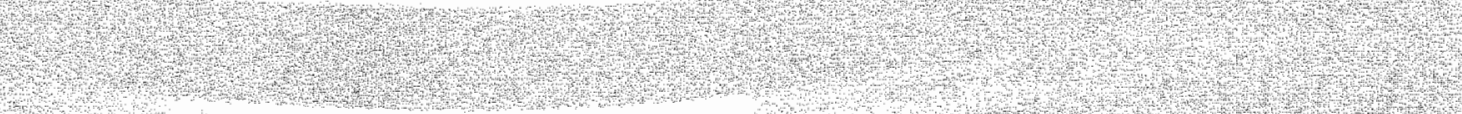




\section{INTRODUCTION TO THE RESEARCH PROJECT}

\subsection{BACKGROUND}

The focus of attention among physicians and other public health professionals has repeatedly shifted from the individual to the collective, while government policy has repeatedly changed its aims from decentralisation to centralisation and vice versa.

This first section describes the development of public health from the nineteenth century onward, as contemporary health education and health promotion are rooted in that era. The second part of the section focuses on the development and organisational structure of public health in the Netherlands and the role of the government.

\subsubsection{An overview of the history of public health}

In the nineteenth century, populations were frequently confronted with outbreaks of infectious diseases. In the early part of that century, physicians regarded epidemics as a disruption of the balance of the natural environment. Later, the general impression was that there was a relationship between poverty, pollution and immorality among the poor and the emergence of (contagious) diseases. There were two crucially different theories about this relationship: 'miasma' and "contagio" (Houwaart, 1991a). The contagionistic approach asserted that living organisms caused disease by transmission from one person to another. Epidemics, in this view, could be contained by vaccination or putting people in quarantine. The miasma theory, on the other hand, concentrated on the adverse effects of the fumes rising from the dirt on the streets and from stagnant water and of the air in the musty, overcrowded houses. In this view, the occurrence of disease was related to the environment and people's lifestyle. Public measures like the provision of clean drinking water and the collection of garbage were thought to be effective in the fight against epidemics. The miasmic point of view became dominant in the mid-1800s. In the early-industrialised countries, people were concerned with impoverishment and the decline of civic society caused by a high level of migration and population growth. The inequalities between rich and poor people in society increased significantly, not only in terms of power and economic status but also in terms of health (ten Dam, 1997). The so-called 'hygienists' advocated public measures to improve environmental and social circumstances (collective hygiene). In fact, they considered the emergence of epidemics as a sign of poor societal organisation (Houwaart, 1991a). The hygienists in England and France also had a strong political bias. They held positivistic ideals: medical science was to make a contribution to an equitable society for everyone, so it had to be be reformed into a practical science (Houwaart, 1991b). 
The hyglenists started to use statistics to describe morbidity and mortality related to people's physical and social environments, and the effects of measures taken to mprove these situations. This work enabled them to assess the health status of collectives instead of individuals, to compare between cities, districts or social groups, and to use the findings as an instrument to pressurise local governments into taking measures and developing health policies. In fact, the hyglenists were able to demonstrate that disease could be prevented and controlled, at least to some extent, by interventions in the public domain. Their attempts, however, to mobilise local or national governments to issue regulations in the public domain were not always fruitful, even though public health was of urban and economic interest (healthy workforce, reputation). At the time, it was very much debated whether the state should intervene in the rights and autonomy of civic society. The hygienists' views revealed the tension between paternalism and the prevaling ideas on individualism. Moreover, independent regions within countries resisted centralisation, because they wanted to maintain their autonomous status, hampering effective public health policy at the state level (van Heffen \& Kerkhoff, 1997).

Physicians attempted to establish social medicine and institutionalise its training and practice. However, when in the late nineteenth century, Pasteur and Koch created the foundations of bacteriology, the theory held by the hygienists became discredited and biological factors were considered the principal cause of disease instead. The level of intervention shifted from the public domain (social and physical environment) to curing individual diseases. The ecological consciousness disappeared and the character of public health changed drastically.

In the course of the twentieth century, the hygienists' approach had been completely replaced by the medicotechnical approach to health, and medicine started to dominate the professional ideology in public health as well. The position of doctors with respect to public health, however, was quite ambivalent; while they wanted to be in control, the medical profession hardly appreciated public health (Porter, 1994), denying its importance. Instead of collective hygiene, they favoured individual hygiene and preventive measures like vaccinations, especially for vulnerabie groups in society (e.g. mother and child care).

Medicine rapidly became a highly developed and valued profession in society, with its own university-level training, professional culture and autonomy. It developed from a marginal sector to one of the biggest industries in society (ten Dam, 1997).

Nevertheless, Porter [1994\} argues that medical knowledge is only one component of public health expertise. Moreover, he asserts that the socio-political environment constrained the power of professionals (i.e., doctors) (p 24). Rosen $(1958,1993)$ also states that the application of knowledge, however powerful knowledge may be, depends on political, economic and social factors, which are bound by culture and nation. This implies that the regulation of health is tied in with politics, that is, the debate about divergent interests in society (van Heffen \& Kerkhoff, 1997].

Some public health historians, such as Rosen, are very positive about the scientific and technical development of understanding diseases in terms of treatment and prevention. They say that the medical approach has indeed proved very effective. Others do not entirely share this opinion and question the individualistic, medical view currently prevalent in public health. They discuss a number of negative aspects of the development of public health. Foucault 
(1976, 1991), for example, asserts that (medical) scientific knowledge dominates western culture and controls people's acts in detail. He says that measures to improve public and individual health have had an enormous impact on people's personal lives and he even calls public health repressive. Lupton (1985) argues that liberalism (freedom of choice) and rationalism (scientific data) of modern public health still serves governmental (utility) interests, instead of the autonomous needs of people. lilich (1976) states that medical practice ("the medical enterprise") is a threat to people's health. He describes three forms of iatrogenesis, that is, (damaging) influences of medicine. The first one, at the individual level, refers to the clinical side effects of medical treatment. The second form, at the social level, refers to the dependency of people on the medical system and the medical system's judgements of normality and deviancy in society. The third form, at the structural level, refers to the expectations that are raised by medical practice about the manipulability of life. Mc Keown (1976) argues, like Illich, that it is not medical knowledge or public health practice that has raised the life expectancy of the population, but the improved nutritional status and standard of living.

Indeed, over the last decades, humanity has been confronted with a number of interrelated changes in public health and health care that are leading us back to the old views of the hygienists. To start with, experts have observed shifts in disease patterns, from infectious to chronic diseases (e.g. cardiovascular diseases, diabetes, cancer). These diseases have emerged due to the ageing population and the modernisation of society, and are characterised by multicausality (in terms of lifestyle and social and environmental factors). A wide range of specialists and high-tech diagnostic and therapeutic means are commonly employed to assist people with these chronic diseases and their complications. The interventions are very costly and deliver ever smaller health gains. Since government expenditures on illness and medical care have risen dramatically, the governments are currently retreating from a central, hierarchical position in which they regulate almost all aspects of life (the caring state) to a decentralised position. Furthermore, health inequalities between people of different socio-economic status have continued to increase, in spite of increased prosperity and medical care (R. G. Evans, Barer, \& Marmor, 1994; Programmacommissie Sociaal-Economische Gezondheidsverschillen tweede fase, 2001). The ideas of Mc Keown and others, that medical care only addresses a small subset of the determinants of health, have recently been gaining ground (see also section 2.11. Given the multicausality of contemporary health problems and the fact that these determinants are situated outside the reach of medical care, other interventions are called for (ten Dam, 1997). Prevention of disease and health promotion have slowly become accepted in public health. On top of that, the conceptualisation of health itself has changed. Whereas health used to be merely regarded as the absence of disease, it has now become a multidimensional, positive concept. For example, in operational terms it has been defined as "the extent to which an individual or group is able, on the one hand, to realise aspirations and satisfy needs, and, on the other hand, to change or cope with the environment' (de Leeuw, 1989b p.12).

The above developments have led to a renewed focus on the relationship between people's health and their lifestyle. Once again, local governments are required to intervene with 'new' health policies to promote the health of their citizens. It is the World Health Organisation (WHO) that has been leading the way in the conceptualisation (e.g. Declaration of Alma Ata, 
Ottawa Charter) and operationalisation (Health For All by the year 2000, Healthy Cities) of what is called the 'new public health'. See chapter 2.

\subsubsection{Public health and governance in the Netherlands}

This section focuses on two major points in the development of public health in the Netherlands: the role of national and local governments in public health and the establishment of public health services.

At the start of the nineteenth century, it was the local administration and private initiative that controlled health care practice. At that time, the social and political influence of doctors (and civilians) was restricted, as consequence of which the national government did not adopt proposals for reforms to the medical profession. Like other western countries, albeit at a later point in time, the Netherlands saw the rise of the hygienic mowement. The hygienists wanted central govermment to take an interest in health matters and to tell local administrations to intervene in the public domain to control disease. Interference by the state, however, clashed with the prevailing political climate of liberalism. The amendment to the Constitution of the Kingdom of the Netherlands (1848) and the enactment of the Municipal Act (Gemeentewet, 1851) gave the hygienists room to slowly exert more influence. Also, the results of their studies of pathogenic factors in people's living conditions in certain localities, and the classification of the health status of collectives, gradually came to play a role in national and local political debates. By enacting a number of medical laws in 1865 , the state recognised public health as a topic of national interest, even though responsibilities remained with the local admiristration (Houwaart, 1991a). Local government was brought under the control of the state.

This did not mean, however, that local government always acted vigorously. Due to the lack of interest among local administrations, a variety of private initiatives arose for the prevention of disease (for example in the fight against tuberculosis and sexually transmittable diseases, and in mother and child care). Even today, these organisations, by now institutionalised and subsidised, remain important local actors in the field of public health. By the end of the nineteenth century, the authorities (mainly) in the cities systematically implemented improvements in public hygiene to face the rapidly growing social and sanitary problems (Houwaart, 1991 a). Urban administrations were also the first to create basic (public) health services: interventions were carried out to control infectious diseases, doctors took care of the sick poor, and doctors were hired to check on schoolchildren. Apart from this, the treatment of disease and the care of patients was primarily the domain of religious and private initiative.

The public measures and policies developed in the big cities provided an example to other municipalities but were also authoritative in terms of the development of national health policies (Kerkhoff, 1994). Municipal authorities established a public health service according to their own interests and needs. They were not willing to collaborate at regional level, as had been proposed by the national government in 1920 (Kerkhoff, 1994). After World War II, central government became more concerned with the health and well-being of the population and wanted to control societal forces that supported them. This period was characterised by a massive growth in medical and health care services (subsidised but not owned by the government), the development of scientific knowledge, and very importantly, the development 
and promulgation of social laws (e.g. unemployment benefit, health insurance) (van Heffen \& Kerkhoff, 1997). The municipal administrations lost part of their autonomy and became the implementers of national policies (Kerkhoff, 1994). Again, the national government stimulated the establishment of a network of public health services throughout the country. This time, it was the numerous (non-governmental) health and social organisations that frustrated the plan.

In the 1970s, the so-called welfare state seemed to have lost control over the structure and costs of the health care system. Since that time, the national government has published a number of memoranda, whose objective was partly to regain control over the health system and partly to delegate responsibilities to the regional and, especially, the municipal level. The 'Structure Memorandum' (Structuur Nota), published in 1974, recommended reducing curative services and instead stimulating primary health care and the official establishment of basic public health services. State subsidies greatly helped to expand the national network of public health services.

The Lalonde report and the activities of the WHO (see section 2.1) did not go unnoticed, and formed the basis for a new memorandum called 'Memorandum 2000' (Nota 2000) published in 1986. This memorandum was of crucial importance in that it acknowledged multiple determinants of health and signalled the re-emergence of disease prevention and health promotion on the governmental agenda. However, this memorandum was quickly overshadowed by other considerations, because in the same period, the government introduced 'market forces' to the health system, which is not very compatible with preventive activities (de Leeuw, 1989a; van Heffen \& Kerkhoff, 1997). After another attempt by the government to control the structure of the health care system and to cut expenditures in this sector had failed, the government decided to finally regulate and decentralise activities, responsibilities and finances in preventive care by passing a law on collective prevention in public health (WCPV) in 1989 (van Heffen \& Kerkhoff, 1997).

The WCPV describes a number of new tasks, while leaving traditional autonomous tasks at the local level untouched (Kerkhoff, 1994). The WCPV mentions a number of executive tasks, viz. the control of infectious diseases and the provision of preventive (medical) care for school children, and a number of health promotion tasks: assessing the health status of the population on the basis of epidemiological data, giving advice about the impact on health of public policy decisions, promoting hygiene and psycho-hygiene, and developing and implementing preventive programmes, including health education (for further reading see Meijer, 1991; Meijer, 1994). The WCPV obliges all municipalities to establish and maintain a public health service, in a regional context where appropriate (RPHS). The Netherlands ultimately became completely covered by a network of public health services (see Figure 1.1 ).

The compulsory nature of the tasks given to the municipal authorities and the public health service as an executive instrument is assumed to be a guarantee that the municipal administrations will act upon national policies concerning collective prevention (Meijer \& van den Ouwelant, 1998; van Heffen \& Kerkhoff, 1997). Collective prevention has been described as the protection and promotion of the public's health, or that of specific groups in the population, as well as the prevention and early detection of diseases. The WCPV did not change the responsibilities concerning collective prevention; it only regulated the involvement of the 
health officers, and was to demonstrate how community health promotion could work. This was feit to be especially relevant because the municipal authorities had to act on the upcoming obligation to establish a local health poilicy. In turn, the municipal authorities, which were looking for ways to develop such a local health policy, tried to determine in what way their public health service, the RPHS, could and should contribute to this task. In this situation, still full of questions and lacking much clarity, the RPHS wondered how local health policy-making would develop, how to intervene in this process and what contribution local health initiatives developed by the community-based project Hartslag (Midden) Limburg could make to policy development. The simultaneous emergence and future development of both local health policy and community-based health promotion was unique. This situation offered outstanding opportunities to study the dynamics of both processes, and their interrelations, at the local level. It has laid the ground for a large study, embedded in the day-to-day operations of the RPHS and the municipalities in the central part of the province of Limburg.

The University of Maastricht, which was already involved in a pilot study on selecting 4 of the 14 municipalities in the region to participate in the community-based project, provided the researcher and supervised the entire study.

\subsubsection{Objective and research questions}

Public health care (OGZ) and the establishment of local health policy became a topical matter in the Netherlands for some time. Although municipal authorities and the RPHSs were familiar with their tasks in the domain of collective prevention, they were not familiar with policy development in the broader context of health promotion in their own area. This was especially true of the smaller municipalities.

The first development of local health policy was an ideal occasion to study such a policymaking process and its outcome. In addition, it was known from the literature that local health projects are exemplary but do not guarantee the establishment of health policy (Goumans, 1998). In what way community health promotion contributes to the development of local health policy, and how such policy favours the integration and sustainability of local health initialives, was still unknown. Furthermore, although much research had been done on the existence and formation of sectoral health policies (for example anti-smoking regulation), there had been far fewer studies on policy development processes in a broader context. Finally, we were specifically interested in the question who were able to influence policy development, rather than trying to answer only the traditional questions in policy research of why and what (de Leeuw, 2001 p.189).

The purpose of the research presented here was to generate knowledge about health policymaking at the local level and the significance of community-based health promotion to this policy process, as well as to make this knowledge accessible at a scientific as well as practical level. This brings us to the research questions.

The central question 'How is local health policy developed and how does community health promotion contribute to the development of local health policy?' was specified in three research questions. 
1. Which actors and factors contribute to health policy development at the local level, and how do they contribute?

2. Are there major differences in health policy development and its outcome between municipalities, and to what variables can they be attributed?

3. How does the Hartslag (Midden) Limburg community-based cardiovascular prevention project contribute to policy development and how are the activities of the project integrated in local health policy?

\subsection{RESEARCH DESIGN AND METHODS}

\subsubsection{Multiple case study}

The research questions presented above deal mainly with the 'how' questions about a new phenomenon, that is, local health policy, and the specific actors involved in it. The research aimed to study local health policy in the context and daily reality of municipalities and the Regional Public Health Service (RPHS) in Central Limburg. This induced us to choose a case study research design. Such a research design is specifically applicable in those situations where the context and the phenomenon studied are not clearly demarcated or distinguishable, and the contextual circumstances are of great importance to the object of study and cannot be controlled by the investigator (Yin, 1994). Controlling variables or to measure their effects is not of primary concern in case studies (Hammersley \& Gomm, 2000). According to Stake, case study is the study of the peculiarity and complexity of a single case, to understand its actions within important contextual circumstances, 'the real business is particularization not generalization' (Stake, 1995 p.8). Yin states that case study allows an investigation to retain the holistic and meaningful characteristics of real life events.

Including multiple cases in a study makes the findings and conclusions more compelling and the study more robust. These individual cases, however, should serve a specific purpose within the overall scope of the study (comparable to the situation in multiple experimental studies) (Yin, 1994). Case studies use 'analytical generalisation' instead of 'statistical generalisation'. This means that the empirical data are compared with previously developed theory; case studies are generalisable to theoretical statements but not to populations (Silverman, 2000).

Our study in Central Limburg was a multiple, embedded case study. It selected 4 of the 14 municipalities in the region as the cases to be studied. Embedded means that each case comprises multiple units for analysis (e.g. regional organisations, individuals, see Table 1.1). In cases studies information is gathered and analysed about a large number of characteristics of each case (Hammersley \& Gomm, 2000).

Case selection is an important element in the multiple case study methodology. The four cases, that is, municipalities, were also the communities that participated in the communitybased Hartslag (Midden) Limburg project, which is a very important contextual factor in our study. The municipal administrations were invited to participate in the community-based project on the basis of the outcomes of a preliminary study on predisposing factors in the municipalities for the development of community health initiatives (Hoeijmakers, 2000a). Two municipalities were 
found to take a positive basic stance towards community health (having enabling characteristics, supporting community health initiatives) while the other two took a negative basic stance (having less favourable characteristics). We expected the same characteristics also to be favourable for policy-making; the municipal administrations would take the lead and the participants (health professionals and community representatives) would be communicating on local health pollcy and using existing (collaborative) structures to join forces. To meet the criterion of multiple case studies, i.e., that each case has to serve a specific purpose, another distinction was made between the cases; the RPHS was to intervene actively to support two of the four municipal administrations in the development of their local health policy. We expected this intervention to have a formative influence on public health officers and aldermen.

Table 1.1 Methods and types of data in investigating local health policy

\begin{tabular}{|c|c|c|c|c|}
\hline Units of analysis & Total system & Four municipalities & $\begin{array}{l}\text { Intermediate units } \\
\text { Regional } \\
\text { municipal } \\
\text { meetings }\end{array}$ & RPHS \\
\hline and & 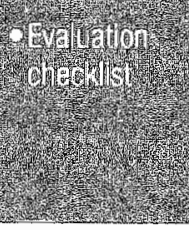 & 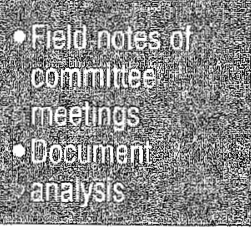 & (1) & 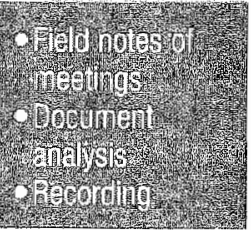 \\
\hline
\end{tabular}

$\begin{array}{ll}\text { Policy network } & \text { - Structure: } \\ & \text { cohesion and } \\ & \text { centrality }\end{array}$

$\begin{array}{llll}\text { Stakeholders } & - \text { Position } & \text { - Involvement } & \text { - Involvement } \\ & - \text { Interests } & & \\ & - \text { Involvement }\end{array}$

\begin{tabular}{|c|c|c|c|}
\hline $\begin{array}{l}\text { Community- } \\
\text { based project }\end{array}$ & $\begin{array}{l}\text { - Degree of } \\
\text { consultation }\end{array}$ & - Involvement & $\begin{array}{l}\text { - Importance of } \\
\text { the project }\end{array}$ \\
\hline
\end{tabular}

$\begin{array}{lllll}\text { Municipality } & \begin{array}{l}\text { - Vision } \\ \text { - Role of } \\ \text { politicians and } \\ \text { civil servants }\end{array} & \begin{array}{c}\text { - Behaviour in } \\ \text { policy-making } \\ \text { - Vision, priarities, } \\ \text { action plan }\end{array} & \begin{array}{l}\text { - Importance of } \\ \text { local health } \\ \text { policy }\end{array} & \begin{array}{c}\text { - Communication } \\ \text { and support }\end{array} \\ \text { RPHS } & \begin{array}{l}\text { - Entrepreneurial } \\ \text { role }\end{array} & - \text { Involvement } & - \text { Collaboration } & \begin{array}{l}\text { - Strategy } \\ \text { - Behaviour in } \\ \text { policy-making }\end{array}\end{array}$


Finally, of the four municipalities included in the study two were small $(8,000-11,000$ inhabitants) and two were large $(45,000-50,000$ inhabitants). The other ten municipalities in the region were only included in a few specific data collection methods (for very specific reasons]. These methods are presented below (see also section 2.5 ).

\subsubsection{Methods}

The study used multiple research methods and multiple data sources. At the outset of the data collection phase in the four cases, we identified the stakeholders (see section 2.3) of local health policy. Stakeholder identification was done by snowball sampling and one Delphi round, after which we conducted semi-structured interviews with these stakeholders.
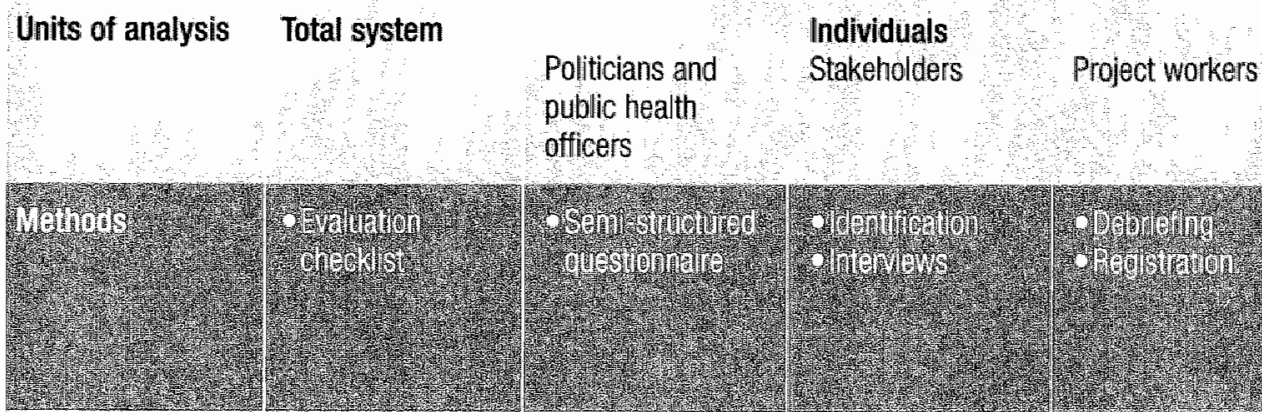

\begin{tabular}{|c|c|c|c|}
\hline Policy network & $\begin{array}{l}\text { Structure: } \\
\text { cohesion and } \\
\text { centrality }\end{array}$ & $\begin{array}{l}\text { Position } \\
\text { - Role } \\
\text { - Communication }\end{array}$ & $\begin{array}{l}\text { - Interrelations } \\
\text { - Exchange } \\
\text { - Positions }\end{array}$ \\
\hline Stakeholders & $\begin{array}{l}\text { - Position } \\
\text { - Interests } \\
\text { - Involvement }\end{array}$ & $\begin{array}{l}\text { - Communication } \\
\text { - Entrepreneurial } \\
\text { role (see chapter 2) }\end{array}$ & $\begin{array}{l}\text { - Individual } \\
\text { characteristics } \\
\text { - Involvement in } \\
\text { policy-making }\end{array}$ \\
\hline
\end{tabular}

\begin{tabular}{|c|c|c|c|c|}
\hline $\begin{array}{l}\text { Community- } \\
\text { based project }\end{array}$ & $\begin{array}{l}\text { - Degree of } \\
\text { consultation }\end{array}$ & - Involvement & & $\begin{array}{l}\text { - Process } \\
\text { - Activities } \\
\text { - Efficiency }\end{array}$ \\
\hline Municipality & $\begin{array}{l}\text { - Vision } \\
\text { - Role of } \\
\text { politicians and } \\
\text { civil servants } \\
\text { - Agenda status }\end{array}$ & $\begin{array}{l}\text { - Collaboration } \\
\text { - Importance of } \\
\text { local health } \\
\text { policy }\end{array}$ & $\begin{array}{l}\text { - Type of } \\
\text { relationship }\end{array}$ & $\begin{array}{l}\text { - Collaboration } \\
\text { - Irivolvernent }\end{array}$ \\
\hline RPHS & $\begin{array}{l}\text { - Entrepreneurial } \\
\text { role }\end{array}$ & $\begin{array}{l}\text { - Communication } \\
\text { - Entrepreneurial } \\
\text { role }\end{array}$ & & $\begin{array}{l}\text { - Integration } \\
\text { - Communication }\end{array}$ \\
\hline
\end{tabular}


We repeated this procedure after two years, during which policy development had been effectuated, in order to observe any changes. In addition, we analysed policy documents (long-term plans drafted by local administrations, local health policy memoranda).

The context of the four individual cases in terms of local health policy-making exceeded the local level, as the individual cases interacted with other municipalities in the region and with the RPHS. At the level of regional collaboration between municipalities, observations were made during their public health meetings, and the minutes of such meetings were studied. At the level of the RPHS, observations were made during meetings at the department of health promotion, policy documents were studied and communications on local health policy to and from municipalities were recorded and analysed.

Finally, we monitored the development of the community-based project Hartslag (Midden) Limburg (see chapter 3).

Table 1.1 summarises the types of data generated by applying the above methods to the different units of analysis. The operationalisation of the inquiry is described in more detail in section 2.5 and chapter 6 .

\subsubsection{Quality of the research}

The quality of a research design can be assessed on the basis of a number of design parameters: construct validity, internal and external validity and reliability. According to Yin (1994), internal validity tests do not apply to explorative or descriptive case studies because no causal relationships are established in such research. In the following, we discuss what measures have been recommended to ensure the quality of a multiple case study like ours. Subsequently, a schematic overview (Figure 1.2) of the research design shows the measures we have taken.

Internal validity concerns the problem of making justifiable inferences. Maso and Smaling (1998) refer to internal validity as the soundness of the arguments and the line along which reasoning has developed. Although internal validity is considered important in causal case studies, descriptive and explorative case study research is less concerned with this issue (Yin, 1994.). Besides, it is difficult to identify specific tactics to deal with internall validity in case studies.

Construct validity refers to the establishment of correct operational measures for the concepts being studied. The use of multiple sources of evidence, the establishment of a chain of evidence, and letting key informants review a draft of the case study report are measures recommended to ensure a good match between conclusions, empirical data and theoretical concepts.

External validity has been considered a major barrier in case studies (Yin, 1994). It refers to the establishment of the domain to which generalisations can be made. Whereas survey research uses statistical generalisation, multiple case studies use the replication logic to make analytical generalisations (generalising a particular set of results to develop some larger theory) by means of the replication of cases instead of statistical generalisation. This replication logic in multiple case studies is twofold: (1) literal replication, in which cases produce similar results and (2) theoretical replication, in which cases produce contrasting results but for predictable reasons. Of course, this means that the selection of cases and the decision what number of cases to include is of crucial importance. Another important aspect is the development of a clear theoretical framework. 
Reliability refers to the repetitive qualities of the study, that is, whether repetition of the procedure (the operationalisation] to the same case(s) will produce identical results. In qualitative research, reliability has a somewhat different meaning. The exact replication of qualitative research by other researchers is often not feasible because the object of study changes over time. In this type of research, people often refer to 'virtual repeatability', meaning that the study, or parts of it, could be repeated in exactly the same way with the same methods and techniques if the situation had not changed. The criterion for reliability is then the 'trackability' of the research (Maso \& Smaling, 1998) or the creation of an 'audit trail' (Baum, 2003; Seale, 1999), that is, whether others can examine the course of the research precisely. The development of a case study protocol and an exhaustive case study database may increase the reliability of the study results.
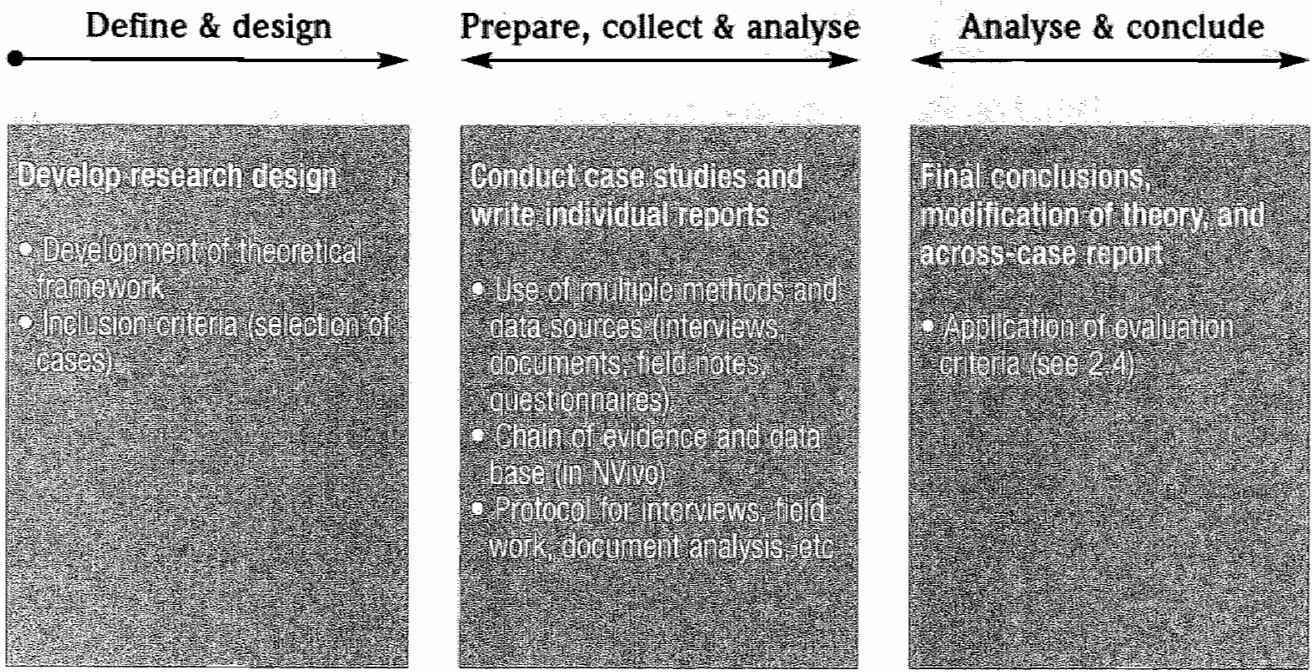

Figure 1.2 Case study method and qualitative measures in the study of local health policy

\subsection{OUTLINE OF THE THESIS}

In the first chapter of this thesis on an inquiry into local health policy-making in Central Limburg, the Netherlands, we have outlined the background and reasons for this study and presented the research questions, design and methods. To further set the stage for the present study, chapter two provides a comprehensive theoretical framework including concepts from health promotion and policy sciences. It also presents and describes stakeholder and network analysis, the tools that have enabled us to study the actors involved in local health policy-making and policy network structures. Finally, it presents the instrument we have developed to evaluate the policy-making processes in the four municipalities included in the present study.

Part II, comprising three chapters, is concerned with the community-based Hartslag (Midden) Limburg project, which aims at the prevention of cardiowascular disease in the population. Chapter three presents the project and the monitoring instrument used to evaluate it. Chapter four elaborates on theoretical concepts underpinning community-based projects, discusses the 
findings of the evaluation of the project and draws some conclusions regarding the efficacy of the project and the relation it was supposed to have with local health policy-making. Within the same context, chapter five reflects on the evaluation of health promotion interventions like the Hartslag (Midden) Limburg project. This part is a more or less self-contained unit, which can be read separately from the other three parts.

In part III, the focus is on local health policy-making. Chapter six reflects on the iterative character of the inquiry and prepares for the presentation of the findings in the next chapters. Chapter seven presents the four cases (municipalities) included in our study, after which it reports on the findings of the first stakeholder identification round and the interviews held in 2001 , prior to the start of local health policy-making. Chapter 8 presents what we found while the process of policy-making developed. It starts by outlining four propositions on the involvement of different actors in policy-making. The chapter then goes on to present the results of an interim assessment at the end of 2002 . It continues by describing the stakeholder identification round held in 2003 , which provided the starting point for the interviews held in the same year: The chapter also presents the results of the application of the evaluation instrument for each case. Finally, it compares the findings for the four cases.

In the final part of this thesis, the theoretical framework is linked to the findings.

Chapter nine first discusses methodological quality issues of this study, and then reflects on the findings for local health policy-making in relation to the items of the evaluative framework. Chapter ten draws conclusions from these reflections in the light of the propositions and research questions of the present study and provides some implications for practice and suggestions for further research. 
S IN

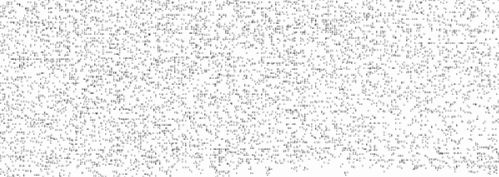
अै।

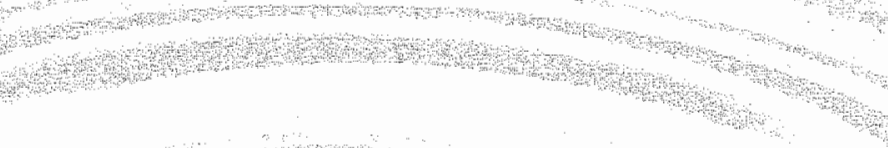

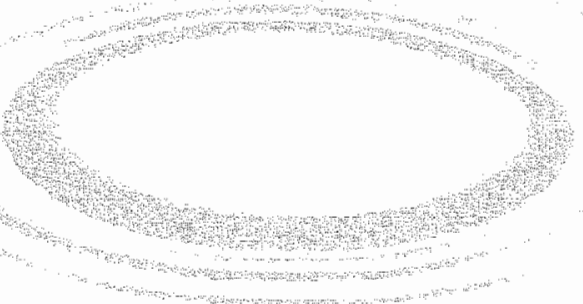

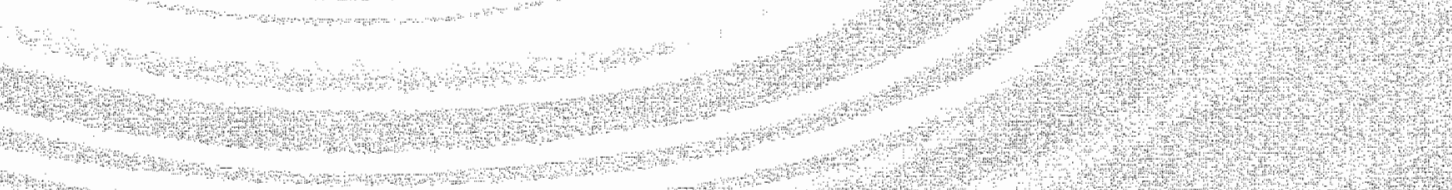
(4) S4P (4) (

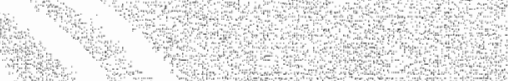

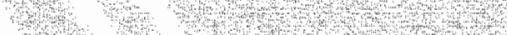

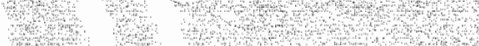
तै। ?ִ 


\section{THEORETICAL PERSPECTIVES ON THE EVALUATION OF HEALTH POLICY- MAKING AT THE LOCAL LEVEL}

Health promotion and policy development are both complex processes. Evaluation of such processes should be theory-based but also rooted in the local context. The second chapter of this thesis elaborates on different theoretical perspectives on local health policy-making. It first describes concepts from health promotion theory and policy science, then identifies tools for the analysis of health policy-making and presents an evaluation instrument that combines different theoretical concepts in a comprehensive, multilevel framework. The chapter ends writh a description of the research methods and operationalisation used in this inquiry.

\subsection{Health Promotion theOry and Practice}

Health promotion emerged in the late 1980 s and has become a new movement for health. This section describes the realm of health promotion: it briefly outlines the origins of health promotion and then discusses theoretical and practical aspects of the field. The principles of health promotion are part of the evaluation of health policy-making at the local level.

\subsubsection{Introduction}

Chapter 1 described the history of public health, which alternately focused on the individual and the collective, and on environmental and biomedically oriented interventions. We also briefly mentioned the growing criticism of the achievements attributed to medical and public health interventions. In reviewing this discussion, McKeown $(1972 ; 1976)$ argues that there is a considerable range of other determinants of health that should be considered in health interventions and policy formulation, apart from public health and medical services. Canada was the first country in the world to acknowledge, in an official ministerial report on the health status of its population, such multiple determinants of health (human biology, lifestyles, environment and organisation of medical care), as broad categories of a 'Health Field Concept' (Lablonde, 1974). The same report officially introduced the term "health promotion' as a strategy to improve the health of a population.

This drive towards a determinants-based health policy, involving community participation, has been compounded by the declaration of Alma Ata on Primary Health Care in 1978 (WHO, 1978), the Health for All by the year 2000 ideology (WHO, 1981) and the establishment of concepts and principles of health promotion by the World Health Organisation (WHO, 1984). These pioneering documents have set the stage for the first international declaration on health promotion in 1986: the Ottawa Charter. 
The Ottawa Charter (WHO, 1986) outlines five action areas: creating supportive environments, strengthening community action, developing personal skills, reorienting health services and building healthy public policy. The latter establishes the context in which the other four actions are made possible (see also section 2.2). Furthermore, three strategies are called for in all action areas.

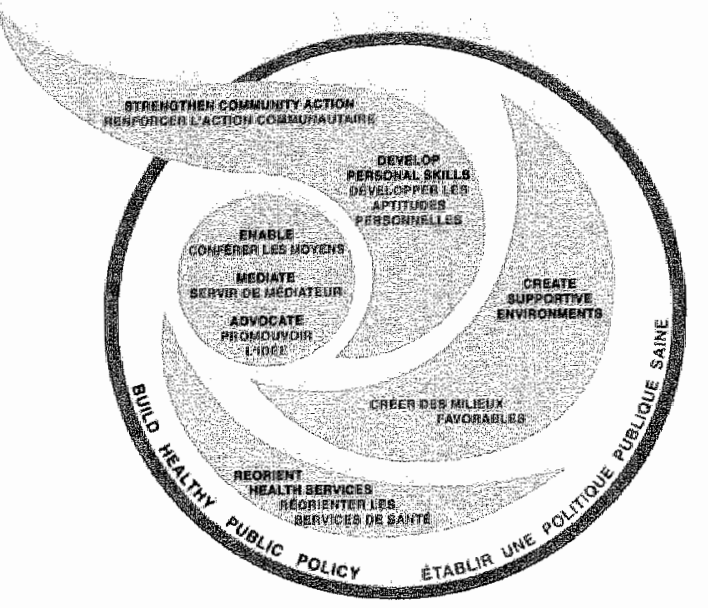

Figure 2.1 Graphic representation of the Ottawa Charter
- Advocate: making conditions lenvironment, politics, culture) favourable for health.

- Enable: making it possible for people to reach their fullest health potential by ensuring equal opportunities and resources. This strategy expresses, above all, one of the underlying concepts of health promotion: empowerment.

- Mediate: coordinating the actions of all actors concerned, including actors in non-health sectors (e.g. education, social sector, interest groups, media, industry).

Health promotion in the Ottawa Charter is presented as a comprehensive, multi-strategy approach that is well adapted to the locall situation in terms of culture, social and economic systems, and the physical environment.

What was so innovative about this Charter? To begin with, it emphasised the conceptualisation of health as a positive concept and a resource for everyday living and not merely as the absence of disease. This reflected the adoption of a perspective known as the salutogenic approach (Antonovsky, 1987). This positive concept is also seen in the shift of focus from modifying individual risk factors to addressing the multiple determinants (e.g. environmental, political actions) that keep people healthy. Another shift that it introduced was that from disease prevention to 'capacity building for health' (among individuals, groups, professionals and policymakers). This implies the development of skills, organisational structures, resources and commitment to improve health in more than the health sector alone (for further reading see Hawe, King, Noort, Gifford, \& Lloyd, 1998]. Furthermore, the charter offered a new role to professionals, namely, to enable, advocate and mediate beyond the educational and preventive role. A final inrovation that is relevant to our present purpose was the responsibility of governments for the outcomes of policy in terms of the health of populations rather than for the input in terms of the provision of health services (Kickbusch, 2003). Government authorities at the national but also at the regional and local levels were stimulated to become more accountable for the impact of their policy decisions on health. These policy decisions include those on the conditions that create health or ill health and are administered by other departments in government than those responsible for health (e.g. road safety, employment, development plans and distribution of income). 
The Ottawa Charter on health promotion has remained the basis on which theory and practice have developed over time. It has continued to exert significant influence on health promotion practice, health policy development and the public health debate in many countries (Kickbusch, 2003). The notion of health being determined by multiple factors and the idea that it is most effectively addressed by a consistent package of multiple health interventions (communication, facilities, regulation) addressing multiple levels is now widespread and generally accepted (Amhof, 2002). This applies to academics, practitioners, donors, managers, policymakers and even the World Bank (Catford, 2004). Although there thus seems to be some theoretical support for these assumptions, the question remains whether this is also reflected in health promotion theory and practice.

\subsubsection{Theory of health promotion}

Several health promotion specialists have reviewed the variety of definitions found in theoretical writings to find out whether health promotion as outlined above is really reflected by theory (Amhof, 2002; Poland, Green, \& Rootman, 2000; Rootman, 2001). A few definitions from this variety are reproduced here by way of illustration.

'Health promotion is the process of enabling people to increase control over, and to improve, their health.' (Ottawa Charter WHO, 1986)

Health promotion 'is seen as comprising three overlapping spheres of activity - health education, prevention and health protection." (Tannahil. 1985, 1988), (United Kingdom)

'Health promotion represents a comprehensive social and political process, it not only embraces actions directed at strengthening the skills and capabilities of individuals, but also action directed towards changing social, environmental and economic conditions so as to alleviate their impact on public and individual health. Health promotion is the process of enabling people to increase control over the determinants of health and thereby improve their health. Participation is essential to sustain health promotion action.' (Health Promotion Glossary, Nutbeam WHO, 1998)

'Any planned combination of educational, political, regulatory, and organizational supports for actions and conditions of living conducive to the health of individuals, groups, or communities.' (Green \& Kreuter, 1991, 1999), (USA)

'Health promotion aims at lifestyle factors and 'healthy' environmental characteristics, e,g. using information campaign or coordinated social action. ' (van Oers, 2002). (National Institute for Public Health and the Environment, RIMM, The Netherlands)

It seems obvious that all definitions see health promotion as an endeavour to improve health. There are, however, distinctions in terms of the leve] of intervention (individual, community, population), the main components (behaviour change, alteration of physical, social and economic environment and policy development), the concept of control, competencies and empowerment expressed in the process of health promotion and the application of strategies and activities. 
According to Rootman et al (2001), differences in these definitions do not lead to fundamental conflicts. Amhof (2002), however, argues that there are crucial differences in the statements, especially on what needs to be undertaken to improve health. The approach to health improvement sometimes varies greatly, not only between countries but also over time (Amhof, 2002; Catford, 2003). The question what defines the field of health promotion is also reflected in contemporary debates on the effectiveness of health promation and consequently on the use of appropriate theory and evaluation methods. According to Labonte [1992] and Baum (2003), three paradigms can be identified within public health: the biomedical, the behavioural and the socio-environmental (seeTable 2.1). These paradigms influence the types of problem definitions, preferred solutions and indicators of success for interventions and policies. Health promotion principles are closest to the socio-environmental paradigm.

Currently, there is no such thing as a unifying theory for health promotion. Discussions on whether health promotion needs such a theory are still going on (Baum, 2003; McQueen \& Anderson, 2001; Pelikan, 2004].

On the basis of the main concepts of the Ottawa Charter and the more dominant definitions, Green et al. (2000) and Rootman et al. (2001) listed a set of indicators that can be used to decide whether an intervention 'may' be called health promotion:

- The extent to which an initiative involves the process of enabling or empowering individuals or communities;

- Attempts to encourage public participation (critical for the process of empowerment);

- Taking a broad view of health and its determinants;

- Emphasising equity and social justice;

- Fostering intersectoral collaboration.

The above indicators can help to recognise the complexity of the field. In the present study, we used them to operationalise the concept of health promotion into a number of evaluation criteria (see section 2.4 ).

Apart from this general description of indicators, more fundamental issues have been raised. Health promotion should be distinguished from public health because the two differ crucially in the aim and object of their action, as well as in epistemology and practice (Potvin, 2003). Public health aims at improving health indicators for populations and uses the bio-psycho-social model of disease to manage risk factors (by providing the conditions to make healthy choices). Knowledge about the object and effects of interventions is obtained by means of the epidemjological doctrine', or reductionist paradigm.

Rigorous research (experimental designs) provides the scientific evidence determining the value of the intervention. The above relates to the medical and behavioural paradigm presented in Table 2.1.

\footnotetext{
I Research on mortitity and morbidity based on individual determinants (risk factors) and the physical environment.
} 


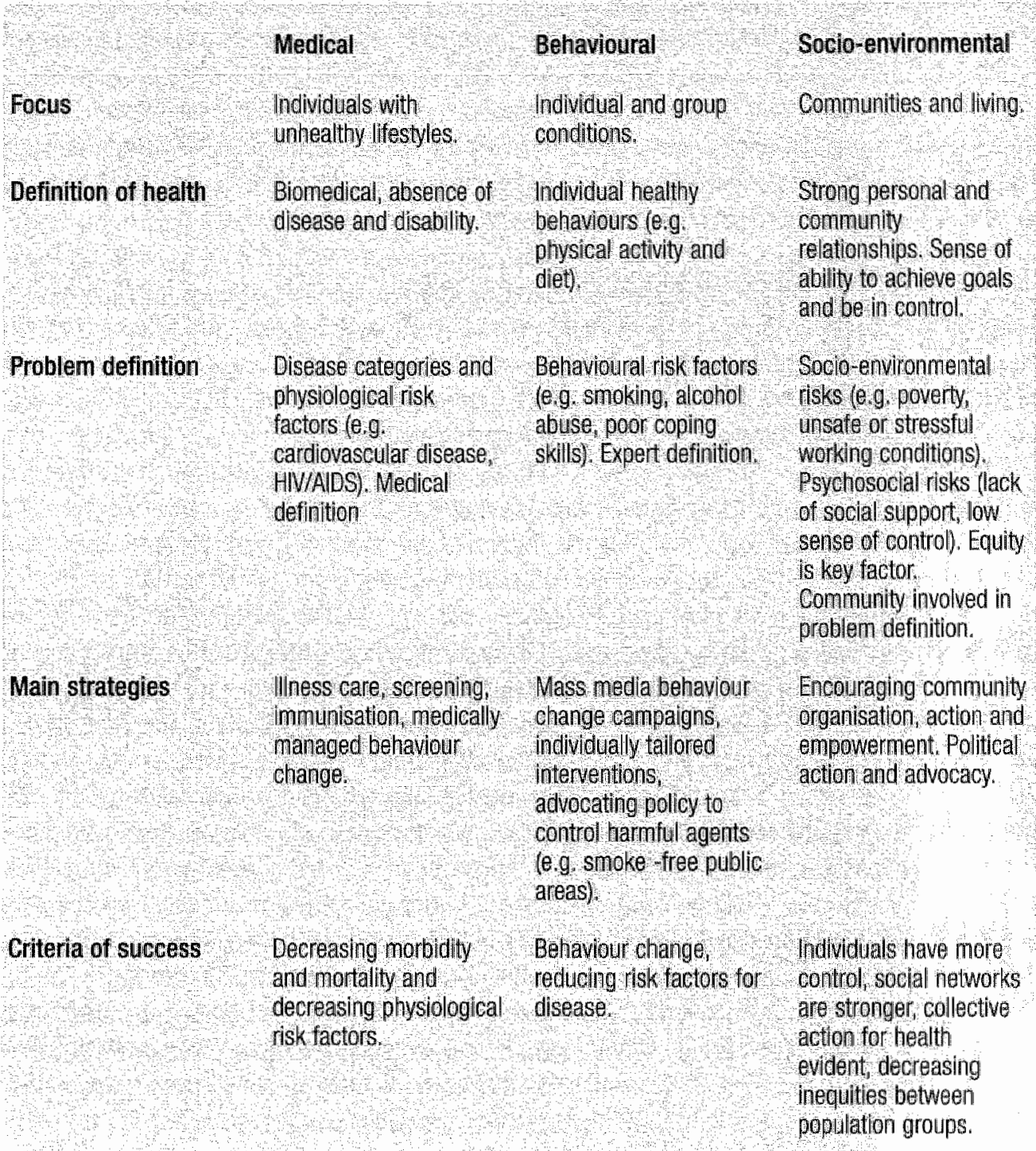

Based on Baum (2003)

Conversely, health promotion aims at reducing health inequalities by enabling people to take control of the conditions for their health and aims at making health a significant issue on the collective agenda (including that of government officials). Activities in this field are led by the salutogenic approach. The generation of knowledge in health promotion is much more a hybrid between the application of epidemiological research and the research tradition of the social sciences. Participatory research and evaluation methods are more commonly used in 
health promotion (see also chapter 5). These methods use 'dialogue' between researchers, practitioners and the 'objects of research' to generate knowledge that is often overlooked in more rigorous research. Health promotion relates to the socio-environmental paradigm for public health (see Table 2.1). De Leeuw (2003) adds to the above by saying that health promotion provides a comprehensive vision of health to the field of public health and population health. Public health is predominantly action-driven, while population health specialises in research on changes in the health status of groups and populations. Both make use of the broad view of health promotion but have their own ideology and practice.

\subsubsection{Health promotion practice}

Despite the broad and lasting support for the principles of health promotion, it is not easy to apply and implement them in practice, because of their complex and abstract nature compared to single-jssue interventions. To study differences in practice, the same distinction can be made, in terms of the levell of intervention, the main components, the concept of control, competencies and empowerment expressed in the process of health promotion and the application of strategies and activities. The gap between practice and the concepts and principles of health promotion is much more evident. Many interventions under the umbrella of health promotion address health at an individual level and/or focus on behaviour change through educational activities or, less frequently, on environmental and policy strategies. Consequently, the main topics addressed are physical activity, smoking or tobacco control, nutrition and the prevention of specific diseases like cancer and cardiovascular disease. The same goes for applied actions mentioned in the Ottawa Charter. Although the Charter's terminology is often used, the actions are mainly restricted to developing personal skills and creating supportive environments (Amhof, 2002). Such interventions still rely on the individual risk approach and fail to acknowledge the multi-dimensional and interactive nature of the causal process that shapes health and the functioning of people (Dean, 1996). The interventions are based on theories that are compatible with this point of view (theories on individual behaviour change), not on the more complex and integrated theory needed in health promotion practice and evaluation. Consequently, they will not provide the knowledge and type of evidence one is looking for (Birckmayer \& Weiss, 2000; Eriksson, 2000; Merzel \& D'Afflitti, 2003). Rychetnik and Wise (2004) and Nutbeam (2004 b) argue that the available evidence on the effectiveness of interventions is restricted to evidence resulting from research evaluations of programmes targeting behavioural determinants. Over the last two decades, investments in programmes addressing social, economic and environmental determinants of health have fallen seriously behind those in behavioural interventions. It is not surprising, therefore, that evidence of the effectiveness of the former type of intervention is unlikely to be found. The lack of evidence of the effectiveness of interventions that target contextual and structural determinants of health creates at least hesitation and reservation among practitioners (and policymakers) about implementing and investing in such interventions (Nutbeam, 2004 b). This obviously creates a vicious circle.

Moreover, practitioners prefer to use evaluative examinations of similar existing programmes as a criterion to choose and implement interventions (Amhof, 2002). Academics and researchers, however, advocate the active application of theory to tailor interventions more closely to the 
targeted problem and increase their effectiveness (Bartholomew, Parcel, Kok, \& Gottlieb, 2001; Birckmayer \& Weiss, 2000; de Leeuw, 2001; Dean, 1996; Glanz, Lewis, \& Rimer, 1997; Nutbeam \& Harris, 1998, 2004). The present study made extensive use of different theoretical concepts.

The short history of health promotion has added a third dimension to the behavioural and environmental dimensions. This is the so-called settings approach, and emerged in the $1990 \mathrm{~s}$ (Catford, 2003). Examples of traditional settings are schools, workplaces, hospitals and geographical communities. These settings are generally used as a vehicle or access point to easily reach specific target groups and disseminate health messages (e.g. programmes on safe sex at secondary schools), although it must be said that fundamental changes in the environment (e.g. the creation of Jabour committees to have a say in the management of an enterprise) influence the health and weill-being of people just as well or even more (R. G. Evans et al., 1994; Whitelaw et al., 2001). This indicates once more that the application of the concept of control, capacity building and empowerment in health promotion is still 'under-developed", and most probably also less fully documented in practical guidelines and scientific health journals (Baum, 2003). An illustrative example of the difficulties of actually applying health promotion concepts and principles in practice, viz., the Dutch cardiovascular prevention project called Hartslag (Midden) Limburg, is described in chapters 3 and 4 of this thesis.

\subsubsection{Conclusion}

The discrepancy between the generally accepted health promotion principles and their application in practice is obvious and emerges in many economically developed countries (Amhof, 2002; Merzel \& D'Afflitti, 2003). However, the myriad of activities and programmes in health promotion contributes to the development of the field and more agreement seems to have grown on the importance of empowerment and participation.

Both theory and current practice show that health promotion is based on several perspectives and is still full of unresolved tensions. [Rootman, $2001 \mathrm{p} .15$ ). This is not surprising for a young discipline originating from public health, which has a long established tradition in the medical and the behavioural paradigm. Adopting a new mind-set and proposing a new role to heal th and health promotion professionals takes time. At the same time, professionals and researchers are in great need of new tools, especially to address desirable social changes and develop integrated health policies (addressing the multiple determinants of health). Research has already demonstrated the impact on health of factors beyond individual genetic and behavioural domains, such as socio-economic status, culture, education, and equity and access issues. (Berkman \& Kawachi, 2000 ; R. G. Evans et al., 1994; Smedley \& Syme, 2000). Up to now, health promotion professionalls have not been confident or skilled enough to address these determinants of health and also effect social change (Catford, 2003), although health promotion principles are closest to the socio-environmental paradigm, see also Table 2.1. Health promotion will have to open up these new horizons to practitioners and policymakers, in as concrete a way as possible.

The present study provides an instrument for the analysis of policy-making at the local level. This evaluative framework (introduced at the end of this chapter), which takes the form of a set of criteria, is based on health promotion principles, but also on theories from policy and organisational science. These two aspects will be further developed in the next sections. 


\subsection{Health POLICY}

\subsubsection{Introduction}

The previous section mentioned building healthy public policy as one of the action areas of health promotion. This concept was developed further at the Second International Conference on Health Promotion in Adelaide, Australia (1988). The main aim of healthy public policy is to create a supportive environment to enable people to lead healthy lives. It facilitates citizens in making healthy choices and it makes social and physical environments health-enhancing (WHO, 1988). Moreover, it aims to put health on the agenda of policymakers in all sectors and at all levels. It was generally acknowledged that national, but also regional and even local governments were to be held responsible for the development of healthy public policy, as they were to be accountable for of all policy decisions in terms of their impact on the health of people. However, every day practice in policy-making is refractory, as the following quotations demonstrate.

Health promotion has contributed to a reorientation in thinking and strategy, yet the focus of health policy remains medical care expenditures rather than investment in health determinants (Kickbusch, 2003 p.387)'

The essential perspective is that the making of policy is intimately connected with implicit assumptions, interests and power positions (de Leeuw, 1993 p.50).

The first quotation shows that health care policies are much more prominent and common than healthy public policies. It also demonstrates that what is said about health promotion is not reflected in the allocation of money. In the Netherlands, for example, more than $98 \%$ of the national budget for health goes to medical and health care services (Peeperkorn, 2004). The underlying assumption of both quotations, however, is that knowledge (provided by scientific research) does not automatically lead to the desired policies. In addition, Rütten (2000) argues that healthy public policy initiatives have to overcome many obstacles in the established policy environment before they can be implemented. Therefore, we need different strategies for the implementation and evaluation of healthy public policy initiatives.

Besides healthy public policy, many other names have been given to policies concerning health, including 'health policy', 'public health policy', and 'health care policy'. Hence, we must first decide what we mean when we talk about policies that are promoting people's health.

This section offers, first of all, general perspectives and classifications of policy, resulting in a definition of policy that will be used in this thesis. After reflecting on the terminology, it elaborates further on the policy process, showing that contemporary health policy-making is an interactive process. The Theory of Streams, developed by Kingdon $(1984,1995)$, provides an appropriate interactive, dynamic perspective on policy-making. This theory is described extensively here because it is part of the theoretical framework of the present study. A number of the evaluation criteria on local policy-making presented in section 2.4 have also been derived from this theory. 


\subsubsection{Defining policy and health policy}

Many authors have defined policy. Most of them (e.g.Hoogerwerf, 1998; van Heffen \& Kerkhoff, 1997; Walt, 1994) see policy essentially as a purposive course of action in dealing with a problem. In pursuit of these goals, certain means are employed and a certain time frame is set. Policies establish the links between goals, means and time frames. In their view, policy reflects the vision of the policymaker(s) and the intended actions to change a problematic situation or a matter of concern. Milio (2001) and Stone $(1988,1997)$ take a somewhat different view. Milio emphasises the influence and actions of actors who have an interest in the matter, which makes policy an ever moving and evolving goall. Stone argues that policies are the result of a struggle over ideas that are at the centre of all political conflicts in the polis 2 . The former authors regard policy-making mainly as a strategic and instrumental endeavour to solve problems, whereas Milio and Stone regard it as a process strongly influenced by interaction and communication between a number of actors. The interaction between participants in the policy process determines the quality of the process and thereby the implementation and effectiveness of the policy. Sections 2.2 .2 and 2.3 elaborate further on this point of view.

Based on the work of above-mentioned authors, we define policy as a set of agreements between a number of involved actors to act, separately or jointly, to alter a problematic situation or a matter of concern. The agreements concern the commitment, e.g. in terms of money, manpower and actions, of the actors involved, within a given period.

These components evolve and change over time, depending on the stage of the policy process, the interests of the actors (including the gowernment) and contextual factors.

Public policy concerns issues brought to the attention of the government and the courses of action that are taken to address these issues (Nutbeam, 2004 a). Public policy is an attempt by the government to influence social processes. In ather words, the government tries to influence the policies and actions of actors in the policy domain (e.g. industries, professionals, students) with instruments like education, regulations, legislation and subsidies (Hoogerwerf, 1998). Public policy is also considered to have a profound impact on population health (Milio, 1986). Although other decisions and actions may have a similar effect (e.g. in the private sector), the present study looked exclusively at public policy.

Public policies can be classified as 'high politics' or 'low politics' $(G$. Evans \& Newham, 1992). High politics are issues of major importance and interest to the national state, e.g. security or economic crises. Low politics do not concern issues of a state's national interest or those of important groups within the state; examples include education and health. Local administration

IStone (1907) compares the market and 'polis' models of society. Reason and the individual are central to the market madel, whereas the 'polis' model centres on the community. Policy and politics can only emerge in communities. Public policy signifies the efforts of the community to achieve something a a community /collective targets. Public interests are planned for and emulated at all times. There is, however, a constant tension between public and individual interests (called 'commons problems') in the "polis', which is neutralised by strong forces like influence, collaboration and loyalty. 
also deals, with issues of either high (e.g. municipal restructuring, economic matters, criminality) or low interest or political importance (e.g. sectoral. policies on education, welfare, preventive health). Public policies of great interest may have consequences for sectoral policies (low politics). For example, policies involving budget cuts have consequences for the subsidies allocated to sports clubs.

A dominant concern in current policy research is the influence various actors may or may not have on decisions that determine the policy process. The literature makes a distinction between elitism, pluralism and bounded pluralism (Walt, 1994). There is a group of policy scientists who adhere to the elitist view, in which political choice and change are considered to be dominated by a ruling or influential class. The policy-making process is not accessible to outsiders beyond this restricted group. The pluralist view, however, regards power as being diffusely distributed throughout society. Public policy emanates from the coalescing of stakeholder positions and powers that become more influential over the decision process than other clusters of stakeholders. Bounded pluralism takes an intermediate position: an elitist group takes decisions on issues of high politics, while issues of low politics are open to participation.

According to Walt (1994), health issues can be classified as low politics. The fact that health does not regularly appear on the policy agenda also demonstrates the low status of the subject (Gooskens, Kornalijnslijper, \& Veen, 1997). Therefore, health policy-making in general is open to interested parties outside government, like professional organisations and special interest groups or population groups.

\section{Defining health policy}

Health policy has been addressed from different points of view and covering different activities. Goumans (1998) distinguishes two approaches to health policy development. One approach starts from a health perspective. It centres on health problems, and the idea is that these can only be addressed through contributions by multiple actors and sectors. Health policy-making is therefore an intersectoral endeavour. A second approach starts from a sectoral perspective. The starting point in this approach is the assessment of actions, plans and policy decisions of all policy sectors, and their impact on people's health. This is already the generally accepted practice for the economic and environmental consequences of public policy decisions. The latter policy approach is also called healthy public policy. De Leeuw [1989) asserts that healthy public policy specifically aims at health promotion and that, while the development of healthy public policy may take place through multisectoral approaches, it is guided by one governmental health sector crossing traditional departmental and ministerial boundaries (p. 42).

Local health policy provides a framework based on traditional public health, which centres on the prevention of illness and accidents in the population. The description of local health policy given by Belleman (1994) distinguishes four fields of activity: health protection, disease prevention, health promotion and health care (see section 1.1.2). Health protection policies aim to protect people against exposure to harmful substances or environmental hazards. Disease prevention policies aim to prevent and reduce diseases in the population or specific groups. This can be achieved through health education but also by vaccination and screening programmes. Health promotion policies comprise measures and programmes to influence people's health 
behaviour and lifestyles, as well as current social norms concerning health in society. It aims at making health and well-being the goal of action. Health care policies aim at the health care sector and focus on the care and cure of disease. Although the above encompasses many strategies to promote people's health and provides a clear linkage between cure, care and prevention, it remains disease-centred. On the other hand, the conceptualisation of health as a resource for living, and the idea of health promotion (as described in the previous section) provide a different vision for the development of local health policy. In this sense, the obligation to develop local health policy explicitly invites municipal authorities to go beyond collective prevention and the tasks defined within it. It challenges municipal authorities to actively create healthy living conditions for their citizens and to enable them to participate in this process. Local health policy may embrace all planned actions of other administrative and societal sectors besides health.

To define concepts like health policy is an intricate issue. Duhl $(1993,2000)$ argues that it does not mean favouring one approach over another but having available several ways of thinking about health and many ways of applying conceptual structures in concrete interventions, which one can choose from or combine.

The present study investigated what approach municipal administrations have used in local health policy-making and how they have defined their responsibilities and those of others.

\subsubsection{The policy-making process}

The process of policy-making can be characterised by a rational approach or by an interactive approach. Hoogerwerf (1998) says that policy development takes place according to a certain process characterised by dynamism, interaction between factors and actors, and a clearly identifiable coherent chain of events between two points in time. These characteristics indicate that there are several phases or constituent processes to be recognised in the policy process. In general, the policy process can be divided into the following phases: (1) agenda setting, the process through which issues in the social domain are brought to the attention of the public or the policymakers, (2) policy preparation, the process of designing and planning the policy, (3) policy formulation, the decision-making process about the content of the policy, (4) policy implementation, the implementation of the policy (5) evaluation of the policy, (6) adjustment of the policy on the basis of evaluation findings and (7) termination of the policy. Hoogerwerf says that going systematically and consciously through these phases is the most effective way of analysing problems and dealing with them. This rational approach seems to be based on the classical model of policy-making in which a small number of people, mainly the civil servants and governor or administrator form and decide upon a policy. It implies a rather top-down activity from government to society, mainly by means of regulations. This fits in with the view of policy in terms of strategic and instrumental planning (see section 2.1).

The rational, prescriptive approach described above has been criticised by many policy scientists (de Leeuw, 1989a; Milio, 2001; Stone, 1988, 1997; van Heffen \& Kerkhoff, 1997; Walt, 1994) over the last decades. They conceive of the policy development process as an interactive process influenced by the warious stakeholders involved. They doubt, for a variety of reasons, that (governmental) policymakers behave in a rational and objective way in solving (health) 
problems. This is demonstrated by the fact that objective knowledge developed by scientific research, although available, does not lead to congruent policy decisions (Catford, 2003; de Leeuw, 1993; Dean, 1996; Glouberman \& Millar, 2003; Nutbeam, 2004 a).

The grounds for criticism, and at the same time the reasons to assume the contemporary policy process to be interactive and dynamic, are summarised below. The distinction made here, between complexity, politics and communication, is rather artificial because in reality these aspects are highly intertwined.

\section{Complexity}

One of the criticisms of the rational approach is the complex character of many contemporary health problems (e.g., health inequalities, ageing, deprivation). This complexity does not allow for a detailed problem analysis or for a correct estimation of the effects of a proposed solution to the problem [Kenis \& Schneider, 1991). It requires consulting various specialists, resulting in the increasing participation in public policy-making of actors outside the government and in mutual interdependency (see also section 2.3.2, which discusses the network perspective of policy-making]. Van Heffen (1997) argues that problems are 'coloured' because they are always perceived from a certain perspective (which is formed by factors like training, norms and values). In this light, problems can take on another meaning for people with different backgrounds, interests or (power) positions ( $\mathrm{H}$. de Bruijn \& ten Heuvelhof, 2000). Addressing complex problems involves a range of actors. Also, different views of the problem emerge, which have to be discussed to solve the problem. This brings us to the next point: politics

\section{Politics}

In low politics, issues have to compete with other issues to get the attention of policymakers and to reach the poiltical and policy agenda. Some of the agenda setting theories emphasise certain criteria that the problem or issue has to meet before it can reach the policymakers' agenda (e.g., legitimacy, feasibility, support, social relevance, long, term relations, and the importance in comparison with other issues) (Cobb \& Elder, 1983; Hall \& Quinn, 1983). They ignore, however, conflict aspects such as the different interests stakeholders introduce into the policy development process, and aspects of power distribution (de Leeuw, 1989a). Stone $(1988,1997)$ says about the formulation of issues that they are created in the minds of people by other civilians, leaders, organisations and governments, and not through objective analysis.

Walt $(1994)$ and Stone $(1988,1997)$ state that policy-making has less to do with problem solving than with a political process. Problem definition is always a strategic activity to gain support for a certain point of view or a particular side in a conflict. Problem definition occurs through stories, metaphors, ambiguities and symbols, of which figures (counting) are the most popular (Stone, 1988,1997).

\section{Communication}

The participants in the policy process affect policy-making, each with their specific interests in the matter at stake. According to the incremental model described by Lindblom (1959), the divergent interests of the numerous participants involved in the policy-making process result 
in a bargaining, negotiation and adaptation process among these participants. As a consequence, new policies resulting from this process differ only marginally from existing ones. De Leeuw (2000b) argues that the policy process has a complex character because policy-making is increasingly a matter of communication. The opportunities and abilities of participants in a policy network to communicate, and the factual communication and exchange of information, expertise and other resources that take place determine whether policy is made and what its content is (Laumann \& Knoke, 1987).

Other policy scientists take an even more extreme view, by characterising the policy process as complex, disordered, coincidental and hardly open to analysis (Hogwood \& Gunn, 1984; Kingdon, 1984, 1995). The next section outlines the view of Kingdon on agenda setting and policy-making.

\subsection{4 'Theory of Streams'}

'The rise of an item is due to the joint effect of several factors coming together at a given point in time, not to the effect of one or another of them singly" (Kingdon, 1984, 1995 p.179).

Kingdon has studied policy-making at national level in the USA, and has developed the "Theory of Streams' (Kingdon, 1984, 1995). This theory presents a distinction between 'agenda setting' and 'specification of alternatives'. The former deals with the appearance of an issue on the political and policy agenda, while the latter concerns the process of specification (development) of policy proposals in such a way that they become highly likely to be chosen as solutions to a certain problem. The distinction between 'agenda setting' and 'specification of alternatives' is a conceptual one. It does not indicate a time order, as the two concepts may emerge simultaneously.

\section{Three streams: problem stream, political stream and policy stream}

The model presents three streams: the problem stream, the political stream and the policy stream. Each stream has its own typical process, which is rather independent from those in the other streams. The process in the problem stream is characterised by problem recognition. A number of factors focus the attention on a problem or issue of concern: the magnitude of a condition, a change for the worse, a shocking event like a disaster and results of the evaluation of interventions. Much of the information on these factors is provided by professionals and researchers. For an issue to rise on the political and finally, on the policy agenda, administrators and politicians need to be convinced of the seriousness and magnitude of the issue.

The fluctuations in the general political mood (among citizens) and in the ruling political ideology (of political parties) determine the dynamics in the political stream. The results of elections and the subsequent government programme can either include or exclude certain issues.

Many ideas (alternatives) tend to be present in the policy stream. These ideas or policy proposals are selected on the basis of certain criteria, such as feasibility, harmonisation with current norms and susceptibility of politicians. Alternatives go through a lengthy process of socalled softening-up before becoming accepted. Professionals and researchers create and test new alternatives, and bring them to the attention of policy makers, other professionals and the public, in an iterative manner. Softening-up means that incremental changes to existing solutions 
or a recombination of known elements into new formulas are more relevant than inventing completely new solutions. Atternatives per se are not linked to a certain problem but are softened-up in such a way that they can be linked to a variety of problems. For example, community-based work is a solution to security problems in a communiry but also serves to reduce health inequalities. This contradicts the problem-solving view of policy-making, which assumes that after having objectively analysed and defined a problem, the most appropriate solution can and will be chosen. In the theory of streams, solutions look for problems to be connected with.

\section{Participants}

In all three streams (problem, politics and policy), Kingdon presents visible and invisible participants who take part in the process. The visible participants are the official (government) administrators, political leaders and the media, who particularly influence agenda setting. The invisible participants are the civil servants, specialists (professionals) and researchers, who mainly influence the specification of alternatives. Among these visible and invisible participants, one can take the role of poilicy entrepreneur. This may be any of the participants, as there is not one typical participant who dominates the pool of possible entrepreneurs. Policy entrepreneurs: are active for a long time; they invest in the forming of policy by bringing in key resources (their claim to a hearing, their political connections and their negotiating skills and persistence) to safeguard their interests in the long run. A policy entrepreneur presents participants in the prepolicy processes ('the streams") with alternative representations of the same issues in problems, politics and policies.

\section{Coupling of streams}

An issue reaches the political agenda when the problem stream is coupled with the political stream. This can happen at a predictable occasion, for example in a pre-election period or at annual budget debates, or after an unforeseen event, such as a disaster. $A$ decision is made to really act on an issue (the issue has reached the policy agenda) when all three streams are coupled (see Figure 2.2). Thus, a problem has been recognised, the solution is acceptable and the time is

\section{Kingdon: streams \& windows}

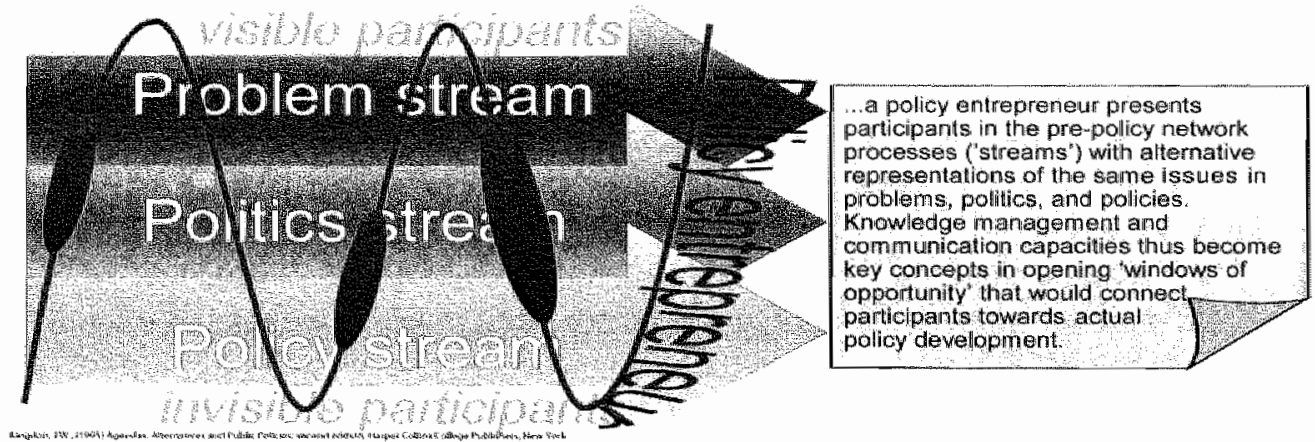

Figure 2.2 Representation of the 'Theory of Streams' (Hoeijmakers, 2004) 
ready. When this coupling of the three streams takes place, a so-called "window of opportunity" is open. According to Kingdon, this is the most opportune moment for policy-making. A window of opportunity' is open only for a short time and needs the adequate intervention of a policy entrepreneur at that very point in time. Such an entrepreneur is, however, only able to couple the three streams due to her/his permanent readiness and activities in agenda setting and the specification of alternatives. Knowledge management and communication capacities are the key concepts in opening a 'window of opportunity' that would connect participants towards actual policy development (see Figure 2.2).

\section{Critical appraisal}

Kingdon points out the complexity and unpredictability of (unstructured) policy processes, but also gives some indications how to intervene in these processes, of which knowledge management and communication are the most important ones. Policy decision-making occurs at the interface of the development of the three streams, situational factors and the interaction of the participants in the process.

Kingdon gives an explanation of policy-making based on an interactive policy approach. He acknowledges the presence of stakeholders and emphasises their roles and actions, in particular those of pollicy entrepreneurs, in the problem, political and policy processes.

The stakeholders described by Kingdon are mainly individuals: politicians, experts, policy entrepreneur and bureaucrats. This focus on individuals runs counter to modern insights into the type of actors participating in the policy process (see also 2.2.2). Laumann and Knoke (1987), for example, assert that policy-making is a corporate endeavour. This may be particularly true for the health domain, where intersectoral collaboration in policy-making is said to be a prerequisite (Goumans, 1998; Milio, 2001; Ruitten et al., 2000). Advocates of a healthy public policy also call for the participation of the population in policy development (Baum, 2003; de Leeuw, 2000; Smedley \& Syme, 2000; WHO, 1988).

Another shortcoming in Kingdon's theory is the fact that he does not explain why the stakeholders (hidden and visible participants) can exert influence and how their interrelatedness and interactions affect the policy-making process. In fact, he neglects the network perspective on policy-making. Nor does Kingdon explain whether the policy entrepreneur has a specific position within the network enabling her/him to play the described role.

\section{Conclusion}

The policy process moves through a number of distinct phases, but not in a very orderly fashion. Health policy-making is open to several actors. We have argued in this section that policy-making is about communication and interaction between the actors involved. The way they exert their influence depends on individual characteristics but also on their interrelationships. These factors are closely linked to health promotion principles which emphasise the participation and collaboration of different actors and sectors in the health domain, including policy-making. However, the theories described in this section do not provide much insight into these issues. We are left with questions about the composition of policy networks: who is able to influence the policymaking process, is there a policy entrepreneur at work and who is in the best position in the 
network to assume such a role? To answer these questions and add to our understanding of policy-making processes, we have integrated the literature on stakeholder analysis and network. analysis in this study. The next section describes this work.

\subsection{STAKEHOLDER AND NETWORK ANALYSIS}

Section 2.1 , on health promotion, described the complexity of the health domain, including the need for participation by the population and for the collaboration of several sectors to address commonly perceived (health) problems. In section 2.2 we further elaborated on this complexity and argued that health policy-making is characterised by communication and interaction between numerous actors, and by their interdependency. in this perspective, the role of the government in the policy process is no longer considered to be necessarily central.

The analysis of positions and connections between actors in more or less stable sets or networks originates from policy and political sciences, but is rooted even more deeply in social science in general [Kenis \& Schneider, 1991; Knoke, 1990; Scott, 1991, 2000). This section explores the possibility of integrating knowledge about individual actors and their interrelatedness in our study on local health policy-making. It starts with a description of stakeholder analysis, followed by network analysis.

\subsubsection{Stakeholder analysis}

Stakeholder analysis has become popular in a range of settings, including organisations (from a managerial perspective), the development of projects and programmes, and policy-making (Brugha \& Varvasovszky, 2000).

In general, stakeholder analysis is a tool used to obtain information about actors (e.g., behaviour, interests, involvement, influence and resources) to see if particular actors are relevant to a particular organisation, project or policy. Managers in orgamisations use stakeholder analysis as a tool to achieve specific targets and advantages in the negotiations with other organisations. Organisations use the identification and knowledge about stakeholders to create alliances in order to reinforce their position and to ward off threats. In the development of projects and programmes, stakeholder analysis provides information on the support or resistance from parties involved in planning, implementation and evaluation. The aim of stakehclder analysis in policy-making is two-fold. First, it can be used to create support for policy decisions and commitment for the implementation of policy. Welsh and McGinn (1997) have worked on a methodology of stakeholder analysis (specifically stakeholder identification) in this sense. Second, stakeholder analysis is used to examine policy processes. It highlights the importance of actors and interest groups in the policy-making process. Such information may be used to assist policymakers in making policy choices and in predicting and influencing policy development, as well as to assist in policy implementation (for further reading see the review by Varvasowszky \& Brugha, 2000j. The strength of stakeholder analysis, and at the same time its principal limitation, is its use to predict and provide information to influence the future, because such use requires the application of a short-term perspective, as information 'expires' quickly.

Although stakeholders may be defined, according to the context, in different ways, in the 
present study we adhered to the definition of stakeholders given by Varvasovszky and Brugha (2000 p. 341). They define stakeholders as actors who have an interest in the issue under consideration, who are affected by the issue or who - because of their position - have or could have an active or passive influence on the decision-making and implementation processes. They may include individuals, organisations and different individuals within an organisation, as well as networks of individuals and/or organisations, e.g., alliances.

In our study, we have assumed that health policy-making is an interactive process open to public officials and private individuals, groups, organisations and/or alliances with different backgrounds. We decided to use stakeholder analysis as a tool to get to know the stakeholders in local health policy-making. The information generated by the stakeholder analysis was expected to provide us with insights into the policy-making process. More specifically, we were interested in knowing how the characteristics of the stakeholders involved relate to the development of the policy process and its specific outcome. We studied the policy-making process from the outside, that is, not with the purpose to feed back our findings directly to the cases. Our stakeholder analysis was not only interested in the identity of the stakeholders but also in their individual characteristics in terms of interest in the development of health policy, involvement (in policymaking and in the health domain in generall, the perceived impact of the issue, the perceived influence and the relations between the stakeholders.

For 36 months, we monitored the change or stability of the stakeholders and their characteristics. Stakeholders were identified by means of snowball sampling. The analysis took place at the local level (four municipalities) including local stakeholders as well as stakeholders who were organised at the regional level but active locally. We were able to reach and interview all identified stakeholders individually on several occasions in the above period.

\subsubsection{Network analysis}

Stakeholder analysis provides information at the micro-level, that is, the individual level of actors involved in and affected by the policy process. However, we also needed information at the meso-lewel, that is, the relationships and connectedness in a set of stakeholders in the lhealth domain. The network perspective on policy-making has already been mentioned briefly in section 2.2 , but will be developed in more detail in this section.

According to Kenis and Schneider (1991), a decentralised concept of social organisation and governance is at the core of the network perspective of society. This also indicates the limitations of the government's capacity to guide social processes, individuals, groups and organisations, and necessitates adaptation of co-coordinative arrangements (J. A. de Brujin, Kickert, \& Koppenjan, 1993; Godfroy, 1993). When this concept of networks is applied to policy analysis, it helps to improve our understanding of the evolution of contemporary policy arrangements. Kenis and Schneider assert that contemporary policy processes emerge from complex actor constellations and resource interdependencies, and that decisions are often made in a highly decentralised and informal manner (p. 27).

Thinking about policy-making in terms of policy networks has been triggered by a number of changes in modern society and in concepts of governance and coordination. We highlight only some of the main points here. First of all, modern society has become highly organised, 
in the private as well as the public aomain. In addition, organisations have become extremely specialised, which is reflected in a high degree of functional differentiation and 'sectoralisation' in society and within organisations ( $\mathrm{H}$. de Bruijn \& ten Heuvelhof, 2000). A comparable development has been observed at the governmental level. For policy-making, this implies an increasing number of participating social and political actors. The fragmentation and specialisation of society in general and government in particular causes an increase in policy issues and a need for horizontal communication, collaboration and coordination between sectors and disciplines (Godfroy, 1993). As a result of these developments, boundaries between the private and public domain have faded and interdependencies have been formed (J. A. de Bruijn et al., 1993).

Knowing why the network perspective emerged, we now turn to a brief description of the properties of policy networks and their definition to come to grips with this concept. A number of characteristics, based on the work by Hufen and Ringeling (1990), Godfroy (1993), Kenis and Schneider (1991) and de Bruijn and Heuvelhof (2000), are described below:

- Variety of actors: the actors in a policy network differ in terms of size, interests, means of exercising power and, very importantly, perception of problems.

- Reservations on the part of individual actors: the actors involved in the network are only willing to cooperate if an intervention fits in with their identity or interests. They strive for autonomy.

- Mutual dependency: the actors depend on each other's resources and decisions to develop their own actions. Moreover, each actor is capable of steering the actions of other actors in the policy network.

- Fragmented problem solving abillity: actors also depend on each other's resources and capacities to solve the policy problem.

- Coordination by bargaining: decisions in the policy network result from consultation and a bargaining process, and are based on unanimity.

The field of public health in the Netherlands is currently also characterised by a decentralisation of steering and coordination responsibilities from central to local government (see section 1.1.2), a process which applies to an increasing number of subjects, such as public mental health, domestic violence and preventive youth care. These subjects, as well as the established issues in public health, are in the hands of numerous specialists. Thus, municipal authorities will have to get involved with many professional and non-professional organisations and groups, within as well as outside their hierarchical control, which are indispensable for policy development and implementation in the public domain. Part III of this thesis describes what position local government has in the policy network, how it relates to other stakeholders in policy-making and how municipal administrations have perceived their role in policy-making.

A general conceptualisation of policy networks as patterns of interaction between mutually dependent actors who are formed around policy problems or programmes, is given by de Bruijn (1993). Since, however, we prefer to acknowledge the above core components of policy networks, we prefer the definition of policy networks given by Kenis and Schneider (1991), who claim that policy networks should be understood as 'those webs of relatively stable and 
ongoing relationships which mobilise dispersed resources so that collective (or parallel) action can be orchestrated toward the solution of a common policy problem' (p. 36).

\section{Practice of network analysis}

Network analysis can be a powerful tool for policy analysts to describe and measure the interactions between actors and the structure of the network. Brass et al (2004) recently evaluated organisational network research, which focuses on relations among actors (individuals, work units or organisations] instead of focusing on attributes of actors in isolation. The network perspective argues that actors are embedded within a network of interconnected relationships that provide opportunities and constraints on behaviour (p. 796). Knoke (1990) has analysed networks from a structural perspective. In this perspective, the basic units of analysis are the positions taken up by social actors and the relations or connections between these actors. Knoke and Kuklinski (1986) assert that the structure of relations among actors and the location of individual actors in the network have important behavioural, perceptual and attitudinal consequences for both the individual units and for the system as a whole.

The relations that connect pairs of actors in a network have both form and content. Form refers to the intensity of the interaction (the strength or frequency of interaction and the level of joint involvement in activities), while content refers to the type that is the meaning of the connections (reason for interaction) between actors in the network (e.g., political, and exchange of information, resources or expertise) (Knoke, 1990).

Data on these relations between social actors in a network can be displayed in matrices and network graphs, and can be used in computerised statistical programs. In network analysis, many measures can be used to describe network-level properties and structures. For further reading, see Knoke and Kuklinski (1986), Scott $(1991,2000)$ and Wasserman and Faust (1994). Provan and Milward [1995] assert, however, that even when properties and structures are described at network level, issues of network outcomes are mostly ignored (p. 2). Assessing network effectiveness becomes important when overall outcomes not only depend on the actions of individual actors but on the co-ordinated action of the network as a whole (the whole is bigger than the sum of the parts). In our opinion, this argumentation is extremely relevant to policy-making in the field of health. Because of the interactive perspective on policymaking and the low level of interest allocated to health, health policy-making involves many stakeholders. Moreover, individual actors cannot solve health problems and the complexity of the field requires the co-ordinated action of multiple disciplines.

This raises the question whether there is any relationship between the structure of local health policy networks and the effectiveness of these networks in creating integrated local health policies in an interactive and intersectoral manner. Although this question is relevant, we can only relate network features to the outcomes of the criteria (see the evaluative framework in section 2.4 ) in the evaluation of policy-making. Thus, we used only those very specific features and measures in network analysis that serve the research questions described in chapter 1 , and the operationalisation of a number of the evaluation criteria described in the next section. In this respect we focused on the density of the networks and centrality measures (point centrality, closeness and betweenness). These network features and their applications are explained briefly below, and more in detail in chapter 6 . 


\section{- Density}

Density describes the extent to which all actors in the network are linked to each other. It refers to a general level of cohesion and integration of the network. Density is expressed as the ratio of the number of actually observed relations to the potential number. The structure of a network can also be described by characterising the connections (paths) between actors: for instance, a network is strongly connected if every pair of actors is reachable through direct and reciprocal ties.

The density measure serves our purpose because it gives information about the participation of specific stakeholders in policy-making, their relations and their integration in the network. More specifically, it indicates whether the participative and collaborative character of policy processes advocated by health promotion specialists has materíalised.

\section{- Centrality}

The centrality of an actor (point centrality) is defined as the extent to which an actor is visible within a network through direct and indirect ties to other actors. It describes whether the cohesiveness of the network is concentrated around particular actors in the network and whether particular actors are more in control of the network activities than others. This measure served our purpose by answering questions on the coordination of the policy-making process, and the position specific stakeholders have in the network and the influence they can exert in policy-making. Moreover, we used actor centrality to indicate the position of a possible policy entrepreneur in local health policy-making.

\section{Conclusion}

To study health policy-making at the local level, we have developed a broad theoretical framework with key components of health promotion and current perspectives on policy-making. To analyse the policy processes and their outcomes in the four cases of our study we have added two new tools for health promotion research: stakeholder analysis and network analysis. Stakeholder analysis can provide us with information at the micro-level, that is, the characteristics of individual stakeholders, while network analysis can help us examine the structural aspects of networks, that is, the meso-level.

The theoretical concepts are combined in a comprehensive evaluative framework, presented in the next section. Stakeholder and network analysis will assist us in assessing the presence of a number of these evaluation criteria and their indicators in the policy processes studied.

\subsection{AN EVAlUATIVE FRAMEWORK FOR LOCAL HEALTH POLICY-MAKING}

Section 2.1 asserted that the development and implementation of health interventions should be guided by theory, and the same applies to research. Evaluation research in policy-making should be informed by theories on the structure and dynamics of the policy process and theories that can guide research in complex circumstances (Rütten, 2001). Although it may seem obvious, 
it might be useful to mention that a sound theoretical framework is at the basis of data collection, and in our study it was indispensable for analytical generalisation (Birckmayer \& Weiss, 2000).

In the preceding sections of this chapter, we have revised essential theoretical issues in health promotion and policy development that were relevant to our study on the development of health policy at the locall level. Both fields are characterised by complexity, which means that singular theoretical concepts do not suffice. Moreover; we identified two analytical tools: stakeholder analysis and network analysis. This theoretical framework, and the rationale behind the legal obligation for municipalities to make local health policy, formed the basis on which we constructed an evaluation instrument, which is outlined below. Evaluation of policy development in terms of principles used by policy analysts of the rationalist school has not been considered, as it did not fit in with the research questions and the chosen perspective on policy-making.

Since no instruments were available to evaluate health policy-making at the local level, we had to develop an instrument specifically for the purpose of this study. The framework presented below resulted from a carefully and purposively implemented development process. It reflects the multiple units of analysis and levels of data collection presented in Figure 1.1. The concepts were derived from health promotion, policy theory and network theory. Subsequently, these concepts were operationalised as criteria and indicators. Finally, the instrument was presented to a number of experts in the health promotion domain and in organisational and policy sciences. After the adjustments recommended by them had been made, it was presented to them once more for final comments.

\subsubsection{Criteria and indicators}

This section presents a comprehensive and coherent framework of criteria, with respective indicators, which assisted us in evaluating the policy process and its outcome at the municipal level. The criteria are categorised into five themes: perspectives on local health policy, the municipal administration's role in policy-making, stakeholders, policy network and the Regional Public Health Service (RPHS). Finally, a checklist is presented, featuring the same criteria in a condensed form.

\section{PERSPECTIVES ON LOCAL HEALTH POLICY}

We have described two approaches to health policy: one from a health perspective and one from a sectoral perspective, and we have presented a generally accepted subdivision of local health policy into four fields of action: health protection, disease prevention, health promotion and health care. Furthermore, we have argued that health promotion is a comprehensive, multi-strategy approach, addressing multiple levels, but well adapted to the local situation.

The theme discussed here comprises four criteria, which assess how the municipal administration and other actors involved in the policy process perceive and develop local health policy.

\section{Local health policy is integrated policy (criterion)}

1.1 (indicator) Local health policy involves other departments within the local government organisation than the health department, for instance the education, social affairs and housing departments. Involvement refers to the participation of these departments in the 
palicy-making process, which may be a symbolic or a tangible participation. In addition, the involvement of other departments can be either pro-active or re-active.

1.2 (indicator) The policy-making process involves actors (organisations, groups, individuals) outside the local government, such as social work agencies, health professionals and interest groups. Inwolvement refers to the same aspects of participation as described under 1.1.

1.3 (indicator) The local government sets objectives for all four components of local health policy referred to in section 2.2 .2 (health protection, prevention of disease, health promotion and health care).

2. Local health policy is a translation of the perspective and choices regarding health made by the municipal administration.

2.1 Local health policy is informed by data emanating from the municipal level, but not necessarily from epidemiological research alone.

Policymakers have access to and use different sources of information: epidemiological data at municipal or sub-regional level (including data on social determinants of health), data from practitioners and data from civilians.

2.2 Local health policy is in line with the municipal development plan. In other words, the general mission statement of the current municipal administration and the municipal approach to health matters are compatible.

2.3 Local health policy reflects a certain perspective on health, either the health perspective or the sectoral perspective.

\section{Local health policy is based on epidemiological considerations.}

3.1 Health problems are prioritised according to national or regional epidemiological reports on the health status of the population.

\section{Local health policy improves the situation of individual patients or clients, target} groups or the population as a whole.

4.1 The policy consists of objectives and a set of coherent instruments, resources and facilities. The local health policy memorandum proposes concrete instruments, means and facilities to achieve specific objectives, is in search of them or does not mention them at all.

\section{MUNICIPAL ADMINISTRATION'S ROLE IN POLICYMAKING}

Chapter I described the historical background of local health policy-making. The Minister for Health, Social Welfare and Sports at the time, late 1990's, wanted to stimulate, revive public health at the local level and decentralise responsibilities for it from national to local government. One of the instruments to achieve this goal was to oblige local governments to develop a local health policy every four years.

This theme comprises six criteria, which refer in general to the role of the municipal administration in policy-making (5-6) and in particular to those of the politicians and officials responsible for public health $(8-9)$. We also examined whether health has become a topic of debate at the local level. 
5. The municipal administration bears the chief responsibility for the development of local health policy.

5.1 The municipal administration facilitates the policy process, creating favourable practical conditions, for instance by selecting and inviting participants in the development of local health policy.

5.2 The municipal administration creates the necessary opportunities for stakeholders to collaborate with them. It assesses which organisations, groups or individuals could contribute to the solution of identified problems.

6. The municipal administration provides financial and other resources needed to achieve the objectives. In our study we examined what resources the municipal administration provided and whether these were allocated to the actor $[s]$ who was/were in the best position to achieve each objective. Four situations can be distinguished:

(a) resources are allocated to the municipal authorities because they are in the best position to solve the problem; (b) resources are allocated one of the stakeholders because he/she is in the best position to solve the problem; (c) resources are allocated to the municipal authorities even though another party is in the best position to solve the problem; (d) resources are allocated to another party even though the municipal authorities are in the best position to solve the problem.

7. Health is a political issue.

7.1 The long-term policy plan proposed by the local administration ('college programma', 'raadsprogramma') mentions health explicitly.

7.2 Apart from the obligation to develop local health policy, health appears as an item on the political agenda.

8. The development of local health policy requires political commitment.

This refers in particular to the involvement of the politicians responsible for public health and other members of the municipal administration.)

8.1 The character of the political parties represented in the local administration reflects their point of view on health.

8.2 The politician responsible for public health in a particular municipality represents a political party with clear ideas on health issues.

8.3 If so (8.2), this politician has made an issue of health in the coalescing negotiations after the municipal elections in March 2002. The outcome of this process relates to the point of view on health presented in the long-term policy plan of the same administration.

9. The development of local health policy requires commitment on the part of public health officers.

9.1 Public health officers take a broad view of their task in policy-making. They put in great effort to develop local health policy. 
9.2 Public health officers do not work in isolation but have an internal and/or extemal reference group. Internally, they may consult with colleagues or the head of their department, externally with colleagues in the region or professional consultants.

\section{Other departments within the municipal organisation review their policy decisions in terms of their impact on health.}

10.1 Other departments than the health department mention health in their policies.

\section{STAKEHOLDERS}

Policy-making has increasingly become an interactive process, in which the interests and influence of the stakeholders involved have considerable impact on the policy process and its outcome. At the same time, health problems require the involvement of and collaboration between stakeholders from different sectors.

This theme comprises three criteria relating to the involvement and contribution of individual or groups of stakeholders in the policy process (including some aspects of the implementation of local health policy).

\section{Local health policy is based on the interests of stakeholders.}

11.1 Stakeholders give information. They participate in meetings with public health officers and politicians and share their experience and knowledge of health problems and the solutions to these problems.

11.2 The information given by stakeholders is represented in the policy.

12. The better the organisational interests of stakeholders are served, the stronger their involvement.

12.1 This refers to the creation of a strong basis of support and involvement by stakeholders, by giving them a well-defined task in the process of achieving of the policy objectives.

12.2 A division of tasks among stakeholders in relation to the described objectives is included in the Jocal health policy memorandum.

13. Local health policy is based on existing strategies of stakeholders to solve current health problems.

13.1 Stakeholders (in particular professionals) regard the policy process as an occasion to reformulate and propose their favourite solutions as policy proposals.

13.2 Stakeholders perceive their influence as positive. Stakeholders think that their contribution is valued and they see their contribution reflected in the local health policy memorandum.

\section{POLICY NETWORK}

The actors involved in policy-making make up the policy network. Their positions and interrelatedness may create opportunities for them to influence the policy process. We have seen above that health problems are complex and have to be addressed by integrated health policies. Moreover, we have argued that it takes the involvement of actors from different sectors 
to develop such an integrated health policy, but that at the same time the active intervention of a policy entrepreneur is required.

This theme comprises two criteria to assess the positions taken up by the actors involved in the policy process and to assess whether one of them acts as a policy entrepreneur.

\section{The structure of the policy network at the municipal level plays a part in the development of local health policy.}

14.1 Central actors recognise their coordinative role in the process.

Actors identified as being central in the network (actor centrality) acknowledge that their interactions with the other actors in the network are of great importance.

14.2 Peripheral actors recognise that they have a minor role in the process.

Actors identified as being peripheral to the network acknowledge that they do not have many opportunities to influence policy.

\section{One of the stakeholders adopts an entrepreneurial position and attitude.}

15.1. Stakeholders identify one or more of them as a policy entrepreneur.

The actors of the policy network regard and identify one of the actors as an entrepreneur in the policy process, that is, someone who takes initiatives, enthuses, and connects participants in defining problems and choosing solutions.

15.2 This stakeholder/entrepreneur occupies a central position in the policy network (actor centrality).

\section{THE REGIONAL PUBLIC HEALTH SERVICE}

We have assumed that the RPHS plays an important role in policy-making at the municipal level because of its advisory task in municipal health affairs and its expertise in public health issues. In the initial phase of the present research project, we had expected the community. based 'Hartslag (Midden) Limburg project to play a crucial role (see chapter 1): to provide an impulse and example for policy development.

This theme comprises two criteria, one relating to the entrepreneurial role of the RPHS and one relating to the implementation of local health initiatives by the "Hartslag' project.

\section{The RPHS is a policy entrepreneur.}

16.1 Stakeholders identify the RPHS as a policy entrepreneur.

16.2 The RPHS considers the entrepreneurial role appropriate for their participation in local health policy-making. The RPHS anticipates the new legal obligation for municipalities to develop local health policy, and their own active part in the policy process. The RPHS lobbies to get problems on the political agenda, 'softens up' favourite solutions and takes advantage of political events to get local health policy established.

17. Local health initiatives developed and managed by the RPHS' "Hartslag (Midden) Limburg' project create a favourable climate, allowing municipal authorities to base their objectives and interventions on a community-based approach. 
17.1 Local healh nitiatives are implemented in consultation with muicipal authorites and public health officers.

In the mallin, the degree of consultation between the project, the muncipal authorities and public health officess determines whether new policy based on these local health initatives will be developed. We distinguish four degrees of consultation: (1) information: the RPHS informs the municipal authorities about the implementation of local heath intiatives; 2 ) fachitation: the municipal authorites render services for the development and implementation of acivities; (3) municipal authorities play an active role in and make a tangible contribution to the development and implementation of activities; and 4) other actors (besides municipal auhorities and RPHS) are involved.

The above evaluation criteria and their indicators are once more presented in the following checklist, entitled Evaluation criteria for local health policy. This checklist also presents the concordance of the evaluation criteria with the theoretical concepts and the data sources to which the criteria were applied. 
chapter 2

Table 2.2 CHECKLIST OF EVALUATION CATEERIA FOR LOCAL HEALTH POLICY

\section{criteria}

1 Local health policy is integrated poilcy
Concordance

History of public: health in the Netherlands

$\checkmark$ Health promotion theory

$\checkmark$ Defintion of local health policy
2 Local health policy is a transtation of the perspective and choices regarding health made by the municipa: administration $\checkmark$ Perspectives on health policy

$\checkmark$ Health promotion
3 Local health policy is based on epidemiological considerations.

4 Local health policy improves the situation of individual patients or clients, target groups or the population as a whole.
5 Municipal administration bears main responsibility for the development of local health policy.

\section{Indicator}

1.1 Other departments than the health department within the local governmental organisation are involved, e.g., education, social affairs and housing departments.

1.2 Actors (organisations, groups, individuals) outside the local government are involved in the policy-making process, e.g., social workers, health professionals and interest groups.

1.3 The local gowernment sets objectives for all four components of heath policy referred to in section 2.2 (health protection, prevention of clisease, health promotion and health care).

2.1 Local health policy is informed by data emanating from the municipal level, but not necessarly from epidemiological research alone.

2.2 Local heatth policy is in the with the municipal development plan. In other words, the mission statement of the current administration and the approach to health matters are compatible.

2.3 Local health policy reflects a particular perspective on health: the health or sectoral perspective.

3.1 Health problems are prioritised according to national or regional epidemiological reports on the health status of the population.

4.1 Policy consists of objectives and a set of coherent instruments, resources and facilitites.

\section{$\checkmark$ Healthy Cities research \\ $\checkmark$ Healthy Cities principals}

What is represented by stakerolders

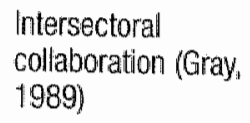
collaboration (Gray, 1989)

5.1 Municipal administration facilitates the policy process. It creates favourable conditions in a practical sense.

5.2 Municipal administration creates necessary opportunities for stakeholders to collaborate. 


\section{Check list}

participation. atutude

number of sectors

participation

atticude

number of actors

number of faids

पepi

9 completely

Inot at all

Dyes

somewhat

Dno

\section{Data source}

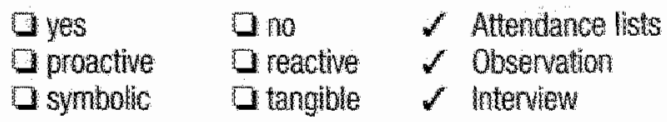

$3+12$ more

Dyes $\square$ no

Q proactive

9 reache

$\square$ tangibe
$\checkmark$ Attendance hists
$\checkmark$ Observation
$\checkmark$ Intervew

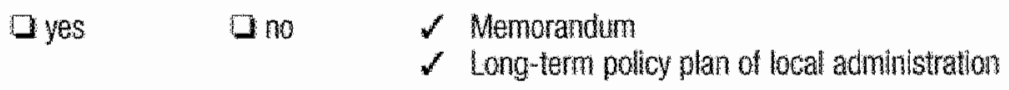

$\square$ somewhat $\square$ no $\checkmark$ Memorandum

9 concrete

Dymbolic

$\square$ no

$\checkmark$ Memorandum

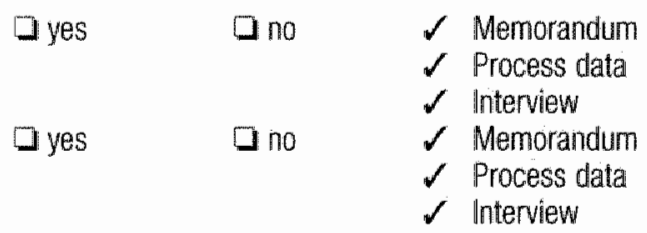




\section{Criteria}

6 Municipal administration provides (financial) resources to achieve the objectives.

7 Health is a political issue.

\section{$\checkmark$ Agenda setting theories}

\section{Concordance}

Allocation of (financial) resources is the best proof of policy-making.

\section{Indicator}

6.1 Resources allocated to municipal authorities because they are in the best position to solve the problem.

6.2 Resources allocated to one of the stakeholders because he/she is in the best position to solve the problem.

6.3 Resources allocated to municipal authorities, even though another party is in the best position to solve the problem.

6.4 Resources allocated to another party, even though the municipal authorities are in the best position to solve the problem.

7.1 The long-term policy plan of the local administration ("college van B\&W)" mentions health explicitly.

7.2 Apart from the obligation to develop local health policy, health appears as an item on the political agenda.

8.1 The character of the political parties represented in the local administration reflects their point of view on health.

8.2 The politician responsible for public health comes from a political party with wellformulated ideas on health issues.

$8.3 \mathrm{f}$ so (8.2), this politician has made an issue of health in the coalescing negotiations after elections in 2002.

9.1 Public health officers take a broad view of their policy-making task. local health policy requires enthusiasm on the parts of officials.

10 Other departments within the municipal organisation review their policy decisions in terms of the impact on health.

11 Local health policy is based on the interests of stakeholders. on local health policy

Research on political commitment

Findings of the first interviews (2001)

$$
\begin{aligned}
& \text { Health promotion } \\
& \text { (healthy public } \\
& \text { policy) } \\
& \checkmark \text { National reports } \\
& \text { (NSPOH, RVZ) }
\end{aligned}
$$

\section{Theory of Streams} (Kingdon, 1984, 1995)

$\checkmark$ Stakeholder analysis

$\checkmark$ Interactive perspective on policy-making

\subsection{Stakeholders give information.}

11.2 The information given by stakeholders is reflected in the policy. 


\section{Check list}

a+

$\square+$

-

$\square$ yes

no

on the agenda

$\square$ incidentally

$\square$ permanently

$\square$ yes

$\square$ no

$\square$ yes

$\square$ no

Dyes

口no

$\square$ plus

$\checkmark$ Observation

$\checkmark$ Interviews

0 in isolation

G internal

Dexternal

\section{Data source}

$\checkmark$ Memorandum

$\checkmark$ Action plan $\checkmark$ long -term policy plan

of local administration

$\checkmark$ Interviews

$\checkmark 2002$ Questionnaire

$\checkmark$ Minutes

$\checkmark$ Nvivo attributes

$\checkmark$ Memorandum

$\checkmark$ Unknown

$\checkmark$ Unknown, improbable

$\checkmark$ Not feasible
$\square$ yes
$\square$ no
$\checkmark$ Interviews
$\checkmark$ Process data
$\square$ yes
$\square$ no
$\checkmark$ Memorandum
$\checkmark$ Interviews 


\section{Criteria}

12 The better the organisational interests: of stakeholders are served, the stronger their involvement.

13 Local health policy is based on existing strategies of stakeholders to solve current health problems.

14 The structure of the policy network at the municipal level influences the development of local health policy.

15 One of the stakeholders adopts: an entrepreneurial posiltion and attitude.

16 The RPHS is a policy entrepreneur.

17 Local health initiatiyes devaloped and managed by the RPHS' "Hartslag (Midden) Limburg" project create a favourabile climate allowing municipal authorities to base their objectives and interventions on a community-based approach.

\section{Concordance}

$\checkmark$ Intersectoral collaboration (Gray. 1989

Theory of Streams (Kingdon: 1984, $1995)$

Network perspective on policy-making

$\checkmark$ Theory on network analysis

Theory of Streams (Kingdon, 1984, 1995)

Theory of Streams Kingdon, 1984. 1995)

Community health promotion

\section{Indicator}

12.1 A division of tasks among stakeholders in relation to the described objectives is included in the memorandum.

13.1 Stakeholders (in particular professionals) consider the policy process an occasion to reformulate and propose their favourite solutions as policy proposals.

13.2 Stakeholders perceive their influence as positive.

14.1 Central actors recognise their coordinative role in the process.

14.2 Peripheral actors recognise they have a minor role in the process

15.1 Stakeholders identify one or more of them as a policy entrepreneur.

15.2 This stakeholder/entrepreneur takes a central position in the policy network.

16.1 Stakeholders identify the RPHS as a policy entrepreneur.

16.2 The RPHS considers the entrepreneurial role appropriate for its participation in local health policy-making.

17.1 Local health initiatives are implemented in consultation with municipal authorities and public heaith officers. 
Check list

ayes

ana

$\square$ yes

$\square$ yes

$\square$ yes

$\square$ no

$\square$ yes

$\square$ no

$\square$ no

Dno

Dyes

$\square$ yes

D no

aproactive

$\square$ reactive

0 information

facilitation

a active role

other actors

\section{Data source}

$\checkmark$ Memorandim

$\checkmark \sqrt{ }$ Interviews

$\checkmark$ Interviews

$\checkmark$ Interviews

$\checkmark$ Interviews

$\checkmark$ Network graphs, centrality measures

$\checkmark$ Interviews

$\checkmark$ Network graphs, centrality measures

$\checkmark$ Interviews

$\checkmark$ Questionnaire

$\checkmark$ Network graphs, actor centrality

$\checkmark$ Interviews

$\checkmark$ Interviews

$\checkmark$ Data from Hartslag (Midden) Limburg community project 


\subsection{RESEARCH METHODS}

Chapter 1 briefly introduced the multiple research methods used in this study of local health policy. Sections $2.1-2.4$ described the theoretical framework of this study, resulting in a checklist for the evaluation of local health policy, and identified two tools to assess the above evaluation criteria and indicators, or at least some of them. This section elaborates on the specific research methods we used to operationalise our inquiry. Each method is discussed in terms of the development of the measuring instrument, its application and the analysis of the data collected.

\section{Stakeholder identification}

Stakeholder identification was applied twice, in 2001 and 2003. Stakeholders were identified by means of a snowball technique. Potential stakeholders in each case were approached by telephone with two questions: do you have an interest in the development of local health policy, and who are possible other stakeholders? After this, respondents were asked to list the ten most important stakeholders in their own municipality. Reports were made for the four cases (municipalities) separately and across cases.

\section{Interviews}

The stakeholders identified as the most important ones in the four municipalities were interviewed once in each year of the project period. In 2001 and 2003, stakeholders were interviewed personally, in a semi-structured way. The interview questions were formulated around a number of broad, key categories, e.g., the stakeholders' perspective on local health policy, their interests and their influence on policy-making (see Appendix 1). These categories were derived from the literature, and based on the theoretical framework used for this study. In addition, we consulted experts in the field of public health and policy development, and studied working documents and national reports.

In 2002, telephone interviews were held with the same stakeholders, using a structured questionnaire, to see whether they were active in policy-making at that time. At the same time, we also interviewed the aldermen and public health officers in the other ten municipalities of the Central Limburg region by telephone. These interviews were semi-structured and concerned the progress in developing local health policy in the region.

All interviews used the same protocol. The categories, interview questions and interview scheme had first been submitted to four experts for comments. The research questions had been pre-tested on foul different stakeholders in the northern part of Limburg. The researcher interviewed stakeholders at their oflice or their home (e.g., in the case of interest groups). The interview evolved on the basis of the set questions, but not in a fixed order. In addition, a form on network relations (in terms of communication, collaboration and exchange of expertise) was filled in together with the respondents (2003 interviews). For further details see chapter 6.

The interview was recorded with the respondent's permission. In 2001, the recordings were not transcribed verbatim but summarised. Three public health professionals assessed the summaries. In 2002 and 2003 , the records were transcribed verbatim. In each year, we lost the data of two respondents due to technical problems. 
We used NVivo, a software package for the analysis of qualitative data, as a tool for efficient and systematic data management and analytical procedures (Gibbs, 2002). The analytical process started by building a conceptual scheme in the form of a node structure. The nodes were generated using both a conceptual and a data-driven approach. The former approach is based on pre-established concepts from the literature, while the latter approaches the data with an open mind and generates nodes through close reading of the transcript. The central activity in qualitative research, that of coding text into nodes, started after a node book had been developed. Although such a book may seem to be a static entity, modifications to the nodes were made throughout the study, as our understanding of the data evolved. These modifications were noted in a $\log$ (a memo) in NVivo itself. This analytical log was kept during the various phases of the study, next to a log of interpretative memos. The coding of the 2001 interviews was submitted to a fellow researcher for assessment. The interview transcripts were further scrutinised through searching and linking. Information obtained from all types of documents (interviews, reports and field notes) and memos was in fact linked throughout the study, to create a comprehensive set of data providing a chain of evidence (see sections 1.3 .3 and 9.1 ).

Data obtained from the interviews on the collaboration between stakeholders and on their interrelatedness was studied in more detail. We entered these data into matrices and then entered them into Visone (www.visone.de). This program for network analysis computes, among others, density and centrality indices and creates visual network graphs.

\section{Observations and field notes}

Observations were made at two levels: the regional and the municipal level. At the regional level, the researcher attended meetings of public officers and politicians responsible for public health, as well as meetings of the health promotion department of the RPHS. At the municipal level, observations were made at meetings called because of the health policy-making process le.g. advisory committees for public health consisting of councillors; study group on local health policy; interactive sessions with actors within and outside the municipal organisation\}. In these activities, the researcher took the role of external observer or participating observer, although her participation was never similar to that of the persons observed (Angrosino \& Mays de Pérez, 2000; Maso \& Smaling, 1998). Field notes were taken and analysed on the basis of a form developed specifically for this study, with items based on the "Theory of Streams' (see section 2.2.4 Kingdon, 1984, 1995). Before the form was used, two experts had reviewed it. Field notes were imported in NVivo and linked to other information. The extent to which observational data were available in each case (municipality) depended particularly on the way the policy process was organised in the specific municipality.

\section{Document analysis}

After the municipal elections of March 2002, the long-term plans of the municipal authorities were collected from all fourteen municipalities in Central Limburg, with the aim of obtaining a general impression of the priorities (including public health issues) set in the region and to assess whether the four municipalities serving as cases were different from the other ten municipalities. The analytical scheme for these documents was based on the 'Health Force Field' (Lalonde, 1974) 
(see 2.1.1) and more specifically on two national reports, one on Health Impact Assessment (GES) (Netherlands School of Public Health, 1999) and the second on the screening of political programmes in the national election campaign of 2002 (Alphen van, 2002).

When data collection finished by the end of 2003, three of the four municipal administrations had developed and approved a local health policy memorandum. These memoranda were studied on the bases of an analytical scheme derived from the evaluation criteria (see section 2.4\%.

\section{Additional data}

Minutes from regional meetings of the aldermen and officers for public health, as well as the data recording forms (developed for this study) filled out by the policy assistant of the RPHS, were screened for issues like communication on local health poilicy between the RPHS and the municipal authorities, attention devoted to the development of local health policy in meetings, and roles assigned to either the RPHS or the municipal authorities.

The contribution made to local health policy-making by the community-based Hartslag (Midden) Limburg project was assessed using a number of research methods. A description of these methods and levels of application is presented in chapter 3.

The findings resulting from the above research methods were triangulated and then used for the application of the evaluation criteria (see Figure 2.3). The results of this application are reported per case and across cases in chapter 8.
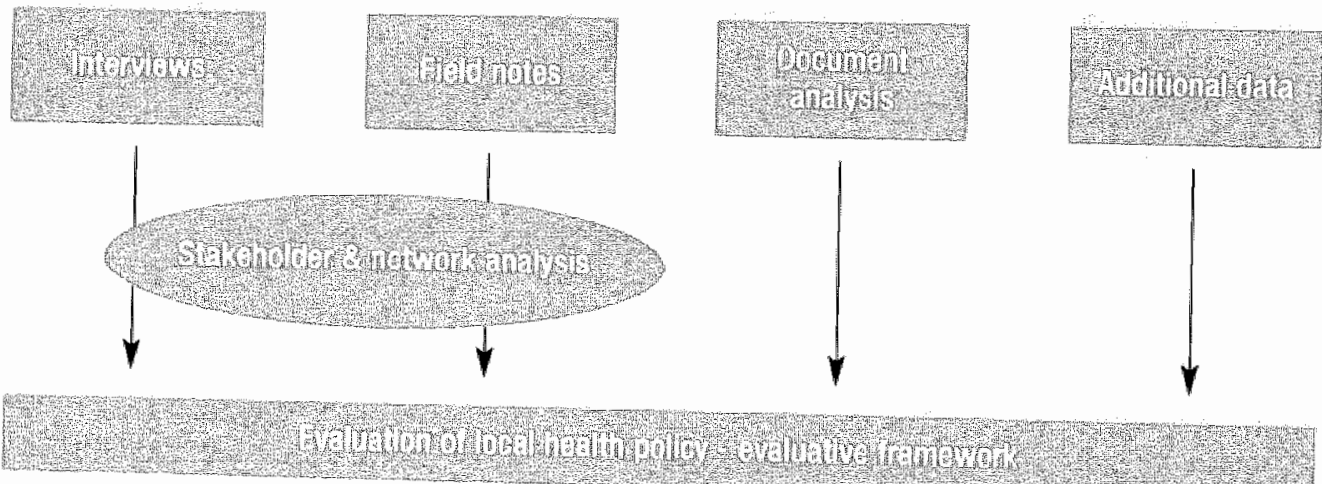

Figure 2.3 Thiangulation of methods

Part one of this thesis has set the stage for investigating local health policy-making in Central Limburg, the Netherlands. It has moved from the history of public health to health promotion theory and practice, and from the rational, instrumental model of policy-making to an interactive and network perspective. We have also looked into the changing position and role of (local) government. Finally, it has presented the research questions and design, and the tools and research methods we used to evaluate the policy development process and its outcome. The present study investigated a complex phenomenon in which we combined 
health promotion and network perspectives on policy-making, addressed multiple units of analyses and used different research methods including new instruments for health promotion research. In our opinion this combination is the strength of this study.

The results of our study of health policy-making at the municipal level are presented and discussed in part III and part IV of this thesis, respectively. First, part II describes and discusses the development of the community-based Hartslag (Midden; Limburg project and how it related to local health policy-making. 



\section{PART II}

\section{EVALUATION OF A COMMUNITY PROJECT: HARTSLAG (MIDDEN) LIMBURG}

Hartslag (Midden) Limburg was a community health project initiated by the Regional Public Health Service (RPHS) and implemented by its department of health promotion, in the central part of the province of Limburg (the Netherlands). The Prevention Programme of the Netherlands Organisation for Health Research and Development (ZON-MW) and the RPHS financed the project, which ran over a period of four years (1999-2003).

The second part of this thesis discusses the efficacy of this community health project in the context of daily practice and its suitability as a subject for the research project into policymaking in the same context. We expected to find a clear relationship between the project and local health policy development in the sense that the project would be a stimulant for the development of local health policy and that local health policy would integrate local health initiatives (see section 3.1.2).

Chapter 3 describes the 'Hartslag (Midden) Limburg' project itself. It gives an overview of the aims of the project and the additional function it was supposed to have as a catalyst for research on local policy-making. Furthermore, it presents the monitoring instrument cour assessment toolkitj used to evaluate the project. Chapter 4 first elaborates on the theory of community interventions. A continuum of health interventions is proposed to help characterise community-based health projects. The chapter then presents and discusses the results of applying the monitoring instrument. The Hartslag (Midden) Limburg project did not achieve its full potential, due to insufficient investments in project structures. Finally, chapter 5 discusses the appropriateness of the methods used to evaluate the project and the role of the evaluator. 


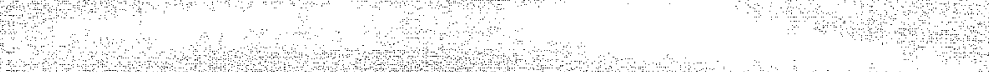

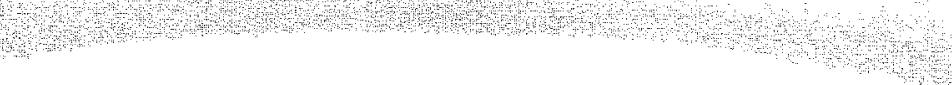

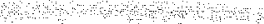
(n)

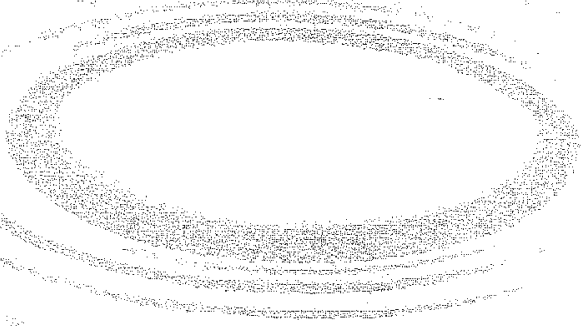

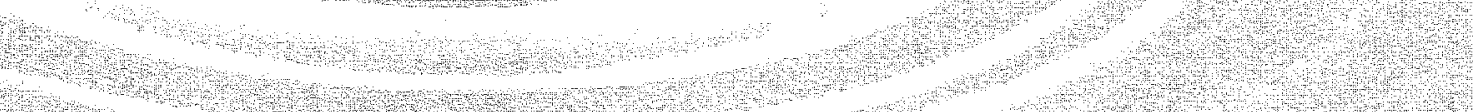

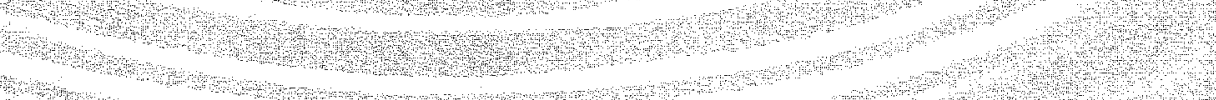

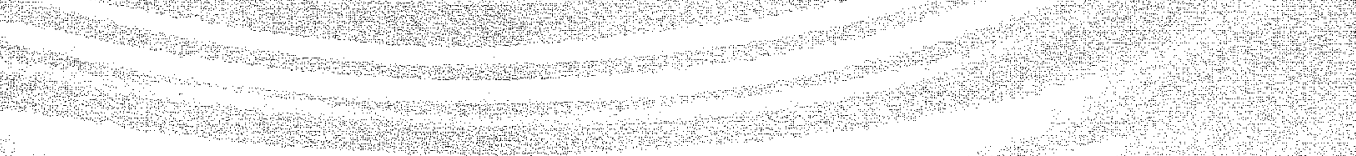

P. 1
l

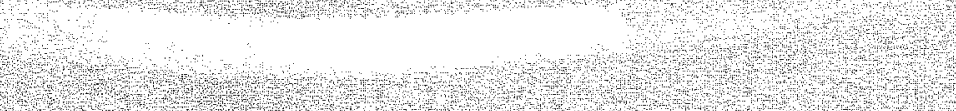




\section{HARTSLAG (MIDDEN) LIMBURG: DESCRIPTION AND MONITORING}

Hartslag (Midden) Limburg was a community-based project for the prevention of cardiovascular disease. It started in 2000 and ended in 2003. This chapter describes the project and the monitoring instrument that was developed to evaluate it.

\subsection{Description OF THE PROJeCT}

\subsubsection{Background}

A large part of the mortality and morbidity in the Netherlands can be attributed to cardiovascular disease (CVD) (Jansen, Schuit \& van der Lucht, 2002). This is also the case in the central part of the province of Limburg, the area known as Midden-Limburg (GGD-en Limburg, 1999). CVD is partly determined by unhealthy lifestyles. Besides other risk behaviours, unhealthy dietary habits, lack of physical activity and smoking have become common in our western society (Schram, Maas, Poos, \& Jansen, 2001). The RPHS monitors the health status and health behaviour of the population of its service area in a large survey held every four years, and in some smaller surveys targeting specific groups. The 1999 health inquiry report described a high prevalence of the above risk behaviours. In response to this major public health problem, the RPHS's policy plan stated an objective of reducing and preventing CVD in the population by developing several new activities (Houben et al., 1998). One of these activities was the creation of a community-based project called 'Hartslag' (Heartbeat).

Another reason for introducing this new strategy was the increasingly accepted idea that health behaviour change is not achieved by interventions aimed at individuals only, but that changes in health behaviour patterns and values are also needed at community level (Jonkers-Kuiper, 1991; Thompson \& Kinne, 1999). A few of such so-called community-based projects had already started in the Netherlands, including Limburg. In fact, the project called 'Hartslag Limburg', in the south of Limburg, was. used as an example, since it had shown promise in terms of its development and operating procedure after its first years ((Ruland, 2000). Hartslag (Midden) Limburg was a small-scale fouryear project, covering four municipalities in the region, and was run by the RPHS. The project aimed to address the most important risk behaviours, like unhealthy dietary habits, lack of physical activity and smoking, in the general population. The project initially adopted a number of principles of community projects: participation, the use of multiple media and multiple methods, intersectoral collaboration and the use of social networks. Health promotion principles like participation and intersectorall collaboration are commonly seen as the underlying mechanisms in community-based work, promoting changes at individual, organisational and social level. 
The planning of the project was initially developed, although not in detail, on the basis of the community-organisation stages model developed by Bracht (1999), involving the stages of community analysis, design and initiation, implementation, maintenance and consolidation, and dissemination and reassessment. A brief plan of action was drawn up for both the project and the research into policy-making (van de Kar, 1999).

Although the project was originally based on theoretical concepts, theory was not actively used to develop the interventions. In fact the objectives, methods and actual interventions of the project were not worked out in a written operational plan, even though it is a generally accepted procedure in health education and health promotion practice to integrate theory into practice and to carefully plan implementation and evaluation, in fact, "to map interventions" (Bartholomew et al., 2001; Green \& Kreuter, 1991, 1999).

The Hartslag (Midden! Limburg project started in the year 2000. A project leader and one project assistant, both employed on a part-time basis by the RPHS, initially set up the project. Resources were provided by the RPHS and ZON-MW. Although the community-based approach was new to the organisation, the RPHS management gave the project leader room to introduce and develop this innovation.

The intended innovations were not implemented in a stable organisational environment. In 2001, preparations were made for a merger of the Central Limburg RPHS with its counterpart in the northern part of the province. This merger became effective in January 2002. A new organisational culture was developing and much energy was spent on internal organisational matters (the integration of existing structures and products, and the adoption of entirely new structures and product parameters) (GGD-NML, 2002). Of course, the project had to be embedded in this new organisation. For the project leader, who was also a member of the management team of the old organisation, the merger had considerable consequences. Not only was she given a new position, but also important tasks in getting the new organisation going were assigned to her, because she was a senior expert in health education and health promotion.

\subsubsection{Process}

The project was based on a process that is supposed to enable professional organisations and local authorities to integrate health promotion into their core business and to enable the population to promote their own health. This process was viewed and planned for as follows. The point of departure was a conmunity analysis yielding basic knowledge about the strengths and needs of the community, existing health initiatives and the social network of the community; in fact, all the elements needed to design the project. On the basis of this analysis, local health committees were to be established, which were to become active in each municipality. The committees consisted of residents, volunteers, professionals, the civil servants and the politicians, aldermen responsible for public health, clubs and local groups. The working committees were supported by the project assistant and discussed problems, solutions, activities etc. The project was subsequently intended to connect with local, existing health initiatives. The local authorities had to promote the project and participate in the local health committees, thereby also acquiring new ideas about health promotion at the local level. Health, social welfare and other organisations were to collaborate more closely on health issues, and health 
issues would be placed on the agenda of more organisations, including the municipal authorities and non-health sectors. By consequence, actors involved in the project would be connected to the policy network and be able to promote their interests in the local policy-making process. This participative policy-making process was to take place in the same period as the Hartslag project. In summary, the project assumed that an increase in community health action would lead to an increased likelihood of health issues being included in local policy-making. Section 4.3 analyses whether this process really took place.

\section{The dyadic relation between the 'Hartslag' project and local policy-making}

The community-based Hartslag (Midden) Limburg project was expected to be a stimulant for the development of local health policy, which was introduced as a new task for all municipal authorities in the Netherlands in 2003 (see section 1.1.2). Conversely, the fact that health policy now had to be developed at the local level as well was thought to be an excellent occasion to integrate the project in the policy-making process, securing sustainability and durability of the local health initiatives developed in the project (Goumans \& Springett, 1997). Moreover, it was expected that the municipalities where the project would intervene would develop more health promoting activities than other municipalities in the region. It was also expected that these activities would be incorporated in the municipal health policy. All this was to be done in cooperation with other sectors and with the participation of civic society. In fact, clear similarities in the working processes of both Hartslag and local health policy were assumed to support each other.

Within the research on health policy-making, the "Hartslag (Midden] Limburg' project served to provide a contrast between four participating municipalities and ten other, nonparticipating municipalities in the service area of the RPHS. This research on local policy-making had an observational character, which meant that its influence on the development of the intervention itself had to be as small as possible. Therefore, the role of the researcher evaluating the community project had to be one of participating observation (Maso \& Smaling, 1998; Silverman, 2000). This means that the researcher participates in some of the everyday activities of those being researched but not with the same intensity as the actors themselves. In this role, observing and interviewing are the main activities of the researcher (see also chapter 5).

\subsection{MONITORING}

At the start of the study, it was decided that a full effect and process evaluation of the Hartslag (Midden) Limburg project would not be useful. A similar community-based project (Hartslag Limburg, see 3.1) with comparable objectives was already underway in the southern part of the province and was being evaluated extensively by the University of Maastricht (for further reading see Ronda, 2003). The Hartslag (Midden) Limburg project was modelled on this project, though in full awareness of the uniqueness of each community and each community project. What was needed was insight into the mechanisms underlying community-based interventions and information on whether the project developed as initially intended. An instrument enabling continuous monitoring of the project could adequately achieve these goals. 


\subsubsection{Levels of monitoring}

The monitoring instrument was to allow us to collect data at different levels (the project, the RPHS and the municipality through debriefing sessions, registration forms and participatory observation during meetings (Hoeijmakers, 2001 a). The fieldwork and collection of data started in the beginning of 2001 after the registration forms and debriefing questions had been pretested.

\section{Project level}

At project level, debriefing sessions were held with the project leader every two weeks. In each session, questions were asked about the events in the project, important decisions or changes taking place, collaboration, bartiers or stimulating factors, and planning. These conversations yielded much information on the progress or impediments to progress. Debriefing with the project assistants took place every two or three months. The main questions in these sessions were concerned with ideas and events that were decisive for the development, planning and implementation of project activities.

Data at project level were also collected by means of monthly registration forms specifically developed for this study. The project leader filled in a form about her contacts, and the outcomes of these contacts in terms of implications for actions and collaboration, in each of the four municipalities. The number and nature of requests made to the project staff were recorded. The registration form for the project workers dealt with the project activities; what activities had been developed, implemented and evaluated in which municipality, with the assistance of which external co-openating parties, what meetings had been held with the health committee and what mass media products had been brought out by the project staff.

In the preparation phase of the project, the plan had been to establish a health committee in each of the four municipalities participating in the intervention. The collaboration process, the integration of activities and the level of support in the different participating organisations were to have been followed by means of informed interviews with the members of the health committees. However, these committees were not created, for reasons that will be presented in chapter 4 , and this type of information could thus not be consistently collected.

\section{RPHS}

Regular interviews were held with the RPHS policy advisor, who was also the liaison officer for the fourteen municipalities in the service area of the RPHS, about the contacts she maintained with the municipalities. The interviews addressed the question whether the project had featured in these contacts in any form. Every two months, a form on the development of local health policy was filled in. These inquired about incoming and outgoing communications, whether at the in itiative of the municipalities or that of the RPHS.

The project was embedded in the tasks of the department of health promotion of the RPHS. The researcher attended meetings of this department where policy matters were discussed about five times a year.

\section{Municipal level}

Observations were made during regular meetings of the regional public health authorities. The researcher was particularly interested to find out if, and in what way, the project or the development 
of local health initiatives in the fourteen municipalities was discussed. The meetings involved both civil servants and aldermen and the minutes of these meetings were analysed as well.

The findings of the above monitoring activities were reviewed regularly and summarised in two reports, one on the period April 2001 - March 2002 and one on the period April 2002 June 2003. These findings and conclusions were not reported to or discussed with the project workers or the RPHS, in line with the proposed evaluation of the project.

The findings are presented and discussed below, after the next chapter has presented a theoretical framework for community projects. 


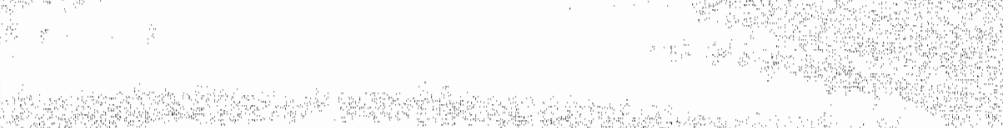

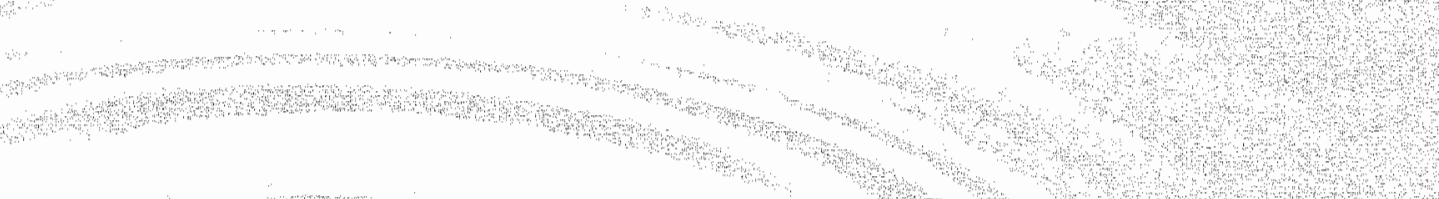

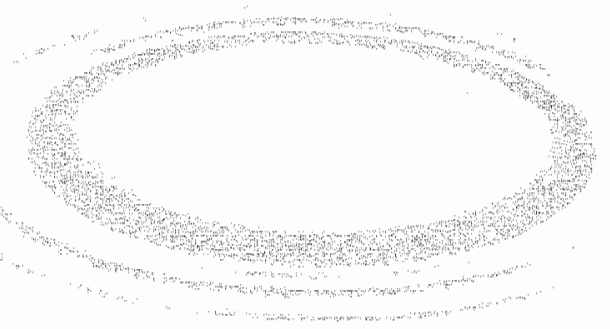

Pra

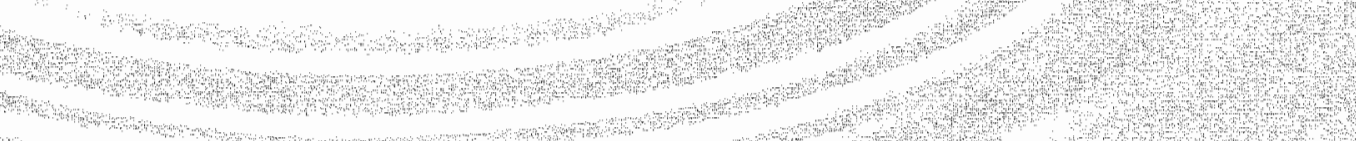

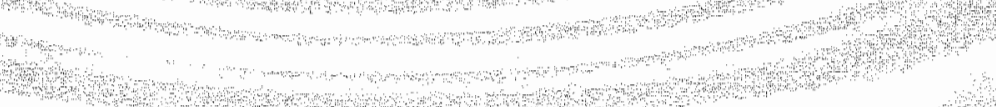
14\%: tur

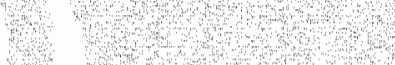
1) ?) crets:

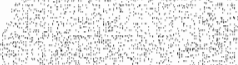
SCl $14:$ S

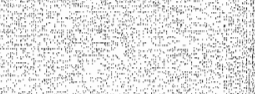




\section{POTENTIAL OF A COMMUNITY PROJECT}

There has been growing interest in community-based approaches to health promotion since the 1970s. Until that time, health education was aimed directly at individuals, stimulating them to adopt healthy behaviour and to change risk behaviour. This notion, however, has expanded towards a more holistic and ecological approach to health promotion (de Leeuw, $1989 \mathrm{~b}$; Green \& Kreuter, 1991, 1999), see also section 2.1. This implies that individuals are seen in the context of their social and physical environment, which also produces opportunities or constraints to healthy behaviour (Blum, 1983; de Leeuw, 1989b; Thompson \& Kinne, 1999).

This chapter defines community projects in the domain of health education and health promotion, using theoretical and ideological concepts and a continuum of health interventions. This exploratory introduction will be followed by findings from the Hartslag (Midden] Limburg project in the central part of the Dutch province of Limburg. Finally, it will be argued why this community-based project did not achieve its full potential, developed into traditional health education activities and was therefore not suitable as a subject for the research project presented in this thesis.

\subsection{THEORY OF COMMUNITY INTERVENTIONS}

\subsubsection{Introduction}

The concept of 'community' can be interpreted in different ways and is difficult to define unambiguously. One might expect that communities would be demarcated by geographic boundaries, but this is not always the case (Boutilier, Cleverly, \& Labonte, 2000). Many definitions refer to groups of people who share values, interests, institutions or identity. The observation, however, that relationships between people in a community have a specific character and pattern is also a defining aspect (Boutilier et al., 2000; de Leeuw, 2000). A community is also identified by the engagement of its members in joint action (MacQueen et al., 2001; Mittelmark, 2001). Taking these elements into consideration, community is defined here as a group of people that may change over time in terms of composition and level of activity, but whose members have a sense of belonging together because of their shared identity, habitation, problem or action.

Interventions at the community level (e.g., the community based approach and community development) are often included in the generic term community organisation. Despite the variety of ideology and methodology in these interventions, they all share the idea that health problems are determined by factors in people's physical and social environment. Consequently, the promotion 
of health can be focused on changes at the community level, such as changes in social norms and values, policy-making, regulations and in organisations. These changes then support individuals in achieving healthy behaviour. These interventions aim at groups or whole communities, using their own social structure and means to achieve self-formulated objectives and strategies (Minkler \& Wallerstein, 1997; Rissel \& Bracht, 1999). At the same time, this shows the main difference with traditional health education, which targets individuals, and whereby people are relatively passive consumers of health messages and interventions.

Despite the fact that al] community organisation models focus on organising communities, with the aim of helping them solve their problems, there are also differences between such models. They differ, for example, in the degree of participation by the population and the ownership of the project. In community-based projects, (for example cf. Hartslag Limburg, Ronda, 2003), professionals play a dominant role in aspects like the definition of problems and objectives. In community development (for example the Arnhemse Broek project, see Abbema, submitted) the agenda is much more open to the inclusion of contributions and needs formulated by the population. People are more in control of the process and actions, and they build their own community.

To illustrate these differences, this thesis proposes a continuum of heaith interventions (see Figure 4.1). One end represents a traditional perspective on health education, aiming at individual behavioural change and proposed from the outside, while the other end represents community development, seen as an empowering process in which people determine and implement their own strategy for social change. In between these extremes, there are many forms of health education and community organisation, which over time have become more and more complementary, instead of being opposites.

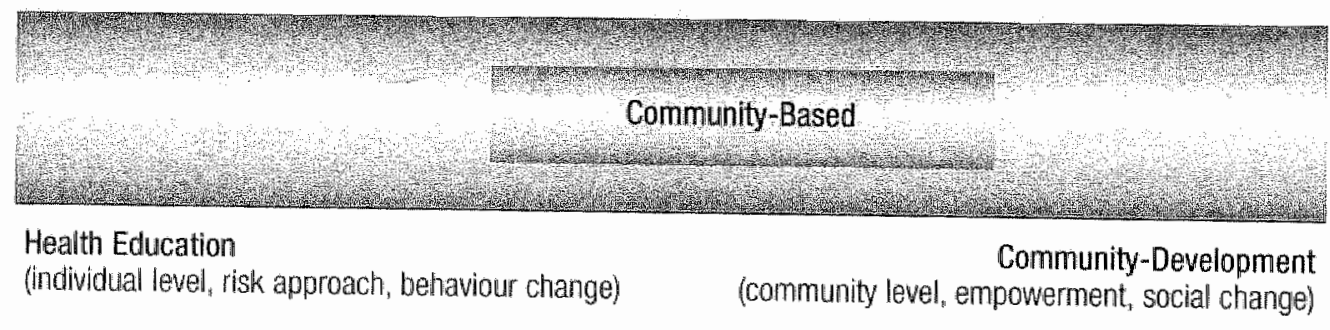

Figure 4.1 Continuum of health interventions

Hartslag (Midden) Limburg was called a community-based project. This type of intervention generally aims at behavioural change and disease prevention. The formulation of problems is mainly based on epidemiological information, and objectives and strategies are more or less determined by outsiders, the professionals. Ownership of the project therefore rests primarily with the professionals (Boutilier et al., 2000; Goumans, 1998). Nevertheless, participation, intersectoral collaboration and the use of social networks are crucial elements to bring about the desired change. 
Along the proposed continuum of health interventions, community-based projects can be placed somewhere near the mid-point.

\subsubsection{Characteristics of community projects}

Applications of community organisation models are generally called community programmes. These interventions aim at the community as a whole, although target groups are sometimes specified because of their status, specific problems or setting (like schools). Aiming at the whole population means pursuing a small health gain for everybody instead of a large heaith gain for a small at-risk group within the population (Rose, 1992). Potvin \& Richard (2001) described five essential characteristics to identify community programmes or projects: magnitude, complexity, participation, longevity and flexibility. Obviously, these characteristics are associated with the evaluation of community projects.

\section{Magnitude}

Community projects aiming at the whole population are large in magnitude and scope, even when the geographical area is not sizeable. The working methods, activities and partners are diverse.

\section{Complexity}

Community projects intervene at several levels (from individual to societal) and make use of multiple strategies to change the behaviour of individuals (Bracht, 1999). The idea that various elements in people's environment influence health and health-related behaviour is generally accepted. Changes in individual behaviour are thus achieved by also modifying the social context (local values, social norms, institutions, policies) (Thompson \& Kinne, 1999). Many partners have to be involved for the project to be successful. These elements make community projects complex endeavours.

\section{Participation}

Participation is a critical element of any change process. Participation aims at improvement at the individua] or collective level. It enables people to make the most of existing capacities and to increase their opportunities for development. In the end, people should have become more able to solve their own problems and stand up for their own interests (Minkler, 1997). The direct involvement of the population in all phases of community projects improves the achievement of health outcomes and favours sustainability (Bracht, 1999; van Assema, 1993]. The degree of participation in community projects, however, varies markedly, and with it the ownership of the project, from professional authority to community authorities and members.

\section{Longevity}

The process used by community projects is time- and energy-consuming. All steps, from mapping the community to activities and evaluation, need careful planning and the involvement of many partners, community actors and professionals from the health sector as well as from non-health sectors. 


\section{Flexibility}

Adaptability and flexibility are characteristics of community projects, because projects need to adapt to changing capacities, needs, problems and circumstances in the community (Minkler \& Wallerstein, 1997). In fact, projects are shaped and developed through constant interaction with the community and collaborating partners (Potvin \& Richard, 2001). It is advantageous if the project is able to respond to changing realities (Judd, Frankish, \& Moulton, 2001).

Community projects, however, are also constantly influenced by contextual factors, which are beyond the control of the community but determine the success of the project. For example, the organisation coordinating the project or the funding agency may influence the ability of workers in the project to create opportunities for active participation by the population and to balance power issues (Lafferty \& Mahoney, 2003).

\section{Implications for the implementation of community projects and programmes}

The above theoretical considerations have some implications for the implementation of community projects like Hartsiag (Midden) Limburg.

In the first place, community projects require a comprehensive and large input of financial and human resources. Comprehensive, because the programmes have a large sphere of action and use a variety of perspectives and disciplines. The input needs to be large because of several reasons. First, the project needs to be accessible and project workers need to communicate continuously with the community and collaborating partners. Secondly, these inputs are needed over a long period of time. Not only funding agencies but also the organisation coordinating the project and project workers easily get frustrated when resources run short before results can be shown. Thirdly, to implement the processes as described, community projects benefit from intensive planning and coordination. Fourth, establishing sustainable collaborative relationships and a common working agenda with the partners in the project is indispensable. This includes an appropriate project structure, in which the organisation coordinating the project guides and stimulates the collaborating partners.

\subsubsection{Defining objectives, methods and outcomes in community projects}

Defining outcomes in community projects has become important from several perspectives: those of the funding agency, the professionals (project workers) and the community. From the funding agency's and professional's perspective, effectiveness and accountability are the key elements. In addition to this, understanding the progress of the project and creating learning opportunities are also considered important from the perspective of the professional and the community. Up to now, community projects have not been very successful in meeting these needs (Merzel \& D"Afflitti, 2003).

Professionals usually define thealth outcomes as changes in the health of an individual or group, which are attributable to an intervention or series of interventions (Nutbeam, 1998). These changes are generally formulated in terms of disease reduction or prevention. Furthermore, this view supposes a linear relationship between the intervention and the expected change, and a Randomised Controlled Trial (RCT) is likely to show the effectiveness of the intervention. 
In an RCT, a method originating from the biomedical and behavioural science paradigms, the contextual elements that might confound the results are controlled as much as possible.

In health education and health promotion, however, it is not always possible to strictly control the context of interventions. In fact, this even runs counter to the principles and desired outcomes of health promotion interventions like community projects. Although community projects may aim at individual behaviour change, this will be enhanced by changes at other levels, like social mobilisation, empowerment, networks for intersectoral collaboration, public policy and regulations. Community projects have become more and more comprehensive and complex (Goodman, 1998). They have broad and multiple goals and make use of multiple change strategies, which require interaction with a diversity of actors in different settings. Furthermore, community projects are developed on the basis of information, not only from an epidemiological and behavioural diagnosis but also from a community analysis (Green \& Kreuter, 1991, 1999; Hancock \& Minkler, 1997; Rissel \& Bracht, 1999]. This community analysis reflects aspects like the capacities and strengths of the population and their needs for change, and can be an empowering tool in itself. The findings from community analysis are the basic elements of the process of formulating the objectives, strategies and outcomes of a project, and at the same time represent the flexible and ever-changing context influencing the intervention itself. For" the above reasons, defining clear and measurable outcomes in community projects is a difficuit and intricate, but vital task for community members, professionals and academics.

To overcome these problems and to meet the need for plamining and evaluation tools, Nutbeam (1996; 1998) proposed an outcome model of health promotion based on the Ottawa Charter; with different levels and types of outcomes (see Fig. 4.2). The model distinguishes four levels. At the highest level are social and health outcomes (quality of life, functional independence and equity, and mortality, morbidity and disability]. In between the top and bottom there are two further outcome levels.

Health and

social

outcomes
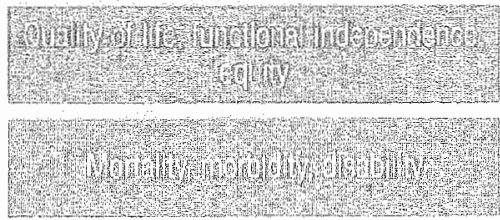

Intermediate

health

outcomes
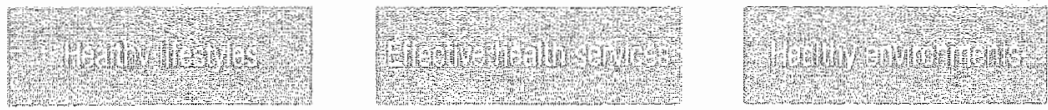

Health

promotion

outcomes
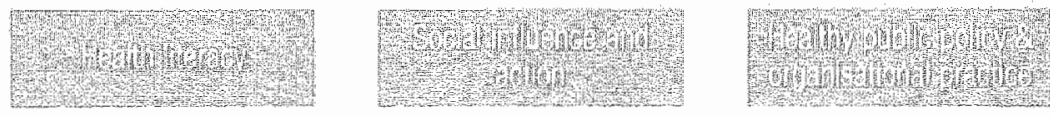

Health promotion

actions
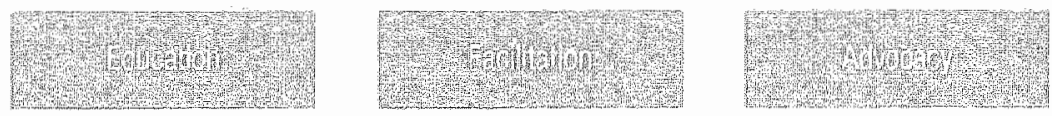

Figure 4.2 An outcome model for health promotion (Nutbeam, 1996) 
The first one represents intermediate outcomes determining the health and social outcomes: healthy lifestyles, effective health services and healthy environments. The second level is that of direct health promotion outcomes of the actions: health literacy, social influence and action, and healthy public policy and organisational practice. At the bottom are the health promotion actions of education, facilitation and advocacy. There is a dynamic relationship between and within levels. The model creates an opportunity to guide the process of deciding whether to concentrate on one specific action or to combine different actions in space and time. Moreover, it stimulates a broad debate on ways to implement the complex task of logically linking problems, objectives, outcomes, strategies, activities and evaluation based on the principles of health promotion.

\subsubsection{Underlying mechanisms of community-based projects: participation, intersectoral collaboration and activation of the social network}

Participation, intersectoral collaboration and the operation of the social network are considered to be underlying mechanisms of community-based projects, bringing about changes in people's social, physical and organisational context (Bracht et al., 1999). Alternatively, these changes support the individual in making healthy choices and changing risk behaviour. Each of these mechanisms has unique features and dynamism, and the degrees to which projects make active use of participation, intersectoral collaboration and social networks differ markedly. All three mechanisms will be briefly described here in terms of their development and relevance to community-based projects.

\section{Participation}

Participation is seen as an indicator for health promotion (see section 2.1) and as an essential condition for the success of health promoting activities. Since there are many definitions of the concept, Robertson and Minkler (1994) called it chameleonic. The essential elements in all these definitions are development processes at individual and community level, shared responsibilities and decision-making, and active involvement by the population. These definitions are based on one of two perspectives on participation (Morgan, 2001). The first perspective considers participation as a 'means', signifying that population involvement leads to more effective, efficient or inexpensive achievement of project goals (e.g. improvement of health services, promotion of healthy behaviour). In the second perspective, participation is seen as an empowerment tool, implying that people go through a process of critical awareness, increased sense of control, social. action and decision auchorisation (Hoeijmakers, 2000b). The empowerment process enables people to assume their responsibilities in diagnosing and working out their own health or development problems (Rissel, 1994). In this perspective, participation is seen
as an 'end'.

The degree of participation has often been described in the literature, and a hierarchical order of form and degree has been proposed (Arnstein, 1969; Rifkin, 1986). These authors distinguish more or less active from passive forms of participation, and generally value the active forms of participation more than the passive forms. This appreciation, however, should be coherent with the particular type of intervention and its objectives. 
Van Assema (1993) made another distinction, based on the phases of a community based project in which the population can be involved: planning and preparation, implementation and evaluation.

Creating opportunities for participation, however, is not as easy as it sounds. Getting people involved requires a minimum level of awrareness of the problem, as well as the subjective capability to influence the problem. The latter applies especially to the involvement of people with a low socio-economic status who generally feel powerless (Wallerstein, 1992). In communitybased projects, participation is mostly seen as a means, implying that empowerment is not regarded as a principal objective and that less active forms of participation are applied.

\section{Intersectoral collaboration}

The literature describes health as a multidimensional concept with a physical, a psychological, a social and a spiritual dimension (WHO, 1998). Not having simple unilateral determinants, health promotion requires the dedication of multiple disciplines. In addition, problems in the health domain are multicausal and exceed individual disciplines, so they cannot be solved by the health sector alone (see also section 2.1).

Gray (1989 p.5) defines collaboration as a process through which parties who see different aspects of a problem can constructively explore their differences and search for solutions that go beyond their own limited vision of what is possible'. From this point of view, collaboration is a process that implies changes in organisations as new mechanisms evolve to bridge differences. Collaboration takes time to achieve and occurs to varying degrees.

According to Gray (1989) collaboration develops through three phases: problem setting, direction setting and implementation. In the first place, partners must develop a shared understanding of the problems that have to be solved and the goals to be achieved. Other fundamental aspects are a shared commitment to proceed with the process and agreement on the collaborative rules, including the resources each stakeholder will contribute. All parties must expect to gain something from participating.

Over time, a successful process establishes a new set of institutional arrangements within the problem domain. There will be new understandings that are shared, new ways of working together and new ways of working within organisations to achieve goals that are common to the participating arganisations (Walker, 2000).

If intersectoral collaboration can be established in community-based projects, health problems can be dealt with in a much more fundamental way. This requires, however, that a sufficient diversity of stakeholders is involved, to bring all aspects of the problem forward, as well as a stimulating chair (preferably the host organisation), and managerial commitment by participating organisations to enable implementation of solutions agreed upon.

\section{Social network}

The last principle of community-based projects described here is the use of social networks. This means that information is disseminated through members of the existing social network. Some people make use of mass media sources to obtain the information they want, while others obtain this information mostly from the people in their own immediate social environment. 
People who have a low socio-economic status tend to use especially the latter source (Rogers, 1995). To reach this part of the population, therefore, information has to be diffused through the members of their social network (Weenig, 1991 ).

According to Rogers (1995), the right persons to diffuse new information and engage in new behaviour are those called early adopters. Early adopters are not the first to adopt an innovation but do so after balancing the pros and cons. They are the ones in the social network who are respected and often are the opinion leaders in the community. Early adopters can act as "social models' and influence the adoption of new ideas by other members. It is not easy to identify these early adopters in a social network because they are often highly educated and are not closely connected to the network. The community analysis, however, should yield information about the mature of the social network and the leadership, and the capacities and readiness for change of the community (Rissel \& Bracht, 1999).

One of the factors favouring the effective diffusion of messages in a social network is the structure of the network (whether it is a close-knit network or not). Another important factor is the frequency of spreading messages, and the information must fit in closely with the beliefs, values and experiences of the network members (van Assema, 1993; Weenig, 1991 ).

Using the social network enables community-based projects to reach those people who are difficult to reach through mass media health messages, but who have the heaviest disease burden and the highest health risks. Furthermore, it puts health on the agenda of the opinion leaders and increases their commitment to contribute to the project. Finally, the active use of social networks by community-based projects promotes gradual changes in social norms, beliefs and culturally determined behaviour patterns (van Assema, 1993).

\subsection{Results of the Hartslag (Midden) Limburg project 2001 - 2003}

This section presents the findings of the evaluation of the 'Hartslag' project, collected by means of the monitoring instrument described in Chapter 3. It first reports on the period from April 2001 to March 2002 and then on the period from April 2002 to June 2003.

\subsubsection{Exploring the field: April 2001 - March 2002}

The collection of data from the project leader, project assistants and other sources started in April 2001; at that time the project had already been underway for about a year. In this phase, the project still needed to be further shaped by several activities that were planned: inviting and contracting four municipal authorities to join the project, analysing the communities of these four municipalities, forming health committees and starting the collaboration process, and preparing a 'kick-off' event in each of the communities. Furthermore, the project team was to study and select possible appropriate products/activities that could serve to promote physical activity, healthy dietary habits and smoking cessation.

Some characteristics of municipalities, which had been examined beforehand, were decisive in inviting four of the fourteen municipalities in the region to participate in the project: the presence of local health initiatives, examples of intersectoral collaboration and poiitical commitment (for further information see Hoeimakers, 2000a). This also refers to the inclusion as cases in 
the research on local policy-making (see 1.3.1). The project leader and the director of the RPHS invited the responsible public health officers and aldermen to participate, in writing and through verbal communication. Two municipal authorities agreed to participate, while two refused due to a lack of manpower. Thereupon, the authorities of one other municipality were invited, but they refused as well. One municipality itself took the initiative to join, and finally the RPHS management decided that in one (originally invited) municipality, activities would take place without active participation of the municipal authorities, so a total of four municipalities were evantually included. In fact, all municipal authorities had questions about the contributions in terms of manpower and financing of activities) they were required to make. To make things easy for the participating municipalities, it was agreed that the project workers would take the lead in organising and promoting the project and that the RPHS would finance the activities in 2001 . These and other agreements, however, were never confirmed in a written contract between RPHS, the project team and the municipal authorities.

Having a contact person (the public health officer) in three municipalities was a starting point for getting to know the community. The geographical borders of the municipalities were used in this case to define the community, and the aim was to reach the general public. In this view of community, it is assumed that the population of the municipality shares certain values, social norms and institutions and that it has a sense of belonging (see the definition of community in the introduction to this chapter].

Epidemiological data that were not yet available were collected, and municipal handbooks were used to obtain information on existing organisations, groups and services in the municipalities. A complete community analysis, including interviews with key persons and other inhabitants, would have required too much time and energy from the small project team. Instead, the line of action was largely determined by the input of the contact persons, who were supposed to act as spokespersons and relay the needs of the population to the project team.

By March 2002, the idea to have a 'health committee' installed in each community was abandoned, due to lack of time and enthusiasm among the contact persons to participate in yet another committee, and the project's staffing shortage. At that time, the project leader had been working alone for about half a year, because the project assistant's contract had not been renewed. New staff was hard to find, as there was insufficient support from other departments in the RPHS. As a consequence, very little time could be spent in 'the field', to link up with community representatives.

Besides the idea to closely connect with the knowledge and input of the contact persons at the local level, there was also a need to link up with national campaigns on the targeted health issues and to use the products developed by national organisations like STIVORO (Dutch Foundation on Tobacco Control) and the Dutch Heart Association. Furthermore, the project leader studied opportunities to collaborate with regional organisations and projects in the field of health and well-being, such as central Limburg home services, the University of Maastricht Department of Health Education and Health Promotion and the welfare sector. Using existing products and initiatives was thought to be in line with the principles of community projects. Much effort was indeed spent on making contacts, mostly with professionals, to discover opportunities for collaboration, and to find appropriate and feasible activities. The first 


\section{chapter 4}

activities in this year were not part of a broader plan and were meant to bring the project to the attention of the population. For example, the project took part in the 'World Heart Day' and 'a fair for the elderly'. Beside these activities, a pilot study was implemented on the intake of fruit and vegetables at a primary school and cooperation was started with a project on tailored nutritional advice developed by the University of Maastricht. An overview of the project activities from 2001 to 2003 is given in Table 4.1 .

Table 4.1 Activities of the Hartslag (Midden) Limburg project

\section{Activity}

World Heart Day

Meeting to inform elderly

Pilot study on fruit and vegetable intake

'Heart menu' hospital restaurant

Tailored nutritional advice (NOM)

Meeting to inform, CVD patients

Fair for the elderly

Junior Heart Day

Junior Heart Day, educational package

Tailored lifestyle advice (ALOM)

Information fair \& calendar

Heart to heart, walking tour

Fair for the eldierly $(55+)$

Open day at physical activity centre

Holiday activities for children

Leaflet stand

Fruit and vegetables project (schools)
Theme

physical activity

healthy lifestyle

healthy diet

healthy diet

healthy diet

healthy lifestyle

healthy lifestyle

physical activity

physical activity

healthy lifestyle

'safety"

physical activity

physical activity

physical activity

healthy diet

healthy lifestyle

healthy diet
Request

yes

yes

no

no

yes

yes

no

no

yes

yes

yes

no

yes

yes

no

yes

no

" (W) Weert, (R) Roermond, (RN) Roggel \& Neer, (RD) Roerdalen 
As of January 2002, two new project assistants started to work on the project, one working on communication activities and the other as an assistant to the project leader. The team worked together intensively and enthusiastically. A final comment about this period concerns the merger between the RPHS in central Limburg with its counterpart in the north of the province. This became effective as of January 2002, but preparations in terms of reconciling the organisational cultures and reorganising structures required time, energy and much input from the project leader, as had indeed already been the case in 2001 .

\section{Collaborating organisation}

Professional /non-prof.

\section{local /regional /national}

professional

non-professional

professional (primary school)

professional

professional

Non-professional

professional

professional (primary schools)

professional

professional

professional

professional

professional

non professional

non professional

professional local and national

local

local

regional

regional $(>1)$

local

lacal

lacal(schools) and national

local

regional and local

local

local and national

local

local

local ( >1)

local

regional and national

\section{Municipality}

$\mathrm{RD} / \mathrm{R} / \mathrm{W}$

W

$\mathrm{R}$

R

$\mathrm{RD} / \mathrm{R} / \mathrm{W}$

R

R

$\mathrm{RD} / \mathrm{R} / \mathrm{W} / \mathrm{RN}$

$R / W$

$\mathrm{RD} / \mathrm{R} / \mathrm{W} / \mathrm{RN}$

RD

2002

RD

2002

R

2002

R

2002

2003

2003

W

R

Period

2001,2002

2001

2001

2001

2001,2002

2001

2001

2002 , 2003

2002, 2003

2002

.

R

2002, 2003 


\subsubsection{The implementation: April 2002 - June 2003}

This period was characterised by ongoing contacts with a great variety of organisations and the implementation of a range of activities in the four municipalities. Attention was also given to continuing and integrating these activities in the existing structures.

\section{Contacts}

Contacts with a variety of organisations, to promote the project and seek opportunities to collaborate in the implementation of activities, remained a key element in this period as well. Contacts were made with local organisations rather than with regional ones, for example a restaurant affering cooking classes for children, a guide who leads exercise and recreational walks, and a library. Most of these organisations are professional bodies; there were fewer contacts with local nonprofessional initiatives like the 'holiday activities for children'. The contacts that had been built up in the first reported period were sustained and extended to other organisations. More projects, such as a 'fruit and vegetable project' at primary schools, were linked up with Hartslag (Midden) Limburg. Apart from promoting the Hartslag project, the project leader had to fulfil other tasks for the RPHS as well, resulting in an extensive network with a great variety of possible partners for the project. Some of these partners participated in single activities (see Table 4.1 , in the preparation, but mostly in the implementation phase. However, partnerships were not developed at a structural, sustainable level to such a degree that organisations became committed to the project. Section 4.3 (under Intersectoral collaboration) elaborates further on this point.

The project team continued to use campaigns, activities and materials developed by national organisations. The project workers acted as intermediaries for these national organisations and used their products for project purposes as well.

Although the project leader communicated with the public health officers and the relevant aldermen in the municipalities at irregular intervals, their cooperation and support for the project was maintained to some extent.

The project team met every other week to discuss existing and new activities and the division of tasks. The project leader discussed problems with the RPHS management and informed colleagues about the development of the project. This, however, did not automatically lead to support within the RPHS.

\section{Activities}

Most of the activities were implemented in 2002, some in collaboration with other organisations. Deciding which activity was going to be developed was primarily dependent on requests for assistance received by the RPHS. For instance, the request from a local library in one of the municipalities to participate in a day of activities on the theme of 'security' that they had organised led to the development of an educational "birthday calendar" and a presentation on the project on that same day. Other such activities were: the distribution of educational packages on physical activity for primary school students ("Junior Heart Day") and the fair for the elderly. This type of activity does not require close collaboration with representatives of the population or other organisations for its preparation or implementation; only the requesting partner 
is involved. The recruitment of businesses that were willing to invite their staff to participate in a lifestyle study by the University of Maastricht was a time-consuming but (in the view of the project workers) not very fruitful activity. Physical activity was the subject of more activities than the other lifestyle themes. The number of activities implemented in the four municipalities varied (see Table 4.1). The municipal authorities concerned were asked to contribute to the costs of the different activities.

The promotion of the project itself by means of publicity materials was one of the key points in this period. These materials ( $\operatorname{logo}$, cards, letters, pamphlets) were developed by one of the project assistants and were used for the general promotion of the project as well as for the announcement of the activities (posters, reminders). Furthermore, some materials were produced to support the implementation of activities (placemats, birthday calendar, certificates). As a result, the project developed a recognisable image, which increased public awareness but was also beneficial for the various parties involved (e.g. politicians and collaborating organisations) to identify with.

Finally, health education materials were provided to a community centre in one of the municipalities in 2003, as a continuous activity of one of the project assistants. This was one of the few opportunities to be out in the field. The project leader often mentioned the lack of field visits ('I would like to meet the contact persons in the municipalities more often", 'we need a fieldworker'). The need to describe the project in terms of objectives, strategles and progress was also expressed regularly in these two years. The project leader, however, could hardly meet this need because she also was responsible for other activities of the health promotion department than the Hartslag project. The progress was in fact only secured through the continuous contact and solidarity between the team members.

\section{Follow-up}

Finally, the project team started to develop ideas to integrate the project activities in the actual organisational and product structures of the RPHS, which were dominated by the reorganisation after the merger. The RPHS in Central Limburg had to change its organisational structure fundamentally. Before the merger, the RPHS had supplied a complete, standardised package of services to fourteen municipalities: an input-oriented practice. After the merger, this was developed towards service delivery based on specific requests by individual municipal authorities or a group of them (which numbered 27 after the merger). In this so-called 'diversified products provision model' (Keuzemodel Producten Aanbod, KPA), municipal authorities have the opportunity to put forward health problems in their area and to request the RPHS to develop specific interventions (products) to address these problems. In fact, this system is ideal for health policy-making from a rational perspective (see section 2.2.2). RPHS and the municipal authorities both hope that this method will improve effectiveness and accountability and their collaborative relationship. However, for economic and practical reasons, products have first been described on the basis of 'current' and 'desired' services. The products are divided into three categories: (1) products RPHS is legally obliged to provide (WCPV; described in section 1.1.2); (2) highly recommendable products that RPHS is not legally obliged to provide; and (3) optional products. 
The transformation of the Hartslag (Midden) Limburg project into an optional product under this KPA model was the only way to secure the benefits of more than three years of work as a community-based project. The project team devoted much time and energy to documenting and describing the work they had done (van de Kar, 2004), to make it available for future use. In January 2003, Hartslag was presented as a K.PA product to promote a healthy lifestyle, linking up with the intentions formulated in the same period by the municipalities in their memorandum 'local health policy'. The further development of this and other products of the RPHS' department of health promotion, in order to meet the needs of the municipalities iseen in this context as purchasers of RPHS products], became the main concern of the project leader in particular. This continued after June 2003. No more project activities were implemented in the last months of this reported period.

\subsection{Discussion and Conclusions}

The Hartslag (Midden] Limburg monitoring instrument provided information on the implementation of the project as planned and on the application of the concepts underpinning community projects like participation, intersectoral collaboration and the use of social networks. This section compares the planned process (see section 3.1) with the results. It first discusses to what extent the characteristics of the Hartslag (Midden) Limburg project correspond to those described in the literature on cormmunity interventions. (see section 4.1), after which it surveys the results in terms of participation, intersectoral collaboration and the use of social networks, and finally the involvement of the municipalities. The section ends with some concluding remarks on the roles of the project workers, the structures needed to develop community projects and the dyadic relation (mutual and interdependent) between 'Hartslag' and the research on local policy-making.

\subsubsection{Community-based health interventions in Central Limburg: discussion}

\section{Characteristics of community projects: magnitude, complexity, participation, longevity, flexibility}

The Hartslag (Midden) Limburg project was developed, implemented and then integrated in the RPHS product structure within four years. This is rather short in view of the long time span needed for community health promotion interventions to grow to their full potential [Goodman, 1998; Potvin \& Richard, 2001]. The project addressed activities for the general population of four municipalities (with 113,100 inhabitants). The project did indeed have considerable ambitions, particularly in view of the small size of the project team. The actual scope of the project, however, was not that large. The activities were restricted to the individual level, educating people mainly on healthy physical activity and healthy food intake, whereas alternating and repeatedly addressing multiple health behaviours is known to be necessary to achieve any behavioural change (Ronda, 2003; van Assema, 1993). No interventions aiming at modification of the social and physical environment were identified within the project, even though this type of intervention is considered even more important than the educational activities 
in community projects (Berkman \& Kawachi, 2000; Smedley \& Syme, 2000). A combination of interventions at different levels (individual, organisational, policy and community) has frequently been advocated in the health promotion literature (e.g. Goodman, 1998). This is also reflected in the outcome model for health promotion (Nutbeam, 1998) illustrated in Figure 4.1. The activities of the Hartslag project all fit in the left-hand column, that of educational actions aiming at health literacy. But they were not combined with activities on advocacy and facilitation aiming at healthy public policy and organisational practice, or on social influence and action. There seems to have been no relationship or interaction between the health promotion actions within the (bottom) level or within the level of direct outcomes. The interaction between levels of the model cannot be assessed because no effect evaluation was done in this case. The above-mentioned one-sided attention for or emphasis on educational activities is still common in (community) health promotion practice, as was also argued in section 2.1 .

\section{Participation}

Although participation was considered an important means to achieve the objectives of the project, it was the professionals who drove the project in almost all respects, from the defining of the problem to establishing the objectives and proposing solutions and strategies. Requests for health education or to join in with any planned activity, submitted by clubs or local professionals, were greatly welcomed and enthusiastically responded to by the project team. The general public and intermediaries, for example in schools, only participated in the actual implementation of project activities. In fact, they were the consumers of the activities. Arnstein (1969) calls this passive form of participation symbolic or non-participation. Rifkin (1986) calls it benefits, meaning that the community passively receives services and education provided by health professionals.

The project team's intention (see 3.1) had been to set up health committees, facilitating the participation of representatives of the community in all phases of the project. However, this pivotal element for the success of any health promotion intervention in bringing about change at the community level (Bracht, 1999; Minkler, 1997; Morgan, 2001) never materialised, and the project operated at a certain physical and psychological distance from the community. It was fully owned by the RPHS. The lack of (specifically trained) staff, lack of time and the fact that no community analysis had been done, may have contributed to this low degree of community participation.

\section{Intersectoral collaboration}

The project team thought it would be beneficial and necessary to start collaborations with various disciplines in different sectors and representatives of groups and clubs, who were active in the community. They succeeded in linking Hartslag with several existing projects and activities of other professional and non-professional organisations, but were less successful regarding the follow-up to these shared activities in order to create coherence and motivate organisations to participate in a sustained collaboration process. Factors which facilitate such sustainable intersectoral community mobilisation have been described by Bourdages (2003). The main points are involvement of concerned and influential community members, instalment of local coordinating committees with clear leadership and decision-making mechanisms, clear objectives, tasks and responsibilities of involved partners and official support. In addition, the 
project leader did not have enough time to act as an "entrepreneur" (which is thought to create commitment by different stakeholders to contribute to the solution of a commonly perceived problem) (de Leeuw, 1999).

Because no sustained collaboration process developed, it may be assumed that coalitions or partnerships (of profiessional organisations or groups), which might have had a strong influence on local health policy-making, did not materialise.

\section{Social network}

The social network in the four communities was not mapped out and since no community analysis was available, the project team could not identify opinion leaders or so-called "early adopters' (see 4.1). The project workers were not familiar with mapping and the use of social networks, in which opinion leaders and early adopters are considered important. In fact, this concept was not even actively used to disseminate information and health education messages. The team used mass media communication channels like pamphlets, periodicals and a billboard at a community centre. It may be assumed that the general public received these health messages, but this was probably less true for people with a low socio-economic status.

\section{Municipal authorities}

The project team succeeded in informing the municipal authorities (mainly by addressing the local public health officers) about the progress of the project. Where necessary, activities were approved and financed. Nevertheless, the involvement of the public health officers and especially the aldermen of the four municipalities remained passive and the initial enthusiasm of some of them waned over time. The municipal authorities showed no intention to assume an advocacy role, nor did they invite the project leader to participate in the local policy-making process on health issues. This may be attributed to the lack of a 'contract' describing clear tasks and responsibilities of the municipal authorities or of the RPHS. Furthermore, it may be explained by the crucial differences between the routine operating practices of municipal authorities and public heal th professionals. Finally, the irregular and scarce contacts, which were mainly aimed at the implementation of activities, may have maintained the distance between the offices and practices of the two parties involved.

External factors have influenced the development of the project more than anything else. The team members (with their non-specific expertise and experience regarding community health promotion, their small number and personnel changes and the merger process of the RPHS had an enduring impact on the project. This resulted in the abandoning of a number of crucial principles of the community-based approach, like the establishment of a project structure that promotes participation of the population but also a continuous collaborative process between different sectors for health promotion in the community. In addition, the extensive planning and co-ordination needed for this type of health intervention was reduced to a minimum. Finaly, the project turned out to be an expression of creative health education in a number of municipal settings, addressing certain aspects of the unhealthy lifestyle of persons. According to the settings typology, this could be called a 'passive' model (Whitelaw et al., 2001). Whitelaw et al. argue that such a model assumes that both the problem and the solution are situated at 
the individual level. This setting is seen and used as an ideal place to deliver health educative messages and to offer activities to the target group, so merely as an access point.

The original plan, however, was very different from this. The project may therefore be situated more to the left of the health interventions continuum (see Figure 4.3) than might be expected for a community-based project.

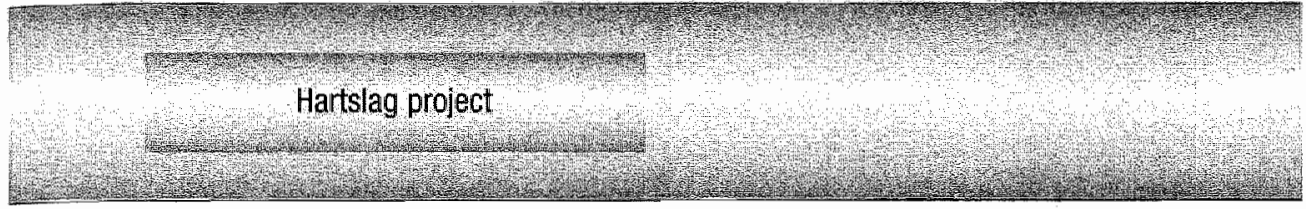

Health Education

Community-Development

Figure 4.3 The position of the Hartslag project on the health interventions continuum

\subsubsection{Concluding remarks}

\section{Structural conditions}

The Hartslag (Midden) Limburg project copied its principles from community-based projects in other parts of the country (especially Hartslag Limburg) and from internationally renowned projects (like the North Karelia project in Finland). During its implementation, the project gradually changed course, because a number of structural conditions were insufficiently met. Even though the project leader invested a great deal of effort in meeting basic conditions like materials, goodwill and support, manpower and networks, these remained limited. These and other structural conditions, however, seem to be of fundamental importance to make community interventions work. In other words, taking over best practices is fine but only if the specifically required investments are fully provided.

\section{Roles of the project team}

A community project involves different roles, relating to the preparation and implementation of interventions in the community, strategic activities and networking activities. In this case, all these roles were combined in the project leader. The RPHS leadership and management, however, should have actively contributed as well, specifically in the strategic and networking activities or in creating structural conditions. This might have involved training facilities for leadership and expertise, development of the project strategy and organisational policy, manpower and the creation of goodwill and support within the RPHS as well as at municipal levels and in other professional organisations.

\section{Dyadic relation between 'Hartslag' and local health policy-making}

Our study hypothesised that the actions and direct outcomes of a community-based project would provide a stimulus for policy-making at the local level. As has been described above, the project did not evolve along the planned course. It slowly drifted away from pivotal elements 
of community health promotion interventions, and failed to achieve a connection (in terms of collaborating actors and the population] with the policy-making process. Therefore we cannot expect to find clear indications for a dyadic relation between the project and the policy-making process at municipal level. 
औै।
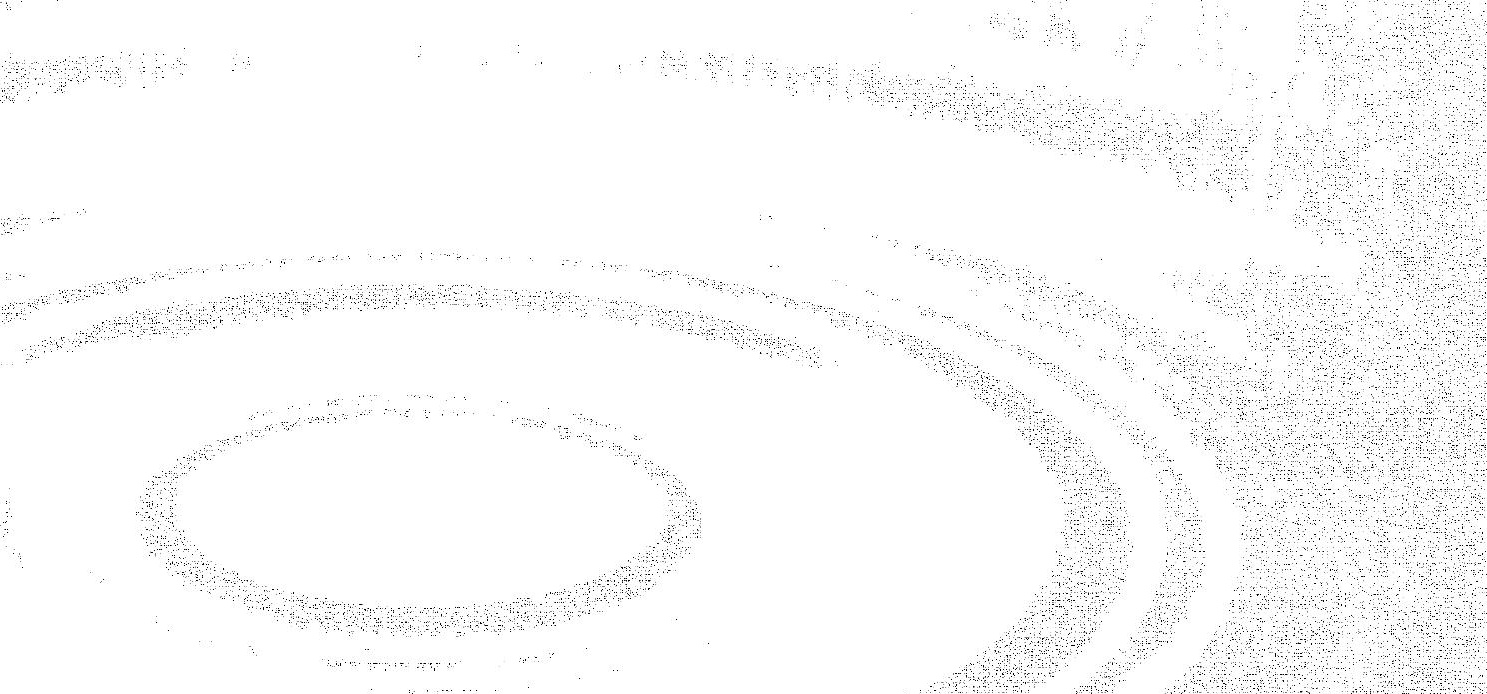

a

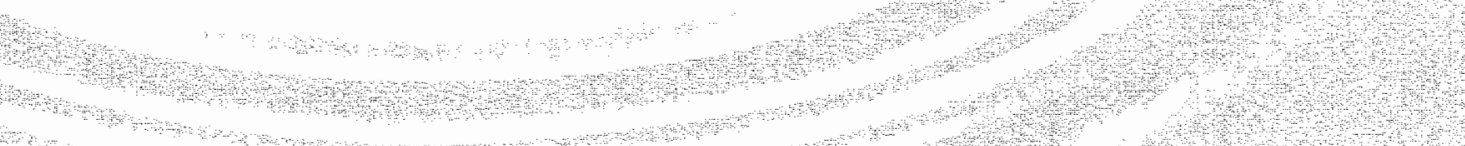

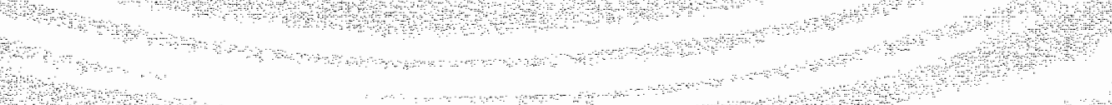




\section{REFLECTIONS ON EVALUATION: APPROPRIATENESS, ROLE OF THE EVALUATOR, CHALLENGES}

Chapter 4 suggested that a combination of structural conditions and process elements has had considerable impact on the functioning of the "Hartslag" project in central Limburg. This chapter discusses the appropriateness of the methods used to evaluate the project and the role of the evaluator. It is argued that participative evaluation or action-guided methods are more appropriate but also more challenging in evaluating community projects, compared to positivistic approaches.

\subsection{ThE PREVENTION AND heALTh PROMOTION PARADIGM}

Preventive programmes and projects are often characterised as a risk factor approach to public health (Potvin, 2003). The ailm of these programmes is to improve the health indicators for general populations, or in other words, to reduce morbidity and mortality rates in the population for specific diseases like cardiovascular disease, cancer, diabetes and respiratory diseases. Knowledge in this field derives mostly from epidemiology, with risk factors as the main concept. The focus of this approach to prevention is on the individual and the disease. In this perspective, disease is largely viewed as an objective state (Springett, 2001a), and interventions aim at managing risk factors and correcting the problematic situation. Health education and interventions providing the conditions for healthy choices characterise the practice of prevention (see also Table 2.1).

Health promotion, as it has evolved over the last decades, has a different set of characteristics. What distinguishes health promotion from prevention is its focus on health instead of disease, whereby health is seen as sacially constructed and a resource for everyday life (Kickbusch, 2003). Health promotion focuses on persons in their context and on society (Rootman, 2001; Springett, $200 \| \mathrm{b}$ ). Capacity building for health, empowerment and participation are the terms used to emphasise the central position of people in the whole concept. In health promotion, complex social phenomena are identified, requiring complex interventions (Koelen, 2001 ). Potwin (2003) called this a social development approach to public health (see alsoTable 2.1). By implication, health promotion practice is socially constructed. Furthermore, it is a multidisciplinary endeavour with intersectoral collaboration as a key feature. All actors contribute, in varying degrees, to the process and the final outcome. Knowledge is 'created' from dialogues between a variety of partners (lay persons, professionals and scientusts).

\subsubsection{Creation of knowledge: positivism and constructivism}

Without ignoring the existence of interventions that combine characteristics of both health promotion and prevention, the two can be distinguished in terms of the values underpinning 
the approaches. By consequence, one can also distinguish two, more or less contrasting, paradigms on the creation of knowledge about the process and value of health interventions: positivism and constructivism.

Positivism originated in the natural sciences. In this approach, objectivity is crucial and understood as knowledge generated by preferably experimental or quasi-experimental research. Variation in context must be controlled as much as possible (Potvin, 2003; Rootman, 2001). This allows causality to be demonstrated, which is therefore the main topic of research. The knowledge obtained, by external observers, is mostly provided to decision-makers at the end of the intervention or programme.

In the constructivist paradigm, 'critical subjectivity' prevails. Personal perceptions and observations are critical elements in the construction of reality, a construction which reflects the values of different actors in a programme. Objectivity and causality are denied [Rootman, 2001). Emphasis is put on unique processes and the complexity of the specific, situational context. The knowledge obtained is mostly used for the (on-line) improvement and development of the programme at hand, and generalisability is therefore a much-debated issue. The essential tools in constructivism are considered to be participatory methods and critical dialogue, which are thought to empower the participants working with these methods (Springett, 2001b).

In sum, the basic difference between these two paradigms is to be found in their contrasting views of reality, which in the former is a fixed, controlled reality and in the latter a dynamic, complex and socially constructed reality (Nguyet \& Otis, 2003).

\subsection{ADDRESSING THE ISSUE OF APPROPRIATENESS AND THE ROLE OF THE EVALUATOR}

Some elements, besides those common to evaluation, are pivotal in the evaluation of health promotion interventions and programmes (Rootman et al, 2001). One of these elements is participation, which is closely connected to the potential of an evaluation to empower individuals, organisations and communities (see also 5.3 under Challenges). Furthermore, evaluation should be introduced early and should be integrated in all stages of the programme. As health promotion interventions are complex, with no clear linear relationship between input and outcome, an evaluation framework must be flexible enough to capture this complexity.

\subsubsection{Appropriateness}

Evaluation can serve different purposes, depending on the aim and type of intervention, the type of knowledge required and the resources available. In this regard, questions need to be answered about the appropriateness of the evaluation, that is, its appropriateness for what is being evalluated and for the parties for whom it is evaluated (Springett, 2001a).

As regards the Hartslag (Midden) Limburg project, it would seem at first glance that the positivistic paradigm is most congruent with the type of intervention, which involves prevention of disease and changing individual behaviour through the interventions. Nevertheless, a closer look at the aim of the project evaluation shows that it is also about social change. The project seeks to bring about change in the collaboration between sectors, increase participation by the population 
and build bridges between policymakers and local groups and organisations. The purpose of the present study was to assess the meaning and value of these mechanisms, partly for the purpose of local health policy-making. Hence, constructivism seems a more appropriate perspective. This, however, has major implications for the evaluation design and the methods to be used.

Looking at the issue of the parties for whom the evaluation is carried out raises the question whose interests will be served by the outcomes of the evaluation. This also determines whose values are used to assess the intervention. In the evaluation of health promotion, people are the central issue and the evaluator adopts their values. In the case of Hartslag (Midden) Limburg, criteria to assess the outcome of the project as successful or not were determined by the evaluator (on the basis of goals specified by the project). The perceptions of the collaborating organisations and the population concerning the activities and functioning of the project were not investigated. This may have narrowed our perspective on the process and results, as well as on the factors determining these results.

\subsubsection{Role of the evaluator}

The role of the researcher as an evaluator in the positivistic paradigm differs fundamentally from that in constructivism. An evaluator who expects knowledge to be objective, as in positivism, takes an external position. The evaluator is the expert, who uses scientific methods and generates general knowledge about an object. The interaction between the programme evaluated and its context is controlled. An essential feature is the non-interference with the intervention and the power to control the process of collecting facts (Springett, $2001 \mathrm{~b}$ ). The evaluator is a specialist who relates means to desired ends, assuming that this is primarily a technical endeavour (Schwandt, 2001).

In the constructivist paradigm, the evaluator is an active participant in the evaluation, as are other stakeholders. Knowledge is generated by partners in a systematic inquiry based on their own categories and frameworks (Springett, 2001a). Every situation is viewed as unique and the knowledge obtained is also called practical wisdom (Karlsson, 2001; Schwandt, 2001). The emphasis is on learning and change. The key to the learning and change process is dialogue, in which the exchange of ideas allows a more integrated and better understanding of the situation and may finally shape a new social reality. The role of the evaluator is to create conditions that enhance dialogue (Karlsson, 2001; Springett, 2001b) and to be a critical interlocutor and interpreter. In fact, the evaluator is not concerned with technical and methodological rules, although she takes knowledge and the tradition of evaluation into account (Schwandt, 2001).

In the 'Hartslag' project, the task of the evaluator was to monitor the activities and development of the project. Furthermore, we wanted to obtain in-depth information about the factors influencing this specific development and the mechanisms leading to the social change described above. It was up to the evaluator to check the collection of the required information (in terms of, e.g., type of information, amount and frequency]. Most of all, the evaluator attributed value and interpreted the data collected. Although it became clear, even at the end of the first year of monitoring, that the project was deviating from its objectives, weakening its potential as a community project, these findings were hardly communicated to the project team and the RPHS, let alone to the collaborating partners and participants in the project.

Some advantages and disadvantages of such an external role are listed in Table 5.1. 
Table 5.1. Advantages and disadvantages of having an external evaluator

\section{Advantages}

The evaluator is trained in evaluation and regarded as an expert by programme participants.

The evaluator is not part of the project nor of the organksation eriving the project and therefore not part of its normal power structure.

The evaluator can take a fresh look at the project.

The evaluator can lake a detached view of the difficuities and possible failures because s/he is not personally invoved in the project

It is easier for the evaluator to be objective.

No confusion can arise about roles and tasks of the evaluator.

\section{Disadvantages}

An outsider may not understand the context and the people involved.

There is a danger of misinterpretations of the perceptons, behaviour and motivations of the actors involved in the project.

Leaming opportunities are inited to the evaluator and sharing of the findings takes place at the end only

There is no gain for the project as such, except in terms of prestige.

The evaluation cloes not involve stakenolders of the project, so the tindings and recommendations are aasily ignored.

Based on: Springett (2001a; 2001b) and Karisson (2001)

\subsection{Challenges and conclusion}

The final section of the second part of this thesis reflects further on how we have applied our monitoring instrument, and compares this with current insights into the evaluation of community health projects.

\section{Challenges}

Gurrent evaluation of health promotion interventions is not always congruent with its underiying values and the complexity of phenomena these interventions address (Koelen, 2001 ; Schwandt, 2001). Springett proposed a framework for (participatory) evaluation in health promotion, which is heavily based on the tenets of participatory research and action research. Fourth-generation evaluation is another participatory scheme of reference, which challenges positivistic evaluation methods 1 Guba \& Lincoln, 1989. Differences between the three fparticipatory evaluation, participatory research and action researchy are blurred, and a wide diversity is seen in practice. All three, however, challenge the notion of the independent and objective researcher and the relationship between the evaluated and the evaluator, and aim for this to be changed. Participation in participatory evaluation means engaging in dialogue at all stages of the process of evaluation. 
By consequence, those who are being researched are empowered (van der Plaat, 1995). The process is considered to be as important a product of the evaluation as is the evaluation report (Springett, 2001a). The process continues after the evaluation or research has ended. Evaluation contributes to sustainability of the change induced by the project (Green, Daniel, \& Novick, 2001; Koelen, 2001). This makes participatory evaluation particularly appropriate for community hea]th promotion (Potvin \& Richard, 2001).

The approach described above and the current debate on the evaluation of health promotion interventions challenge the way we evaluated the community-based Hartslag (Midden) Limburg project. We used dialogue between the project workers and the evaluator as a tool to understand the development of the project. The perspective of the project workers on problems and solutions was systematically explored, but mostly by consulting them, while the perspective of other stakeholders was hardly invesigated. The ideas of the evaluator herself were shared only sparingly with the project workers. The evaluator gave meaning to the data and wrote periodical (personal) reports, but after more than two years, the findings still had not been specifically and formally communicated to the stakeholders of the project. In sum, the dialogue was one-sided and was not used to its full potential.

\section{Table 5.2. Advantages and disadvantages of evaluators as co-participants}

\section{Advantages}

The evaluator helps to win the support of programme or project staft and other groups during the implementation of the study.

Stakeholders learn about evaluation.

People who have participated have a greater interest in and commitment to using the results.

Evaluation becomes a means of staff development, in such a way that they gain insight into what they are doing.

Information from stakeholders makes the study more valid; they know which questions are most relewant and thus which data need to be collected.

Concentration on narrow issues, mainly determined by the evaluator, is prevented.

Issues of power are more balanced. Participation tends to level the field and stakeholders acquire ownership.

\section{Disadvantages}

Professionalism may suffer when the actual conduct of the study is turned over to stakeholder groups (in the extreme case).

The knowledge generated by this approach is less appreciated by scientists and decision-makers (i.e., funding parties》.

The evaluator risks adopting the interests of one or the other interest group and lose objectivity.

The evaluator has to manage a range of tasks, such as facilitation and coordination of the process, being a partner in the dialogue, and interpretation of different realities.

An inordinate amount of time is required because consensus has to be reached at different phases of the study.

It is difficult to choose the 'right' representatives of interest groups. 
A more participative approach might, in this case, have provided an arena for sharing ideas and perspectives among all actors in the project (RPHS, project workers, collaborating organisations and community) as well as for shared decision-making. Regular feedback and discussion of the progress of the project might have led to the involvement of the different actors becoming stronger, continuous and sustainable. The empowering process could also have contributed to an active involvement of organisations and local groups in policy-making. While a participative approach might not have prevented the project from developing in the unforeseen way it did, from a professional or scientific point of view, it could have at least taken a form based on the values and consensus of all actors involved. Although participatory evaluation, with the evaluator acting as a co-participant, seems most appropriate for the evaluation of health promotion interventions, there are still some criticall points to overcome. These are listed in Table 5.2 below.

\section{Conclision}

The evaluation of the Hartslag (Midden) Limburg project might have been more appropriate and meaningful if a participative approach had been chosen, for three reasons. First, apart from being more appropriate for community health promotion in general, it would have been more congruent with the purpose of the evaluation, the project itself and the type of knowledge required, which was in-depth knowledge of the mechanisms underlying a community-based project that aimed at changing risk behaviour. A more participatory evaluation might have facilitated the understanding of an evolving and dynamic situation. Secondly, participative evaluation would have provided astructure to render the actual involvement of all stakeholders of the project more likely and continuous. In turn, such an involvement would probably have led to sustainable collaboration and actions to improve people's health. Thirdly, and perhaps most importantly, participatory evaluation has an empowering potential. Giving professionals and community members the opportunity to learn enables people to take control over the conditions that create health, including the ability to influence policy-making. 
\begin{tabular}{ll}
\hline \\
\hline
\end{tabular}

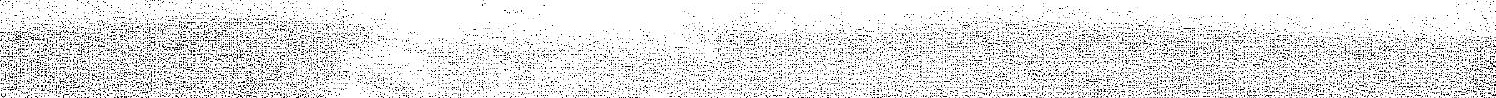

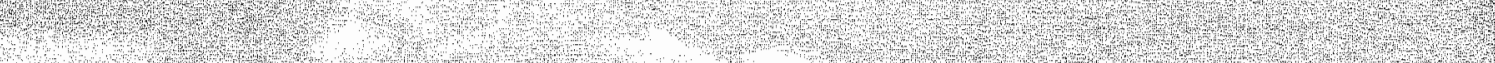

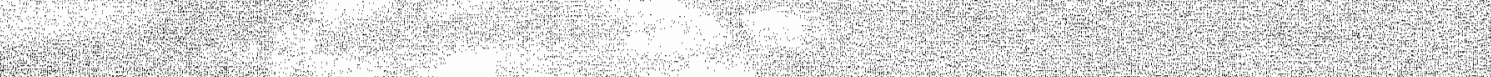

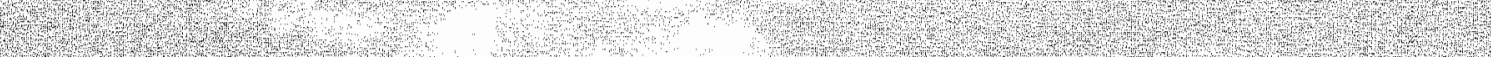

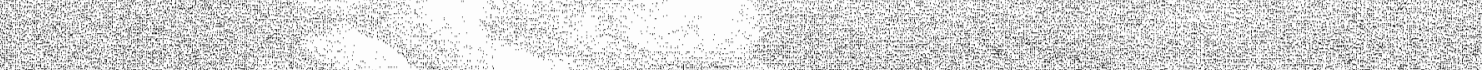

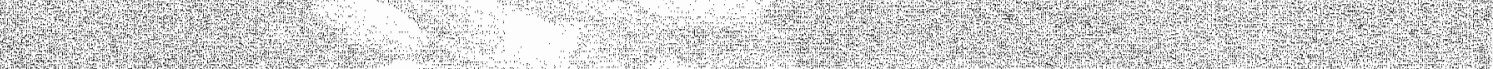

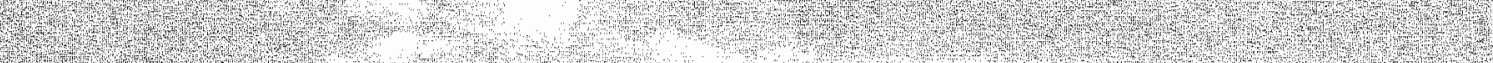
2.

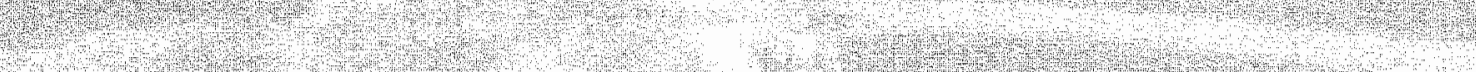
\begin{tabular}{ll}
\hline \\
\hline
\end{tabular}

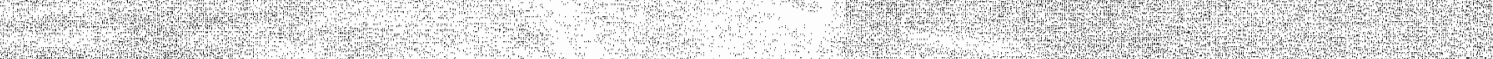

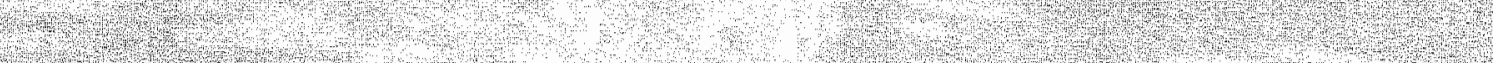

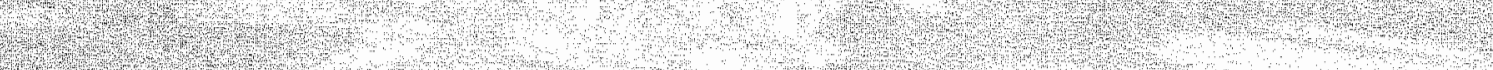

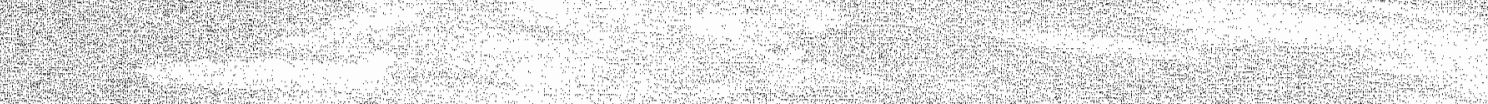

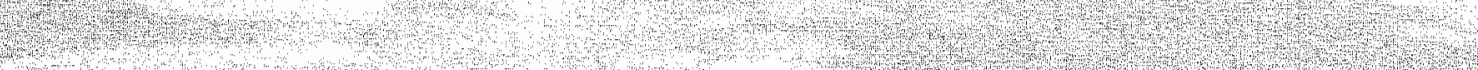
\begin{tabular}{llllll}
\hline \\
\hline
\end{tabular}

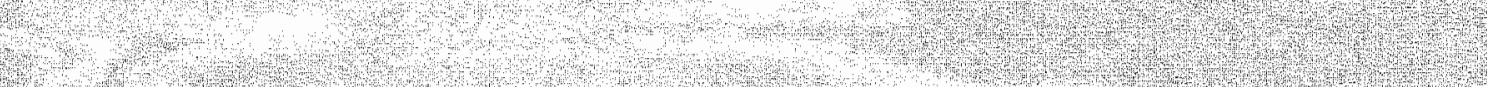
\begin{tabular}{lll}
\hline \\
\hline
\end{tabular} C. W. 4 (1)

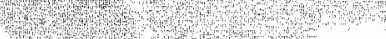
(1.)
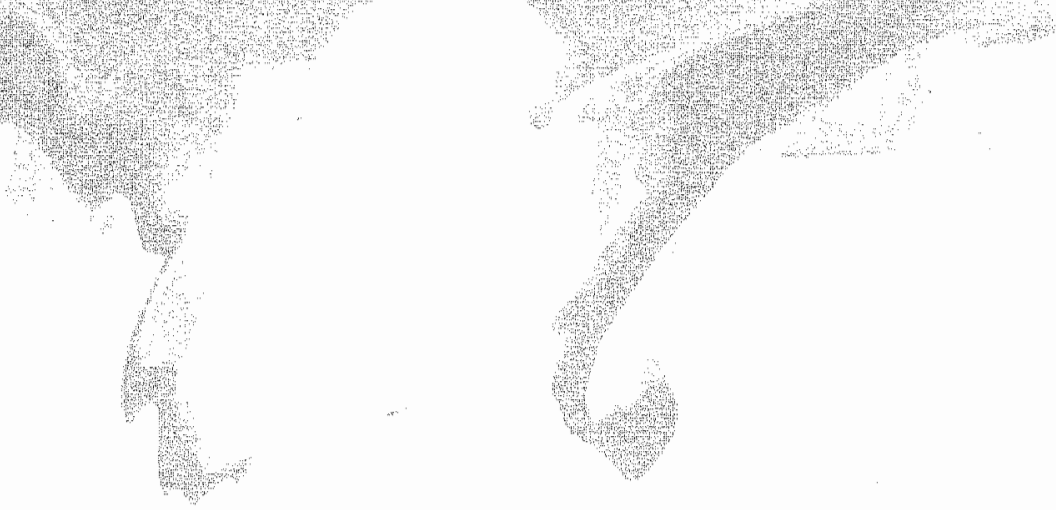<smiles>CC#CC#C[Si]C</smiles>

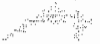
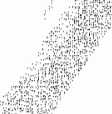

?t?

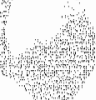




\section{PART III}

\section{RESULTS RELATING TO LOCAL HEALTH POLICY-MAKING}

The first part of this thesis outlined the background to our inquiry into local health policymaking. The Dutch Minister of Health, Welfare and Sports has made the development of local health policy obligatory, because of the unsatisfactory implementation of the law on collective prevention in public health (WCPV) by the Dutch local administrations and the sometimes problematic relationship with their regional public health services (RPHS). The RPHS in the Central Limburg region, which was charged with implementing local health promotion and advising the fourteen municipalities in the region, initiated a community-based project, which was discussed at length in part II, as well as the research underlying the present thesis.

Part LII, comprising three chapters, presents the results of our inquiry into local health policy. making in four municipalities in Central Limburg. Chapter 6 reflects on the operationalisation of this inquiry in more detail. Chapter 7 presents the cases (municipalities) used for our case study, and describes the situation at the time when the development of local health policy-making started. Chapter 8 presents the findings of our research during and after the development of local health policy. 


\section{FURTHER REFLECTIONS ON OPERATIONALISATION}

This chapter prepares for the presentation of the findings in the next chapters by elaborating on the operationalisation of the present study and the methods we used. These explanations are needed to understand the findings resulting from this operationalisation.

The present study on the development of local health policy devoted specific attention to the contribution made by local health promation interventions and to the involvement by and interactions between stakeholders in the policy process. The theoretical framework for this study (see chapter 2) is based on principles and concepts of health promotion and an interactive dynamic perspective on policy-making. The Theory of Streams (Kingdon, 1984, 1995) contributed greatly to this perspective on policy-making.

In part II of this thesis we have described the development and implementation of the community-based cardiovascular prevention project called Hartslag (Midden) Limburg. One of our conclusions was that the project was ultimately unsuitable as a topic for the present inquiry. This forced us to focus even more closely on the evaluation of the policy-making process as such. The change of focus of the inquiry had major implications for its operationalisation, as will be described below. Although the Hartslag (Midden) Limburg project was thus no longer the focus of our study, we did consider it to be an important contextual factor and included it in the evaluative framework (see section 2.4.1).

This chapter elaborates on methodological issues in the policy development processes. After we had developed the theoretical framework for our investigation, we identified the necessary research methods and tools, and subsequently adapted them to the unique research context. In section 2.5 we have described these various research methods used in this study in terms of the development of the research instrument, its application and the analysis of the data collected. The interviews held in each year of the study formed the largest data source. In this chapter we reflect mainly on this part of the work and discuss, how the first results informed subsequent data collection(s) and how this iterative process affects the interpretation of the findings presented in the next chapters. Naturally, other data sources, field notes and document analysis were also used to support the findings.

\section{Operationalisation}

The iterative nature of the operationalisation of theoretical concepts into interview questions eventually led to the refinement of our study by concentrating on the interactions between stakeholders.

Operationalising theoretical concepts as interview questions was based on a number of specific research domains: the stakeholders" perspectives on local health policy, their interests, 
their influence on policy-making and their involvement and relations in collaboration processes. With respect to the latter domain (collaboration and interrelatedness), the 2001 interview questions were rather open: "Could you tell me with whom you collaborate?" and 'What is the purpose of this collaboration?" (See Appendix 1.a) A list with the stakeholders identified previously as the most important ones in local health policy-making helped the respondents answer these questions (see section 7.2). In the first analysis of these data, we categorised the answers into collaborative activities at operational level and at policy level. After further scrutiny of the same data, we set up matrices for each case (municipality), representing the relationships among the stakeholders at the operational and policy levels, to a total of eight. At a later stage, these data were entered in Visone (www.visone.de), a program that we used to compute network graphs and density and centrality indices (for explanation, see below).

On the basis of our chosen theoretical framework and the insights gained from the interviews held in 2001 before policy-making really started, we developed a comprehensive set of evaluation criteria (see evaluative framework in chapter 2 ) and formulated four propositions to further specify the expectations we had about the development of the policy process in Central Limburg (see section 8.1 ).

Our newly gained insights and the evaluative framework guided our thinking on what we needed to know in assessing the progress of lacal health policy-making by the end of 2002 and the next round of interviews, to be held by the end of 2003 . We refined the interview questions according to the evaluative framework (see Appendix 1.b), in order to improve our understanding of the interactions and interrelatedness of the stakehoiders. We developed a form (see Appendix 1.c) to further structure the questions on this subject. The interactions and relations between stakeholders were the subject of five items. Three of these related to local health policy-making: (1) communication, (2) informal contacts and (3) exchange of expertise. Two items related to collaboration: (1) close involvement with other stakeholders in public health (e.g. partnerships, delegation of tasks, financial) and (2) strategic collaboration (coordinating with other stakeholders on important decisions) between stakeholders on the list (i.e., the stakeholders identified as the most important ones in 2003, see section 8.1.2). These data were again entered in matrices (18 in total) and further studied with Visone. Finally we asked the respondents to identify a policy entrepreneur among the stakeholders on the form, if possible.

After all data had been gathered and analysed, we finally used the different data sources (interviews, field notes, documents and the Hartslag (Midden) Limburg monitoring instrument) to apply the evaluation criteria. Figure 6.1 reflects the evolution of the operationalisation of our inquiry as described above.

\section{Understanding the findings}

The following chapter presents the network graphs resulting from our analysis of the 2001 interviews. It only shows the graphs for policy networks (not those at the operational level), since the focus of the present study was on policy-making, and to simplify matters. The computed density and centrality indices complete the findings on the interactions and relations between stakeholders. A further conceptualisation of these indices is presented below. 


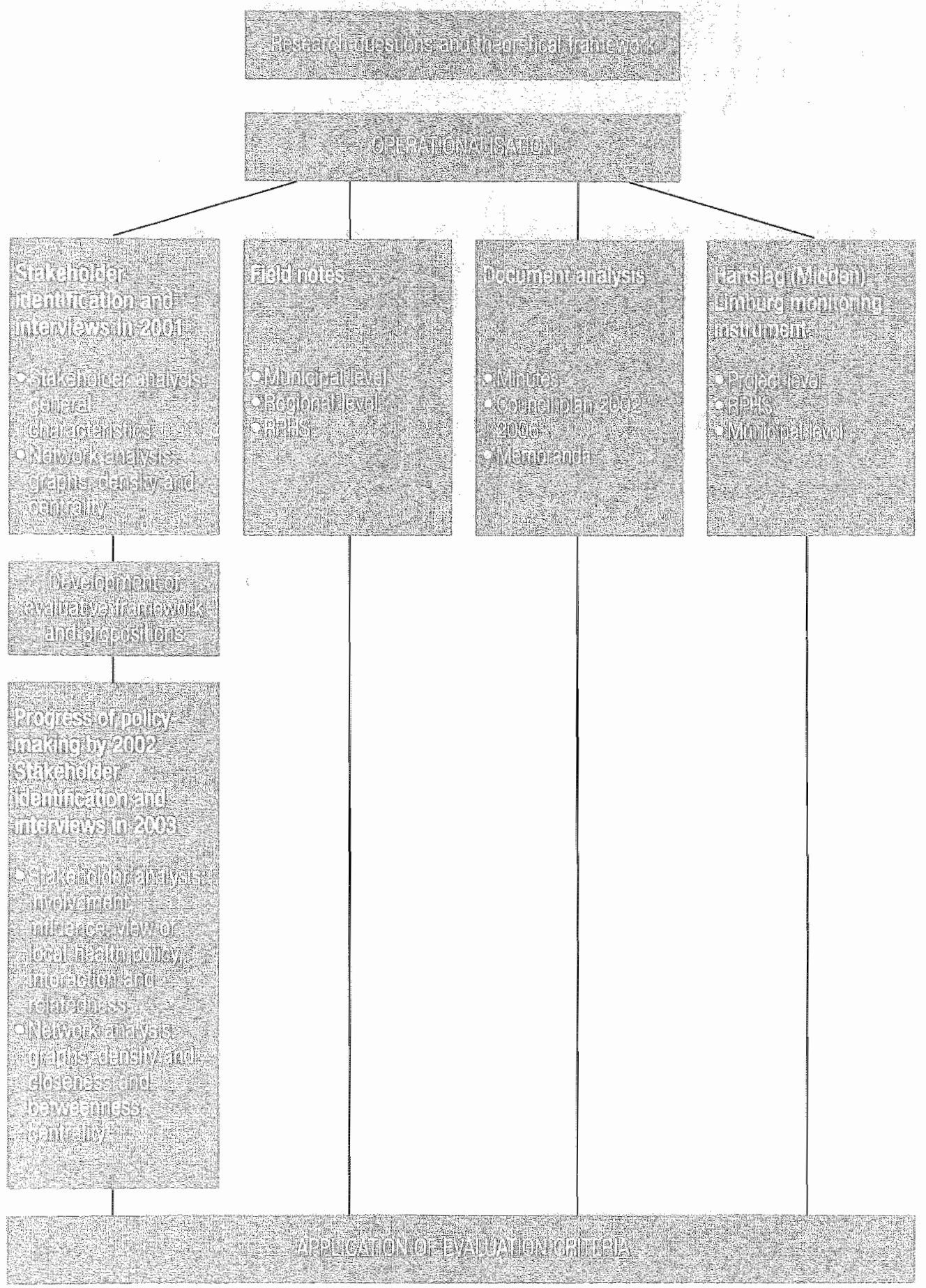

Figure 6.1 The development of the operationalisation of the inquiry 
Density clescribes the extent to which all actors in the network are linked to each other. It refers to a general level of cohesion and integration of the network. Density is expressed as the ratio of the number of actually observed relations to the potential number (ranging from 0 to 1). The centrality of an actor in this respect is defined as the extent to which the actor is visible within a network through direct ties to other actors. It describes whether the cohesiveness of the network is concentrated around particular actors (nodes) in the network, that is, whether particular actors are more in control of the network activities. We also computed closeness centrality for the municipal administration and the RPHS (explained below). The networks for 2001 show confirmed and unconfirmed relations ${ }^{3}$. Our study of these networks at the start of the process of local health policy development only required a general understanding of above properties.

The presentation of the findings on the policy-making process (the 2003 data) includes three network graphs for each case after local health policy had been effectuated (at least in three of the four municipalities). It shows the networks for communication with respect to local health policy-making, for close involvement with other stakeholders in public health and for strategic collaboration. The other two networks, for informal contacts and exchange of expertise, are not presented because they did not provide much links. The 2003 networks presented below show only the confirmed relations (see footnote). The network graphs are complemented by density and centrality indices (see above). Compared to the 2001 data, the 2003 analysis computed more precise actor centrality indices, viz. closeness and betweenness centrality indices for the municipality, the RPHS and the welfare service. These indices are compared with the centralisation of the network as a whole. Network centralisation was computed as the mean of the individual actor centralities. Closeness and betweenness indices served specific purposes in our study. Closeness centrality refers to the pattern of direct and indirect ties for a specific actor, which allows him/her to access all the other actors in the network more easily than anyone else. It expresses the length of the paths between an actor and all others, that is, whether the actor is close to everyone else. This measure helped us search for a possible policy entrepreneur in the policy-making process, that is, an actor who is in the best position to monitor the information flow and has the clearest idea of what is happening in the network. Betweenness centrality refers to the position of a specific actor in the network where s/he is between two important parts of the network; $s$ /he prevents other actors from being cut off from the network or part of it. This measure aljowed us to study the position of the community, which in our viewpoint should be enabled to play a role in policy development and take part in the flow of information and knowledge through the network.

${ }^{3}$ Confinmed relation: the network graph only shows a link between two actors if both actors confirm the relation. Unconfirmed relation: the network graph shows a link between two actors even if the relation is not confirmed by one of the two actors. 


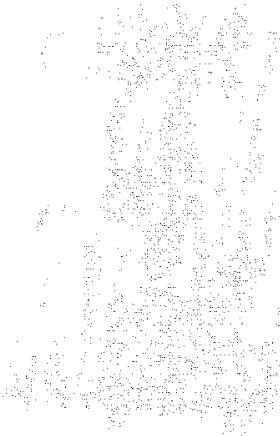

में क्ष

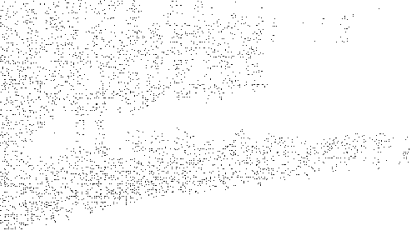

,

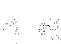

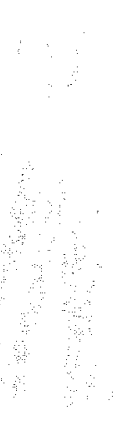

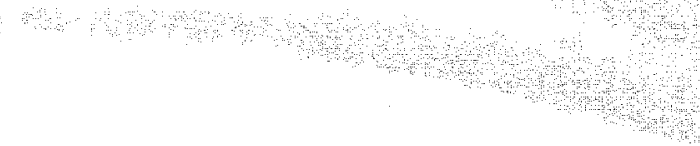




\section{THE START OF LOCAL HEALTH POLICY- MAKING}

This chapter presents the four cases (municipalities) included in our study, after which it reports the findings of the first stakeholder identification round and the interviews held in 2001 , prior to the start of local health policy-making.

\subsection{Presentation of the four cases: baseline situation}

First, let us outline very briefly the municipal context as regards local policy-making. Usually, a civil servant (oficial) prepares policy on the subjects assigned to him and which he has specialised in. He writes a policy document (plan) and submits it to the alderman who is politically responsible for the issue at stake. The municipal executive (mayor and aldermen) discusses the proposal, after which the alderman submits the policy proposal (after some alterations if necessary) to a committee of councillors. Finally, the complete council discusses and approves or rejects the policy. After approval, the civil servant is charged with the implementation of the policy, but the alderman remains (politically) responsible. The policy process also includes a formal opportunity for the population to comment on the policy plan.

This section presents the four cases included in our study: two urban and two rural municipalities, of the fourteen in Central Limburg (the selection process is described in section 1.3 and 4.2.1 1. It describes their most important features, the reason for inclusion in this study, and their approach to developing local health policy.

\subsubsection{Weert}

The municipality of Weert comprises the largest town in Central Limburg and its immediate vicinity. It has 48,785 inhabitants ${ }^{4}$. Weert functions as a so-called 'reglonal centre' (centrumgemeente). meaning that it acts as a regional pioneer in matters like the development of new policy, also for the benefit of the smaller municipalities in the area. The municipal authorities' longterm plan 12002 . 2006) specifies the importance of this role and the intention to invest in the status of the lown. Being a central municipality also implies that a number of care organisations like health care, psychological care and social work are organised within the town, but serve, and are used by, people from a much larger area. Important institutions in this respect are: the social and welfare service, a regional centre for mental health care, a hospital, home care service and two nursing homes.

\footnotetext{
4 The numbers of inhabitants in this and other chapters are taken from CBS (Statistics Netherlands) and reflect the sitcation on /anuary 1, 2003
} 
Weert was included as a case in our study because it appeared to have a positive basic stance towards community health initiatives, in the sense of enabling community health promotion by having the following characteristics: supporting community participation, intersectoral collaboration and showing political commitment. Moreover, the municipal authorities had agreed to participate in the community-based Hartslag (Midden) Limburg project.

In 2002, Weert started a joint process with the neighbouring municipality of Nederweert $(16,104$ inhabitants) to develop local health policy in close collaboration. Due to a lack of manpower in the public health office, the administrations of both municipalities decided to hire an external consultancy agency to assist their policy-making process. The two public health officers and the external consultant formed the principal working group. The aldermen responsible for public health in both municipalities, as well as the policy advisor of the Regional Public Health Service (RPHS) joined the other three in a steering group, which coordinated the process. At a work conference, held in March 2003, about one hundred participants discussed problems in the health domain and directions to solve them, in five thematic workshops. The participants themselves had chosen the themes of these workshops in advance, from a list sent with the invitation.

The town council approved the local health policy memorandum by the end of 2003 .

\subsubsection{Roermond}

Roermond is a renowned historical town, and the second largest town in Central Limburg, with 45,344 inhabitants. Like Weert, it functions as a regional centre for other, smaller municipalities in the area, although their intermunicipal collaboration is not very strong. A number of facilities, including health care and welfare service, are concentrated in the town, and also cater for the surrounding villages. Important organisations in this respect are: the social and welfare service, mental health care, a hospital, a shelter for the homeless, home care service and several nursing homes. The main priority for the Roermond town council for the years 2002-2006 is the town's economic development and alleviating social problems in certain neighbourhoods.

Roermond was included as a case in our study because it presented itself for participation in the Hartslag (Midden) Limburg project. Although the town did nor completely meet the inclusion criteria for participation in either that project or the present research project, the initiative was much appreciated, as two other municipal authorities had declined an invitation to participate (see 4.2.1). Roermond appeared to have a neutral basic stance towards community health initiatives.

The municipal administration decided (in 2002) to appoint a local health policy officer for the period of one year. This official was charged with policy development and writing the local health policy memorandum. Money was also allocated to pay the RPHS to organise interactive sessions. Two of such sessions were held: one addressing the problems and bottlenecks in the heaith domain, and the second discussing directions for solving these problems. About sixty people participated in these sessions: professional organisations (health and welfare services), schools, the police and representatives of the population (interest groups or associations of, e.g., young and elderly people).

The town council approved the memorandum on 'local health policy' in July 2003. 


\subsubsection{Roggel \& Neer}

Roggel \& Neer, having 8,415 inhabitants, is the smallest municipality among our four cases. It is located in a rural area and comprises three villages. Although Roggel \& Neer is situated at some distance from the two towns in the region, its population depends for a number of regionally organised health services on the cities of Roermond and Weert (e.g. home care service, mental health care and social work). Other health and social facilities are organised at a subregional (e.g. welfare service, nursing home) or local level (e.g. general practitioners, physiotherapist]. A day care centre for elderly people run by volunteers is a renowned and long-established local facility in Roggel. The main priority for the Roggel \& Neer council is the promotion of citizen participation and, where possible, collaboration, with other small municipalities in the region.

Roggel \& Neer was included in our study as a municipality with a positive basic stance towards community health initiatives, having the enabling characteristics of support for community participation, intersectoral collaboration and political commitment. The municipal authorites did not agree to actively participate in the community-based Hartslag (Midden) Limburg project, due to a lack of manpower. Nevertheless, the project did organise a few activities at Rogget Neer [see Table 4.1].

The municipal administration started preparations for the development of local health policy as early as in March 2001. From the start, Roggel \& Neer did so in collaboration with five other small municipalities in the sub-region known as 'Leudal Thorner Kwartier' (with a total of 46,779 inhabitants]. In fact, these municipalities chose to develop a sub-regional health policy. All six municipalities allocated financial resources to hire additional expertise from the RPHS. The regional administrative office ('concernbureau', the regional office that assists municipal administrations in the development of policy on issues which are jointly defined by all municipalities in the region; see also section 1.1.2) was requested to coordinate the policy process, to prevent a conflict of interest within the RPHS. Both organisations appointed one of their employees as project leader. To strengthen the project structure, the project leaders, together with two municipal public health officers, formed an organising committee. In addition, all six municipal public health officers met with the project leaders in a steering group. Finally, professional organisations and representatives of the population were requested to participate in one of four study groups, each focusing on one of four target groups at which the health policy would be aimed (young and elderly people, groups at risk and the general population). They met separately to discuss problems in the health domain and directions to solve these problems. In addition, two conferences were held, one at the start and one at the end of the workgroup meetings, involving a large number of participants from all six municipalities.

The council in Roggel \& Neer approved the local health policy memorandum in the summer of 2003.

\subsubsection{Roerdalen}

The municipality of Roerdalen is situated in a rural area south of the town of Roermond. The municipality comprises three villages, totalling 10,557 inhabitants. The inhabitants of Roerdalen depend on various services and facilities provided by Roermond, including the regionally organised heaith services like a hospital, mental heal th care, social work and home care service. 
Locally, only a few facilities are available, like a general practitioner, a welfare service and a nursing home. The municipal administration is much concerned with the liveability of the villages. Its priority is to develop the following projects: physical reconstruction of the centre of the village of Herkenbosch, provision or renovation of sports facilities and a school with extended function in the care for young children (brede schoot).

Roerdalen was included as a case in our study because it appeared not to have a favourable stance towards community health initiatives, in the sense of showing few indications of community participation, intersectoral collaboration or political commitment. However, the Roerdalen municipal authorities were the first to agree to participate in the community-based Hartslag (Midden) Limburg project.

The municipal administration has as yet not presented a memorandum on local health policy. In 2003, the municipal public health officer started collaborating with two other municipalities in the region on the development of local health policy, but this initiative foundered in its first phase and was not followed up.

\subsection{STAKEHOLDER IDENTIFICATION}

Before the characteristics of stakeholders and their importance for local health policy-making can be examined, the stakeholders must first be identified. We identified stakeholders at the local level, that is, in the four individual cases (municipalities), as well as at the regional level. Starting from the municipal administration, potential stakeholders were identified by means of snowball. sampling: each potential stakeholder was in turn asked to tick the ten most important stakeholders on a list sent to them. During the 2001 stakeholder identification round, 59 of the 72 lists that were sent out were returned; a response of $82 \%$, see Table 7.1 .

Table 7.1 Response to 2001 stakeholder identification

2001

Regional Organisations

Weert

Roermond

Roggel \& Neer

Roerdalen

TOTAL

\section{Sent}

11

19

16

18

8

72

\section{Response in \%}

100

79

69

94

75

82

For each case and for the regional organisations, the stakeholders that were mentioned most often were ranked as the most important ones. The resulting lists of the ten individuals, organisations and groups that were considered most important to the development of local health policy in each municipality differed in the ranking order. However, there were also similarities. Respondents mentioned both regional and local stakeholders as being important. 
In general, professional, mainly regional, health organisations appeared high on the lists, while interest groups and other representatives of the population or population groups, that is, the non-professionals, appeared at the bottom of the lists. Among the health professionals, the organisations for home care and general practitioners scored highest in each case. Aldermen and public health officers did not rank highly, occupying intermediate positions. The regional professional organisations for health and other issues ranked each other at much higher positions than they ranked local or non-professional organisations, individuals or groups, including the municipal administration. Regional and local level respondents agreed on the above sequence of importance. Combining the rankings for all four cases showed that the five most important stakeholders were active in health care, assistance and prevention.

\subsection{Stakeholder chaRaCteristics}

Representatives of the organisations, groups and individuals identified as the most important stakeholders for health policy-making in the four cases (municipalities) were interviewed in 2001. There were 34 respondents in total (whereas one might expect ten respondents for each case), because there were two non-respondents and because most of the regional stakeholders were active in all four municipalities. The respondents had a wide range of identities and backgrounds. They can be roughly divided into three groups, see also Table 7.2: professionals, non-professionals (platform for disabled people, council for the elderly, volunteers - in short, those who would be identified in the Anglosaxon literature as 'the community') and municipal respondents (public health officers and aldermen). The professionals were those who were organised at the local or the regional level (but acting at municipal level) and worked in health care (home care, mental health care, public health service, general practice, youth care, care and treatment of drug addicts) or non-health care (e.g. social work, welfare service, housing association). The distinctions made above are used for the presentation of our findings in this and the following chapters.

Table 7.2 Classifications of respondents in 2001

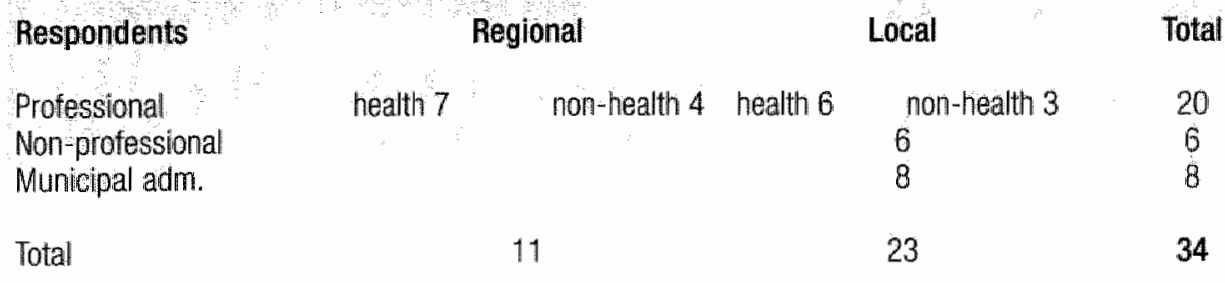

NB There were two non-respondents, (local health professionals)

Unfortunately, two tape recordings of interviews with two aldermen were not usable for analysis, reducing the number of respondents associated with the municipal administration for some analyses to six. 
in the analysis of the interviews, not all answers could be coded (because they did not encompass the categories or codes established], which is reflected in lower response rates.

Each of the following sections deals with one of the domains studied at the baseline situation: (1) defining local health policy, (2) interests of stakeholders, (3) involvement and stakeholders' expectations of their own influence, (4) collaboration and relations between stakeholders, (5) networks and (6) the role of the municipal administration and the RPHS in local health policy-making.

\subsubsection{Defining local health policy}

Local health policy is a relatively new domain to the rather small municipalities in Central Limburg, and surely also to many of the stakeholders identified as most important in local health policy-making. At the start of the policy process, respondents were hardly able to clearly express their ideas about local health policy.

The way respondents interpreted local health policy was often associated with their tasks and daily practice. Unlike respondents associated with the municipal administration, professionals said that local health policy was an integrated policy or umbrella policy, coordinating other policy domains.

When talking about local health policy, respondents did not mention all four types of activity of local health policy as described in section 2.2 (health protection, health promotion, prevention of disease and care). The type of activity mentioned most frequently by respondents from all three groups was care, including the provision of services, collaboration between service providers and health care policy development. Next after care, the professionals mentioned health promotion

Mijn eerste idee is: proberen de gemeente betrokken te krijgen bij de OGGZ (Riagg).

My first thought would be to get the municipal authorities involved in public mental health. (A representative of the Regional institute for Outpatient Mental Health Care RIAGG)

Het welzijn van bewoners. Voor mij zou dat heel belangrijk zijn: "mensen betrekken bij de zorg" (Jozef Muis).

It's about the well-being of the residents. That would be a major priority to me: 'getting people involved in health care. "A representative of the Jozef Huis day care centre for the elderly)

Ik heb geen idee wat daar onder valt, maar er zijn hier zaken waar we ons zorgen om maken (huisarts).

I have no idea what that includes, but I know there are things going on here that we worry about. (A general practitioner)

Gezondheid in de brede zin van het woord, "daar kan je veel aspecten in onderscheiden". Een integrale benadering is een belangrijke aanpak (AMW, Algemeen Maatschappelijk Werk). Health in the wider sense of the word, 'that includes a lot of different aspects'. It's important to take a comprehensive approach. (A representative of the AMW social work agency) 
and disease prevention as important types of activity; non-professionals limited themselves to care and prevention of disease. The answers given by respondents associated with the municipal administration showed greater variety: they mentioned all four types of activity, which might indicate a broader frame of reference.

\subsubsection{Interests of stakeholders}

It was not easy for respondents to articulate the interests or stakes they had in the development of local health policy. Approximately one fourth (all local actors) said they had a very great interest, while the others said they had hardly any interest, if any (see Table 7.3).

Table 7.3 interests of stakeholders

Interest

\section{Professional \\ $\mathrm{N}=11$}

High

Hardly

None

3
7
1

\section{Non-professional \\ $\mathrm{N}=4$}

1

2

1
Municipal adm.

$N=7$

Total

$\mathrm{N}=22$

6

14

2

The interest professionals have in policy-making is a practical one, and serves their own professional interest. They view their interest in local health policy-making in relation to their tasks (mostly individual assistance), in which they experience a great need for collaboration and in which activities need to be coordinated. The non-professionals also linked their interest in local health policy-making to the organisation's or group's own interests (e.g., obtaining proper facilities for the disabled). The interest municipal respondents had was particularly based on the statutory obligation to develop local health policy for their own municipality.

In fact, the development of local health policy was expected to serve different purposes for

Het belang voor de organisatie zit hem erin dat je in beeld blift (Thuiszorg)

What matters to our organisation is to maintain a high profile. (A representative of a home care agency)

Vooral het samenwerken met gezondheidsorganisaties (WLT, welzijnswerk)

The main thing is to collaborate with health care arganisations. (A representative of WLT, welfare service)

Je hebt verantwoordelijkheid naar jezelf en je inwoners dan moet je dat goed op papier zetten (ambtenaar)

You are accountable to yourself and to the residents, which means you have to set down who is responsible for what. (A civil servant) 
different respondents. Professionals wanted to improve coordination and collaboration in their work in order to improve the situation of individuals requesting assistance from them. The local non-professionals expected to gain more support for their target group and to maintain or improve local facilities. The public health officers and aldermen wanted to develop a decent public health plan, but did not have a sense of urgency yet.

\subsubsection{Involvement and expectations about influence}

The professionals were usually involved in policy-making at the regional level. Non-professionals were not involved in policy-making, neither at the regional nor at the local level, see Table 7.4, with the exception of officially recognised advisory boards (e.g. platforms for the disabled). These were involved in the formation of policies relevant to the target group they were working for: The municipal authorities were involved in policy development at both the local and the regional level. It was the position (whether in the health domain or in the community) and expertise of a specific respondent, which determined whether they were invited to participate in policy-making and whether such an actor could adequately contribute to the policy development at issue. Half of the respondents involved in the development of local (i.e., municipal) policies had a financial relation with the municipal authorities and were at the same time involved in the implementation of municipal policy in their field of activity.

Tabje 7.4 Involvement in policy-making in the past

\section{Involvement}

Regional policy yes

no

Local policy yes:

no

\section{Protessional}

13

8

5

8

\section{Non-protessional}

1
5
2
5

\section{Municipal adm.}

\section{5}

3

4

1
Total

19

16

11

14

At the start of the process of local health policy-making, the professionals expected to be influential, because of their position and expertise in the health domain and their social status. They thought that they had a contribution to make and that local health policy related to their tasks and activities in one way or another. General practitioners, however, doubted whether they would be permitted access to the policy process by the municipal authorities or doubted whether they wanted to become involved. Professionals expected to contribute their expertise and to use consultative structures to exert their influence. The non-professionals were also predominantly positive about the influence they could exert, because they already had many contacts at the local level and had specific expertise. They expected to use informal contacts and local structures to influence policy-making, in addition to the more formal consultative structures. The respondents associated with the municipal administration suggested that their position was important but did not explicitly mention their decisional power. They expected to facilitate consultation among stakeholders. In general, municipal authorities said they expected to use financial resources to influence policy-making. 
Those respondents who expected not to participate in policy-making said that they expected their position or expertise not to be highly valued. Few respondents said that they had no time to participate.

Table 7.5 Stakeholders" expectations about their influence

\begin{tabular}{|c|c|c|c|}
\hline $\begin{array}{l}\text { Expectation about } \\
\text { influence }\end{array}$ & $\begin{array}{c}\text { Professional } \\
\mathrm{N}=20\end{array}$ & $\begin{array}{c}\text { Non-professional } \\
\mathbb{N}=5\end{array}$ & $\begin{array}{l}\text { Municipal adm. } \\
\mathrm{N}=6\end{array}$ \\
\hline Positive & 11 & 4 & 4 \\
\hline Negative & 6 & 2 & 3 \\
\hline Do not know & 8 & 2 & 1 \\
\hline
\end{tabular}

In sum, most of the respondents had positive expectations about their ability to become involved in the policy process and to influence the development of local health policy, see Table 7.5. They all expected that their position, although different for each group of respondents, would decide whether they had access to the policy process. The means of contributing to and influencing policy-making varied between the different groups, from consultations to informal contacts and financial resources.

\subsubsection{Collaboration and interrelatedness}

Professionals cooperated most closely with other professionals (individuals or organisations]. They worked together at both implementation and policy level but largely in a patient- and client-centred manner, although in some cases they were also involved in projects or specific networks. Collaboration in projects and policy formulation had a more permanent character. In addition, they collaborated with the municipal authorities, the RPHS and non-professionals. There was more collaboration at the local than at the regional level.

Non-professionals reported using individual contacts with others in their network to contribute to projects and sometimes to policy development. They also contributed material support for the benefit of patients or specific target groups. They collaborated mostly with professionals and with the municipal authorities, in local initiatives with a permanent character:

The municipal administrations worked together with others primarily at the policy level. They collaborated in local projects, in which they often commissioned other parties to implement the project. Their collaborative relations were permanent as regards policy implementation. Their collaborating partners were mainly professional organisations, including the RPHS, and to a lesser extent local initiatives and colleagues in other policy domains within the municipal organisation.

The majority of the respondents said they depend on others in the health domain; this was true for professionals as well as non-professionals and respondents associated with the municipal administrations, see Table 7.6.

Professionals said to have knowledge and expertise in very specific parts of the health domain, which at some level created interdependency in the implementation of their activities. 
Table 7.6 triterdependency of stakeho/ders

$\begin{array}{lcccc}\text { Interdependency } & \text { Regional org. } & \text { Local org. } & \text { Municipal adm. } & \text { Total } \\ \text { Yes } & 9 & 11 & 4 & 24 \\ \text { No } & 1 & 3 & 1 & 5\end{array}$

The municipal administration was able to contral and guide the policy and activities of local actors (volunteers and some professional organisations) through subsidies. The relationship with the larger regional health organisations was more informal, but changing towards increased contacts and cooperation. in terms of local health policy-making, the municipal administrations regarded themselves as depending primarily on the input from professionals.

Als gemeente zie ik niet direct zelf een initiërende rol. De specifieke organisaties en de GGD zijn de belangrijke actoren. (portefeuillehouder Roggel en Neer).

I don't think it's up to the municipal authorities to take the initiative. The main actors are the specialised organisations and the RPHS. (Alderman responsible for public heaith in Roggel \& Neer)

Interest groups and other local initiatives were generally in a more dependent position visà-vis the municipal authorities and professionals (on whom they depended for money, approval of policy and support) except for the few that were autonomous and self-reliant.

In sum, it seems that the professionals had a central position. They were involved $\mathrm{n}$ all forms of cooperation. Non-professional organisations and interest groups were involved at the policy level when they were officially recognised as consultants to the municipal authorities. Local initiatives were often developed and maintained by non-professional organisations and volunteers, who were in turn assisted by professionals.

\subsubsection{Networks}

We studied the collaboration between the individual stakeholders and their relations in more detail by means of Visone, a computerised programme for network analysis. This allowed us to present and discuss in the present section the connectedness of stakeholders in the four cases (municipalities), in the form of networks at the operational and policy levels. Two characteristics of networks, density and centrality (for further explanations see section 2.3.2 and chapter 6), which were derived from the data, are described below.

\section{Density and connectedness}

The density of a network describes the extent to which all actors in the network are connected to each other. It refers to a general level of cohesion and integration of the network as a whole (see also Figure 7.1). 


\section{Municipality}

Weert

Roermond

Roggel \& Neer

Roerdalen
Network at operational level

0.36

0.38

0.57

0.27
Network at

policy level

0.17

0.21

019

0.13

NB. For a specification of the actors in these networks, see Figure 7.7

Table 7.7 shows that the integration of the networks at policy level was considerably lower than at the operational level. The density of the networks at Roerdalen, especially at the operational level, was (much) lower than that in the other three cases, meaning that the participants in the networks did not have many links with each other. This might be a reflection of a lack of collaborative structures in this case. The density of the network at operational level in Roggel \& Neer was much higher than in the other three cases. This means that the participants in this network had more links with each other than in the other three cases; the network showed greater cohesion.

Still looking at the networks as a whole, we can observe that two municipalities, Roggel \& Neer and Roerdalen, had a disconnected network at policy level (see Figure 7.1). This means that a particular actor, or set of actors, is not connected to the other actors in the network. In both cases, these disconnected actors were only local stakeholders: non-prolessional groups or organisations, general practitioners, nursing homes. The policy networks in Weert and Roermond were weakly connected, which means that all actors were connected, but via paths of different directions. The policy network in Roermond seemed to be more strongly connected, as it showed the largest number of reciprocal ties between stakeholders or small groups of them (see Figure 7.1). The presence of small groups with reciprocal ties (cliques) indicates that these actors were in a good position to lobby for their common interests.

\section{Centrality}

The extent to which a particular actor is linked directly to all other actors in the network is called degree centrality. This can be expressed in outdegree and indegree indices, referring to the visibility of an actor in the network as sender and receiver, respectively.

In the networks at the operational level, the general practitioners were the principal senders and receivers; they had the largest numbers of direct (bi-directional and unilateral) connections with other actors. In other words, they were the central actors in this respect, followed by other professionals, especially regional organisations and the municipal authorities. It should be noted that the implementation networks are first and foremost problem-centred at the individual (patient, client) level.

The policy networks (presented in Figure 7.1) clearly differed from the networks at the operational level, in that the municipal authorities occupied a central position. The municipal authorities had more receiving links than sending links with others in the networks. In 


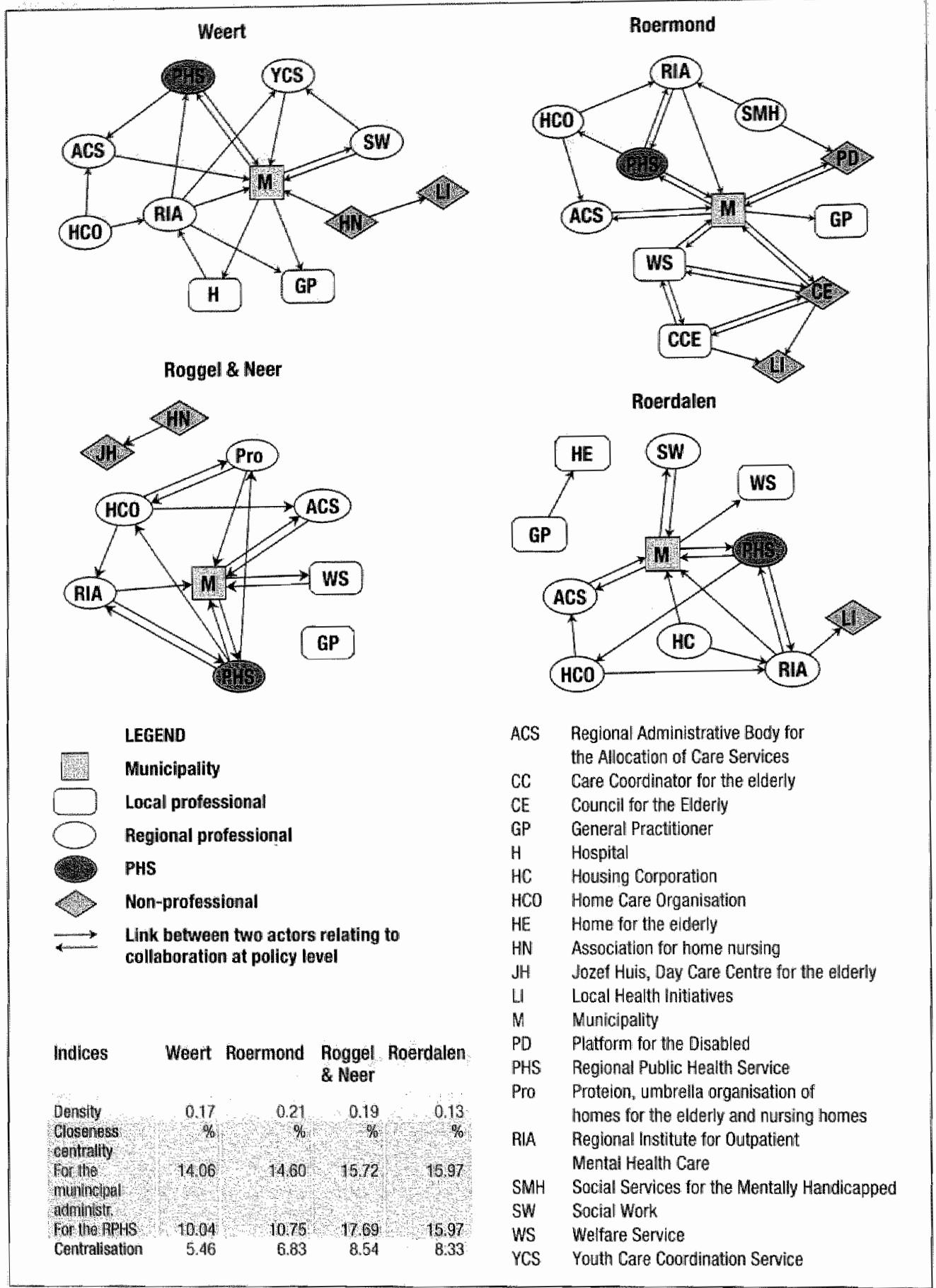

Figure 7.1 Networks at the policy level (2001) 
addition, they had reciprocal connections with those actors who received financial support or who implemented specific tasks for the municipal authorities. The regional professional organisations had the second highest degree centrailty, after the municipal authorities, in all four cases. These health professionals had many connections among themselves (relating to policy formulation related to specific problems or target groups) and with the municipal authorities. Non-professional organisations and groups had the lowest degree indices, indicating a peripheral position in the network.

The centrality of the various actors was also studied in terms of the ability to easily access all other actors in the network (to coordinate the policy process], a property called closeness centrality. Because we focused on the interactions between stakeholders as regards policymaking, we computed closeness centrality only for the networks at policy level. Once again, the municipal authorities were the most central actors in all four cases. In the two small municipalities, Roerdalen and Roggel \& Neer, the RPHS was the second most central actor, followed by other regional health organisations. In the policy networks of Roermond and Weert, those actors connected to local (health) initiatives also played a central role. This applied to the council for the elderly, to the local home nursing association and to the welfare service, all of which were easily able to access all actors in the policy networks and to provide access to these local non-professionals to the other actors in the network.

In sum, networks at the operational level were more integrated than at the policy level; there was less interaction between the actors at the policy level. The central actors in the implementation networks were not the same as in the policy networks. The municipal authorities were the most central actors in the policy networks. The RPHS was also easily able to access all actors of the policy networks, especially in the two small municipalities, although in these cases a number of local actors were disconnected. In the networks of the other two municipalities, the intermediaries of the locai non-professional groups were also central actors.

\subsubsection{The roles of the municipal authorities and the RPHS in local health policy-making}

The 2001 interviews showed that the administrations in the four municipalities differed in their views of their own roles and the role of the RPHS in local health policy-making. The difference was especially clear between the views of the two small municipalities and those of the larger two. The two smaller municipalities lacked the necessary expertise and manpower in their public health offices to take the lead in local health policy-making. In addition, they preferred to develop local health policy in close cooperation with other municipalities. The small municipalities quickly, almost automatically, turned to the RPHS for guidance. The municipal authorities of Roggel \& Neer, for example, asserted that policy development is a task assigned to the RPHS. The RPHS' know-how was expected to guide them in determining the content of the local health policy, in terms of health problems to address and solutions, as well as to guide the policy process. The municipal administrations of Roermond and Weert were of the opinion that they themselves were the central actors in the whole policy process and they were not sure about an active role of the RPHS, which they tended to regard as an implementing body. Nevertheless, they also saw a supportive role for the RPHS, especially in supplying epidemiological data and other information 
as building blocks for the development of local health policy. Respondents associated with the municipal administration generally stated that they wanted to involve others in policy-making: firstly health professionals and secondly representatives of the population (Hoeijmakers, $200 \mathrm{lb}$ ).

In all four municipalities, the municipal administration felt obliged to initiate and coordinate/ facilitate the policy process, though no exact plans had been drafted yet.

At the time, the RPHS regarded the municipal administrations primarily as being in charge of the development of local health policy. It saw its own task as providing insight into the health situation of the population, upon which the municipal authorities could base adequate policy decisions. It was considered inappropriate by the RPHS to interfere directly in the policy process, because this could cause a conflict of interest, the RPHS also being an implementing body.

Als gemeente zle ik niet direct zelf een initiërende rol. De specifieke organisaties en de GGD zijn de belangrijke actoren. $D e G G D$ is voor ons een verlengstuk van de gemeente. We zien het als een dienst zoals ook bv de dienst openbare werken. Ontwikkelen van beleid is een taak van de GGD. (dat hebben ze ook opgepakt) de uitvoering berust dan bij de organisaties die daarvoor uitgerust zijn (gemeente Roggel en Neer).

1 don't think it's up to the municipal authorities to take the initiative. The main actors are the specialised organisations and the RPHS. We regard the RPHS as an extension of the municipal administration. It's another local service, like the department of public works. Policy development is one of the tasks of the RPHS, and they have indeed accepted that task. The policies can then be implemented by the organisations that are equipped to do so. A representative of the Roggel \& Neer municipal authorities)

We zien de GGD als een van de partners, zij het een speciale, en niet als degene die ons lokaal gezondheidsbeleid formuleert. De GGD kan gegevens verstrekken. De GGD is ook zeker als uitvoerder en ook coördinator van een aantal projecten heel belangrijk.

Roermond wil haar eigen visie daarin kwijt, haar rol maar ook beleidsinhoudelijk; waar willen we met name aandacht aan besteden (gemeente Roermond).

We regard the RPHS as one of the partners - although with a special status - and not as the party that should formulate our local health policy. The RPHS can supply data, and it certainly has an important role to play in implementing and coordinating a number of projects.

The Roermond mumicipal administration wants to express its own views, its role and the content of its policies, that is, the aspects that we want to focus on. (A representative of the Roermond municipal authorities)

\subsubsection{Summary}

In 2001, most respondents were not familiar with local health policy, and some had not even heard of it. Respondents' ideas about the form or content of local health policy were not very concrete at this stage, meaning that the policy process was still completely open. In general, respondents gave the impression that the development of local health policy offered a (new) 
opportunity to promote their interests or those of their organisations. These interests, however, were not urgent enough for respondents to become active at this stage, or to take the lead. The municipal administration, which was considered to be mainly responsible for local health policy-making, did not undertake specific actions in this respect. They felt a great need to be assisted in the development of local health policy. How this assistance was to be specified, and in what way the RPHS would be involved in each case, was not clear yet.

The different groups of respondents said - each from their own perspective - that participating in and influencing policy-making depended on expertise and status in the health domain or the local community. In addition, the relationship with the municipal authorities was important. To what extent the different types of expertise, status and relationships would be appreciated would become apparent after the policy-making process was completed.

The municipal authorities occupied a central position in the policy networks. They had the largest number of direct and indirect links, so they could easily access all other actors in the network. The RPHS and a regional health organisation could also be regarded as important actors in the policy networks, as could some specific actors in Roermond and Weert. Local actors, especially non-professionals, accupied peripheral or even disconnected positions in the policy networks, except if they were officially recognised as an advisory board. 
प्र 4 (4)

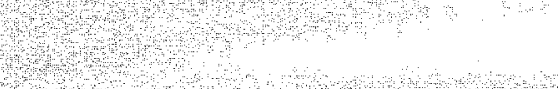

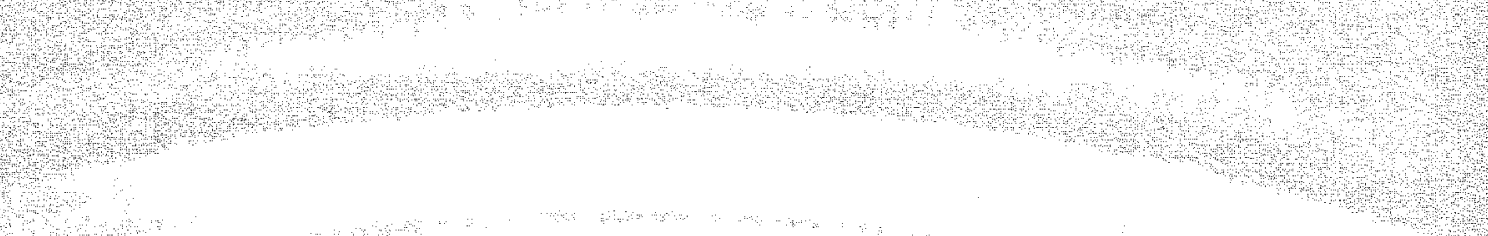

\begin{tabular}{llll}
1 & \\
\hline
\end{tabular}

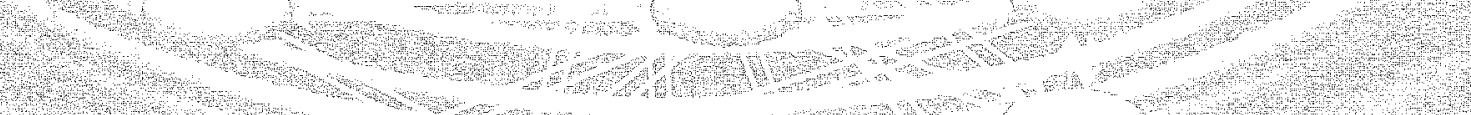

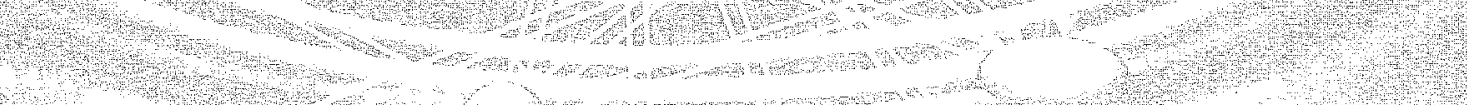

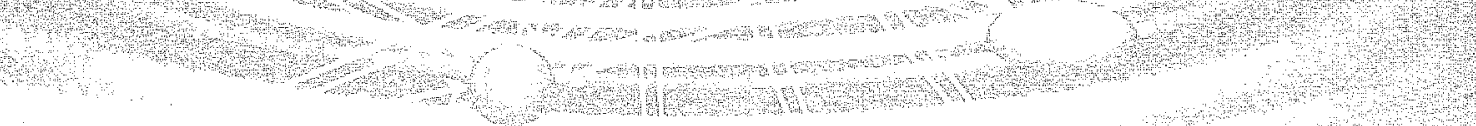

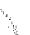

(2)

(2)

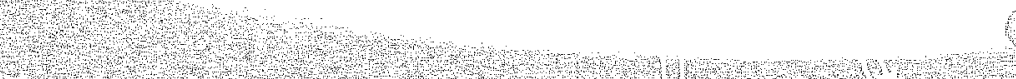

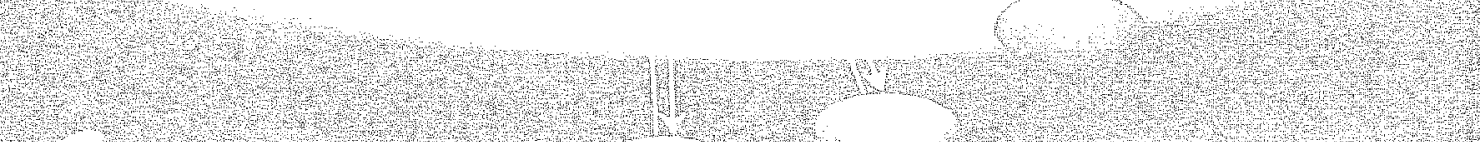

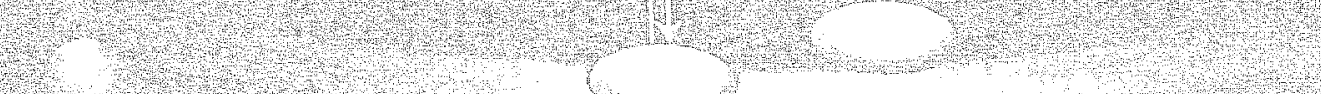




\section{HEALTH POLICY-MAKING AT THE MUNICIPAL LEVEL}

The previous chapter has described the stakeholders for local health policy, their interests, expectations and their interrelatedness in networks in 2001, at the start of the local health policy-making process in Central Limburg. Chapter 8 presents what we found while the process of policy-making developed, as reflected in interviews, observations and document analysis. The research activities were guided by a number of propositions formulated after the data obtained in the first year of the inquiry had been analysed. After outlining these propositions, the chapter goes on to present the results of an interim assessment (in the form of structured interviews) at the end of 2002. It then describes the stakeholder identification round held in the summer of 2003, which provided the starting point for the interviews held in the same year: The results of the application of a series of evaluation criteria (the evaluative framework presented in 2.4), based on the above data sources, are presented for each case. Finally, the chapter compares the findings for the four cases.

\subsection{Propositions}

After we had analysed the first data collected by interviews and developed the evaluative framework, we formulated four propositions, relating to the evaluation criteria, on the participation of different stakeholders in the policy process (see also chapter 6 and Figure 6.1). These propositions describe more precisely our expectations about the actual involvement and roles of the municipal authorities, the RPHS, other professionals and the community in the policy process, and why we expected this.

Municipal authorities are locally active in promoting the health and well-being of the population. The municipal authorities are primarily responsible for the development of local health policy (a task imposed on them by law). Moreover, they were the central actors in the policy network and therefore able to communicate with all stakeholders. The municipal authorities entertained reciprocal relationships with a number of local and even regional (health) organisations, which can easily be asked to become involved in policy-making. This is specifically true of the RPHS. The other stakeholders are most likely to approach the municipal authorities often for consultation, when necessary. Our first proposition was therefore:

1. Because of its central position in the policy networks, the municipal administration will actively communicate with and mobilise the other actors in the network, and will coordinate the network. The favourable starting position of the municipal administrations in Weert and Roggel \& Neer will reinforce this role. 
The intricate character of health problems and the fact that health professionals all tend to concentrate on their own specific tasks mean that the policy-making process requires the active intervention of a policy entrepreneur.

From the very start, the RPHS has had an opportunity to play an active role in policymaking, for a number of reasons. First, they are the public health specialists par excellence (having a great interest in the development of health policy). Second, the RPHS had a close reciprocal relationship with the municipal authorities and was also easily able to access other stakeholders in the policy networks. Third, the municipal authorities sometimes turned to the RPHS for assistance. Our second proposition was therefore:

2. The Regional Public Health Service will act as a policy entrepreneur, connecting the participants in the policy process through advocacy and negotiation, if it is requested to assist in policy-making. In network terms, the RPHS will have a central position.

Professional actors saw an opportunity to promote their interests or those of their organisation in the development of local health policy. All stakeholders considered them to be important actors, and the municipal administrations want to use their knowledge and expertise as input for local health policy. Moreover, they had direct access to the municipal authorities, the central actors in the policy network. Our third proposition was therefore:

3. Health professionals will participate in local health policy-making and compete with each other to stimulate interest in the health problems they are responsible for and their favourite solutions.

Local non-professionals were considered important but only in the second instance. In addition, they had a peripheral or even disconnected position in the policy networks. Local interest groups with an official status as advisory boards to the municipal authorities had direct access to this central actor: Our fourth proposition was therefore:

\section{Local non-professional groups will participate in the policy process but have a weak position when it comes to influencing the policy-making process.}

\subsection{Progress in local health POLICY-MAKING}

In July 2002, the Lower Chamber of the Dutch Parliament formally approved the amendment to the law on collective prevention in public health (WCPV). The amendment, which took effect on 1 January 2003, implied that each and every municipality should have presented a local health policy memorandum by July 2003 . Some municipalities had actually already started the policy development process. To assess the state of affairs in Central Limburg, and inspired by the evaluative framework, we held short interviews by the end of 2002 . We telephoned 36 stakeholders in the four municipalities who had previously been interviewed, 
asking them about their involvement in local health policy-making, using closed and semistructured questions. We did the same with the 25 aldermen and civil servants, officers responsible for public health in all fourteen municipalities. We asked these respondents more or less open questions about the importance of health issues on the municipal agenda and the progress of local health policy-making in their municipalities.

\subsubsection{The state of affairs in late 2002}

This section describes the findings of the interviews with stakeholders in the four municipalities and with the aldermen and civil servants responsible for public health in all fourteen municipalities of the Central Limburg region.

\section{Stakeholders}

The process of local health policy-making might be characterised as rather static in 2002 . The majority of the respondents had not yet communicated about local health policy with other stakeholders, including the municipal administrations. Although the respondents associated with the municipal administrations were concerned with local health policy, they were mostly interested in organising the policy process and getting it started. They were primarily consulting their colleagues in other policy domains, colleagues in other municipalities and the RPHS. The municipal authorities in Roermond and Roggel \& Neer had already invited professional organisations and non-professionals to suggest policy content. A number of the professional stakeholders [regional organisations] had started to participate in poljcy-making in these two municipalities. The initiative for participation, however, had come from the municipal authorities. Stakeholders who were already participating, as well as those not (or not yet) participating, said that they wanted to get involved in policy-making but would not take the initiative themselves. Their reasons for involvement referred directly to the way they defined their tasks and their current or future activities. in the public health domain, as well as the need to tune in with the activities of other actors.

At this point in time, it was not clear to stakeholders whether a policy entrepreneur was active or not. Only eight respondents had observed an active policy-making role of the municipal administration, the RPHS and a single other professional stakeholder.

\section{Public health aldermen and officers in Central Limburg}

At the end of 2002, the key question for the municipal administrations in Central Limburg was how to organise the policy process and who else to involve in policy-making. With a few exceptions, they developed, or wanted to develop, local health policy in collaboration with neighbouring municipalities. All were seeking external assistance, from the RPHS or consultancy firms. Aldermen were consulting with their colleagues in the region and their public health officers. The latter were also consulting their colleagues in other policy domains, as well as the RPHS and, if applicable, external consultants. Before the policy process could actually start, the municipal council had to approve the proposed approach (including the budget), after which interactive sessions with stakeholders were planned.

Public health in general, and specific health problems in particular, were not high-priority issues for the municipal administrations; health policies had up to then an unstructured, ad hoc character. 
Het (wolksgezondheid, MH) heeft geen structurele aandacht, laat ik het zo zeggen. Op het moment dat er zaken gebeuren die de gezondheid kumnen schaden, dan heeft dat gelijk, ja zeg maar even, de hoogste prioriteit (portefeuillehouder Maasbracht).

That subject (public health - MH) is not being consistently discussied, let's put it that way. As soon as something happens that could adversely affect public health, it immediately gets priority in fact, you could say top priority. (Alderman responsible for public health in the Maasbracht municipality)

(wat is prioriteit in de gemeente? MH) Ja, goed dat is natuurlijk altijd een momentopname. Vandaag ligt de prioriteit toch weer anders als bij wijze van spreken de volgende week. Ik wil daar niet zo dramatisch over doen maar dat wisselt (ambtenaar Heythuysen).

What are the main priorities for the municipal authorities? - MH) Well, it varies a lot. Today's priorities may differ from those in, say, a week's time. I'm not trying to dramatise things, but priorities do shift. (public health civil serwant with the Heythuysen municipal authorities)

The priorities of the local authorities lay with other subjects, like municipal organisation (both internal organisation, e.g., the development of a long-term strategy, and external organisation, e.g." citizen participation, policy development for specific target groups like young and elderly people, homeless people) and the liveability of certain villages and city districts (e.g. in terms of services and facilities). With respect to health, priority issues mentioned by the respondents as having the attention of the local administration included preventive youth care, social care like shelters for the homeless (maatschappelijke opvang), a policy for the elderly (in terms of housing, well-being and care) and the establishment of care facilities [e.g. general practices\}. Our examination of the municipal authorities" long term programmes [for the year's 2002-20041, drawn up after the municipal elections in March 2002, aiso showed that the municipal administration was not purposefully targeting health promotion in its activities, although the policy proposals did relate to people's health.

Table 8.1 Health issues on the municipal agenda

\section{Agenda status}

High

Average

LOW

Total

\section{Aldermen}

\section{3}

7

3

13
Public Health Officers

Total

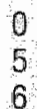

11
0. $\quad 9 \div 3$

5.12

9

24

NB there was one missing value.

Only three respondents (aldermen) thought that health issues were high on the municipal agenda; the others reported that health had an average or low agenda status. The public health 
officers gave a lower estimate of the agenda status of health issues than the aldermen; see Table 8.1.

Respondents gave different reasons for the "low" agenda status of health issues. For one thing, health had to compete with other policy domains and matters of concern to the municipal authorities (see above). In addition, public health was seen as a general and broad concept, and a number of respondents felt unable to come to grips with this policy domain. They said they lacked the appropriate knowledge and some matters exceeded their decisional competencies. Moreover, health was not often perceived as an urgent matter. Half of the respondents said they were not aware of specific health problems in their municipality. Their general approach was to develop policy and act in response to problems reported to them by citizens. The fact that local health policy-making was to become obligatory would in fact put health on the agenda or raise its status.

Dat lokaal volksgezondheidsplan is wel een punt waar de gemeenten zich nu ook echt druk over willen en moeten maken, het is ook een wettelijke taak. En daarom is het op de agenda komen te staan. Maar was het een jaar later gekomen, ben ik ervan overtuigd dat het een jaar later op de agenda was komen te staan (portefeuillehouder Haelen).

This local health policy plan is an issue that municipal authorities currently want to, and actually have to, take seriously. It's their statutory task now. That's what has put it on the agenda. But if the statutory obligation had come a year later, I'm sure the issue would also have appeared on the agenda a year later. (Alderwoman responsible for public health in the Haelen municipal administration)

Many respondents expected that public health would be considered regularly in the future because of the permanent and recurrent nature given to local health policy by law.

\subsubsection{Stakeholder identification in 2003}

In 2003, we used the same procedure for stakeholder identification as in 2001. Starting with the municipal administration, potential stakeholders were listed by means of snowball sampling. These stakeholders were identified at the local level (in the four municipalities) as well as at the regional level. They were in turn asked to indicate the ten most important stakeholders on the list sent to them. Sixty of the 81 lists that were sent out were returned, that is, a response of $74 \%$ (see Table 8.2 ).

For each case and for the regional organisations, the stakeholders ticked most often were ranked as being the most important ones. Compared to the stakeholder identification in 2.001, we found some similarities but also a number of striking differences.

\section{Similarities 2003-2001}

There were differences between the four cases in the exact order of the individuals, groups and organisations listed as important for the development of local health policy. In general, professional 


\section{3}

Regional Organisations

Weent

Roermond

Roggel 8 Neer

Roerdalen

Total
Sent

16

14

24

13

14

81
Response in \%

69

79

71

69

86

74

health organisations still appeared high on the list, while interest groups and other representatives of the population or of various groups, that is, the non-professionals, ended up at the very bottom of the list. Among the health professionals, the organisations for home care and the general practitioners ranked highest in each of the four cases. The regional health professionals chose the most important stakeholders from among themselves, with the exception of the general practitioners and the municipal administrations.

\section{Differences between 2003 and 2001}

Public health officers and aldermen responsible for public health were ranked somewhere in the middle of the list, but the aldermen had somewhat higher scores than in 2001. An interesting case is that of Roermond, where the alderman for public health was ranked number one and the public health officer did not appear on the list at all this time.

Interest groups and other non-professionals no longer featured on the final list of the ten most important stakeholders as indicated by the regional professional (health) organisations. In three of the four municipalities, the list featured only one group or organisation of non-professionals, in tenth position. The exception was Roggel \& Neer, where four of the ten important stakeholders were non-professionals, none of whom occupied the bottom position on the list.

The RPHS was one of the five most important stakeholders, except in the case of Weert, where it shared the bottom position (remember that Weert hired an external consultancy firm). The top five in 2003 did not exclusively consist of health professionals as it did in 2001 , as the aldermen and welfare services were now also among these five.

Finally, the welfare services now appeared on the list for all four cases and for the regional organisations (whereas they were only mentioned twice in 2001). Local stakeholders gave them higher rankings than the regional stakeholders.

\subsubsection{Introduction to the 2003 interviews}

For the interviews that were to be held after the stakeholder identification (in late 2003), we decided to expand the number of interviewees in each case, by including more stakeholders identified in the group of non-professionals. In three cases, this group had been so small that it would not allow us to get a good idea of their involvement and experience in local health 
policy-making. Table 8.3 shows that in the end, we interviewed 41 people. The majority of the respondents were the same as those in 2001.

Table 8.3 Classification of respondents in 2003

\begin{tabular}{|c|c|c|c|c|c|}
\hline Respondents & \multicolumn{2}{|c|}{ Regional } & \multicolumn{2}{|c|}{ Local } & Tota \\
\hline $\begin{array}{l}\text { Professional } \\
\text { Nen-professional } \\
\text { Municipal adm. }\end{array}$ & Health 6 & Non-heaith 3 & bealth 10 & $\begin{array}{l}\text { non-health } 4 \\
9 \\
8\end{array}$ & \\
\hline Total & & & & 32 & \\
\hline
\end{tabular}

NB There were four non-respondents (two non-professionals and two professional health organisations).

In the interviews, we asked respondents to reflect on their involvement in local health policy-making, in terms of their interests in, contribution to, influence on and importance in policy-making, and their views on local health policy. In addition, we filled out a form about their engagement in communication and the exchange of expertise on local health policy and their involvement in public health and collaboration with other stakeholders in this field isee also chapter 6 and Appendix 1.c).

\subsection{POLICY-MAKING IN FOUR CASES: APPLYING THE EVAlUative FRAMEWORK}

The comprehensive checklist presented in section 2.4 consists of a set of criteria and indicators grouped into five themes that are relevant to evaluating local health policy-making: perspective on local health policy, the municipal authorities' role in policy-making, the stakeholders, the policy network and the Regional Public Health Service. The criteria were applied to the data about the four cases obtained from the interviews, observations and document study, and the stakeholder and network analyses.

This section first presents the results for each case (the detailed checklists on 'Evaluation criteria for local health policy' for the four cases are included in Appendix 2), and then the differences and similarities between the cases. The description of the results follows the five themes mentioned above.

\subsubsection{Local health policy-making in Weert}

\section{Perspectives on local health policy}

The municipal administration in the town of Weert had invited many actors (internal and external to the municipal organisationy to participate in local health policy-making. The attitude of these actors was mostly reactive and symbolic, although some of them had contributed in a more tangible way by commenting on draft documents or discussing local health policy in meetings outside the municipal organisation. 
The local health policy memorandum set objectives for prevention and care. The stakeholders Weert viewed local health policy as a broad concept but they still found it difficult to defin precisely.

Local health policy was informed by epidemiological data (disease/health problems a risk behaviour in the population). These data originated from epidemiological research carri out by the RPHS and from national reports by the RIVM (National Institute for Public Hea and the Environment). Local health policy was also informed by problems (mostiy relating services) signalled by professionals and non-professionals active at the municipal level.

No explicit perspective on health or health promotion was found in the memorandum in our observational or interview data. The starting point for the Weert local health policy $h$ been the problems and barriers in the field of health mentioned in a series of workshor Nevertheless, themes and planned actions were related to other policy domains in the municipali and to existing or planned collaborations with actors outside the municipal organisation. TI long-term policy plan of the current administration did not reflect a specific view of publ health or envisage actions that directly aimed to promote the health of the citizens of Weert

Although the local health policy memorandum was called a framework for further pollic development, it did mention clear objectives and actions, and allocated financial resources $t$ implement the activities. It did not mention, however, how and to whom these resources wel to be allocated.

In sum, we might say that the interactive nature of the policy process, in which loc: health policy is regarded as a comprehensive concept and is informed by different sources, ha led to a number of abjectives and planned activities for the municipal public health departmer. and others.

\section{Municipal authorities' role in policy-making}

Health appeared infrequently on the municipal political agenda. It was not a political issue o a matter for debate. The municipal administration felt compelled to develop health policy ane carried out this task conscientiously and with the flair of a pioneer for smaller municipalitie in the region.

The municipal administration facilitated the policy process in practical respect; it had se

Ik merk wel vaak dat de gemeente een organisatie is waarvan verwacht wordt dat die de regierol op zich neemt. Dit amdat de gemeente de meeste contacten heeft met de verschillende organisaties binnen de gemeente. Zij doen dat ook vaak: de gemeente is waak de spil waar het om draait zij sturen het vaak aan (Woningcorporatie).

I've often noticed that people expect the municipal administration to coordinate matters. That's because the municipal administration has the most contacts with various municipal organisations. And the municipal administration does indeed often assume this coordinating role: it is often pivotal in the whole process, and tends to coordinate it. (A representative of a housing corporation) 
aside money to hire an external consultancy agency to organise a work conference and to draft the memorandum. The municipal administration also created opportunities for cooperation with stakeholders. Stakeholders, professionals as well as non-professionals, expected the municipal administration to adopt an active attitude and to be the key actor in policy-making but also in collaborative processes at the municipal level.

The public health officer had more than a formal view of local health policy: he initiated an interactive policy process and remained actively involved in the whole process, although the actual work was delegated to the consultancy agency. During the process of policy development, he collaborated with various people, both internal Icolleagues at the public health and other departments) and external to the organisation (the consultant, a colleague from a neighbouring municipality, the RPHS).

\section{Stakeholders}

Stakeholders did not find their own involvement in policy-making of paramount importance. Local health policy was new to them and they regarded it as just another opportunity to promote their interests in the health domain. Non-professionals liked to get involved at an early stage. The health policy memorandum, however, showed that a large number of objectives and actions were based on the information supplied by the participants of the work conference held in Weert. The participating professionals themselves claimed -- more so than non-professional participants - that they had supplied information on prevailing problems they encountered in their daily practice in the field of health and well-being, and that they had proposed directions to solve these problems. Although more than $50 \%$ of the stakeholders were positive about the amount of influence they thought they had on policy-making, they were less optimistic about their input being reflected in the memorandum.

The contributions that the various stakeholders could make to the implementation of local health policy were not described in the memorandum. However, the intention to form study groups around specific themes and activities was expressed in meetings and interviews. Also, several stakeholders expected to become involved in the implementation of activities.

Although the contributions of stakeholders to the policy process were being considered, they had not been assigned, so this may not be sufficient to secure their commitment in the implementation of activities.

\section{Policy network}

Professional stakeholders saw themselves and the municipal authorities as the important actors in policy-making. The non-professionals perceived the professional stakeholders as the most important ones. The respondents associated with the municipal administration took a neutral stance, asserting that all actors were equally important. Half of the stakeholders in Weert percelved the municipal administration as a policy entrepreneur.

A look at the networks in Weert (see Figure 8.1) shows that the municipal authorities did indeed occupy a central pasition in all the networks, being able to easily communicate with all other stakeholders. The professionals generally had direct access to the municipal authorities and to other professional organisations. Local non-professional groups and organisations occupied 


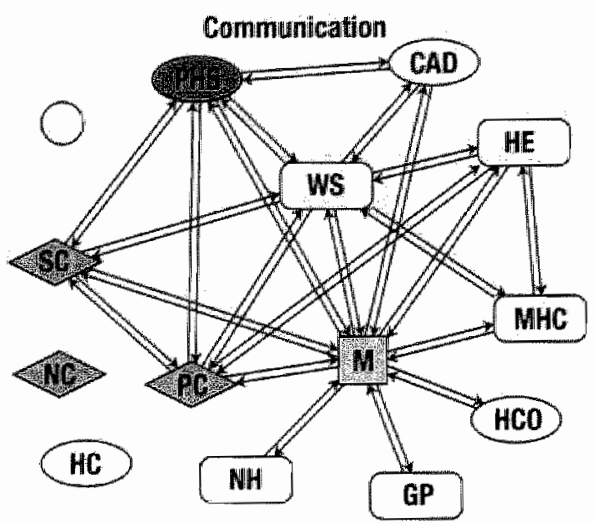

Link with actor relating to communication on local health policy

\section{Involvement}

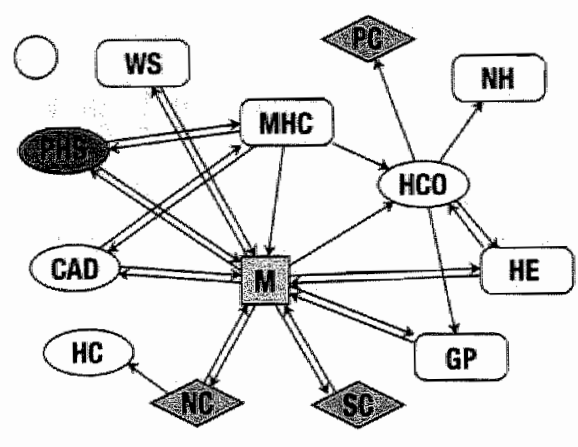

Link with actor relating to the involvement with other actors in public health

\section{Strategic Collaboration}

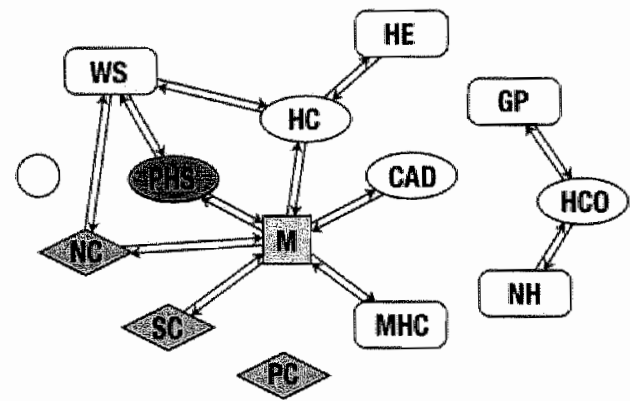

$\longrightarrow$ Link with actor relating to their strategic collaboration

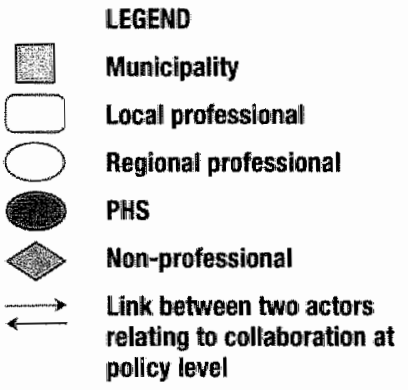

Indiees for

Weart

Density $(0-1)$

Actor centrality $(\%)$

Municipal adminin.

BPHS

Weilfare services

Centrailisation ( $($ \%o

Actor centrality (\%)

Municinal admini.

PPH 15

Wellare service

Centralisation (\%)
Comminication involvement strateglc.

0,18

Closeness

$14: 07$

9.38

10.82

8.34

Bëtweenness Betweennes

83.84

202

11.11

82,76
6230

278

0.15

Closeness

14.97

9.58

8.87

8.43

80

59.40
0,13

Closeness

14.88

0.92

9.30

8.33

Betweenness

58,57

3.81

7.14

55,38
CAD

Agency for care and treatiment of addicts

GP General Practitioner

GP General Practitioner

HC Housing Corporation

HCO Home Care Organisation

HE Home for the elderly

M Municipality

MHC Regional Centre for

Mental ithealth Care

NC Neighbourhood Council

NHH Nursing Home

PC Coordinating Platform for Health Care Consumers

PHS Regional Public Health Service

SC tocal Sports Council

WS Welfare Service

Figure 8.1. Networks in Weert (2003) 
peripheral positions. In the communication network, the welfare service was closely linked to the local non-professional organisations and provided these non-professionals access to the central and other actors in the networks. The communication network was highly integrated; the stakeholders also communicated among themselves and not exclusively with the municipal administration. There were fewer relations among stakeholders in the other networks. If we leave the communication network out of consideration, the RPHS did not have many links with the other stakeholders in the overall network.

\section{Regional Public Health Service}

The RPHS was not perceived as an active actor or policy entrepreneur in policy-making in Weert. Nevertheless, the RPHS would like to act as such. The RPHS and the Weert municipal administration obviously had different perceptions of the RPHS" task and its role in policymaking. The municipall public health officer saw it as follows. Asking the RPHS' advice is obvious because it is one of their statutory tasks. But since the RPHS is at the same time perceived as the principal instrument in implementing local health policy, he feared conflicts of interest, which had to be avoided. The RPHS had been formally approached during the whole process. They had been requested to participate in a steering group and to comment on the draft memorandum. The RPHS had also participated in two workshops at the work conference.

The municipal authorities facilitated the development of local health initiatives under the Hartslag (Midden) Limburg project by annually setting aside financial resources for their implementation. The authorities openly regretted the delay in the implementation of the project.

\subsubsection{Local health policy-making in Roermond}

\section{Perspectives on local health policy}

The municipal authorities in Roermond invited many actors (both internal and external to the municipal organisation) to participate in local health policy-making. The attitude of these actors was mostiy reactive and symbolic.

Objectives had been set for all types of activity in local health policy; a number of tasks assigned under the law on collective prevention in public health (WCPV) were mentioned explicitly in the local health policy memorandum. Three types of data informed local health policy in Roermond and were used as a basis for the memorandum. The first type consisted of national and regional policy documents addressing the central issues in public health. The second type was epidemiological data (disease/health problems and risk behaviour among the population'. These data were obtained from epidemiological research carried out by the RPHS and from national reports by the RIVM. The third type of data related to problems and barriers signalled by professionais and non-professionals active at the municipal. level. The Roermond municipal authorities presented a broad vision on health (acknowledging multiple determinants), and health policy was considered an integrated and interactive policy, both in the memorandum and by the stakeholders. However, this had not resulted in a description of intersectoral activities or links between different policy domains promoting health. 
Making local health policy was perceived as a statutory obligation. According to the public health alderman, health was not a political issue in Roermond; he thought it would have been better to develop policy whenever health problems were brought to the attention of the municipal authorities.

The fact that reducing health inequalities was one of the broadly framed objectives of local health policy was in line with the description of social problems in a number of town districts as a key issue in the municipal administration's long-term programme.

The memorandum on local health policy was called a framework for further policy develop. ment. It did not mention clear objectives and activities were still broadly defined. Financial resources were not yet allocated for the implementation of the activities. This was to be done on the basis of a yearly plan.

In sum, the policy process in Roermond had an interactive character and had been informed by several sources. Local health policy was regarded as a broad, integrated concept. Nevertheless, these ideas had not been incorporated in more concrete abjectives and actions.

\section{Municipal authorities' role in policy-making}

The local health policy memorandum and other data reflect the municipal authorities' role in policy development as well as in policy implementation, as coordinative, facilitative and initiating. The municipal administration initiated the policy process in the first place (by allocating money for extra manpower); it took complete responsibility for the progress of the policy process, and facilitated the process in a practical sense. With such a role in mind, the municipal administration intended to create opportunities for cooperation with stakeholders in the field of health and

Als het aan deze portefe uillehouder ligt dan gaat hij er voor om daar (de nota, MH) handen en voeten aan te geven, of in ieder geval om een aantal zaken uit die nota te willen ontwikkelen. Dan krijg je natuurlijk vervolgens het debat binnen het college, of hem dit gaat lukken want als het college die prioriteiten daar toch aan wil geven boven andere prioriteiten dan zullen er afwegingen gemaakt moeten worden. Prioriteiten verdringen zichzelf. Als je mijn persoonlijke mening vraagt dan zeg ik dat ik het een hartstikke belangrijk thema wind en dat ik er ook echt enthousiast over kan raken. Maar het kost allemaal capaciteit, het kost ook allemaal geld. En dat is éen van de grootste knelpunten: hoe lossen we dat creatief en slim met elkaar op? (ambtenaar volksgezondheid en zorg) To the extent that it's up to this alderman, he's totally committed to implementing it (the memorandum - MH), or at least to further develop some of the issues in the memorandum. But of course you then get the debate in the municipal executive. You have to wait and see whether he'll be able to pull it off, because if the executive want to set priorities, they will have to make choices. Priorities compete with each other. My personal opinion is that it's a crucial area, and one that I get very excited about. But it all requires capacity, it all costs money. And that's one of the main problems; that's what we have to find smart, creative solutions for. (A public health officiall 
well-being. The stakeholders in Roermond expressed the same view of the municipal authorities? role as the respondents associated with the municipal administration.

Health appeared infrequently on the municipal political agenda. It was not a political issue or a matter for debate. Priority was given to other issues like economic development. Although the public health alderman at the time was very committed and the memorandum was quite ambitious and comprehensive, it remained to be seen how much could be implemented (in view of the lack of money, which reflects a lack of political will).

The public health officer took a broad view of her task in local health policy-making, in the sense that she organised interactive workshops, set up an inquiry, informed participants etc. She worked in a rather isolated fashion, without formally consulting any internal (colleagues of the public health and other departments] or external group. In practical respects, she was assisted by the RPHS, in that RPHS employees led the interactive workshops, and the RPHS policy assistant led the inquiry among participants and commented on the draft memorandum.

\section{Stakeholders}

Stakeholders did not have pivotal interests in local health policy-making; it did not really affect their daily functioning or organisational policy in the field of health and well-being.

They did participate to have an opportunity to present themselves and to draw attention to their target group. They did not communicate with each other outside the organised interactive sessions.

The memorandum showed that many of the objectives and actions were based on the information supplied by the participants in the interactive workshops held in Roermond. Although stakeholders were moderately positive about the influence they had on policy-making, they were less satisfied about the way the memorandum reflected their input and interests.

The professional and non-professional participants acknowledged that they had supplied information on prevailing problems they encountered in their daily practice in the field of health and well-being and that they had proposed directions to solve these problems.

The memorandum did not mention what contributions were expected from the different

(reden van particpatie in beleidsvorming. MH) Het is dus tweeledig: allereerst om verslavingszorg hoger op de agenda van de gemeente te krijgen (het taboe daar omtrent ook een beetje te doorbreken) en ten tweede om de ernst van de situatie nog eens te benadrukken (wij zijn ervan overtuigd dat, zeker als het over alcoholisme gaat, we bij ons slechts het topje van de ijsberg zien). Punt drie is dat we willen netwerken, mensen willen leren kennen. (CAD, Instituut voor Verslavingszorg)

What are your reasons for participating in policy development? - MH) There are iwo reasons: the first is to get the care of addicts higher on the municipal agenda, and to some extent break the taboo that still surrounds it, and the second is to emphasise once more how serious the situation is: we are convinced that, especially as far as alcoholism is concerned, we are seeing only the tip of the iceberg. And finally, we want to network, get to know people. (A representative of CAD, an institute for the care and treatment of addicts) 


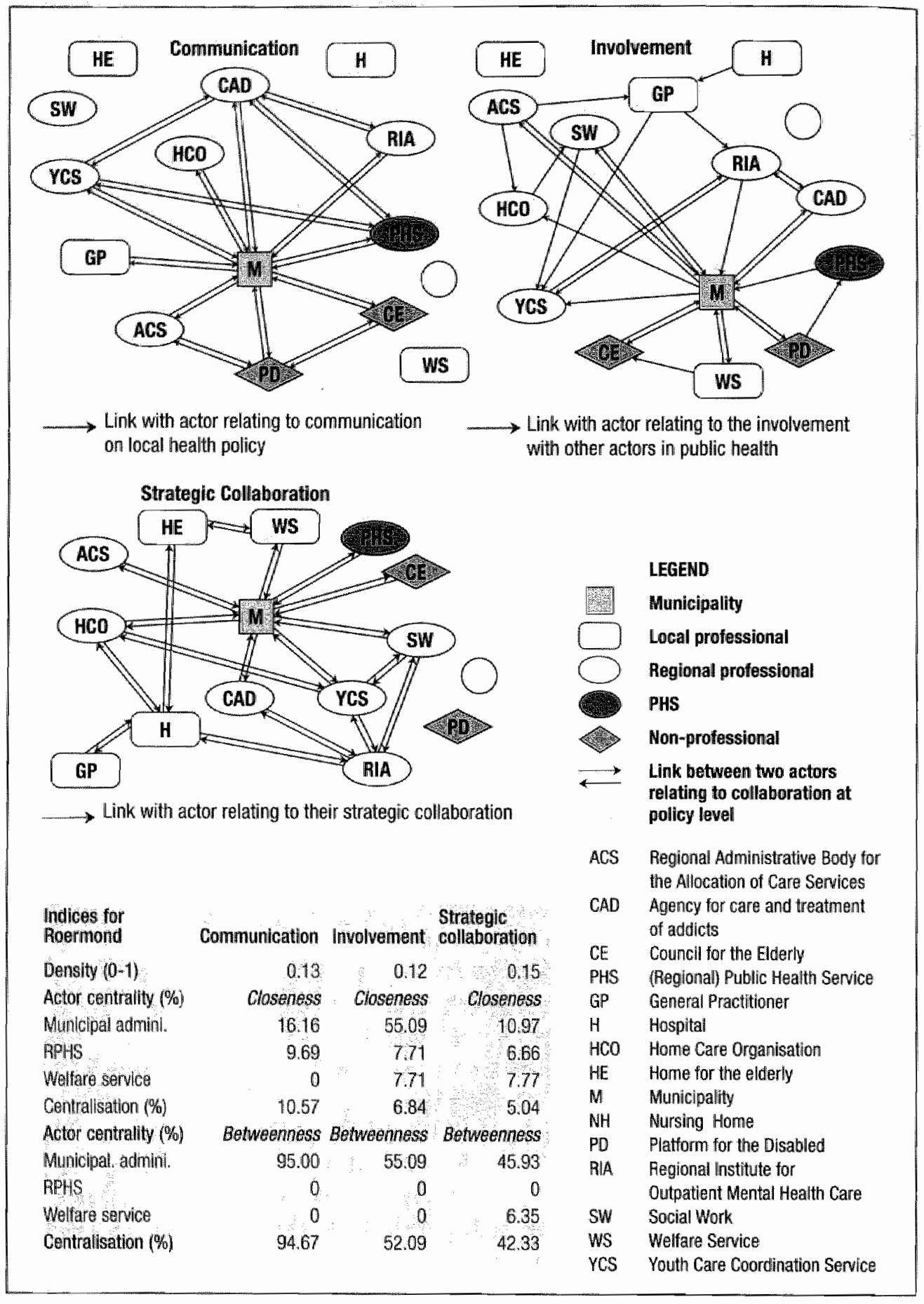

Figure 8.2. Networks in Roermond (2003) 
stakeholders in the implementation of local health policy. However, the intention to involve stakeholders in the development of action plans and their implementation was mentioned in meetings and interviews. Stakeholders themselves were sceptical about the municipal administration's possibilities to implement the developed plan.

\section{Policy network}

Opinions were greatly divided on who were the most important policy-making actors in Roermond. Respondents named different combinations of organisations, including non-professional organisations and groups.

In general, the networks of figure 8.2 show that most actors, both professional and nonprofessional, had direct access to the central actor, the municipal administration. Containing the most regional (health) organisations, we observe a highly integrated network concerning strategic collaboration. Professional health organisations supplied their expertise to the municipal administration.

In 2002, respondents had expected the RPHS or the municipal administration to be a policy entrepreneur. In 2003, a few respondents still mentioned the municipal administration as a policy entrepreneur, due to the obligatory character of the policy-making process. None of the stakeholders in Roermond perceived the RPHS as a policy entrepreneur. A striking feature of the networks in Roermond was the position of the RPHS; it had very few links with other actors except with the municipal authorities. The welfare service was not prominently visible in the public health networks in Roermond.

\section{Regional Public Health Service}

The RPHS was not perceived as an active actor or policy entrepreneur in policy-making, apart from their supportive task. Nevertheless, the RPHS would like to act as one. There was a clear agreement between the RPHS and the Roermond municipal administration to provide practical assistance, which defined the contribution the RPHS made in this case. In the interactive sessions, the RPHS did not create a high profile for themselves in comparison with other participants.

The municipal authorities had been informed about the development of local health initiatives by the Hartslag (Midden) Limburg project.

\subsubsection{Local health policy-making in Roggel \& Neer}

\section{Perspectives on local health policy}

The municipal authorities in Roggel \& Neer collaborated with those at five other (small) municipalities in the region in inviting many actors (both internal and external to the municipal organisation) to participate in local health policy-making. The participation and commitment of municipal departments and councillors was small, and their contributions symbolic. The attitude of the external actors was mostly reactive but their commitment was tangible in that they participated in the study groups and attended the two 'conferences'. In between these meetings, however, participants did not discuss local health policy.

Four types of data informed local health policy in Roggel \& Neer. The first type consisted 
of epidemiological data (disease/health problems and risk behaviour in the population) originating from epidemiological research carried out by the RPHS and from national reports by the RIVM. The second type was derived from the regional document called "key issues for local health policy in North and Central Limburg' published by the RPHS in 2001. The third type of data related to problems identified by professionals and non-professionals active at the municipal level. The fourth type consisted of the findings of a study into the long-term policy programme developed by the municipal administration. The policy directions and proposed actions in the memorandum covered the various types of activity for local health policy, except for health protection. The memorandum expressed an explicit perspective of health and health policy. Health was regarded as being deternined by muitiple factors. It was emphasised in the memorandum but also in meetings of the public health officers (steering group) that problems can best be tackled and health can be promoted through intersectoral collaboration. In addition, we observed a growing awareness that health is also affected by the policy decisions made in other municipal departments and that the officials and aldermen responsible for public health have $\mathrm{a}$ task in developing healthy public policy.

(From the memorandum page 44, MH) Beleidswoornemen: Gezondheid integraal aanpakken en facetbeleid: De gemeente ziet gezondheid niet als een solitair beleidsterrein, maar dat gezondheidswinst alleen kan worden geboekt, als ook andere beleidsterreinen daar hun steentje aan bijdragen.

(From the local health policy memorandum, page 44 - MH) Policy plan: integrated approach to health and facet policy: the municipal administration does not regard health as an isolated policy domain, but is of the opinion that health gains can only be made if other policy domains contribute.

Aithough it was still not easy for stakeholders to define local health policy, they expressed It as a comprehensive policy, going beyond activities relating to illness, towards people's general well-being. The long term policy plan of the current administration did not contain any statement on public health or specific actions to promote the health of the citizens in Roggel \& Neer. The local health policy memorandum was called a framework for further policy development; it did not mention any clear objectives or activities as yet, nor did it allocate financial resources. The municipal council had agreed with the general views presented in the memorandum and with the instalment of a steering group and specific study groups to develop precise action plans for the coming years. These were to be implemented in close collaboration with the same group of municipalities. In sum, the development of local health policy in Roggel \& Neer was a comprehensive process and the memorandum was informed by multiple sources (4). We found indications for a sectoral perspective on health and intentions to further develop this idea by securing the development of intersectoral collaboration and healthy public policy.

\section{Municipal authorities' role in poltcy-making}

The public health officer and the alderwoman were quite clear about the role of the municipal 
administration in health policy-making. This role was seen as facilitative, organising the policy process, establishing the policy and allocating budget, but definitely not as one of initiating activities and determining the content of the policy. External actors, more specifically the professional organisations, would have to provide the latter. In the process of implementing policy, the municipal administration's role was also to facilitate the collaboration process and coordinate the tasks and activities of the collaborating partners. Although the alderwoman felt committed to the subject, she remained at a distance and still found it a complex domain.

Health appeared infrequently on the municipal political agenda. It was not a political issue or a matter for debate. The interest of the municipal administration in developing a local health policy was closely linked to its statutory obligation. Nevertheless, it had set aside money to obtain assistance from the RPHS and the regional administrative office to organise the whole policy process and to compile the memorandum.

The health policy domain was new to the public health officer. He said he had developed a broad view of health and health policy. His view of local health policy went beyond his formal duties, as was apparent from his additional activities, like participating in the steering group and chairing one of the study groups. He collaborated with an external group (colleagues from neighbouring municipalities, the RPHS and the regional administrative office].

\section{Stakeholders}

The interests stakeholders had in local health policy-making were of secondary importance. They regarded the process as an opportunity to make their voice heard, but there were other consultative structures where the specific interests of stakeholders could be promoted best.

A sizeable part of the policy directions was based on the information supplied by the participants in the study groups and conferences. The participants themselves acknowledged that they had supplied information on prevailing problems they encountered in their daily practice in the field of health and well-being. The regional professional organisations said that they had also proposed directions to solve these problems. Whereas stakeholders had been optimistic about the influence they could have on policy-making in 2001, they were quite negative about their experience in influencing the policy process in 2003. Nor were they very satisfied about the way their input and interests were reflected in the memorandum.

Although the contributions the different stakeholders could make to the implementation of lacal health policy were not described in the memorandum, the policy to form a steering group and study groups, including a number of stakeholders, had been approved by the council.

\section{Policy network}

The respondents took a neutral stance concerning the importance of participants involved in policy-making, asserting that all parties were equally important. The public health officer and the alderwoman responsible for public health were happy with the input of all participants and thought that their own input was not of great importance (see municipal authorities' role').

The networks in Roggel \& Neer see Figure 8.3, revealed the municipal administration to be the central actor. The RPHS did not have many links with the other stakeholders, except for their reciprocal relationship with the municipal administration. Of the local professionals, 


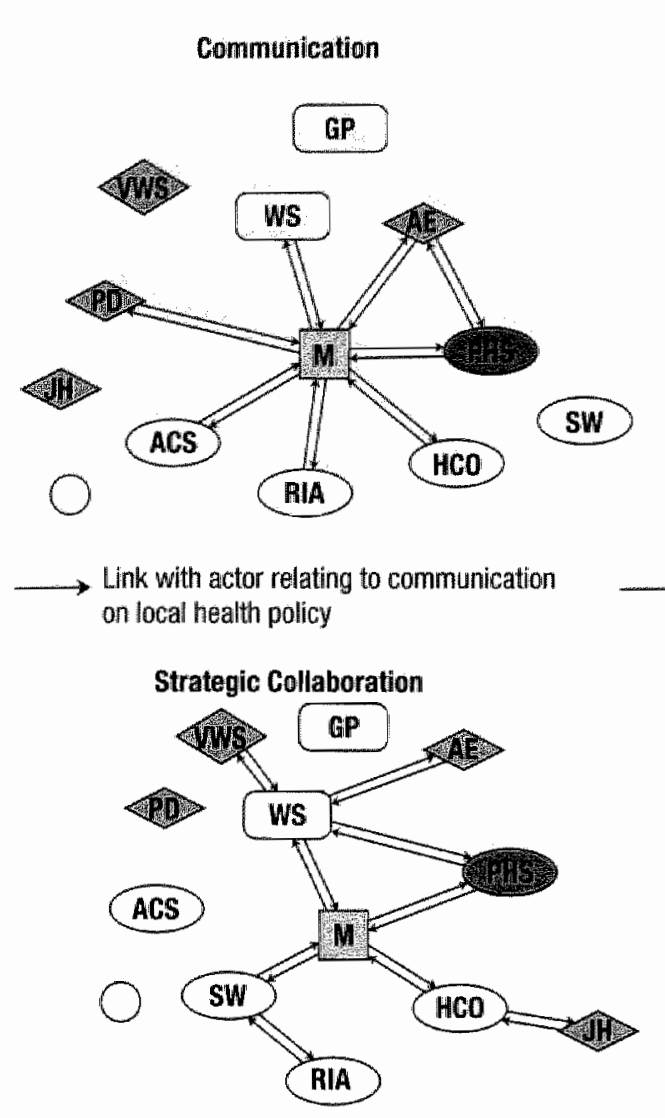

Link with actor relating to their strategic collaboration

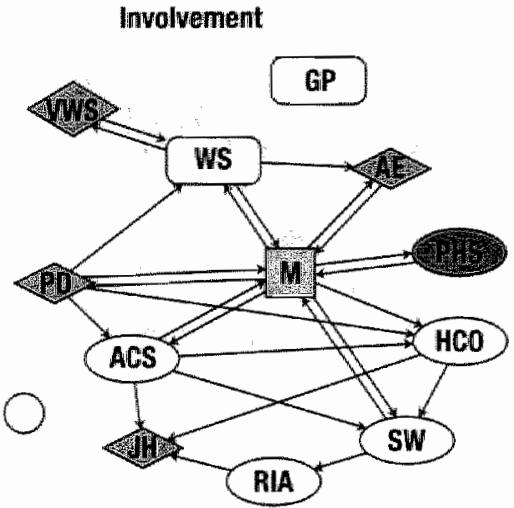

$\rightarrow$ Link with actor relating to the inwolvement with other actors in public health
Indices tor

Roggel \& Neer

Density $(0-1)$

Actor centrality (\%)

Municipal admini:

BPHS

Welare service

Centrallsation (\%)

Actor centrality $(\%)$

Municipal admini:

BPHS

Weltare service

Centralisation (\%)
Communication Involvenent

$$
0.10
$$

017

Coseness

20.58

12.01

11.08

13.96

Closeness

1615

9.54

1105

9.16

Botweenness Betweenness

100

56.70

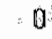

0

100
Betweonness

42.55

strategic

collaboratlon

0,12

Closeness

6.23

12.17

13.91

925

27.66

37.77

\section{LEGEND}

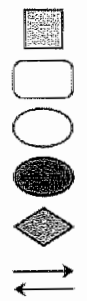

Municipality

Local professional

Regional professional

PHS

Non-professional

Link between two acters relating to collaboration at policy level

ACS

Regional Administrative Body for the Allocation of Care Services

AE Local Association for the Eld enly

GP General Practitioner

HCO Home Care Organisation

JH Day Care Centre for the elderly

M Municipality

PD Platform for the Disabled

PHS (Regional) Public Health Service

RiA Regional Instifute for Outpatient Mental Heallth Care

SW Social Work

WWS Voluntary Welfare Services

WS Welfare Services 
the genera: practitioners were disconnected in all networks. The local non-professionals occupied a peripheral position in the networks. Although they were involved in the more practical collaborative processes, this was much less the case at policy level. However, the welfare service, which assists local non-professional organisations and groups, occupied a central position in some networks, allowing them access to the central actor.

Only some of the stakeholders (professionals) in Roggel \& Neer perceived the municipal administration as a policy entrepreneur. Indeed, the municipal administration's actions were not consistent with such a position (e.g., by actively providing other stakeholders with information and policy proposals).

\section{Regional Public Health Service}

The RPHS was not perceived as an active actor or policy entrepreneur in policy-making, but as the entity responsible for organising the policy process. From the very first, the municipal administration of Roggel \& Neer wanted the RPHS to assist them in the development of local health policy. They regarded the RPHS as an extension department of the municipal organisation with the best expertise in public health. Moreover, they acknowledged a shortage of manpower in their own organisation. The six municipal administrations in the area had commissioned the RPHS to develop a memorandum for them, emphasising the interactive character of policy development, to propose policy directions and to actually write the memorandum. The RPHS also participated in one of the study groups and the conferences.

The municipal authorities did not facilitate the development of local health initiatives by the Hartslag (Midden) Limburg project, though the project leader informed the public health officer about the project activities taking place in Roggel \& Neer.

\subsubsection{Local health policy-making in Roerdalen}

\section{Perspectives on local health policy}

The municipal administration in Roerdalen had not reached the stage of policy preparation, let alone that of actual policy-making. They became stuck in the information and orientation phase, in which they communicated with officials in charge of public health in other municipalittes in the region, as well as with the RPHS and the VNG (Association of Netherlands Municipalities).

Neither the officials in other municipal departments than public health, nor external actors in the field of health and well-being (with the exception of the RPHS) had taken the initiative to discuss local health policy with the municipal administration.

It was apparently difficult for respondents from this municipality to express their interpretation of local health policy. Few mentioned care, prevention or health education in relation to local health policy. This was also true of the municipal administration. The perspective the municipal administration had on local health policy was ambiguous. On the one hand, it clearly stated that policy should be made on the basis of (health) problems, a view which indicates a health perspective. On the other hand, the public health officer favoured the sectoral perspective in the sense that no explicit health policy would be necessary because health was an item in each and every policy made at municipal level. 
In eerste instantie (associeer ik lokaal gezondheidsbeleid, MH) met problemen: zijn er wel gezondheidsproblemen? Ik snap wel dat je niet alleen moet proberen om probleermoplossend te werken maar dat je ook moet proberen om die problemen te gaan voorkomen. Maar een beleid moet altijd gemaakt worden omdat er een probleem is.

Ik moet eerlijk zeggen dat ik zelf ook denk: je moet alles integraal bekijken; de integraliteit levert een bepaalde meenwaarde op en je moet dat koppelen met interne afdelingen en met exteme instellingen. Nu gaat het Rijk daarnaast overal nog specifiek een beleid op maken en voeren: op ouderen, op jongeren, op gezondheid ... In principe ligt dit al in het integrale beleid; je moet dan gewoon op bepaalde beleidsterreinen rekening houden met de gevolgen voor ouderen, de gevolgen voor de gezondheid enzovoorts. (ambtenaar volksgezondheid en zorg)

First of all [I associate locai heaith policy - MH] with problems: are there any health problems? l realise that we shouldn't always concentrate on solving problems but aiso iry to prevent them. But policies are always made because a problem has been identified. I have to admit that I, too, feel that these matters should be looked at in an integrated way. The integrated approach provides a certain added value, which you need to discuss with internal departments and external agencies. Now the government is trying to develop additional specific policies for the elderly, for young people, for health, etc. Basically, these are contained in an integrated policy; it just means that certain policy domains have to take account of the consequences for the elderly or for public health, etc. (A municipal public health officer)

\section{Municipal authorities' role in policy-making}

As indicated above, the policy process in this municipality became stuck in its initial phase. Since this meant that data on the municipal authorities' role in the policy process could not be collected, little can be said about this topic here.

Heal th appeared infrequently on the policy agenda in Roerdalen. Interviews and documents show that health was no issue of political interest. It was issues like education and the upkeep of buildings, roads and sports accommodations which occupied the attention of the municipal authorities. The public health officer had collaborated for six months with colleagues in two other municipalities to develop local health policy together. The idea was to ask the RPHS or a consultancy agency for assistance, but the initiative stranded.

\section{Stakeholders}

Stakeholders, especially the professionals, had positive expectations and experiences from the past about their influence. Stakeholders had not been invited to participate in local health policy-making yet, nor had they taken the initiative themselves. Hence, no assessment can be given of their role and input in (local health) policy preparation or in the future implementation. 


\section{Policy network}

The professionals regarded themselves and the municipal authorities as the most limportant actors in policy-making. The respondents associated with the municipal administration and non-professional stakeholders did not express their opinion. None of the respondents identified any of the stakeholders as a policy entrepreneur.

The networks in Roerdalen presented in Figure 8.4, included a rather small number of participants, of which the municipal administration was the central actor. The networks show that a number of stakeholders, mainly local ones, were disconnected. The other stakeholders

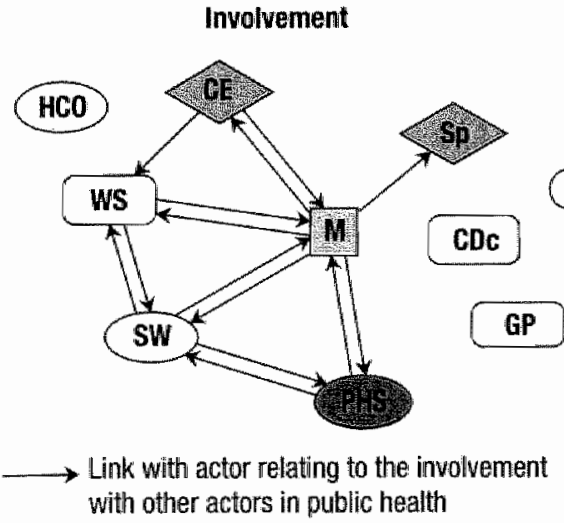

Indtoes for

Roerdalen

Density $(0-1)$

Actor centrality $\%$

Muntopal admini:

PPIS

Werfare service

Centralisation $(\%)$

Actor centrality (w)

Municipal adminit.

PPHS

Wrare service

Centralisation $(\%)$

Involvement
011
Claseness
27.86
17.41
17.41
21.30

Betweenness

86.36

$\therefore 0$

4.55

85: 12
Strategic

collabotation

009

Closeness

2298

13.79

19,69

15.97

Betweenness

63.64

0

36,36

60.33
Strategic Collaboration

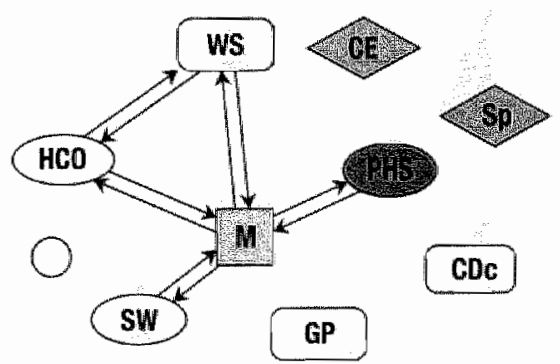

- Link with actor relating to their strategic collaboration

\section{LEGEND}

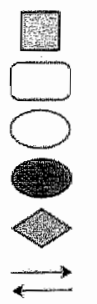

Nunicipality

Local professional

Regional professional

PHS

Nom-professional

Link between two actors relating to collaboration at pollicy level

CDC Child Day Care

CE Cound! for the Elderly

GP General Practitloner

HCO Home Care Organisation

M Municipality

PHS Pegional Public Health Service

Sip Sports club

SW Social Work

WS Welfare Service

Figure 8.4 Networks in Poerdaten (2003) 
(including the RPHS) related directly to the municipal administration, but few had links with each other. Although the municipal administration occupied a central position, it was not developing initiatives in policy-making.

\section{Regional Public Health Service}

Although the other stakeholders in Roerdalen did not regard the RPHS as a policy entrepreneur, the RPHS regarded itself as such. The pro-active attitude of the RPHS was evident in that they actively informed the municipal administration at the time and offered their assistance. At the same time, they did so with great caution, as they did not want to have too high a profile as an organisation.

Roerdalen was the first municipality to agree to adopt the community-based Hartslag (Midden) Limburg project. The municipal authorities assisted the implementation of the project by setting aside money on annual basis for its activities, which was indeed (partly) spent on a few activities. The public health officer rejected the idea of installing and participating in a municipal health committee.

\subsection{COMPARISON OF RESULTS ACROSS CASES}

The previous section gave a detailed survey of the way local health policy unfolded in the four cases. Here we present the findings from a more general point of view by comparing the four cases.

Most of the identified stakeholders did participate in local health policy-making, but their involvement was reactive. Three municipalities had organised interactive workshops or meetings with large numbers of participants, both internal and external to the municipal organisation. Whether parties were invited by the municipal administration to participate depended on their involvement in public health, or on their relationship with the municipal administration. The participants in the policy-making process primarily came from the health and welfare sector. This was true of those internal (civil servants and politicians) and those external to the municipal organisation (e.g. health professionals). The majority were professionals. Respondents only gave general, interest-based reasons for their participation, such as the opportunity to present themselves, to put forward specific problems once more, or to represent a target group or volunteers. Their purposes, and the benefits they might expect from participating in the policy process, were not always clear to them.

The attitude of the participating stakeholders was mostly reactive, and their contribution in most cases was tangible. The latter does not refer to a contribution in a material sense, but to making an extra effort by giving additional information or feedback to the public health officer or comments on the local health policy memorandum. Communication on local health policy primarily took place in planned meetings; informal contacts were hardly used las is shown by the scarce data in these networks, see chapter 6). The networks relating to communication on local health policy also reflected this observation, as they did not contain many links among the participating actors (see Figures 8.2 and 8.3 ). 
Voor ons was het van te voren niet precies duidelijk wat de bedoeling was. Toen we naar die eerste bijeenkomst zijn geweest dachten we: a yes, daar moeten we iets mee.

Voor ons was het gewoon belangrijk om onze stem weer te laten horen bij de gemeente en bij die andere organisaties. Nu weten andere organisaties ook weer beter wie we zijn en wat we doen. (Platform Gehandicapten Belangen, Roggel en Neer)

We weren't exactly sure what it was all about beforehand. After we had attended the first meeting, we thought: right, we have to get in on that.

It was mainly important for us to remind the municipal authorities and the organisations of our existence. The other organisations are now more aware of who we are and what we do. A representative of a platform for the disabled at Roggel \& Neer)

The networks generally included more professionals than non-professionals. In the town of Roermond, it was mostly the regional organisations (having their offices in Roermond) which participated, whereas Weert had more participating subregional or local professional organisations. The networks at Roggel \& Neer included the largest numbers of non-professional groups and organisations. There were important differences between the cases in the degree of density of the networks. This means that the networks showed different levels of integration, which might reflect the differences in collaborative structures and initiatives in the four cases at the start of our study.

Most of the regional professional organisations had a direct (but unilateral) link with the municipal authorities. They were regarded as important actors in policy-making. They were requested by the policy-makers to supply their specific expertise. That they did so was reflected in the findings of the interviews and in the networks on exchange of experience /not presented as explained in chapter 61 , where the professional actors were unilaterally linked with the municipal administration. The local non-professional groups and organisations occupied peripheral or disconnected positions in all networks, and were regarded as less important actors in policymaking. They needed other actors (in some cases the welfare service) in the network to access the central actor, making it more difficult for them to promote their interests. Only those who had an official status as an advisory board to the municipal authorities actually had direct access to the central actor. Local non-professionals did not have mutual or reciprocal relationships.

Local health policy was not of pivotal importance to stakeholders. Local health policy was not of pivotal importance to the functioning of stakeholders or their organisations. This applies to both professional and non-professional respondents and to all cases. In general, health was not a priority to municipal authorities; only the obligatory nature of local health policy development had put health on the municipal agenda.

Although some stakeholders had consulted their colleagues, the subject had not become an issue of debate in their own organisation or group (including the municipal organisation). Stakeholders hardly communicated among themselves about the subject or about joining forces to protect or forward their interests. Nevertheless, the expertise of stakeholders with respect to 
existing problems in the health domain and the solutions they proposed carried a lot of weight in policy development. In fact, our data create the impression that this (varied) input by stakehoiders was given precedence to the priorities derived from epidemiological research. The stakeholders' perception of the visibility of their contributions does not completely match this idea. In Roggel \& Neer, stakeholders thought they had little ability to influence the policy process or the outcomes reflected in the memorandum, while opinions among the Roermond stakeholders varied. Only in Weert were stakeholders quite positive about their influence.

As regards the implementation of local health policy, the respondents associated with the municipal administration wanted to continue to involve stakeholders. And stakeholders, especially the professional stakeholders, said - though cautiously - that they wanted to participate in the implementation of local health policy, as long as it was in line with their current policy and activities. The four local health policy memoranda still lacked a clear division of responsibilities or tasks and activities among the stakeholders involved, as they lacked concrete objectives lexcept in Weerti. Only in Roggel \& Neer had the municipal council approved the proposal to set up a coordinative committee composed of public health officers and specific stakeholders.

The health perspective prevailed in the debates and memoranda on local health policy. For many respondents, especially the non-professional stakeholders, it remained difficult to define local health policy, even after such a policy had already been effectuated. In this respect, respondents often referred to related policies (e.g. youth policy, policy on minorities) and to local policy agreements concerning matters like public mental health and special housing with care facilities for the elderly. Respondents conceived of local health policy as a very broad, even amorphous domain. All stakeholders had their own specific tasks and activities in the field of health and well-being. Their expertise was limited: none of the stakeholders regarded themselves as specialists in public health, except for the RPHS. As a resuit, stakeholders thought they had only limited power to influence the formation of local health policy as a whole.

Als ik kijk naar de onderwerpen zoals ik die net noemde dan zijn wij binnen dat kleine specifieke gebied een belangrijke speler. Maar de onderwerpen die er lagen waren zo breed dat we daar maar een onderdeel van waren. Ik denk dat iedereen maar een klein onderdeel heeft kunnen zijn in het geheel. Dus het is te algemeen gebleven om specifiek veel invioed te hebben (Riagg-ML).

As far as the topics are concerned tha: I just mentioned, we are an important actor in this specific domain. But there was such a variety of topics that, on the whole, we were just a minor component. I think each of the parties involved was only a small part of the whole. So things vemained too general to allow much specific influence. (A representative of a regional institute for outpatient mental health care)

Our data do not reveal a very clear perspective on health policy. In general, the health perspective was most prominent: health problems were taken as the starting point and inter- 
sectoral collaboration was considered important to solve such health problems. Only in Roggel \& Neer was the sectoral perspective on health policy given any attention. Nor could the description of local health policy in terms of the four types of activity, as presented in chapters 1 and 2 , be clearly recognised in the policy intentions or activities described in the memoranda. Whereas the memoranda emphasised health care facilities and the way they were functioning, as well as prevention of disease and heaith promotion in the narrow sense of the term (mostly lifestyle issues), health protection was hardly mentioned.

The attitudes and activities of the municipal authorities were not consistent with their central position in policy-making. The municipal administrations started the policy process with an open mind; they did not have specific suggestions or ideas on the content of local health policy. In the view of the municipal administrations, interactive policy development would create support for the policy among stakeholders and thus make implementation more likely and effective.

Respondents associated with the municipal administration said that they now had more and clearer ideas about how to interpret local health policy and how to intervene to promote the health of their citizens.

Meer dan in het verieden. Nu zie ik in een duidelijk breder scala. Eerst zou ik gezegd hebben: volksgezondheid staat gelijk aan de werkzaamheden van de GGD. Maar er is meer; dat is me nu duidelijk geworden door dat Jokaal volksgezondheidsplan. Denk aan: aangepast bouwen, zorgen dat er opgangen komen voor rolsioelen, moeders met kinderwagens, denk aan milieu, denk aan geluidsoveriast. Aan dergelijke dingen zou ik eerst niet gedacht hebben als ik dacht aan volksgezondheid. (ambtenaar volksgezondheid en zorg, Roggel en Neer)

More so than in the past. I now take a broader view. Before I would have said that public health was simply what the RPHS did. But I now see that there's more to it, thanks to the new locat health policy plan. There's things like building specially adapted housing, ensuring wheelchair and pram access, environmental problems, noise nuisance. Before I wouldn't have thought of those in the context of public health. (Public health officer at Roggel \& Neer)

As regards the implementation of local health policy, they were less optimistic, in terms of the practicability of the policy, the costs (in the light of current cutbacks) and the central role to be played by the local government. The aldermen for public health said they only really became involved when civilians brought serious problems to their attention. In Roerdalen, the value of local health policy was still being doubted.

Many respondents regarded the municipal administration as a binding, coordinative factor in policy-making and in implementation. Professionals as well as non-professionals expected an active, initiating attitude from the municipal administration. There was also some doubt about the capability of the municipal administration to fulfil such a many-sided role. 
Although the municipal administration was the central actor in all cases and all networks, it claimed to lack the (financial) resources, manpower and knowledge to really take the lead in directing local health policy-making. In all cases, they sought outside help.

De gemeente met de regie, dat vond ik fantastisch. Zo dicht mogelijk bij huis moet je zorg aanbieden. Dan lijkt het me ook heel logisch dat je de regierol zo dicht mogelijk bij huis plaatst. Nogmaals; ik vraag me nu wel af of het überhaupt mogelijk is dat betrekkelijk kleine gemeentes zoals ze hier zijn in staat zijn om zo'n specifieke rollen te vervullen. (Riagg-ML)

Coordination by the municipal authorities; I really liked that. Care should be offered as close to people's homes as possible. So it seems obvious to me to have the coordination as close to their homes as possible. But I have to say again: I'm not sure whether relatively small municipalities like the ones we have here are able to fuffil such specific roles. (A representative of a regional institute for outpatient mental health care)

The role of the RPHS in policy-making varied according to the specific requests for assistance from the municipal administrations. The RPHS mostly complied with requests from the various municipal administrations, that is, it had a reactive attitude. The assistance it provided to the policy-making process in the four cases varied from consultation to process guidance and writing the memorandum. From mid-2002 onwards, the RPHS became more active and presented itself as a policy advisor and coach. It also provided epidemiological data in all cases.

The RPHS did feel responsible for assisting local health policy-making and policy implementation. The RPHS presented itself as such with specific (advisory) products in the diversified

Ik denk dat dat ook de twee in het oog springende rollen zijn die een GGO kan hebben. We zijn aan de ene kant een partil die in het hele spel meespeelt waar dan ook heel veel andere aanbieders van zorg en diensten meespelen. Aan de andere kant hebben we denk ik ook de nodig know how in huis om zo'n proces te kunnen begeleiden; dus we zijn in staat om met de gemeente dat hele traject door te wandelen. Dus dat zij ons vragen: we hebben niets en we willen het graag op papier hebben in beleidsvorm; help ons daarbij (GGD-NML).

Ithink those are the two most obvious roles for the RPHS. On the one hand, we are one of the parties in the large game, together with many other providers of care and services. On the other hand, I think we have the necessary know-how to suppont such a process, so we're able to guide the municipal authorities through the entire process. So they can ask us: we have nothing available as yet and we would like to have a policy on paper; can you telo us with that? (A representative of the RPHS) 
products provision model (KPA), developed and presented to all municipal authorities in the region and effective from 1 January 2004. The communitybased Hartslag (Midden) Limburg project (see chapters 3 and 4) was also transformed to a product in the KPA model, helping municipal administrations to implement policy intentions in local health initiatives with an emphasis on the promotion of a healthy lifestyle.

The other stakeholders did not perceive the RPHS as a major participant in the policy process. The Hartslag (Midden) Limburg project had not participated as such in policy development.

The RPHS did not have a very central position in the networks; it had a reciprocal relationship with the municipal authorities, but few connections with other professional organisations and hardly any with non-professional organisations.

The policy process in Roerdalen differs from that in the other three cases. In fact, the initiative of the public health officer in Roerdalen to start up the policy process became stuck at an early stage. A few comments can be made at this point. The alderman repeatedly said that he did not realiy know how to interpret health promotion at the local level and how to relate this to health policy-making. The statutory obligation to develop a local health policy memorandum did not motivate the municipal administration to take action, nor did the suggestions made or the initiatives taken by the public health officer. The mayor and aldermen did not request the council to set aside money to increase the manpower at the public health office or to facilitate the process in other ways. All of this might indicate low political commitment to health issues. Moreover, it should be noted that, on the whole, few actors were active in the health domain in Roerdalen, and that these actors did not interact much with each other (see network graphs and indices in Figure 8.4). The municipal administration as the central actor in these networks was not playing a stimulating and coordinative role. 

We have examined a broad phenomenon, the process of developing local health policy, in a study that acknowledges the multi-dimensionality and unique contextual factors in this process. We have composed a comprehensive theoretical framework and developed a specific evaluative research instrument, neither of which was available beforehand. The findings, presented in the previous part, were collected using multiple methods and data sources.

The final part of this thesis links the theoretical framework to our findings. Chapter 9 first discusses the cogency and methodological quality of this study, and reflects on the findings. Chapter 10 presents the conclusions we draw from these reflections. 



\section{THE DEVELOPMENT OF LOCAL HEALTH POLICY: DISCUSSION}

\subsection{REFLECTIONS ON METHODOLOGY AND THE QUALITY OF THE RESEARCH}

Qualitative research differs from quantitative research with respect to the object of study, the research design, the data collection methods, the type of data and analyses and the role of the researcher. A multiple case study, specifically, is the most suitable method to examine in depth the uniqueness or variation of a phenomenon. In qualitative research, the views and actions of the people involved play a central role. In such situations, the research context ii.e., social life in action) requires a flexible attitude and effort from the researcher (Maso \& Smaling; 1998; Silverman, 2000]. Qualitative researchers direct their attention to the specifics of particular cases (Denzin \& Lincoln, 2003).

In our study on local health policy-making, the object of study is complex and changeable. Moreover, the study focused on a 'new' phenomenon, at least in this form and in the current Dutch context of public health. The research questions, which were primarily how and why questions, were addressed in a multiple case study. In the methodology of this inquiry, research took on the nature of an iterative process in which data collection alternated with analysis. The data gathering methods, mainly interviewing and participatory observation, were open and flexible. Methods to analyse the information included close reading of transcripts, categorising and coding the data and analytical induction. The researcher interfered in the day-to-day reality in which the object of research occurred and related with the researched. Finally, she interpreted the findings of the research and formulated conclusions.

\subsubsection{Strengths and limitations of the inquiry into local health policy-making}

The purpose of this section is to discuss the cogency of our inquiry into local health policymaking. It assesses the soundness of the inquiry on the basis of the interpretation of the validity and reliability of qualitative research in general and of case studies in particular.

\section{Appropriateness of the research design}

For this study, we chose to employ an embedded multiple case research design. This design not only most appropriately addresses the type of research questions and the real-ife context of the study, but also focuses on multiple research levels and units of analysis within the cases [seeTable 1.11). We included four cases (municipalities]. In view of the replication logic, the inclusion of only four cases could be considered too limited a design. The number of cases needed to enable strong conclusions depends, on the one hand, on the desired degree of certainty of these conclusions and, on the other hand, on the complexity of the external conditions that produce the variation in the phenomenon studied. The four cases included in 
this study each served a specific purpose. The inclusion criteria distinguished the cases two $\mathrm{t}$ two (see also section 1.3). The first distinction was based on whether factors in each municipalit predisposing it to the development of community health initiatives were favourable or unfavourable The second distinction was that into a group of two municipalities that would receive focuse policy support interventions from the RPHS and a group that would not. We would have like to study more cases with respect to these inclusion criteria, to demonstrate the variation in th policy processes studied. However, the capacity of the Hartslag (Midden) Limburg projec which was part of our study design, was insufficient to work in more than four municipalitie: Also, the present research had to be done by a single researcher. Therefore, the number of case was limited to four.

The RHPS failed to actually develop and implement the supportive intervention. In sense, this weakens the design we have used but increases the number of cases with respec to the first inclusion criterion [favourable and unfavourable predisposing factors for local healt promation:, which was a positive side effect.

\section{Making justifiable inferences}

Maso and Smaling (1998) refer to internal validity as the soundness of the arguments (the dat: gathered) and the line along which reasoning has developed (the research design and analysis) We have dealt with the issue of internal validity as follows.

In the preparative phase of the inquiry, we developed a theoretical framework based or concepts and insights from health promotion, and drawing on the interactive, network perspectivt on (health) policy-making. The policy processes in the four cases were studied on the basis 0 this common theoretical framework.

The theoretical concepts were operationalised unequivocally in the different phases of the research. Data collection procedures were established and documented. The use of multiple research methods and triangulation of the data for each case enhanced the validity of oul inquiry. The convergence of data was once more demonstrated when we applied the evaluative framework on local health policy to the four cases. These measures allowed the findings of the four cases to be easily compared.

\section{Chain of evidence}

The 'chain of evidence' should be understood in two ways in the present research: first as a systematic line of reasoning that unequivocally links research questions, data collection and conciusions (see above); and second as the establishment of a database in which the operationalisation of the study and analysis of data are exhaustively documented.

The latter refers to the interpretation of reliability in qualitative research. In this type of research, repeatability is a difficult issue because the reality that is researched changes and the exact viewpoint of the researcher cannot be adopted (Seale, 1999). Some experts use the phrase virtual repeatability, meaning that the research, or parts of it, could be repeated in exactly the same way with the same methods and techniques, and would then generate the same findings if the above impediments could be overcome. The criterion for reliability is then the 'trackability' (Maso \& Smaling, 1998) of the research, that is, whether others can examine 
the course of the research in detail. Other authors call for the creation of an "audit trail" (Baum, 2003; Lincoln \& Guba, 1985), providing a systematic, reflexive, methodological accounting for the methods and procedures used. This assures what they call the dependability (consistency) and credibility (truth value) of the research.

The two interpretations given above are more or less interwined. Being able to make sound inferences needs systematic linkage of theoretical concepts to data collection, analysis and interpretation, but is enhanced by the use of protocols and documentation of procedures, which in turn enables others to check the entire operationalisation. Thus, enhancing validity and reliability go hand in hand. Specific measures we used to increase this validity and reliability are discussed below.

The operationalisation of theoretical concepts into interview questions and other variables was reviewed by experts and was pretested after adjustment lexcept for the evaluation criteria for local health policyl, increasing the validity of the inquiry. Keeping different logs (methodological and interpretative reflections) further improved the (internal) validity of our inquiry, as well as its reliability. The logs are part of a large database established in NVivo, which includes data, reports, memos etc. Despite the improvement of reliability by such measures, actively auditing the chain of evidence, for instance by peer examination of coding and interpretations, would have further increased the internal validity and reliability of our inquiry, as would reviewing drafts of case study reports by key informants

\section{Innovation}

The inquiry into local health policy-making was innovative in several ways. This fact is relevant to a reflection on the methodological quality of this study, because it introduced specific problems. First of all, we addressed a complex research question: the contribution of local health promotion to policy development within a single context. We explicitly linked health promotion practice to policy development, studying a relation which often is ignored. In addition, the study focused on stakeholders and their interactions in policy-making and practice, a perspective not commonly used in studies of policy processes and their evaluation. Secondly, to answer the research question $(s)$ we were hardly able to build on previous research or use validated instruments, which obliged us to look for and develop new tools. We have developed a comprehensive and coherent evaluative instrument to assess the processes of developing local health policy. When looking at the stakeholders in local health policy-making and the interactions and connections between them, we found that a combination of stakeholder and network analysis was an appropriate tool to identify the indicators proposed in this evaluative framework. The application of these instruments in the health promotion domain has provided us with new insights (see chapter 1.01.

However, there were some problems and unfavourable (external) conditions affecting our attempts to meet the innovative challenges in this inquiry. As we have seen in part II of this thesis, the Hartslag (Midden) Limburg project did not develop as planned. This strongly influenced the focus of the inquiry and the possibility to answer the principal. research question. Our study of the interactions and interrelatedness of stakeholders in local health policy developed over time, in that the instrument became more precise. However, because of 
various adjustments we had to make, the network graphs for 2001 cannot be fully compare with those for 2003 , in turn preventing firm conclusions about development over time. Finally it should be noted that the evaluation instrument was not pre-tested, due to lack of time an manpower. When applying the evaluation criteria to the data of the four cases, criteria 6,8 an 10 (see section 2.4) appeared to be hardly practicable, if at all. This meant that we were unabli to assess some of the specified features of local health policy. Finally, the innovative characte of this study may have interfered with its construct validity. We did specify the features of the policy processes concerning local health policy and the expectations we had in this respect, bu since the instrument was used for the first time, we cannot demonstrate that it does indeet reflect our concepts regarding the development of local health policy.

\section{The researcher}

The researcher has been working single-handedly in this inquiry. Over a period of three years (2001-2003) she closely followed the flow of events in the development of local health policy in the four municipalities. She did so partly by means of fieldwork, having established good relations with the people in the field. Contacts with the aldermen and the public health (policy) officers at the RPHS and the municipal administrations were regular and continuous. The presence of the researcher as a participatory observer at various meetings was eventually taken for granted, which may have minimised a possible Hawthorne effect. The incidental contacts with the interviewees were characterised by open dialogue but were also regulated by the theoretical perspectives chosen.

Subjectivity on the part of a researcher is generally considered a threat to the validity of research findings. We do acknowledge the possible negative effects of (overjidentification with the researched or 'going native' by the researcher, but agree with Maso and Smaling (1998) who assert that in qualitative research, subjectivity should be valued positively, provided it is used intelligently. Denzin and Lincoln (2003) state: "there are no objective observations, only observations socially situated in the worlds of - and between - the observer and the observed'. Subjectivity definitely provides access to the object of study and creates opportunities for learning. Nevertheless, we did try to ensure greater objectivity of the findings by consistently using theoretical concepts, protocols and computerised analysis techniques.

Another issue regarding the researcher's actions is the unclear distinction between the phenomenon studied and contextual factors. Strict control of contextual variables is often of great importance, for example in RCTs studying causal relations. However, in this more descriptive and explorative research project, the researcher did not even want to be in control of contextual factors but considered them to be important variables which contribute to the processes studied, and whereby the findings are embedded in the real life world (Denzin \& Lincoln, 2003; Hammersley \& Gomm, 2000; Silverman, 2000).

\subsection{REFlections ON THE FINDINGS ON LOCAL HEALTH POLICY-MAKING}

This section discusses the findings on local health policy-making presented in part III. Although it does not follow each of the items of the evaluative framework individually (for reasons of 
readability], the discussion in the following sections is primarily based on the application of this instrument to the data.

The section first elaborates on the involvement of the different actors in the policy process: the ideas and activities of the stakeholders in local health policy-making, the relationships among these stakeholders (represented in network structures) and the position and role of policy entrepreneurs within the networks. Next, it reflects on the useful components of the policy-making processes studied and the Theory of Streams (Kingdon, 1984, 1995).

\subsubsection{Stakeholders' ideas and activities}

\section{Health policy}

Health policy is generally regarded as an integrated policy, encompassing the multiple dimensions and multiple determinants of health. A significant body of literature indicates that such multilevel policies can only come about through interactive endeavours. These imply the involvement of different disciplines in the health domain and even the involvement of professionals from other sectors. Experts generally favour the involvement of the population and some authors even see it as indispensable (Baum, 2003; Bryant, 2002; Coumans \& Springett, 1997 ).

The findings in three of the four cases show that the municipal authorities had indeed organised interactive sessions in one way or another. All participants in these sessions were characterised by their own specific background and involvement in public heaith. Participants" unique connections with specific organisational purposes (e.g., the provision of home or psychiatric care) appears to conflict with the broad and comprehensive character of health policy. Stakeholders generally represent established institutions with an organisational design that is uniquely linked to the delivery of their specified services, thus limiting organisations in transcending their institutional purpose. What we have found, however, is that individuals might be prepared to cross these limitations and develop more comprehensive views. Service delivery parameters have consequences for the positions stakeholders are willing to take in the policy-making process. They often feel, for instance, that their own organisational purpose must be served while engaging in this process; this often leads to 'single-issue' positions and a high degree of specificity driven by self-interest in potential policy contributions. The power or influence that organisations feel they are able to wield over the policy process is related to the possibility of broad perspectives on local health policy. In this study we have generally seen that stakeholders experience a low degree of control over the establishment of health policy. This may be because their specific background prevents a more "visionary' or 'ideological' health perspective. It may also be that the character of local health policy is too comprehensive for them to be able to come to grips with it.

\section{Role of professional knowledge}

According to Labonte (1992) and Baum (2003) three paradigms can be identified in public health: the medical, the behaviourai and the socio-environmental (see Table 2.1). These paradigms influence the types of problem definitions, preferred solutions and indicators of success for interventions and policies. Thus, stakeholders which operate within the medical paradigm generally prefer disease-oriented and often individualistic approaches to health, whereas others, which 
operate within the behavioural paradigm, would favour behaviour change and populati approaches. It should be noted that this typology is not in any way 'naturally" linked to the $t y$, of organisation. For instance, a hospital might be seen as a proponent of the medical paradig although (within the European Network of Health Promoting Hospitals) there are hospit that try to apply socio-environmental perspectives. Thus, a 'modern' public health service cot embrace a socio-environmental perspective, whereas a more 'traditional' public health servi might more easily relate to the medical or behavioural position. In this study, we have genera seen that professional organisations in this region of the Netherlands are being challenged to rega health policy in the context of broader, behavioural or even socio-environmental heal perspectives, whatever their traditional positions.

Bryant (2002) proposes a typology of knowledge as different forms of knowing about a soci issue. She identifies three types of knowledge that can contribute to the policy developmei process in public health: instrumental (or traditional scientific knowledge), interactive ar critical knowledge. Experts usually generate instrumental knowledge, which is regarded objective. In the past, public health policies have primarily relied on instrumental (scientifi knowledge, mostly quantitative knowledge with an emphasis on lifestyle issues. Interactive lay knowledge develops from personal experience and is shared among people in their dai. lives. Critical knowledge is reflective knowledge and involves analysing socio-economic an poilitical forces and influences upon society.

Although our inquiry did not study why some types of knowledge are favoured over othes in policy processes, some interesting observations need to be discussed here. We have see that instrumental and interactive knowledge have informed the policy process, which is als clearly reflected in the memoranda on local health policy. Scientific knowledge was mainl being provided by the RPHS and was based on national (van Oers, 2002) and regione epidemiological research (GGD-Midden Limburg, 1998). The experiences and needs of th community came to the fore mainly during the interactive sessions, where they were pu forward by representatives of the community and professionals. The combined contribution o experts' knowledge and that of practitioners and lay people is very much valued in healtt promotion (Bryant, 2002; Nutbeam, 2004 b). In the present study, however, it was strikin, that forms of interactive knowledge (for instance anectotal information and personal stories seemed to be more persuasive than scientific knowledge. In fact, this type of evidence had the largest share in the memoranda upon which policy intentions were based, while the policy intentions based on the scientific evidence of health problems (epidemiological data) were condensed into one or two general lifestyle issues. The scientific knowledge referred to is still limited in several ways. The medical, behavioural paradigm prevails, which implies that data on social and economic determinants of health are not yet being included. Moreover, the data available from such research come from the regional and subregional level. These might not be very compeling to policy-makers at the local level, who furthermore (so far) feel more comfortable intervening in environmental (i.e., social and physical) factors (Hoeijmakers, 2000 a). Finally, the evidence created by scientific research concerns primarily health problems and to a lesser extent the effectiveness of interventions (Nutbeam, 2003).

The memoranda for local health policy have been presented as a framework. The further 
development of annual action plans and the political debate; the prioritising of problems to tackle and the allocation of money for interventions are still continuing. What type of knowledge is actually emphasised will become apparent at a later stage.

\subsubsection{Interrelatedness of stakeholders and policy networks}

Health promotion is a domain where the active participation of numerous actors in policy-making is highly important, implying interactions and ongoing relationships. As mentioned in section 2.3 , the Theory of Streams is not specific about the way the interrelatedness of and interactions among the participants affect the policy-making process, but Kingdon asserts that the activities of a policy entrepreneur enhance the process. The above made us decide to use stakeholder and network analysis and to describe the interactions and linkages between identified stakeholders. Chapter 8 has shown the network graphs and presented density and centrality indices for these connections between stakeholders as regards the communication on local health policy, the involvement with each other in public health matters and their strategic collaboration.

\section{Cohesion of networks}

Density of the networks indicates the extent to which all actors in the network are linked to each other. It refers to a general level of cohesion and integration of the network (see chapters 2 and 6 ).

The communication networks for the municipality of Weert show that stakeholders there communicated more about local health policy among each other than in the other cases. In the other two cases (Roerdalen is omitted here because the policy process did not develop there) the stakeholders communicated mostly with the municipal authorities. This indicates that in Weert, local health policy is discussed within existing colllaborative structures (some of which have been initiated by the municipal administration), a conclusion that is corroborated by interview data.

The networks reflecting involvement with each other in public health show that the cohesion in the network at the municipality of Roggel \& Neer is higher than in the other three cases. Actors are more involved in joint action at the operational level. In this case, local health initiatives (like the day care center for the elderly operated by volunteers) are recognized and integrated in the practice of public health. This, however, does not automatically mean that stakeholders also communicate about issues like local health policy or become involved in policy-making processes. For instance, we have observed that general practitioners and the home care organisations, which are considered very important stakeholders [see the findings of our stakeholder identification) and are central in the networks at the operational level (see section 7.3.5) are not central in the policy networks or are even not participating at all (for instance at Roggel \& Neer). Community groups or organisations also become disconnected from the policy networks. It seems that the character of the existing relationships between municipal administration and individual actors is of overriding importance.

The density indices for the networks on strategic collaboration are generally the lowest (compared to the densities of the communication and involvement networks). More nonprofessionals are disconnected and the collaborative links are limited in number. Most links exist between professionals and the municipal authorities or among small groups of professionals. The density of this type of network (strategic collaboration) is highest in Roermond, where the 
network consists mainly of the bigger, regional health organisations. These actors are probably more used to adjusting to each other's organisational policy decisions.

Because we cannot really compare the networks for 2001 with those for 2003 (for the methodological reasons pointed out in chapter 6) we cannot draw any conclusions on the influence of the policy-making process on the composition of the networks over time.

In Roerdalen, where the policy process became stuck and no memorandum on local health policy was drawn up, the networks (in 2001 and 2003) included few participants, with few links among them. This hints at a public health practice in which collaborative processes are poorly developed. The municipal administration maintains formal relationships with few organisations, relationships that are limited to financial ties and the delegation of municipal tasks.

At the outset of the study we made decisions as to which municipalities should be included in it: a pilot study identified two of them as having enabling characteristics for local health promotion and two as having less favourable conditions. Our findings further substantiate these conditions as regards collaboration in public health within these municipalities and the active involvement of the public health officer and alderman (political commitment). This also implies that the starting situation has persisted.

\section{Central actors in the network}

The network graphs and the centrality indices (for ar explanation of this measure, see chapters 2 and 6) show that the municipal administration is a central actor in all networks. The other stakeholders consider it responsible for local health policy and its development. In addition, they consider the municipal administration to be important in the collaborative processes in the health domain. Stakeholders expect the municipal administration to play an active, initiating and coordinating role in policy-making and implementation. In contrast to these expectations, the findings tell us that the municipal administration does not consider itself an expert on public health and that it not only lacks knowledge and experience but also human and financial resources. This explains its reticent attitude and mainly facilitative role in the policy process. In other circumstances, a central actor might be expected to actively coordinate the policy process and to connect the other participants in the network as regards problem definition and solution.

The health professionais, including the RPHS, although considered very important players (see above), seem not to play a prominent role in Jocal health policy-making. This might once more point to the difficulty presented by the complex nature of local health policy. To none of the stakeholders, except perhaps the municipal administration and the RPHS, has local health policy become an important issue of debate or great interest. What is remarkable, however, is that the rather independent position of professional organisations in public health has gradually changed through active measures taken by the central government. If we also take into consideration the ongoing decentralisation of prevention and care in the Netherlands, we currently see that the municipal authorities and regional health organisations do 'meet' each other more often than before. They are becoming more interdependent at the local level, in terms of financing services as well as in terms of policy and organisational change with respect to specific fields of action like preventive youth care, public mental health, and de-institutionalising care services so they are provided in the community. This implies a considerable increase in the responsibilities 
of the municipal authorities, which are required to play a more active, coordinating role and to link these specific subjects in a more integrated health policy. Playing such a central coordinating role, however, is still rather new to the municipal authorities. As for the professionais, they use the above specific policy-making settings to promote their organisational interests, decreasing the need to do so in local health policy-making.

The non-professional stakeholders (interest groups, volunteers, local health initiatives - in short, "the community') occupy a peripheral pasition in the networks. They often need another participant in the network as an intermediary to reach the municipal authorities, to promote their interests or to communicate with the rest of the network. Actor centrality for betweenness can indicate such an intermediary actor (for further explanation, see chapter 6). The betweenness indices computed for the RPHS are lower than those for the welfare service. In general, the latter organisation is directly linked with groups and initiatives in the local community, but their field of action obviously does not primarily concern health issues. The RPHS has more links with local and regional (health) professionals.

The Hartslag (Midden) Limburg project has not been able to exert a major influence on the current health promotion practice and to relate with the policy-making processes in the four municipalities we studied (see chapter 4). As such, it did not play an evident or active role in the policy network.

\subsubsection{The presence of a policy entrepreneur}

Within the described networks we have searched for the presence of a policy entrepreneur by looking at closeness centrality. We assumed that a policy entrepreneur would occupy a central position in the policy network, enabling him/her to easily communicate with the other participants. This is necessary to present participants in the pre-policy processes (in Kingdon's terms, 'the streams') with alternative representations of the same issues in problems, politics and policies, in order to connect participants to actual policy development. Furthermore, a policy entrepreneur" should preferably be directly linked to the responsible policy-makers (politicians). Thus, in addition to a central position in the network, communicating skills (to enthuse, advocate, enable and envision) and knowledge management (see also section 2.2.4) are essential to the policy entrepreneurial role to ultimately achieve shared ways of 'knowing' and shared ideas for preferred policy solutions. A policy entrepreneur allows different actors to collaborate in complex matters.

Nutbeam (2003) argues that scientific knowledge to be used in policy-making should fit. in with the political preferences of policy-makers and be practical enough for implementation. Enhancing this fit demands both apt framing of knowledge and timing in the dissemination of knowledge, similar to the opening of a window of opportunity in the Theory of Streams. The present study clearly showed that scientific knowledge (epidemiological data) is contributed and controlled by the RPHS (and national organisations like RIVM). They communicate this evidence directly to the municipal administration (as a separate process) without active dissemination within the policy network to connect it to the knowledge communicated by other participants in policy-making. The RPHS probably assumed that such evidence would directly lead to policy formulation, ignoring the political and interactive character of policy processes. 
Stakeholders did not perceive the activities of any policy entrepreneur (except for some in the municipality of Weert). The municipal administrations did not act as such, although their central position would facilitate the assumption of this role. The RPHS was perceived as an assistant in the organisation of the policy process and as a specialist in public health, but not as a proactive stakeholder, let alone as a policy entrepreneur. The context, in which the municipal administration and RPHS are generally tied to each other and have also established a specific collaborative relationship in each case, might be a complicating factor in this respect (see also sections 1.1.2 and 10.2).

The consequence of the absence of a policy entrepreneur is that the stakeholders have hardly developed clear ideas about the purpose of local health policy, do not recognise their common problems and interests, and do not feel committed to the implementation of such policy.

\subsubsection{Effective components of the local health policy-making processes}

Our evaluative instrument has given us valuable insights into the policy processes in the four cases (as well as across cases) included in our study on local health policy-making in Central Limburg. However, the specific contextual factors and uniqueness of each case do not allow us to fully compare the cases and evaluate these processes or outcomes in terms of good, better, best or, for instance, on an ordinal scale from 1 -to 10. Nevertheless, we can point at some interesting effective components in the policy process in the different cases.

Although the policy process has been perceived as an undertaking imposed by the national government, the public health officers and aldermen have really engaged themselves and others in a complex policy domain. The interactive sessions organised in three of the four cases generally provide evidence of a positive attitude on the part of the municipal administrations towards community participation and intersectoral collaboration in public health. These sessions, and those in the steering committees (as in Weert and Roggel \& Neer) have provided opportunities for discussion and learning for all participants, but especially for public health officers and aldermen. The extensive policy process in Roggel \& Neer shows that more comprehensive and integrated ideas on health and health policy have been developed. In those cases where the policy process is developed in collaboration with other municipalities and with external assistance, as happened in Weert and Roggel \& Neer, the process creates maximum output with a minimum of effort by individual public health officers and aldermen, even in small municipalities.

The communication network in Weert shows a considerably larger number of links between the actors than those in the other two cases. The municipal administration maintains regular contacts with health professionals and community groups, and engages in existing collaborative structures. This has paid off in terms of policy-making; all stakeholders easily become involved and know how to find each other. The stakeholders in Weert are also quite positive about the recognition (by the policy-makers) of their input in policy-making and part of the stakeholders perceived the municipal administration as a policy entrepreneur. By contrast, the Roermond municipal authorities are still trying to find out how to establish enduring collaborative relationships with the health professionals, mainly in regional organisations. The higher density 
indices for networks of participants in more operational processes might, however, be misleading in the sense that this does not automatically mean that the same actors also become involved in policy-making processes (see section 9.2.2). In Roggel \& Neer, for instance, a highiy favourable climate might seem to exist for local health promotion, with the involvement of and interaction between health professionals as well as non-professionals (see the network graph on involvement in public health in Figure 8.3). This is, however, not at all reflected in the communication network. The involvement in policy-making apparently requires a more active role of the municipal authorities in local collaboration processes, as shown in the Weert case.

The official status given to groups in the community, for example to the council for the elderly in Roermond, facilitates the participation and recognition of their involvement in policymaking.

With respect to the implementation of local health policy, the notion of intersectoral collaboration has been worked out to some extent in Roggel \& Neer, where there are plans for a steering committee and working groups consisting of public health officers, professionals and representatives of the community.

Preliminary objectives, instruments and activities have been formulated at Weert, including the links with other policy subjects in the organisation. Funds have already been allocated to this policy plan.

Finally, based on the Roerdalen case, we can note that the development las well as the implementation) of local heaith policy requires political commitment. Political commitment is most clearly expressed in a decisive attitude of the municipal administration, i.e., in the allocation of financial resources for manpower in the public health office and planned activities, as well as the visible involvement in the policy process of the alderman responsible for public health.

\subsubsection{The 'Theory of Streams'}

In the Theory of Streams (see section 2.2.4), Kingdon (1984, 1995) presents visible and invisible participants who take part in processes in the problem, policy and political streams. The visible participants are the official (government) administrators, political leaders and the media: they influence agenda setting in particular (i.e. the appearance of an issue on the political and policy agenda). The invisible participants are the civil servants, specialists (professionals) and researchers; they mainly influence the specification of alternatives (development of policy proposals). One of these participants can take the role of a policy entrepreneur.

Our findings demonstrate that professionals are active both visibly and invisibly. They try to convince others about existing problems but also negotiate possible solutions. They do so with respect to their specific field of action. The fact that politicians and civil servants tended to disqualify themselves with regard to the content of local heaith policy may have caused the professionals to operate more visibly in the cases we have studied. They intentionally invite professionals to inform them. In addition, the processes studied here develop at the local level, and there is a huge difference of scale with the national level; problems are of a different magnitude and the experts consulted by politicians are of lower rank (management or operational level).

The politicians show a preference to act upon clearly stated problems brought to their attention by civilians. They feel that policy should only be made in response to specific issues 
brought forward by their constituencies which was not found to be the case. Politicians and even the civil servants, especially in the small municipalities, do not have concrete ideas about public health problems and the range of possible solutions to these problems. They want to be led by the expertise and actions of professionals. Thus; they see themselves merely as intermediaries between problems and solutions. At the local level, politicians also act upon directives from the national government, more or less regardless of the priorities set by the local administration. Although 'health' does not generally have great priority on the political agenda, politicians feel that national directives in this domain can and should not be ignored.

The involvement of non-professionals, which is not specifically considered in the theory of Kingdon, concerns first and foremost their representation and promotion of interests and problems of certain groups in society. Their contribution to the specification of alternatives was not immediately apparent in this study.

The legal obligation to develop local health policy at a certain moment in time can be regarded as a clear opportunity to link in with the problems and solutions presented in the interactive sessions; in other words, a window of opportunity was opened.

As regards the problem stream, we found that despite the attention given to local health policy by the municipal administration, public health problems as such did not have high priority on the municipal agenda, compared to economic or social projects. Nor were the epidemiological data perceived as urgent enough to put the health problems that were identified high on the agenda.

The rather massive number and diversity of issues presented by the participants in the pollicy-making process, which is also reflected in the memoranda on local health policy, might indicate a lack of coherence in terms of a joint policy direction or goal. The participants in this study did not indicate the presence of a policy entrepreneur (see section 9.2.3). Ideally, it would be the role of such an entrepreneur to lead the way towards this desired cohesion.

In the policy stream, a variety of alternatives were presented and discussed. Some solutions were favoured over others, like the community-based approach and a central office catering for all people who need care (the one portal concept) and solutions were adapted to the local situation (e.g. a mobile central office for the rural municipalities).

In terms of the Theory of Streams, the coupling of the problem and policy stream to the political stream has been faulty, although there was a clear opportunity in time. 


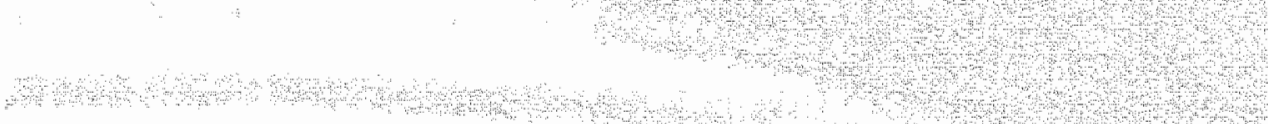

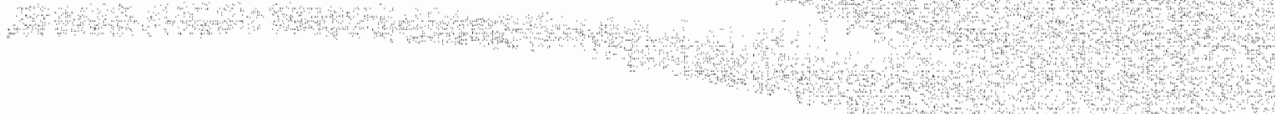

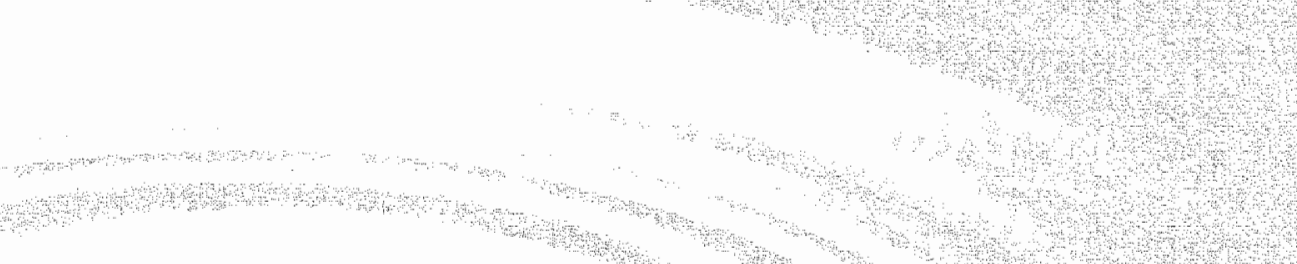

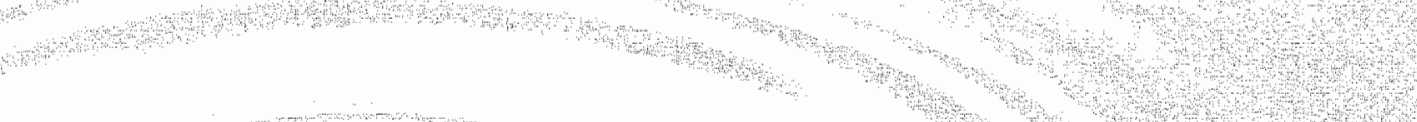

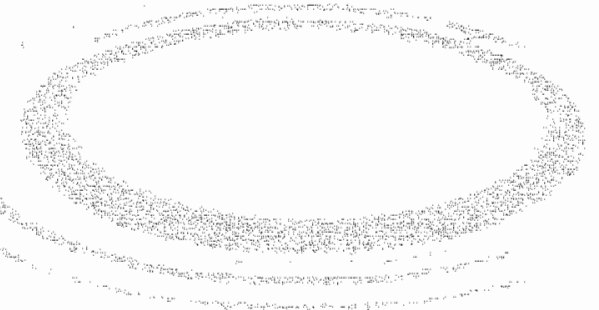

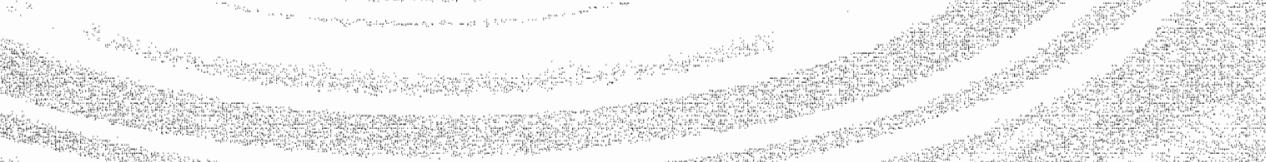

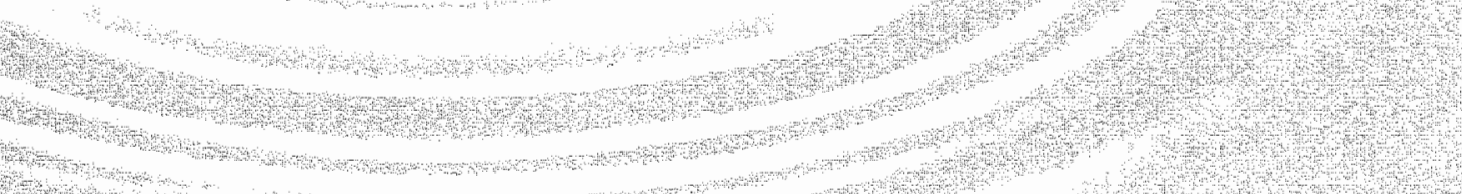

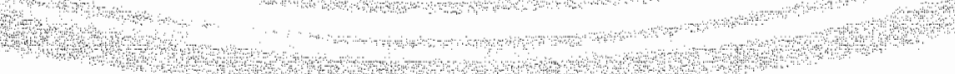
P.. Pै: 


\section{POLICY PROCESSES: CONCLUSIONS}

The final chapter of this thesis starts with a brief summary of the most important components presented and discussed in the previous chapters. It then continues the line of reasoning started there, leading to concluding remarks on the propositions formulated in this inquiry Isee section 8.1). Subsequently, this chapter answers the research questions raised at the very start of the inquiry. The chapter ends with some ideas for further use of the research instrument(s) and some final comments.

\subsection{Introduction}

Local health policy-making, which has been made obligatory by the Minister of Health, Welfare and Sports, is meant to be an integrated policy, going beyond the action domain of collective prevention (as laid down in the recent WCPV). Health is thereby regarded as a multidimensional concept, determined by multiple determinants. This implies that professionals of different sectors in society and the community should participate in the policy process.

The municipal administration, having been made responsible for the development of local health policy, was challenged to address the intricate character of health problems in the public domain at the local level more explicitly than before. The municipal authorities in Central Limburg felt that they lacked expertise and manpower in the field of public health, and that external assistance was needed to develop local health policy. Other stakeholders, when asked for the first time at the outset of the policy process, did not have clear ideas either about this rather new policy domain. They looked at it from their own perspectives, which are rather divergent. Most of them expected to get involved in the policy process and to be able to influence it.

In the network analysis at the outset of policy-making, the municipal administration appeared to be the most central actor in terms of health policy-making in the local context. The RPHS and some other regional health organisations also seemed to be important actors in this respect.

Many stakeholders have indeed become involved in policy-making, but stil] with a rather vague understanding of local health policy. Stakeholders have responded to requests by the municipal administration to contribute their knowledge, field expertise or interests lof specific population groups) during well-organised interactive sessions or workshops. In general, stakeholders of local health policy considered professional expertise more important than that of the communicy. The contribution of professionals in the policy process also appears to go further than that of non-professionals: both try to convince other participants in the policy process of certain problems, but professionals also negotiate solutions to these problems. Although different types of knowledge inform the memoranda on local health policy, they do not yet demonstrate a coherent whole. 
The degree of involvement of stakeholders in policy-making can be said to be limited, in the sense that there was hardly any contact between stakeholders beyond the organised meetings, and local health policy did not become a subject of any importance in the organisations stakeholders represent. Aspects that have determined the restricted involvement of stakeholders include the following. The interests of stakeholders in the development of local health policy are divergent. Local health policy is not of pivotal importance to the stakeholders, because it goes largely beyond their sphere of action. The integrated character of local health policy makes stakeholders think that their contribution is valuable but their influence on the policy process small.

\subsection{Involvement of the stakeholders in the policy process}

The purpose of this section is to continue the line of reasoning started in previous chapters and to draw conclusions on the involvement of the different stakeholders in the policy process. The section ends with some concluding comments on the propositions formulated in this inquiry.

We argue that the divergent perspectives stakeholders bring into the policy process, which at times are quite restrictive, impede the development of a more integrated idea of local health policy if none of the actors in the policy-making process binds these different perspectives together in a shared vision on identified health problems and solutions to these problems.

Network analysis has shed more light on the opportunities the different actors have to influence policy-making. It has visualised the positions of stakeholders and their interrelatedness (cohesion of the network) in policy-making. We have seen that the municipal administrations, as the common central actor in each of the cases, were in the best position to act as such a binding actor, described in sections 2.3 and 9.2 .3 as a policy entrepreneur. In contrast to this position, we have observed that they took a facilitative role instead of actively coordinating the poilcy process in which content choices direct the process. The municipal administrations did not consider health matters an important (political) issue and the legal obligation has been the leading factor in their decision to develop local health policy. Furthermore, they considered other stakeholders more important.

The RPHS, which had been expected to act as a policy entrepreneur, appears not to be in the most favourable position in the networks to fulfill this role. However, their reciprocal relationship with the municipal authorities (the policy-makers) does give them easy access to the other participants in policy-making. Furthermore, their links with other actors in the network mainly concern the other professional organisations, which in turn have direct links with the municipal authorities as well. The RPHS does not bridge the gap between the local community groups or organisations and the central actor, and does not maintain many relations with these initiatives. The Hartslag (Midden) Limburg project did not change this situation, at least not to any extent observable in the present inquiry. Moreover, other stakeholders did not perceive the RPHS to be a policy entrepreneur. The RPHS was partly perceived as an assistant in the more formal organisation of the policy process (e.g. the interactive sessions) and partly as a participant like all other stakeholders (having a rather re-active attitude). In two cases (Roermond, Roggel \& Neer], the municipal administration did indeed ask the RPHS for their assistance. In the third case (Weert), the RPHS participated in the steering committee. 
Here we touch upon two important contextual factors, the relationship between the municipal administration and the RPHS, and how to conceive the role of policy entrepreneur. We argue that the relationship between municipal administrations and the RPHS, and the interpretation of the latter's advisory role in policy-making, determine whether the RPHS can and will assume the role of policy entrepreneur. To clarify this argument, we discuss the following points: (1j the interpretation of the WCPV, (2) the funding of the RPHS and (3) the view on policy entrepreneurship.

The implementation of the WCPV law since 1990 has obliged the municipal administrations and the RPHS to work together very closely (see section 1.1.2). In Central Limburg, 14, and later 27 , municipalities have committed themselves to collaborate in the development of regional public health policies and to maintain a regional public health service. The RPHS in turn implements the tasks laid down in the WCPV in the whole region, on behalf of these municipal administrations. Currently, the municipal administrations want the RPHS not only to take on the regional responsibilities and activities, but also to act upon their individual (municipal) needs. The introduction of the RPHS' diversified products provision model (KPA) in 2002 demonstrates this, as the model comprises not only products that are compulsory for each municipality (decided upon at the regional level), but also optional products for the individual municipalities. The bipartite contract has caused some tensions between the municipalities in the region, as well as between the individual municipalities and the RPHS, and this is extremely relevant to the present study of local health policy-making.

The way the individual municipal administrations now interpret the WCPV (which mentions the policy advisory task of the RPHS, largely determines the extent to which the RPHS is requested to assist them in local health policy-making. In the case of Roggel \& Neer, we have seen that the municipal administration conceives of the RPHS as a policy advisor in every respect, whereas in the case of Weert this advisory role is taken literally in terms of consulting the RPHS when developing new policies. Thus, if the advisory task of the RPHS in municipal policies is interpreted broadly, it should induce the RPHS to assume an entrepreneurial role. In view of the meed for a policy entrepreneur in health policy-making argued above, the municipal administrations could even assign such an entrepreneurial role to the RPHS. Of course, the ambitions of individual municipal administrations in the development of health policy should be taken into consideration. In this study, the two urban municipalities had greater ambitions to take the lead in policy-making than the two rural municipalities.

The above naturally leads to the observation that the RPHS largely depends on the municipal authorities with respect to regional agreements and their individual interpretation and ambitions, but also with respect to organisational matters, including the financial resources required for the organisation's functioning. It is the municipal administrations which define what products and services they purchase, including community-based health promotion activities, epidemiological research and policy advisory services. The financial relationship thus also determines the actual degrees of freedom the RPHS has in developing entrepreneurial activities.

Finally, should the policy entrepreneur be an individual or an organisation? Kingdon says that anyone can take the entrepreneurial role, at least when she/he participates in one of the streams and has a significant long-term interest in the matter under consideration. One might 
question whether the individual participants in policy-making necessarily need the back-up of the management of the organisation she/he generally represents. If so, the attitude and stances the RPHS takes in local health policy-making enable (or impede) the individual policy officer in developing entrepreneurial activities. In our study, the RPHS was originally of the opinion that the organisation should play a modest role in municipal policy development. They considered an active role to be conflicting with their operational tasks. This attitude gradually changed towards a more active role but not (or too late to develop) an entrepreneurial one.

We further argue that the other participants in policy-making do not play a prominent role. The other professionals, at the local and regional levels, contribute their specific perspectives on health problems and solutions. They try to convince the municipal administrations and the other participants in the policy process to formulate policy objectives and actions which are in line with the problems they perceive. They want their interests and input to be recognised in the policy process. Apparently, the professionals did not operate in concord, let alone act within more concrete coalition-type efforts to promote certain standpoints in the policy process. They did not consider local health policy to be the proper opportunity to promote their interests. The reciprocal relationships between a small number of professionals (cliques) shown by the networks in 2001, however, raised such expectations of joint action.

Nor did local groups and organisations join forces to strengthen their involvement in local health policy-making, although their position in terms of influencing the policy process to promote their interests was rather weak. They were more focused on the support of a coordinating organisation (e.g. the council for the elderly) or the welfare service than on supporting each other.

We have now extensively discussed the involvement of the different actors and groups of actors in local health policy-making. The propositions, presented more fully in chapter 8 , concern the positions and roles of these stakeholders in local health policy-making. Each proposition is discussed briefly below.

Because of its central position in the policy networks, the municipal administration will actively communicate and mobilise the other actors in the network, and will coordinate the network. The favourable starting position of the municipal administrations in Weert and Roggel $\&$ Neer reinforced this role.

The municipal authorities in our study primarily took a facilitative role in local health policy-making. They coordinated the policy process in practical respects. The supposed advantage of the municipal administrations in Weert and Roggel \& Neer apparently did not make a difference in the role they actually assumed in policy-making, compared to Roermond. We therefore do not find support for the first proposition in this inquiry.

The Regional Public Health Service will be a policy entrepreneur, connecting the participants in the policy process through advocacy and negotiation, in case it is requested to assist in policy-making.

The requests made to the RPHS to assist in policy-making were different in the three cases where the policy process was implemented. These requests reflect the perceptions among the respective municipal administrations of the appropriate role for the RPHS and their own ambitions in local health policy-making. The RPHS responded in accordance with the specific requests. The main practical assistance provided did not touch upon active knowledge management or 
communication among the different participants in the network to lead the way in a joint policy direction. So once again, our findings do not support the proposition.

Health professionals will participate in local health policymaking and compete with each other to stimulate the health problems they are responsible for and their favourite solutions.

Health and other professionals have indeed promoted their interests in local health policymaking. Their contribution concerned both problems in the public health domain and their favoured solutions. They primarily took single-issue standpoints, although some of them are in a position to assume an entrepreneurial role or to link community groups or organisations to other actors in the policy network. Thus, the findings of the study do support this proposition.

Local non-professional groups will participate in the policy process but have a weak

position when it comes to influencing the policy making process.

Interactive policy-making with community participation is considered important in Central Limburg. However, the ability of the community to influence policy-making processes is impeded by their generally peripheral pasition in the policy networks. The findings of the present inquiry thus also support this proposition.

\subsection{THE DEVELOPMENT OF LOCAL HEALTH POLICY}

The central question of this inquiry was formulated as follows. How is local health policy developed and how does community health promotion contribute to the development of local health policy? Before answering this question, the next sections first answer the three research questions of the present study:

1. Which actors and factors contribute to health policy development at the local level, and how do they contribute?

2. Are there major differences in health policy development and its outcome between municipalities, and to what variables can they be attributed?

3. How does the Hartslag [Midden] Limburg community-based cardiovascular prevention project contribute to policy development and how are the activities of the project integrated in local health policy?

\subsubsection{Contributions of actors and factors to the development of health policy at the local level}

\section{Actors in policy development}

The stakeholders we identified were mainly actors from the health and welfare sectors, actors within the community and actors working for the municipal administration; they (and some other actors) were the actors actually contributing to the development of local health policy. We have argued that the contributions of specific stakeholders to the policy process vary; they inciude process facilitation, practical assistance and different types of knowledge relating to problems and solutions. The activities of the participants in poilicy-making are very much related 
to their (organisational) values and beliefs and the interest they have in local health policy. At the start of this study, we assumed that the interactions and relationships between actors in policy-making would determine their roles in the policy process. In the previous section, we have already stated that the specific positions of actors in policy and other networks and the links between them indicate what roles they can take, but not necessarily do, in the development of local health policy. A number of reasons have been given for this claim.

\section{Enabling factors relevant to policy-making}

First and foremost, we should mention the active presence of a policy entrepreneur as a prerequisite in health policy development. That is because of the intricate character of public health problems, the broad definition and aim of local health policy and the involvement of many different actors, including the community, in the policy process. We have concluded above that there was no policy entrepreneur active at the time when local health policy was being developed in the municipalities included in our inquiry. The main reason for this absence was the lack of high interest in local health policy by the stakeholders. The absence of a policy entrepreneur has strongly influenced the still incoherent character of the memoranda on local health policy that were produced.

Our examination of the policy processes showed that extensive and actively facilitated processes are more effective in terms of exchange of knowledge and interests, and in getting stakeholders to actually commit to the development and implementation of integral local health policies. The formation of steering committees or working groups is useful for this purpose, as well as for advocacy in the political arena.

Political commitment appeared to be a stimulating factor in the development of local health policy. This factor refers to the importance given to health matters in the municipality, either in an immaterial sense (i.e., verbally, in reports, presence) or in a material sense (i.e., allocation of budget, manpower|. The active engagement of the municipal administration in collaborative processes in public health practice, as an indicator of political commitment, was found to facilitate the involvement of the same actors in policy-making. Regular contacts with groups and organisations in the community enable these stakeholders to fully participate in health policy-making.

The participation by the community prowed to enrich the policy process and its outcome by providing interactive knowledge. Granting community members an official status (decision powerl or helping them to become more organised was found to increase their ability to participate in and influence the policy process.

The policy processes studied have not resulted in highly integrated health policies yet. However, we agree with the idea that such plans result from a policy process that is ideally based on the convergence of the different perspectives and types of knowledge of the stakeholders involved (see also our point on the policy entrepreneur above). To enhance the implementation of scientific knowledge into policy, it should be actively managed in the policy process, that is, it should be presented and negotiated in the policy network. Familiarity with the relevant network and its structure thus becomes a prerequisite.

Furthermore, the scientific knowledge that forms the evidence base of integrated health 
policy needs to be extended in two ways; it shouid address not only health problems but also the effectiveness of local health promotion interventions, and epidemiological research should also aim at the social determinants of health, both preferably at the local or sub regional level.

Finally, the establishment of a coherent policy plan is an important factor. Obviously a memorandum on local health policy generally contains policy objectives, instruments and actions, supplemented by a financial estimate. In the developmental phase of the policy processes we have studied, we did not come across detailed policy plans yet, but frameworks have been formulated that are to be further specified by the municipal authorities. The findings support the idea that such a policy plan should also include the agreements on the division of tasks among the stakeholders who will be involved in the implementation of the policy (including other departments in the municipal organisation).

\subsubsection{Differences between municipalities in policy development and its outcome}

In three of the four cases (municipalities) in this study, local health policy has been developed and approved. At first sight, the policy processes in these cases do not differ greatly. The aspects they share were described in sections 8.4 and 9.2. However, the study has uncovered some differences in policy development, which were described and discussed in the previous chapters. Briefly, the policy processes differed in the following respects. First, there were differences in the level of intensity, that is, the duration of the process, which is closely connected to the functioning of steering and working groups or interactive sessions, and the involvement of the public health officers and aldermen. Second, the roles of the municipal administrations and the RPHS in policy-making differed, which was largely determined by external factors and the ambitions of each municipal administration and the RPHS. Third, the network structures demonstrated differences in the cohesion of networks and the connectedness or disconnectedness of the identified stakeholders to the networks in policymaking and public health practice. Community groups and organisations, as well as some professional actors, were not always connected in the policy networks. Fourth, the welfare service was identified in two cases as an important actor in connecting the community to other actors in the network or representing their interests, including those relating to health policymaking. Nevertheless, this can only work if the welfare services recognise that they can assume such a role in health matters (which was, for example, not the case in Roermond) or are explicitly invited to do so by the municipal authorities. Finally, the perspectives on local health policy reflected in the local health policy memoranda differ, ranging from a rather narrow focus on heaith problems to more comprehensive ideas acknowledging the links between health problems and other policy domains and (policy) decisions made at other municipal departments.

Most of the above differences can be attributed to the initial situation in the municipalities, which differed in terms of enabling factors for the development of local health promotion (involvement of the community, intersectoral collaboration and political commitment), that is, the first of the two inclusion criteria (see section 1.3). The enabling factors which were most clearly in evidence were the existence of (intersectoral) collaborative processes and structures, 
as well as political commitment, reflected in the coordination or at least the facilitation of these collaborative processes in practice and the creation of the necessary conditions for policy development. It seems that these factors need to be present simultaneously to create effective networks in health policy-making as shown in the case of Weert. The above strengthens our initial idea that the enabling factors in local health promotion also enhance effective policy. making. This is best demonstrated by the case in which local health policy has not been developed.

This fourth case (the municipality of Roerdalen) is characterised by networks that are hardly integrated, and a central actor (the municipal administration) with an extremely reactive attitude. The professional organisations have links with the municipal authorities, but few with each other, and community groups and organisations are hardly integrated in the networks. In addition, the municipal authorities (including the public health officer) do not assume a stimulating coordinative role in collaborative processes, but a strictly formal one. Finally, the municipal administration has not created the necessary conditions (in terms of fundingl for the public health office to develop local health policy.

\subsubsection{Contributions by the community-based project Hartslag (Midden) Limburg to policy development and its integration in local health policy}

In the second part of this thesis, we have described and discussed the community-based cardiovascular prevention project entitled Hartslag (Midden) Limburg. The project was not successful in achieving the objectives set at the start of the project, nor did it meet the expectations the RPHS and the researcher had about the contribution such a project could make to policy development at the local level. We had assumed that the application of health promotion concepts like intersectoral collaboration and community participation would stimulate the development of comprehensive ideas about dealing with health problems at the local level and enhance the involvement of professional organisations and the community in policy development. Such stimulating effects of the intervention might have shown up in several aspects of the policy process, including changes in network structures (see also the next section!.

Neither the project leader nor the RPHS actively recommended using Hartslag (Midden) Limburg as a possible solution to the problems identified in the local health policy processes studied. It was not tested in the policy network for its acceptability and practicality in the socalled softening up process (according to the Theory of Streams). The project thus did not become integrated in the health policy domain at the municipal level. On the other hand, the project is now integrated in the RPHS' KPA Model and thus available to individual municipal administrations to use in the implementation of their local health policy, or more specifically, the implementation of lifestyle activities tailored to the local needs.

The development of local health policy has been described exhaustively in the previous sections. The second part of the central question, how local health promotion contributes to the development of local health policy, cannot be fully answered, for the reasons outlined above. We conclude that this research question still awaits an answer. However, we think that the tools we have developed for this study could be useful in further research on the same question. The next section elaborates on this idea. 


\subsection{THE USE OF NEW TOOLS IN HEALTH PROMOTION RESEARCH}

We argue that network analysis is a valuable instrument in the evaluation of policy processes.

To evaluate the development of local health policy we have combined essential concepts from theories on health promotion and policy-making in one evaluative instrument. The use of this instrument has provided a comprehensive view of the policy processes in the four cases and the factors influencing the policy process. Most importantly, it has gained us insights into the positions, actions and interactions of the most important stakeholders in policy-making. These specific insights primarily originate from the network analysis we have applied in this study. However, our conclusions on the effectiveness of the relevant network structures are very tentative and can only be related to the findings regarding the other criteria in the evaluative framework, like the perspectives of stakeholders on local health policy and the role of the municipal authorities and the RPHS.

The network perspective on policy-making we have used is complementary to the interactive perspective on policy-making in the Theory of Streams, which was at the basis of this inquiry. Network analysis adds the type of information which is insufficiently provided by the study of the processes in the problem, policy and political streams: zooming in on the coherence and coordination of policy processes.

Notwithstanding the progress we have made, we feel that knowledge of possible linkages between different networks and the effectiveness of networks in public health policy-making might broaden and deepen the insights into policy processes developed so far. Further research should not only focus on the effectiveness of networks for policy-making but also study the influence of the structure of a particular network on the positions, actions and interactions of actors in another network, over time.

Network structures are not static entities, but are aitered by events and actions taken by participants in the network. We are interested to know how the structure (in terms of positions and interrelatedness of actors; of a specific network influences other networks, that is, the links between networks. For instance, we do not have a clear idea of the relationship between the structure of the network showing the involvement of stakeholders with each other's public health work and the network showing communication on local health policy isee also earlier remarks in this and the previous chapter). Does it matter, for instance, how stakeholders usually collaborate (i.e., the practice of collaborative processes), or does the behaviour of the central actor matter? In other words, if the central actor in a particular network assumes an entrepreneurlal role, she/he might not only influence the coordination and cohesion in that specific network but also that in another network, and vice versa. Of course, such an actor would need to be familiar with the contextual factors and be able to manage them.

Making a series of assessments of precisely defined networks and the activities of the actors in these networks over time may shed light on these relationships. Such findings need to be complemented by data from interviews and observations. Insight into the above processes would increase our knowiedge of how to influence the process of health policy-making from another angle.

We further argue that a policy stakeholder diagnosis is complementary to the community analysis that is commonly used in heaith promotion and health education. 
The health education literature mentions different types of diagnosis to help the health educator to precisely define, develop and implement health interventions, for example social diagnosis, problem diagnosis and behavioural and environmental diagnosis (Bartholomew et ail., 2001; Green \& Kreuter, 1991, 1999]. The literature on local health promotion and community projects also regards conducting a community analysis or needs assessment, or mapping community capacity, as a prerequisite for actual intervention (Hancock \& Minkler, 1997; Mc Kright \& Keretzmann, 1907; Rissel \& Bracht, 1999)(see also chapters 3 and 4). Both heaith education and health promotion generally acknowledge the influence of organisational practices and policy on the health of people. They also recognise the influence either of these, or both, may wield over the implementation of health promotion interventions, and even recommend including a study of such factors in the process of developing an intervention. However, the attention paid to organisational and policy aspects in health promotion often ends there. A policy stakeholder diagnosis may fill this gap.

\subsection{FinAl COMMENTS}

We have studied policy processes in local health policy-making in the Dutch region of Central Limburg. We have gained more in-depth knowledge on a number of aspects of these processes, on which we want to make some final comments in this final section of the thesis.

We have applied a health promotion and network perspective to health policy-making, while the Theory of Streams has additionally served as a leitmotiv. We have seen that this theory is also valuable when studying policy processes at the local level. Like the Theory of Streams, policy-making at the local level is not a rational process, which ensures that the most appropriate solution will be applied to abjectively assessed urgent health problems. Rather, the policy process involves divergent perspectives on health problems and solutions being discussed and negotiated; the positions and interactions of the participants in the policy process are decisive for the outcome of this process.

The development of a comprehensive evaluative framework and the use of stakeholder and network analysis as additional tools to analyse the practice of health policy-making is innovative and has proved to be useful in health promotion research. The outcomes of our study using these instruments to examine the interactivity of stakeholders in policy-making and the structures of the networks they participate in contribute importantly to the understanding of policy processes in the health domain and add to the Theory of Streams. They provide more insight into the abilities of stakeholders to monitor and contribute to the policy process.

However, dividing participants in policy-making into visible and invisible participants, as is done in the Theory of Streams, does not work for the present study, so it should not be considered a standard approach. Most important are the findings on the functioning of a policy entrepreneur in the policy process. We have argued that policy-making in the complex domain of health requires the continuous commitment of a policy entrepreneur, precisely to bring into line the divergent perspectives in integrated health policy and to link up with the agenda of the policy-makers. A large variety of actors participate in the policy processes we studied, but none of them, neither the obvious candidates nor a surprise actor, has adopted the role of a 
policy entrepreneur. This has negative implications for the coherence of the local health policy plans established and the commitment of the stakeholders to these plans.

The development of local health policy, alchough a statutory task of the municipal admini strations, has initiated a developmental process creating opportunities for local health promotion, both inside and outside the municipal organisation. This may stimulate further coliaboration in local health initiatives between stakeholders.

Nevertheless, we have learned that the interactions between and relatedness of stakeholders in the field of public health do not automatically lead to involvement in policy-making, and that participation in the policy process in itself does not automatically lead to effective integrated health policy. 



\section{REFERENCES}

ed). Assessing and understanding processes of a Dutch comprehensive community health ion. Health Education Research.

321. Gezondheid Gewogen: screening verkiezingspragramma's 2002 op gezondheids(repont). Abcoude: Public Health Forum.

1. Health promotion in the economically developed world A systematic neview of health on definitions, theories, and interventions in the United States, Canada, Europe and a (review): US Department of Health and Human Services, Centres for Disease Control and on (CDC).

\& Mays de Pérez, K. A. (2000). Rethinking Observation: From Method to Context. In N. \& X. Lincoln (Eds.), Handbook of Cualitative Research (second ed.). Thousand Oaks: Sage lons, Inc.

187). Unraveling the Mystery of Health: How Peopie manage Stress and Stay Well. San :0: Jossey-Bass Publishers.

69). A Ladder of Citizen Participation. Journal of the American Institute of Planners, 35, 4.

., Parcel, G. S., Kok, G., \& Gottlieb, N. H. (2001). Intervention Mapping. Designing theory idence-based health promotion programs (first ed.). Mountain View, Calffornia: Mayfield ing Company.

The New Public Health. Oxford: Oxford Uniwersity Press.

(1994). Gemeentelijke overheid en lokaal gezondheidsbeleid. In H. F. L. Garretsen, W. F. M. s. \& M. F. T. Schrijver (Eds.l, Lokaal Gezondheidsbeled Ipp. 1429). Houten: Bohn Stafleu ghum.

Kawachi, I. [2000). Social Epidemiology (1st ed.). Oxford: Oxford Unwersity Press.

\& Weiss, C. (2000). Theory-based Evaluation in Practice. What Do We Learn. Evaluation $v, 24(4), 407-431$.

Expanding Health Care Horizons: from a General Systens Concept of Health to A National 1 Policy. Oakland, CA: Third Party Associates.

uvageau, L., \& Lepage, C. [2003]. Factors in creating sustainable intersectoral community $z$ ation for prevention of heart and lurg disease. Health Promotion intemational, $18(2), 135 \cdot 144$. verly, S., \& Labonte, R. (2000). Community as a Setting for Health Promotion. In B. D. Poland, Green \& 1. Rootman (Eds.), Settings for Health Promotion. Linking Theory and Practice. mia: Sage Publications, Inc.

(1999). Health Promotion at the Community Level. New Advances (second ed.). Thousand , London, New Delhi: SAGE Publications Inc. 
Bracht, N., Kingsbury, L, \& Rissel, C. 11999. A Flve-Stage Community Organization Model for Health Promotion, Empowerment and Partnership Strategies. In N. Bracht [Ed.], Health Promotion At The Community Level. New Advances (second ed., pp. 83-104). Thousand Oaks, London, New Dehli: SAGE Publications Inc.

Brass, D. J., Galaskiewicz, J., Greve, H. R, \& Tsal, W. [2004). Taking Stock of Networks and Organizations: A Mulilevel Perspective. Academy of Management Joumal, 476), 795.818.

Brugha, R. \& Varvasowszky, Z. (2000). Stakeholder Analysis: a review. Health Policy and Planning, 15(3), 239. 246.

Bryant, T. (2002). Role of knowledge in public health and health promotion policy change. Health Promotion Intemational, $17111,89.98$.

Catford, 1. (2003). Health Promotion - origins, obstacles and opportunities. In H. Keleher \& B. Murphy (Eds.), Understanding Health: A Determinants Approach. Oxford: Oxford University Press.

Catford, J. (2004). Health promotion"s record card: how principled are we 20 years on? Health Promotion International, 1911 , 1.4 .

Cobb, R. W. \& Elder, C. D. [1983). The Dynamics of Agenda-Building. Baltimore, London: The Johns Hopkins University Press.

de Bruijn, H., \& ten Heuvelhof, E. (2000). Networks and Decision Making. Utrecht: Lemma Publishers.

de Bruijn, J. A. Kickert, W. J. M., \& Koppenjan, J. F. M. [1993). Inleiding: beleidsnetwerken en overheids. sturing. In J. F. M. Koppenjan, J. A. Bruijn de \& W. J. M. Kickert (Eds.), Netwerkmanagement in het open baar bestur. Over de mogelijkheden van overheidssturing in beleidsnetwerken. (pp. I. I. 30). Den Haag: Vuga Uitgeverii B.V.

de Graaf, H., \& Hoppe, R. (Eds.). (1989). Beleid en politiek. Een inieiding tot de beleidswetenschap en beleidskunde. Muiderberg: Coutinho.

de Leeuw, E. (1989a). Health Policy. An exploratory inquiry into the development of policy for the new public health in the Netherlands. Uniwersity of Maastricht, Maastricht.

de Leeuw, E. [1989b). The Sane Revolution. Maastricht: van Gorcum.

de Leeuw, E. (1993). Health policy, epideniology and power: the interest web. Health Promotion International, 811], 49.52.

de Leeuw, E. (1999). Healthy Cities: Urban Social Entrepreneurship for Health. Health Promotion International, $14(3), 201 \cdot 260$.

de Leeuw, E. [2000]. Beyond Community Action: Communication Arrangements and Policy Networks. Com. mentary. In B. D. Poland, L. W. Green \& 1. Rootman (Eds.), Settings for Health Promotion. Linking Theory and Practice (pp. 287.300). London, New Delli, Thousand Oaks: Sage Publications, Inc.

de Leeuw, E. (2001). Investigating policy networks for health: theory and method in a larger organizational perspective. In I. Rootman, M. Goodstadi, B. Hyndman, D. McQueen, L. Potvin, J. Springett \& E. ziglio (Eds.l. Evatuation in Health Promotion: Principles and Perspectives. Copenhagen: WHOLEURO).

de Leeuw, E. (2003). Researching health promotion determinants and interventions - an institutional and governance perspective. Paper presented at the 4th Nordic Health Promotion Research Conference, Visterass, Sweden.

Dean, K. (1996). Using theory to guide policy relevant health promotion research. Health Promotion International, $1 \mathrm{I}(1), 26$. 
Denzin, N., \& Lincoln, Y. (2003). Introduction: The Discipline and Practice of Oualitatue Resegrch In N.

Denzin \& Y. Lincoln (Eds.), Strategies of Oualitative Inquiry (2nd ed., pp. 1.45). Thousand Oaks: Sage Publications.

Duhl, J. L. (1993, 2000). The Social Entrepreneurship of Change. Berkeley: Cogent Publishing.

Eriksson, C. 2000 . Learning and knowledge-production for public health: a review of approaches to evidencebased public health. Scandinavian Joumal of Public Health, 28, 298.308.

Evans, G., \& Newham, J. [1992]. The dictionary of world politics. a reference guide to concepts, ideas and institutions. London: Harvester Wheatsheaf.

Evans, R. G., Barer, M. L., \& Marmor, T. R. (1994). Why are some people healthy and others not? The determinants of health of populations. Berlin: Aldine de Gruyter.

Foucault, $\mathrm{M}_{n}(1976,1991)$. The birth of the clinic : an archaeology of medical perception. London: Routlege. GGDen Limburg. (1999). Gezondheidsenquete 1908 (rapportage gezondheidsenquête 1998): GGDen Limburg. GGD-Midden Limburg. (1998). Gezondheidsenquete Limburg, regionaal rapport Midden Limburg. Roemond: GGD.

GGD-NML. (2002). GGD Noord en Midden Limburg. Werk in uitwering. Venlo: GGDNML.

Giblss, G. R. (2002). Qualitative Data Analysis. Buckingham, Philadelphia: Open University Press.

Glanz, K., Lewis, F. M., \& Rimer, B. K. (1997). Health Behavior and Health Education. Theory, Research and Practice (2nd ed.). San Francisco: Jossey-Bass Publishers.

Glouberman, S., \& Millar, J. (2003). Evolution of the Determinants of Health, Health Policy, and Health Information Systems in Canada. American Journal of Public Health, 03131, 388.392.

Godfroy, A. I. A. (1993). Besturen in netwerken: van een instrumentale naar een interactieve theorie. In ]. F. M. Koppenjan, J. A. Bruijn de \& W. J. M. Kickert (Eds.), Netwerkmanagement in het openbaar bestutu: Over de mogelijkheden van overheidssturing in beleidsnetwerken. (pp. 31-50). Den Haag: Vuga Uitgeverij B.V.

Goodman, R. M. (1998). Principles and tools fot evaluating community-based prevention and health promotion programs. Journal of Public Health Management Practice, 4(2), 3747.

Cooskens, J., Kornalijnslijper, N., \& Veen, C. (1997). Een Gezonde Stad.....Zo doe je dat. Den Haag: VNG Uitgeverii.

Goumans, M. (1998). Innowations in a Fuzzy Domain. Healthy Cities and (Health) Pollcy Development in the Netherlands and the United Kingdom. University of Maastricht, Maastricht.

Goumans, M., \& Springett, J. (1997). From projects to policy: 'Healthy Cittes' as a mechanism for policy change for health? Health Promotion International, 124), 311-322.

Gray, B. (1989). Collaborating. Finding Common Ground for Multiparty Problems. (1st ed.). San Francisco: Jossey - Bass Publishers.

Green, L. W., Daniel, M., \& Novick, L. (2001). Partnerships and Coalitions for Community-Based Research. Public Health Reports, $110,20-31$.

Green, L. W., \& Kreuter, M. W. 1991,1999$)$. Health Promotion Planning An Educational and Enwironmental Approach. Mountain View: Mayfield Publishing Company.

Green, L. W., Poland, B. D., \& Rootman, 1. (2000). The Settings Approack to Health Promotion. In B. D. Poland, L. W. Green \& 1. Rootman (Eds.), Settings for Heath Promotion. Linking Theory and Practice. (pp. 1-35). London: Thousand Oaks.

Guba, E. G.y \& Lincoln, Y. S. (1989). Fourth generation evaluation. Thousand Oaks: SAGE publications, Inc. 
Hall, R. H., Ouinn, R. E. (1983). Organizational theory and public policy. Beverly Hill: Sage Publications. Hammersley, M., Gomm, R. (2000). Introduction. In R. Gomm, M. Hammersley \& P. Foster (Eds.), Case Study Method. Key Issues, Key Texts. London, Thousand Oaks, New Delhi: SAGE Publications Lid. Hancock, T. \& Minkler, M. (1997). Community Health Assessment or Healthy Community Assessment: Whose Community? Whose Health? Whose Assessment? In M. Minkler (Ed.), Community Organizing f Community Building for Health (pp. 139-156). New Jersey: Rutgers.

Hawe, P. King, L. Noort, M., Gifford, S. M., \& Lloyd, B. (1998). Working invisibly: health workers talk about capacity-building in health promotion. Health Promotion International, 1344, 285-295.

Hoejinakers, M. (2000a). Wie wragen we voor Hartshg in Midden Limburg? Een werkennend onderzoek onder veertien gemeenten. Universiteit Maastricht, Maastricht.

Hoeijmakers, M. (2000b]. Empowerment en Gezondheid. Unpublished manuscript, Maastricht. Hoeilmakers, M. (2001a). Gemeentelijke Gezondheidsinitiatieven in de Wijk Onderzoeksplan. Maastricht: Unversiteit Maastricht, capaciteitsgroep GVO.

Hoeilmakers, M. [2001b]. Limburgse gemeenten en hun gezondheidsbeleid. GGD Nieuws, 142], 9.13.

Hoeimakers, M. (2004). Local health policy-making. A matter of knowledge and mobilisation of the network? Paper presented at the 18th World Conference on Health Promotion \& Health Education, Melbourne, Australia.

Hogwood, B. W., \& Gunn, L. A. (1984). Policy Analysis for the Real World. Oxford: Oxtord University Press. Hoogerwerf, A. (1998). Beleid, processen en effecten. In A. Hoogerwerf \& M. Herweyer (Eds.), Overheldstbeleid: een Inleiding in de Beleidswetenschap (pp. 17-38). Alphen aan de Rijn: Samson.

Houben, T., van de Kar, A., \& Thijs, C. (1998). Kadenotitie Bevordering Volksgezondheid Midden Limburg. Roermond: GGD Midden Limburg.

Houwaart, E. S. (1991a). De hygiëmisten. Groningen: Historische Uitgeverij.

Houwaart, E. S. (1991b). De stad als patiënt. Medici over stad en gezondheid na 1700 . In E. Leeuw de [Ed.], Gezonde Steden. Lokale gezondheidsbevordering in theorie, politiek en praktijk (pp. 37-62). Assen, Maastricht: Van Gorcum.

Hufen, I. A. M. \& Ringeling, A. B. (1900). Beleidsnetwerken. Overheids, semi-overheids en particuliere organisaties. 's Gravenhage: VUGA.

Illich, I. (1076). Limits to medicine: medical nemesis, the expropriaton of health. Londom: Marion Boars.

Jansen, J., Schuit, A. I., \& Lucht van der, F. (20021. Thid woor gezond gedrag. Bevordering van gezond gedrag bij specifieke groeperi. Bilthoven: RIVM, Rijks linstituut woor Volksgezondheid en Milleu.

Jonkers-Kuiper, L. V. (1991). GVO: een herbezining op methoden. In G. ]. Kok \& L. V. Jonkers-Kuiper [Eds.), Lokate Gezondheidsinitiatieven (pp. 11-18). Assen: Van Gorcum.

Judd, J., Frankish, C. J., \& Moulton, G. (2001). Setting Standards in the evaluation of community-based health programmes, a unifying approach. Health Promotion International, 16!41, 367-380.

Karlsson, 0. (2001]. Critical Dialogue: Its Value and Meaning. Evaluation, 72), 211-227.

Kenis, P., \& 5chneider, V. (1991). Policy networks and policy analysis: scrutinizing a new analytical toolbox. In B. Marin \& R. Mayntz (Eds.), Policy Networks: Empirical Evidence and Theoretical Considerations. Frankfurt am Main: New York, Campus Wetswiew.

Kerkhoff, A. H. M. (1094). Honderd jaar gemeentelike geneeskundige en gezondheidsdiensten. Bussum: Dick Coutintio. 
Kickbusch, I. (2003). The Contribution of the World Health Organization to a New Public Health and Health Promotion. American Journal of Public Health; $93(3), 383-388$.

Kingdion, J. W. 11984, 1995). Agenda's, Alternatives, and Public Policies (2 ed.). Michigan: Harper Collins College Publishers.

Knoke, D. (1990). Political Networks. The structural Perspective. Minnesota: Cambridge University press. Knoke, D., \& Kuklinski, J. H. (1986). Network Analysis (3 ed.). London, New Deihi: Sage Publications, Inc, Koelen, M. A., Vaandrager, L., Colomér, C. [2001]. Health promotion research: dilemmas and challenges. Jounal Epidemiology Community Health, 55, 257-262.

Labonte, R. (1992). Heart health inequalities in Canada: Models, theory and planning. Health Promotion International, 721, 119\%127.

Lafferty, C. K., \& Mahomey, C. A. (2003). A Framework for Evaluating Comprehensive Community Initiatives. Health Promotion Practice, 4(1), 31-44.

Lallonde, M. [1974]. A New Perspective on the Health of Canadians. A Working Document Toronto: Government of Canada.

Laumann, E. O. \& Knoke, D. (1987). The Organizational State. Social Choice in National Policy. Wisconsin: The University of Wisconsin press.

Lemstra, W. C. (1996). Gemeentelijk Gezondheidsheleid. Beter op zijn Plaats. Advies van de Commissie Versterking Collectieve Preventie. Den Haag: Commissie Versterking Collectieve Preventie.

Lincoln, Y., \& Guba, E. G. (1985). Naturatistic Enquity, Beverly Hills: Sage.

Lindblom, C. E. (1959). The science of "muddling through". Indianapolis: The Bobbs-Merill comp.

Lupton, D. (1985). The Imperative of Health. Public Health and the Regulated Body. London: SAGE.

MacQueen, K. M., McLellan, E., Metzger, D. S., Kegeles, S., Strauss, R. P., Scotti, R., et al. (2001). What is Community? An Evidence-Based Definition for Participatory Public Health. American Journal of Public Health, 9l[12], 1929-1938.

Maso, I., \& Smaling, A. (1998). Kwalitatief onderzoek: praktijk en theorie. Amsterdam: Boom.

Mc Knight, J., \& Keretzmann, J. P. (1997). Mapping Community Capacity. In M. Minikler (Ed.), Community Organizing fo Community Building for Health (pp. 157-172). New Jersey: Rutgers.

McKeown, T. (1972). An interpretation of the rise in population in Europe. Population Studies(20), 345.382.

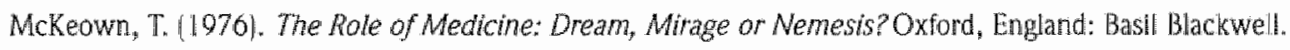

McQueen, D. V., \& Anderson, L. M. (2001). What counts as evidence: issues and debates. In I. Rootman, M. Goodstadt, B. Hyndman, D. McQueen, L. Potvin, 1. Springett \& E. Ziglio [Eds.], Evaluation in Health Promotion: Principles and Perspectives (pp. 63-81). Copenhagen: WHO (EURO).

Meijer, A. W. M. [1991). Plats en functies van de Nederlandse G.G.D.en. in E. de Leeuw (Ed.), Gezonde Steden. Lokale gezondheldsbevordering in theorie, politiek en prakilik (pF. 109.1321. Assen, Maastricht: Van Gorcum.

Meifer, A. W. M. (1994j. De GGD en zinn omgeving. In H. F. L. Garretsen, W. H. M. de Haes \& M. E. T. Schrijver (Eds.), Lokaal Gezondheidsbeleid (pp. 30-44). Houten; Bohn Stafleu Van Loghum.

Meijer, A. W. M., \& wan den Ouwelant, W. (1998). De GGD nader beschouwd. (onderzoeks rapport. Utrecht: Landelijke vereniging, voor GGD'en, Uniwersiteit Maastricht.

Merzel, C., \& D'Aflitti, ]. (2003). Reconsidering commurity-based health promotion: promise, performance, and potential. American Joumal of Public Health, 9314), 557-574.

Milio, N. (1986). Promoting Health through Public Policy. Ottawa: Canadian Public Health Association. 
Milio, N. (2001). Evaluation of health promotion policies. Tracking a moving target. in I. Rootman, $\wedge$ Goodstadt, B. Hyndman, D. V. Mcoueen, L. Potvin, ]. Springett \& E. Zigli [Eds.), Evaluation. health promotion. Principles and perspectives. (pp. 365-386). Copenhagen: WHO (EURO).

Ministerle van Volksgezondheid Welzin en Sport. (2000). Spelen op de Winst. Een visie op de opental gezondheidszorg (national document). Den Haag: Ministerie van Volksgezondheid, Welzin e: Sport. Platform Openbare Gezondheidszorg.

Ministerie van Volksgezondheid Welzijn en Sport, GGD Nederland, VNG, \& Ministerie van Binneniands Zaken. (2001\%. Nationaal Contract Openbare Gezondheidszorg (national document). Leiden Platform Openbare Gezondheidszorg.

Minkler, M. (Ed.). (1997). Community Organtzing and Community Butlding for Health. New Brunswick: Rutgers Unversity Press.

Minkler, M., \& Wallerstein, N. (1997). Improving Health through Community Organization and Community Building: a Health Education Perspective. In M. Minkler [Ed.), Community Onganizing \& Community Building for Health (pp. 30-52). New Yersey: Rutgers.

Mittelmark, M. B. 2001!. Investing in communities: principle, panacea or placebo? Tijdschrift woor Gezondheids. wetenschappen, 8, 532-534.

Morgan, L. M. [2001]. Community participation in health: perpetual allure, persistent challenge. Health Policy and Ptanning, $16(3), 221230$.

Netheriands School of Pubijc Health. (1999). Checklist Gezondheids Effect Screening (CES). Utrecht: NSPH. Nguyet, M., \& Otis, J. (2003). Evaluating the Fabreville Heart Health Program in Laval, Canada: a dialogue between two paradigms, positivism and constructivism. Health Promotion International, 18(2), 127.134.

Nutbeam, D. (1996). Health Outcomes and Health Promotion. Defining Success in Health Promotion. Health Promotion Joumal of Australia, 6(2), 58-60.

Nutbeam, D. [1998]. Evaluating health promotion - progress, problems and solutions. Health Promotion International, 13\{1\}, 27-44.

Nutbeam, D. (2003). Getting 'evidence' into public health policy, and 'policy' into public health research. Tijaschrift voor gezondheidswetenschappen $3 \mathrm{j}, 155 \times 158$.

Nutbeam, D. (2004 a). Engaging in the policy process: Improving policy outcomes for health. The politics, sclence and ant of tackling health inequalities in the UK. Paper presented at the 18th World Conference on Health Promotion \& Health Education, Melbourne Australia.

Nutbeam, D. $(2004 \mathrm{~b})$. Geting evidence into policy and practice to adress heaith inequalities. Health Promotion International, 1921, 137.140.

Nubeam. D., \& Harris, E. (1998, 2004). Theory in a nutshell. a practitioner's guide to commonly used theories and models in heath promotion. Sydney, Australia.

Peeperkom, M. 2004, 15 th March 20041). Kamer: zorg afrekenen op prestatles. De Walkskrant.

Pelikan, J. M. (2004). Health Promotion in Search of a Theory (of Social Systems) Paper presented at the 18th World Conference on Health Pronotion \& Health Education, Melboume, Alustralia.

Platform OGZ. [2001]. Sloidocument Platform Openbare Gezondheidszorg (national document]. Den Haag: Platform Openbare Gezondheidszorg.

Poiand, B. D., Green, L. W. \& Rootman, I. (Eds.). (2000). Settings for Health Fromotion. Linking Theory and Practice. London, New Delhi: Sage Publications, Inc.Thousand Oaks. 
Porte; D. (Ed.). (1994). The History of Public Health and the Modern State. Amsterdam - Atianta: GA Rodopi. Potvin, L. (2003). Toward a reflexive practice in health promotion: contributions of evaluation. Paper presented at the 4th Nordic Health Promotion Research Conference, Vasterăs, Sweden.

Potwin, L., Richard, L. [2001). Evaluating community health promotion programmes. In 1. Rootman, $M$. Goodstadt, B. Hyndman, D. V. McQueen, L. Potvin, J. Springett \& E. Ziglio (Eds.), Evaluation in health promotion. Principles and perspectives (Iirst ed., pp. 213240). Copenhagen: WHO [EURO).

Programmacommissie Sociaal-Economische Gezondheidsverschillen tweede tase. (2001). Sociaat-economische gezondheidsverschillen verkleinen. Eindrapportage en beleidsalabevelingen wan de programmacommissie SEGVII. Den Haag: Zorg Onderzoek Nederland.

Provan, K. G., \& Milward, H. B. (1995). A preliminary theory of interorganizational network effectiveness: A comparison. Administrative Science Ouarterly, 4911, 1-33.

Rifkin, S. B. (1986). Lessons from community participation in health programmes. Health Policy and Planning, $26(9), 240-249$.

Rissel, C. (1994). Empowerment: the Holy Grall of Health Promotion? Health Promotion International, 91), 39.45 .

Rissel, C., \& Bracht, N. (1999). Assessing Community Needs, Resources, and Readiness; Building on Strenghts. In N. Bracht (Ed.), Health Promotion at the Community Level. New Advances (second ed., pp. 59 . 82). Thousand Oaks Califormia: SAGE Publications Inc.

Robertson, A., \& Minkler, M. (1994). The new health promotion movement. A critical examination. Health Education Quarterly, $2 /(3), 295-312$.

Rogers, E. M. (1995). Diffusion of innovations (2nd ed.). New York: The free press.

Ronda, G. (2003). The Dutch Heart Health Community Intervention 'Hartslag Limburg:. University of Maastricht, Maastricht.

Rootman, I., Goodstadt, M., Potvin, L., Springett, I.,. (2001). A framework for health promotion evaluation. In I. Rootman, Goodstadt, M., Hyndman, B., McQueen, D., Potvin, L., Springett, I., Ziglio, E. (Ed.), Evaluation in health promotion: Principles and perspectives [pp. 7-43]. Copenhagen: WHO (EURO).

Rose, G. (1992). Strategies of prevention: the individual and the population. In M. Marmot \& P. Fllot (Eds.), Coronary heart disease epidemiology: From aetiology to public health. [pp. $311 \cdot 324 \%$ Oxford: Oxford University Press.

Rosen, G. (1958, 1993). A history of public health lexpanded edition ed.). Baltimore, London: The Johns Hopkinis University Press.

Ruland, E. (2000). Operationeel Scenario Update 1909. Maastricht: GGD-22L. Hartslag Limburg.

Rütten, A. (2001). Evaluating healthy public policies in community and regional context. In I. Rootman, $M$. Goodstadt, B. Hyndman, D. McQueen, L. Potvin, J. Springett \& E. Ziglio (Eds.), Evaluation in health promotion: Principles and perspectives (pp. 341-364). Copenhagen: WHO (EURO).

Rütten, A., Lengerke, T., Abel, T., Kannas, L., Luschen, G., Diax, J. A. R., et al. (2000). Policy, competence and participation: empirical evidence for a multilevel health promotion model. Health promotion International, 15(1), 35-47.

Rychetnik, L., \& Wise, M. (2004). Advocating evidence-based health promotion: reflections and a way forward. Health Promotion International, 1921, 247-257. 
Schram, D., Maas, I. A. M., Poos, M. J. I. C., \& Jansen, I. (2001). De bijdrage van leeistilfactoren aan de sterfte in Nederland. Tijdschrift voor Gezondheidswetenschappen, 79,211.216.

Schwand, T. A. (2001). Understanding Dialogue as Practice. Evaluation, 72), 228237.

Scot, J. [1991, 2000]. Sacial Network Analysis.s a handbook (second ed.l. London, New Delhi: Sage Publications, lnc

Seale, C. (1099). The Quality of Quatitative Research. London; Thousand Oaks, New Delhi: SAGE Publications.

Silverman; D. (2000). Dong Qualitative Research. A Practical Handbook Thousand Oaks: SAGE Publications.

Smedley, B. D., Syme, S. L. (2000). Promoting Health. Intervention Strategies from Social and Behaviorat Change. Washington, D.C.: National Academy Press.

Springett, J. (2001a). Appropriate approaches to the evaluation of health promotion. Critical Public Health, $1 / 21,139-151$.

Springett, J. (2001b). Participatory approaches to evaluation in health promation. In I. Rootman, Goodstadt, M., Hyndman, B., MoQueen, D., Potvin, L., Springeti, J., Ziglio, E. (Ed.), Evaluation in health promotion. Principles and perspectives (pp. 83-105): World Health Organisation.

Stake, E. R. (1995), The art of case study research. London, New Delhi, Thousand Oaks: Sage Publications, Inc.

Stone, D. $(1988,1997)$. Policy Paradox. The Art of Political Decision Making (2 ed.). New York, London: WW. Norton \& company.

Strauss, A., \& Corbin, J. [1998). Basics of Qualitative Research. Technics and Procedures for developing Grounded Theory (second edition ed.). London: Sage Publication.

Tannahil, A. (1985). What is Health Promotion? Health Education Journal, 44(4), 167-168.

Tannahil, A. (1988!. Health Promotion and Public Health: A. Model in Action. Community Medicine, 194), 48.51 .

ter Dam, J. (1097). Gezonde Stadsgezichten. Een Studie naar Gezondheidsverschillen en Stedelijk Gezondheids. beleid. Universiteit Utrecht, Utrecht.

Thompson, B., \& Kinne, S. (1999). Social Change Theory: Applications to Community Health. in N. Bracht [Ed.], Health Promotion at the Community Level (second ed., pp. 29.46). Thousand Oaks: SAGE Publlcations, Inc.

van Assema, P. (1993). The development, impiementation and evaluation of a community health project. University Maastricht, Maasstricht.

van de Kap, A. (1999). Gefaseerd plan project Gemeentelijke Gezondheidsinitiatieven in de Wijk. 198.4.52, ZON-MWI. Roermond: GGD-Midden Limburg.

van de Kar, A. (2004). Hart/versstag. Roermond: GGD Noord en Midden Limburg.

van der Plaat, M. (1995). Beyond thechniques: issues in evaluating for empowerment. Evaluation, /(1), 81-96. van Heffen, O., \& Kerkhoff, A. H. M. (1997). Beleidswering in de algemene gezondheidszorg 11 ed.). Assen: Van Gorcum.

van Oers, I. A. M. r. (2002). Health on course? The 2002 Dutch Public Health Status and Forecasts Report. Bilthoven: RIVM, Centre for Public Health Forecasting.

Varvasovszky, Z., \& Brugha, R. (2000). A stakeholder analysis. Heath Policy and Planning, 1513), 338-345.

Walker, R. (2000). Collaboration and allances: a review for VicHealth. Victoria, Australia: Victorian Health promotion foundation. 
Wallerstein, N. [1992]. Powerlessness, empowerment and healh: implications for health promotion programs: American Journal of Public Health, $631,197.205$.

Walt, G. [1994). Health Policy. an introduction to process and powen Johannesburg. Witwatersrand University Press.

Wasserman, S., \& Faust, K. (1994). Social Network Analysis. Methods and Applications: Cambridge University Press.

Weenig, W. H. (1991). Information diffusion and persuasion in communication networks: the weak and strong ties. Rijksuniversiteit Leiden, Leiden.

Weiss, C. (1998). Evaluation. Methods for studying Programs and Policies (2nd ed.). New Jersey: Prentice Hall.

Welsh, T., A., \& McGinn, N. (1997). Toward a Methodology of Stakeholder Analysis Educational Planning, $1 /(3), 20-45$

Whitelaw, S., Baxendale, A., Bryce, C., Machardy, L., Young, I., \& Winey, E. (2001), Seltings based health promotion: a review. Health Promotion International, 1644], $339-353$.

WHO. (1978). Declaration of Aima Aia. International Conference on Primary Health Care. Aima Ata, USSR: WHO.

WHO. (1981). Global strategy for health for all by the year 2000. Geneva: WHO.

WHO. (1984). Concepts and Principles for Health Promotion. Report of a working group. Geneva: WHO.

WHO. (1986). Ottawa 1986. Report of an International Conference on Health Promotion. Ottawa, Ontario, Canada: WHO.

WHO. [1988). Second International Conference on Health Promotion. Adelaide Recommendations on Healthy Public Policy. Adelaide Australia.

WHO. (1998). Health Promotion Glossary. Geneva: WHO.

Wijziging van de Wet Collectieve Preventie Volksgezondheid, (2002).

Yin, R. K. (1994). Case Study Research. Design and Methods (second ed. Vol. 5). London, new Dehli, Thousand Oaks: Sage Publications, Inc. 

a

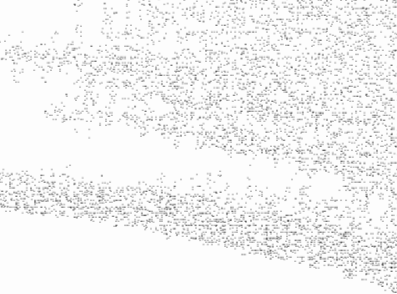
and

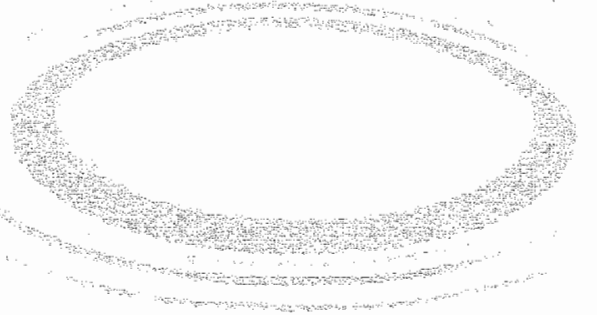

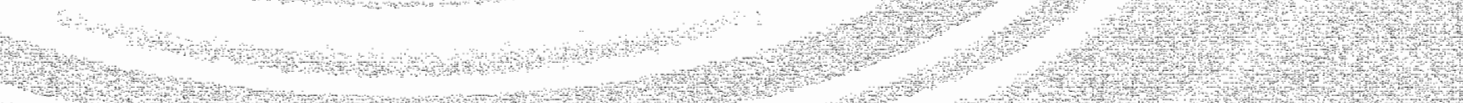

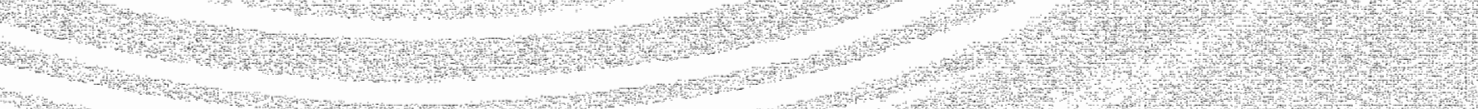
S. S. a)

Plt? + P. 1
$\mathrm{l}$ \begin{tabular}{ll}
\hline \\
\hline
\end{tabular}

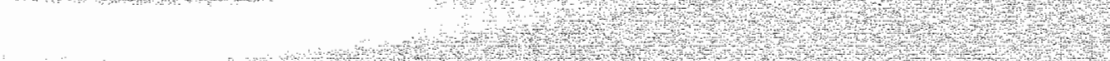




\section{SUMMARY}

This thesis reports on a study into development processes of local health policy in four municipalities in Central Limburg, the Netherlands. Heaith policy is used here in the sense of an integrated policy acknowledging the multi-dimensionality and multiple determinants of health. The aim of the study was to identify the factors and actors infiuencing these processes. It also examined the relation between the community-based Hartslag (Midden) Limburg cardiowascular prevention project and local health policy-making. The study focused on health promotion and network perspectives.

Since the 1990 s, public health care has regained attention among professional organisations and the government. A national promotion programme for public health (1996-2003) and an amendment to the law on collective prevention in public health aimed to increase the active role of local government in public health care. Since 2003 , the Ministry of Health, Weltare and Sports has made the development of local health policy a mandatory task of the municipal administrations. The public health services, being both executive bodies and policy advisors to the municipal administrations, were also confronted with these developments. The regional public health services (RPHS) in Central Limburg at the time happened to be developing new policy, in response to a high prevalence of cardiovascular diseases in the region. One of the policy intentions was to develop and implement a community-based project called Hartslag (Midden) Limburg, which was expected to support the involvement of community stakeholders in developing locall health policies.

Against this national and regional background, the first part of this thesis sets the stage for studying the development of local health policy. Chapter 1 outlines the history of public health and the reasons for undertaking the present study, and introduces the research questions, design and methods. We decided to use a multiple embedded case study and included the four municipalities that also participated in the Hartslag (Midden) Limburg project. The research methods consisted of semi-structured interviews with stakeholders (identified beforehand), participative observation in meetings at several levels and document analysis.

Chapter 2 provides a comprehensive theoretical framework, presents the evaluation instrument and explains the data collection and analysis process. Based on health promotion theory and practice, it moves from the rational, instrumental model of policy-making to an interactive and network perspective. The Theory of Streams developed by Kingdon \{1995) served as a guiding principle. The chapter also presents and describes stakeholder and network analyses, the tools that enabled us to operationalise the criteria used to evaluate the actors involved in local health policy-making. The evaluation instrument is a coherent set of criteria and indicators based on theoretical concepts from health promotion and policy sciences, and on the rationale behind 
local health policy. It addresses five themes: perspectives on local health policy, the municipal administration's role in policy-making, stakeholders, policy network and the regional public health service.

Part II of the thesis, comprising three chapters, is concerned with the community-based Hartslag (Midden) Lirnburg project (1999-2003). Chapter 3 presents the project, which aimed to prevent cardiovascular disease in the population and reduce relevant risk behaviour. The project was also intended as a catalyst for the development of local health policy in the four participating municipalities. To gain insight into the development of the project (as it was originally planned), we developed a monitoring instrument, which was applied at multiple levels: the project, the RPHS and the municipality.

Chapter 4 elaborates on theoretical concepts underpinning community projects, discusses the findings of the monitoring instrument and draws some conclusions regarding the efficacy of the project and the relation it was supposed to have with local health policy-making. The project encountered a number of difficulties, resulting in changes to the planned course. In the end, it did not produce the expected results, neither as a cardiovascular prevention project nor as a support for building local policy.

Within the same context, chapter 5 reflects on the evaluation of health promotion interventions like the Hartslag (Midden) Limburg project. Participative evaluation methods are probably more appropriate to evaluate community projects in general and fit in better with the underlying objectives of Hartslag (Midden) Limburg in particular:

In part III of the thesis, the focus is on local health policy-making. Chapter 6 further reflects on the operationalisation of the inquiry and its iterative character, and explains how the findings presented in the next chapters should be interpreted.

Chapter 7 elaborates on the findings of our analyses prior to the start of local health policymaking. It starts off with a presentation of the four cases (municipalities) included in our study: Weert, Roermond, Roggel \& Neer and Roerdalen. Next, it reports on the findings of the first stakeholder identification round and the interviews held in 2001 . We distinguished three stakeholder groups: civil servants and aldermen responsible for public health, local and regional professional organisations (e.g. home care organisation, social work agencies, general practitioners) and local non-professionals (e.g. interest groups like a platform for the disabled, volunteers). In general, professional health organisations were considered the most important stakeholders, while the community members (the non-professionals) were regarded as less important. The stakeholders were characterised in terms of their ideas on local health policy, interests in policymaking and the collaboration and relations with other stakehoiders. Analysis of the latter data showed remarkable differences in the networks at operational and policy level, in terms of density and the nature of the central actor. The operational networks were more integrated and general practitioners occupied a central position, while in the policy networks, it was the municipal authorities, which occupied the central position. The policy-making process at that point in time was still completely open.

Chapter 8 presents the findings obtained while the process of policy-making was developing. It starts by outlining four propositions on the involvement of the municipal authorities, the RPHS and other professional organisations and the community in the policy process. The 
chapter then goes on to present the results of a second interview round held at the end of 2002 , in which stakeholders in the four municipalities were interviewed about their involve. ment in policy-making and in which officers and aldermen responsible for public health in all fourteen municipalities in Central Limburg were interviewed about the progress of local health policy development in their municipality. The process of local health policy-making might be characterised as rather static in 2002 , which means that the majority of the stakeholders had not yet communicated about local health policy. The municipal administrations were mostly concerned with organising the policy process and getting it started. Health issues still had a low agenda status.

The chapter subsequently describes the stakeholder identification round held in 2003, which provided the starting point for the interviews held in the same year. The results of the retrospective interviews concerned the involvement of stakeholders in the policy development process, their interpretation of local health policy, the interests involved and their own impression of the influence they exerted on policy-making. At the same time, communication, collaboration and relations between stakeholders were mapped.

The data obtained from the interviews, from the participatory observation, document analysis, and the Hartslag (Midden) Limburg project were analysed using the evaluation instrument. The findings, including network graphs and indices, are described extensively for each individual case and compared across cases. We found that most stakeholders did participate in local health policy-making. Their involvement, however, was reactive and inspired by interest-based reasons. The networks were found to include more (regional) professional organisations than non-professionals, with the professionals having direct access to the municipal authorities. The latter occupied a central position in all networks, which was not in agreement with their facilitative rather than coordinative attitude and activities. Community groups and organisations were regarded as less important and occupied peripheral positions in the networks, unless they had an official status as members of advisory boards. The RPHS did not occupy a very central position in the networks, although it gradually became active as a policy advisor and coach, and provided epidemiological data in all cases. Local health policy did not appear to be of pivotal importance to stakeholders. Our data do not reveal a very clear health or sectoral perspective on health policy.

The final part of this thesis, comprising two chapters, links the theoretical framework to the findings. The discussion in chapter 9 starts by considering methodological quality issues. Despite some limitations, the strength of the present study was the application of a coherent evaluation instrument acknowledging the multi-dimensionality of policy processes and combining health promotion and network perspectives on policy-making. In addition, the use of stakeholder and network analyses in health promotion research was innovative and has provided new insights, most importantly concerning the abilities of stakeholders to monitor and contribute to the policy process.

The second part of the discussion reflects on the findings aboul: local health policy-making in relation to the items of the evaluative framework. It first elaborates on the involvement of the different actors in the policy process, in terms of the ideas and activities of the stakeholders, the relationships between these stakeholders (represented in network structures) and the position and role of policy entrepreneurs within the networks. It then reflects on the effective components 
of the policy-making processes: a positive and (pro-l active attitude on the part of the municipal administration towards community participation and intersectoral collaboration in public health practice and policy-making, an official status given to community groups, a consistent policy plan and political commitment expressed in a decisive attitude and visible involvement in the policy process.

Finally, chapter 10 draws conclusions in the light of the propositions and research questions and provides implications for practice and some suggestions for further research. As regards the involvement of stakeholders in the policy processes, we conclude that the municipal administration is a central actor in all networks but does not assume the role of a policy entrepreneur, that health professionals including the RPHS do not play a prominent role in policy-making and that local groups and organisations have difficulties in gaining access to the central actor to voice their interests. We have not been able to detect the presence of a policy entrepreneur in the processes studied, which has negative implications for the integrated character and coherence of the policy plans. We conclude that the following factors have a positive impact on policymaking: the active presence of a policy entrepreneur; involvement of professionals, the community and municipal departments other than those responsible for public health; political commitment; and concrete objectives, instruments, and time paths.

Regarding the Hartslag (Midden) Limburg project, we conclude that it did not contribute to the development of local health policy in the four municipalities.

Network analysis proved to be a valuable instrument in the evaluation of policy processes. Specifically, it has afforded insights into the positions of and the interactions and relations between the most important stakeholders, and their opportunities to influence the policy process. It is recommended that network effectiveness and the changeability of neiworks over time induced by interventions be further investigated. Finally, it is suggested that health education practice might benefit from diagnosing policy stakeholders. 


\section{SAMENVATTING}

Dit proefschrift beschrijft de vorming van lokaal gezondheidsbeleid in Midden Limburg waarbij gezondheidsbeleid wordt beschouwd als integraal beleid. Het doel van de studie was meer inzicht te verkrijgen in de factoren en actoren die van belang zijn bij het tot stand komen van lokaal gezondheidsbeleid. In vier gemeenten zijn het beleidsvormend proces en de uitkomsten geëvalueerd. Tevens werd de relatie tussen lokale gezondheidsbevordering en het maken van gezondheidsbeleid bekeken. De studie is verricht vanuit het perspectief van Health Promotion en de rol van netwerken.

Sinds de jaren negentig van de vorige eeuw staat de collectieve preventie en de openbare gezondheidszorg opnieuw in de belangstelling. Een nationaal stimuleringsprogramma openbare gezondheidszorg (OGZ) (1996-2003) en een aanpassing van de wet collectieve preventie (WCPV) in 2002 beoogden onder andere de lokale overheid te stimuleren een actievere rol te spelen in de OGZ. De aanpassing van de WCPV hield ondermeer in dat de gemeente per januari 2003 verplicht werd elke vier jaar een lokaal gezondheidsbeleid te ontwikkeien en vast te stellen. GGD-en, als beleidsadviseur en uitvoerende dienst van de gemeente, werden ook geconfronteerd met deze veranderingen. Los van deze ontwikkeling formuleerde de GGD in Midden-Limburg in dezelfde periode specifieke beleidsvoornemens naar aanleiding van de hoge prevalentie van hart- en vaatziekten en de factoren die bijdragen aan het ontstaan daarvan in de regio. Eén daarvan was de ontwikkeling en implementatie van het community-based project Hartslag (Midden) Limburg. Het opzetten van een community project zou echter heel goed als katalysator kunnen werken voor de totstandkoming van locaal gezondheidsbeleid met actieve participatie van de community.

Tegen bovengeschetste nationale en regionale achtergrond beschrijft hoofdstuk $l$ van het proefschrift de onderzoeksvragen en globale opzet. We kozen een multiple embedded case onderzoeksdesign om de volgende vraag te onderzoeken: hoe wordt lokaal gezondheidsbeleid gevormd en hoe dragen lokale gezondheidsinitiatieven die ontwikkeld worden door Hartslag (Midden) Limburg bil aan de vorming van dit beleid. De studie werd uitgevoerd in vier cases (gemeenten]. Deze vier waren gelijk aan de gemeenten die deelnamen aan Hartslag (Midden) Limburg. Er werden kwalitatieve onderzoeksmethoden ingezet: semi-gesctructureerde interviews met vooraf geïdentificeerde stakeholders, participatieve observatie in vergaderingen en bijeenkomsten op verschillende niveau's en analyse van documenten.

Hoofdstuk 2 presenteert het theoretisch kader van het onderzoek en het evaluatieinstrument. Ook wordt verder ingegaan op de verzameling en analyse van de data. Het theoretisch kader wordt gevormd door concepten en perspectieven uit health promotion en beleidswetenschappen. Startend met de theorie en praktijk van health promotion wordt een 
interactief- en netwerkperspectief op beleidsprocessen ontwikkeld. De 'Stromentheorie' van Kingdon (1995) is leidraad in dit onderzoek. Deze theorie gaat er van uit dat beleid tot stand komt als er een erkend probleem is, een uitvoerbare, acceptabele oplossing voor handen is en de tijd er rijp voor is. De aanwezigheid en activiteiten van een beleidsentrepreneur verhoogt de kans op het tot stand komen van beleid. Het evaluatie-instrument woor deze studie is ontwikkeld op basis van het theoretisch kader en de rationale achter lokaal gezondheidsbeleid. Het is een samenhangende verzameling van evaluatie-criteria en indicatoren gericht op vijf thema's: perspectief op lokaal gezondheidsbeleid, de rol van de gemeente in het beleidsproces, stakeholders, het beleidsnetwerk en de GGD. Om (een deel van) de evaluatie criteria in te praktijk te kunnen vaststellen hebben we gebruik gemaakt van stakeholder- en netwerkanalyse.

Deel II van dit proefschrift beschrijft en bediscussieert het community-based project Hartslag (Midden) Limburg. Hoofdstuk 3 gaat in op de doelstellingen en opzet van het project. Hartslag (Midden) Limburg (1999-2003) beoogde hart- en vaatziekten te voorkomen en risicogedrag dat hiermee samenhangt te reduceren. Het project had tevens tot doel een katalysator te zijn voor de vorming wan lokaal gezondheidsbeleid in de de vier gemeenten waar het geïmplementeerd werd. Om de ontwikkeling van het project zoals het gepland was te volgen en inzicht te verwerven in de werking van zogenaamde principes van community projecten (0.a bevolkingsparticipatie en intersectorale samenwerking) is een monitor ontwikkeld. Deze monitor was gericht op meerdere niveau's: het project, de GGD en de gemeente.

Hoofdstuk 4 definieert community projecten, presenteert de resultaten van Hartslag (Midden) Limburg en trekt op basis hiervan enkele conclusies. Community projecten worden gekenmerkt door hun grote omvang (in termen van methoden, activiteiten en partners), complexiteit, participatie van de bevolking, een lange tijdsduur en flexibiliteit. Hartslag (Midden) Limburg was actief in vier communities, gemeenten. Gedurende de looptijd van het project waren er een aantal problemen, o.a een fusie van de GGD en personeelsmatig. Dit had tot gevolg dat de koers van het project geleidelijk afweek van de kernconcepten van community projecten. Een relatie met het beleidsvormend proces in de deelnemende gemeenten is niet tot stand gekomen.

Aan de hand van een beschrijving van het preventie en health promotion paradigma en respectievelijk positivisme en constructivisme als uitgangspunt voor het genereren van kennis reflecteert hoofdstuk 5 op de evaluatie van community projecten zoals Hartslag (Midden) Limburg. Een meer participatieve evaluatiemethode past wellicht beter bij community projecten in het algemeen en bij de achterliggende doelstellingen van Hartslag (Midden) Limburg in het bijzonder.

Deel III bespreekt de resultaten met betrekking tot de beleidsvorming van lokaal gezondheidsbeleid. Als gevolg van de ongunstige ontwikkeling van Hartslag (Midden) Limburg heeft het onderzoek verder ingezoomd op het beleidsvormende proces en de evaluatie van dit proces. Hoofdstuk 6 reflecteert daarom nogmaals op de operationalisatie en het iteratieve karakter ervan.

Hoofdstuk 7 start met een presentatie van de vier cases (gemeenten): Weert, Roermond, Roggel en Neer, en Roerdalen. De belangrijkste kenmerken, de reden voor inclusie in deze studie en hun aanpak van de vorming van lokaal gezondheidsbeleid worden besproken. Dit hoofdstuk beschrijft verder de situatie in deze gemeenten vórdat de beleidsvorming daadwerkelijk van start ging. Bij de identificatie van belanghebbenden bij het tot stand komen van lokaal 
gezondheidsbeleid onderscheidden we drie groepen: ambtenaren en portefeuillehouders volksgezondheid in de gemeenten, lokale en regionale professionals (0.a. de Thuiszorg, Riagg, welzijnswerk, huisarts) en non-professionals (belangenbehartigingsorganisaties zoals een gehandicaptenplatform en vrijwilligers). In het algemeen werden de professionals aangemerkt als belangrijkste stakeholders bij het tot stand komen van lokaal gezondheidsbeleid en de non professionals als minst belangrijk. Van de stakeholders werden een aantal kenmerken in kaart gebracht, onder andere: de ideeën over lokaal gezondheidsbeleid, de belangen bij de beleidsworming, de invloedsverwachting of ervaring, de onderlinge samenwerking en relaties. Analyse van de data laat opmerkelijke verschillen zien tussen de netwerken op uitvoerend-en beleidsniveau. De netwerken op uitvoerend niveau vertoonden een hogere cohesie en de centrale actor was de huisarts. De beleidsnetwerken daarentegen waren minder geïntegreerd en de centrale positie werd ingenomen door de gemeente. De gemeente zag de vorming van lokaal gezondheidsbeleid vooral als een verplichting die van hogerhand werd opgelegd. Ze voelden tevens gebrek aan expertise en menskracht. De visie op de gemeentelijke rol en die van de GGD verschilde tussen de twee grote en de kleine gemeenten. De positie van de GGD in de beleidsnetwerken verschilde van tamelijk centraal in de kleine gemeenten en natwelijks centraal in de grote gemeenten.

Hoofdstuk 8 presenteert allereerst onze verwachtingen ten aanzien van de betrokkenheid van de gemeente, de GGD en andere professionals, en de bevolking in het beleidsproces. Vervolgens beschrijft het de resultaten die verkregen zijn tijdens de beleidsvorming. In 2002 vonden per telefoon semi-gestructureerde interviews plaats, met de eerder geïdentificeerde stakeholders in de vier cases en met portefeuillehouders en ambtenaren volksgezondheid in alle veertien middenlimburgse gemeenten. De interviews met stakeholders gingen over hum betrokkenheid in het beleidsproces op dat moment; de interviews met portefeuillehouders en ambtenaren over de voortgang van de vorming van lokaal gezondheidsbeleid in hun gemeente. Het beleidsvormend proces in 2002 is te typeren als statisch. Het merendeel van de stakeholders was nog niet met elkaar in gesprek over lokaal gezondheidsbeleid. De gemeente was voornamelijk bezig met de organisatie van een aantal randvoorwaarden om het beleidsproces vlot te trekken. Gezondheid werd een gemiddelde tot lage agendastatus toegekend. Het hoofdstuk beschrijft vervolgens de stakeholderidentificatie die plaats vond als voorbereiding op de derde interviewronde (2003). Deze interviews keken terug op de betrokkenheid van de stakeholders in het beleidsproces, hun belangen, inwloedservaring en de interpretatie van lokaal gezondheidsbeleid. Op datzelfde moment werden de interacties en relaties van de betrokken stakeholders in kaart gebracht. De evaluatie-criteria uit het theoretisch kader werden tenslotte toegepast op de verschillende databronnen: de interviews, participatieve observatie, de analyse van documenten en de resultaten van Hartslag (Midden) Limburg. De bevindingen, inclusief de netwerkgrafieken en indexciffers, zijn in dit hoofdstuk eerst uitgebreid per gemeente beschreven. Vervolgens zijn ze voor de vier gemeenten vergeleken. De meeste stakeholders hebben daadwerkelijk deelgenomen aan de beleidsvorming. Hun betrokkenheid was gebaseerd op specifieke belangen en voornamelijk reactief. De netwerken bevatten meer (regionale) professionele organisaties die een directe link hadden met de gemeente, dan lokalle non professionals. De gemeente had een centrale positie in alle netwerken. De verwachting dat een centrale actor ook een actieve coördinerende rol speelt 
C. 3 Hoth
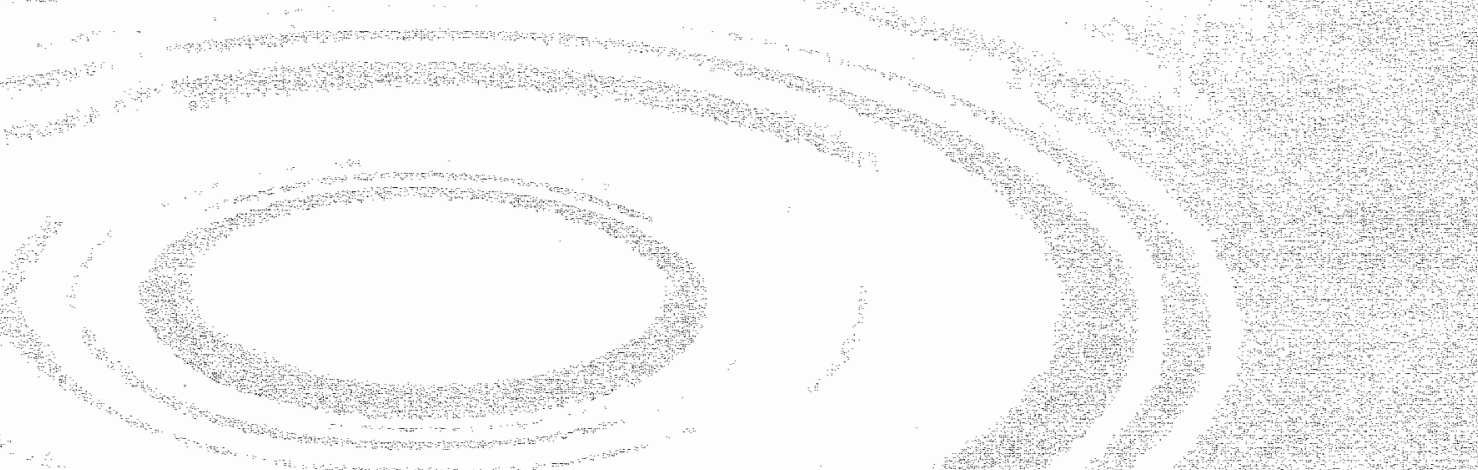

W.

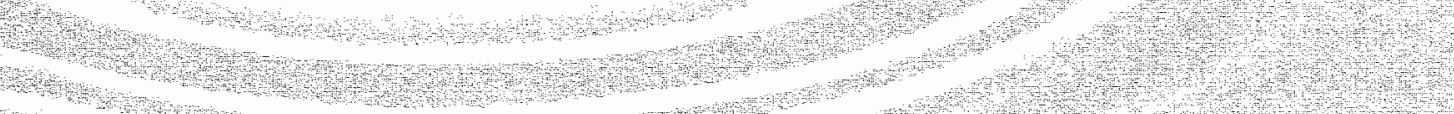

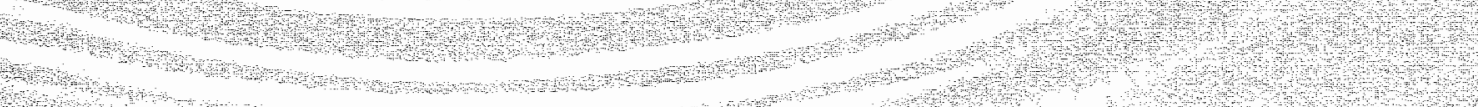
W.

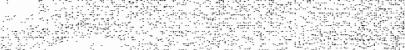

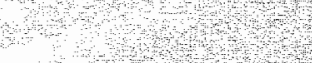
I (4) 


\section{APPENDICES}

\section{APPENDIX 1.A ITEM LIST FOR 2001 INTERVIEWS}

\section{Introduction}

- The purpose of this interview is to gather information about the different organisations and groups that have an interest in the development and adoption of local health policy in your municipality. The interview is part of the research project you are already familiar with.

- I will mostly ask open questions. What I would like you to do is express your ideas, opinions and experience, obviously in your capacity as [job] at [organisation, group, etc.]. There are no right or wrong answers.

- With your permission I would like to tape our conversation, after which it will be processed anonymously. The interview will take 30 to 40 minutes.

- Do you have any questions before we start?

\section{Questions}

1. Municipal authorities have the intention, and will indeed be obliged by the Minister of Health, Welfare and Sports in 2003, to develop local health policy. There are different views on what makes up such a policy. First I would like to ask you to tell me what you would mean by local health policy.

As regatds your own organisation, in which field/ part of health policy are you active? What are the objectives, tasks and activities of the organisation? /For the alderman responsible for public health:y When and how do you become involved in the policy development process?

2. In earlier contacts you have said that the organisation you work for has an interest in the development of local health policy. Could you describe this interest?

Do you consider your organisation to be an important actor in the development of local health policy? What influence do you expect your organisation to exert on the development of local health policy? Do you feel able to help decide the outcomes of the policy process?

3. Let's take a look at some important events in health care and public health, such as making the allocation of care services and facilities for the disabled the responsibility of the municipal authorities, and framing regional vision documents on public mental health care, care for the elderly, youth care and other subjects. What was your experience in terms of influencing and defining the above policies? 
4. With what organisations do you collaborate (see the list of names of identified stakeholders). Could you tell me about this collaboration?

What organisations, groups and individuals do you consult? With what purpose and frequency do these consultations take place, and in what form? Can you identify organisations on which you depend to provide you with the necessary resources for the functioning of your own organisation?

\section{At the end}

- Would you like to add anything to the interview, for instance subjects that were not or insufficiently discussed but that you feel are important to you as regards local health policy?

- Do you have an annual report or mission statement of your organisation that you could let me have?

- would like to thank you for your contribution to our inquiry.

\section{Categories}

Local health policy: interpretation, defining

Tasks and activities in the health field

Interest in local health policy: defining, reasons, dimensions

Influence: degree, defining outcomes, expectations

Involvement in earlier policy-making: regional/local level, role, perceived degree of influence Collaboration: involvement, formal/informal, level of collaboration

Relations: dependencies and interdependencies, formal authority

\section{APPENDIX 1.B ITEM LIST FOR 2003 INTERVIEWS}

\section{Introduction}

- In the previous year, municipal authorities have been developing a local health policy. Perhaps your organisation has been involved in the policy-making process in one or more municipalities. Perhaps you have even been discussing the subject with other organisations outside the formal meetings. In this interview, I would like to look back upon the policy-making process in [municipality] and tell me about your experiences.

- I will mostly ask open questions. What I would like you to do is express your ideas, opinions and experience, obviously in your capacity as [job] at lorganisation, group, etc.]. There are no right or wrong answers.

- At the end of the interview I would like to fill in a form on the relations you maintain with other organisations, groups and individuals regarding local health policy.

- With your permission 1 would like to tape our conversation, after which it will be processed anonymously. The interview will take 30 to 40 minutes.

- Do you have any questions before we start? 


\section{Questions}

1. Could you tell me about your involvement in the development of local health policy (in [municipality])?

Why did you participate? How did you feel involved? In what way were you involved? At what stage in the process were you active or passive? What role did you take in the process? What was your concrete contribution? Could you define the interest your organisation has in local health policy development?

[For the public health officer and alderman./ What is your specific contribution or role in the policy-making process and what interaction takes place between you and the public health officer/alderman.

2. What influence has your organisation been able to exert on the local health policy-making process in [municipality]?

Could you describe your contribution in terms of the influence exerted on the policy process; did your contribution lead to the desired outcomes in terms of the prioritising of problems and solutions or other aspects? Why are you able or unable to exert influence on local health policy-making?

Do you consider your organisation to be an important actor in local health policy-making, compared to others participating in the process? Who is / who else is? Have there been changes in this pattern during the policy process?

3. A few years ago, local health policy was a new term. In the meantime a lot has been said about this policy domain and we are getting used to it. What is currently your interpretation of local health policy?

With what ideas do you associate local health policy? Have your ideas regarding local health policy changed?

If you look at the policy process and the content of the local health policy memorandum, what components should definitely be present for you to be satisfied?

4. Did the municipal authorities or others enable you to promote your interests? In what way did this happen?

Are your organisational interests reflected in the local health policy as it was finally formulated in the memorandum?

5. Since January of this year, developing a local health policy has become obligatory. This has brought 'health' to the attention of the municipal authorities and others.

How does health rank on the agenda of your organisation? Why is this high/low? Did the activities undertaken to develop local heaith policy permanently change the importance. of the subject?

6. Can I invite you to fill in this form with me? (see below).

\section{At the end}

- Would you like to add anything to the interview, for instance subjects that were not or insufficiently discussed but that you feel are important to you as regards local health policy?

- I would like to thank you for your contribution to the inquiry. 


\section{Categories}

Local health policy: interpretation (change), components ensuring 'good' content/process Interest in local health policy: defining, reasons for involvement, interests reflected in memorandum. Influence: perceived degree of influence (change), defining outcomes, important actor Involvement in local health policy-making: participation, role, tnitiative, contribution Health on the agenda: when, why

Interactions and relations: see form below

\section{APPENDIX 1.C FORM - RELATIONS WITH OTHERS IN THE NETWORK}

Below is a list of organisations, groups and individuals who have been identified as stakeholders in the development of local health policy. We would like to know with which of the actors on the list you have collaborated in the development of local health policy and at the operationail level. If any of the organisations that you collaborated with are not on the list, please feel free to add them. We will fill in the form together by addressing six points, namely: (please read this form carefully)

\section{Communication and consultation}

Did you or other employees in the organisation communicate or consult on local health policy with any of the organisations, groups or individuals mentioned on the list? These interactions may have been with several organisations at the same time or in one-on-one situations.

\section{Informal contacts}

Do you or other employees in the organisation employ informal contacts to discuss local health policy with any of the organisations, groups or individuals mentioned on the list? (Contacts may relate to obtaining additional information, coordination or conflict management?

\section{Expertise}

The development (and later on, implementation) of local health policy requires specific expertise. Do you have and contribute such expertise to one or more of the organisations, groups and individuals mentioned on the list? Or are you the one receiving expertise from others? Or perhaps both?

\section{Involvement}

Is your organisation involved with one or more organisations, groups or individuals mentioned on the list? The reason may be that (1) you are the one providing resources (financial, material), commissioning tasks to be implemented or functioning as the principal partner in a project, or (2) your organisation receives resources, implements commissioned tasks or is a co-partner in a joint project. Or both may apply.

\section{Strategic collaboration}

With which of the organisations, groups and individuals mentioned on the list do you consult when important decisions have to be taken? In other words with whom do you establish a joint strategy? 


\section{Entrepreneurship}

Did any of the organisations, groups or individuals mentioned on the list take a very active role in the policy-making process? (E.g. by actively linking problems to solutions at the right moment)

\section{EXAMPLE}

\section{Organisation}

1 Home Care organisation

2 General Practitioner

3 Platform for the disabied

4 Welfare Service

5. Municipal Administration

6 Neighbourhood Council:

7 Regional Public Health Service

8 Nursing Home

9 etc

10

11

12

13

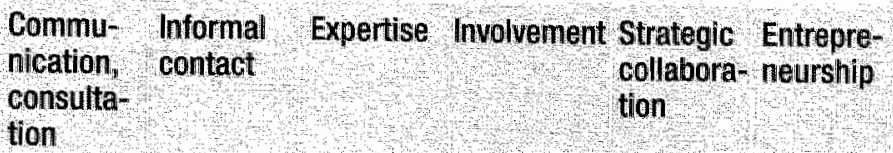

tion

* (S) Sender (R) Receiver

$\begin{array}{llll}\mathrm{S}^{*} & \mathrm{R}^{*} & \mathrm{~S}^{*} & \mathrm{R}^{*} \\ \mathrm{~S} & \mathrm{R} & \mathrm{S} & \mathrm{R} \\ \mathrm{S} & \mathrm{R} & \mathrm{S} & \mathrm{R} \\ \mathrm{S} & \mathrm{R} & \mathrm{S} & \mathrm{R} \\ \mathrm{S} & \mathrm{B} & \mathrm{S} & \mathrm{R} \\ \mathrm{S} & \mathrm{B} & \mathrm{S} & \mathrm{R} \\ \mathrm{S} & \mathrm{R} & \mathrm{S} & \mathrm{B} \\ \mathrm{S} & & & \\ \mathrm{S} & \mathrm{R} & \mathrm{S} & \mathrm{R} \\ \mathrm{S} & \mathrm{R} & \mathrm{S} & \mathrm{R} \\ \mathrm{S} & \mathrm{R} & \mathrm{S} & \mathrm{R} \\ \mathrm{S} & \mathrm{R} & \mathrm{S} & \mathrm{B} \\ \mathrm{S} & \mathrm{R} & \mathrm{S} & \mathrm{B} \\ \mathrm{S} & \mathrm{R} & \mathrm{S} & \mathrm{R}\end{array}$

Health problems are complex and the promotion of health occurs in many different ways and places. When making choices and decisions about complex issues (in our case local health policyl in networks the opinion and ideas of the other actors involved in the network have to be taken into account. Could you define what organisations, groups and individuals mentioned on the list have been most clearly taken into account in the development of local health policy? In other words, what organisations were most influential?

Please indicate three to five influential organisations, groups or individuals from the list by noting the number under which they appear on the list. 


\section{APPENDIX 2 CheCKLIST FOUR MUNICIPALITIES}

\section{Criteria}

1 Local health policy is integrated policy
2 Local health policy is a translation of the perspective and choices regarding health made by the municipal administration.
3 Local health policy is based on epidemiological considerations.
Indicator

1.1 Other departments than the health department within the local governmental organisation are involved, e.g., education, social affairs and housing departments.

1.2 Actors (organisations, groups, individuals) outside the local government are involved in the policy-makjng process. e.g., social workers, health professionals and interest groups.

1.3 The local government sets objectives for all four components of health policy referred to in section 2.2 (health protection, prevention of disease, health promotion and health care).

2.1 Local health policy is informed by data emanating from the municipal level, but not necessarily from epidemiological research alone.

2.2 Local health policy is in line with the municipal development plan. In other words, the mission statement of the current administration and the approach to health matters are compatible.

2.3 Local health policy reflects a particular perspective on health: the health or sectoral perspective.

3.1 Health problems are prioritised according to national or regional epidemiological reports on the health status of the population.

\section{Check list Weert}

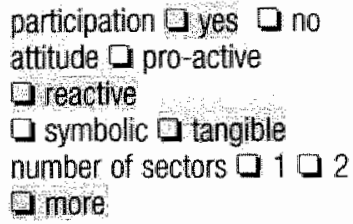

number of fields $\square 19203 \square 4$

\author{
completely \\ $\square$ somewhat health persp. $\square$ no \\ a not at all
}

$\square$ yes $\square$ somewhat $\square$ no in addition, priorities from interactive sessions 


\section{Check list Roermond \\ participation Dyes D no attitude $\square$ pro-active \\ 0 reactive \\ 0 symbolic $\square$ tangible \\ number of sectors $\square 102$ \\ $\square$ more \\ participation $\square$ yes $\square$ no \\ attitude $\square$ pro-active \\ D reactive \\ 9 symbolic $\square$ tangible \\ number of actors $\square<3$ \\ number of fields $\square 102 \square 3 \square 4$ (4 when including WCPV tasks)}

\section{Check list Roggel\&Neer}

participation $\square$ yes $\square$ no

attitude $\square$ pro-active

$\square$ reactive

$\square$ symbolic $\square$ tangible

number of sectors $\square 1 \square 2$

a more

participation $\square$ yes $\square$ no

attitude $\square$ pro-active

$\square$ reactive

$\square$ symbolic $\square$ tangible

number of actors $\square<3 \quad \square \geq 3$

number of fields $\square 1 \square 2 \square 3 \square 4$ number of fields $\square 102 \square 304$

\section{Check list Roerdalen}

participation $\square$ yes $\square$ no

attitude 0 pro-active

Q reactive

$\checkmark$ symbolic $\square$ tangible

number of sectors $\square 192$

a more

participation $\square$ yes 6 no

attitude $\square$ pro-active

D reactive

$\exists$ symbolic $\square$ tangible

number of actors $\square<3 \quad \square \geq 3$
9 yes $\square$ no

Gyes a no
Gyes a no

Depi 1 epi plus $\square$ other

Dyes 9 no

$\checkmark$ complately health persp.

G somewhat sectoral persp.

$\square$ no $\square$ not at all
Gyes I no

$\square$ epi $\square$ epi plus $\square$ other

$\square$ yes $\square$ no

Completeiy a somewhat Ino $\square$ not at all
1 somewhat health persp.

9 no $I$ not at ail $\square$ yes $\square$ somewhat $\square$ no

in addition, priorities from

interactive sessions $\square$ yes somewhat 1 no

a yes 9 no heavy emphasis on priorities

from interactive sessions 
Criteria

4. Local health policy improves the situation of individual patients or clients, target groups or the population as a whole:

5 Municipal administration bears main responsibility for the development of local health policy.

6 Municipal administration provides (financial) resources to achieve the objectives.
Indicator

4.1 Policy consists of objectives instruments, resources and facilities. and a set of coherent

\section{Check list Weert}

$\square$ concrete $\square$ in abstracto

$\square$ no

Dyes Do

\subsection{Municipal administration facilitates the policy process.} It creates favourable conditions in a practical sense.

5.2 Municipal administration creates necessary opportunities for stakeholders to collaborate.

6.1 Resources allocated to municipal authorities because they are in the best position to solve the problem.

6.2 Resources allocated to one of the stakeholders because he/she is in the best position to solve the problem.

6.3 Resources allocated to municipal authorities, even though another party is in the best position to solve the problem.

6.4 Resources allocated to another party, even though the munici authorities are in the best position to solve the problem

7 Health is a political issue.
D-

budget available but distribution is not clear

$\square$ yes $\square$ no
7.1 The long-term policy plan of the local administration ("college programma") mentions health explicitly.

7.2 Apart from the obligation to develop local health policy. health appears as an item on the political agenda.

on the agenda

$\square$ incidentally $\square$ permanently 


\section{Check list Roermond}

$\square$ concrete $\square$ in abstracto

a no

- broad policy directions

$\square$ yes $\square$ no

$\square$ yes $\square$ no

$\square+$

$\square+$

D-

$\square-$

$\square$ yes $]$ no

on the agenda

$\square$ incidentally $\square$ permanently

\section{Check list Roggel\&Neer}

$\square$ concrete $\square$ in alsstracto

$\square$ no

- policy propositions

- establishment of a steering committee

Dyes ano

Gyes $\square$ no

still Intentional, see 4.1

$\square+$

$\square+$

D-

a-

Dyes $\square$ no

on the agenda

$\square$ hoidentally $\square$ permanently
Qyes $\square$ no

$\square$ yes $\square$ no

$\square+$

Dyes 1 no

Check list Roerdalen

$\square$ concrete $\square$ in abstracto

a no

$\square+$

a-

$\square-$

on the agenida

$\square$ incidentally 9 permaniently 


\section{Criteria}

8 The development of local health policy requires political commitment.
9 The development of local health policy requires enthusiasm on the parts of officials.
10 Other departments within the municipal organisation review their policy decisions in terms of the impact on health.

11 Local health policy is based on the interests of stakeholders.

12 The better the organisational interests of stakeholders are served, the stronger their involvement.

13 Local health policy is based on existing strategies of stakeholders to solve current health problems.
Indicator

8.1 The character of the political parties represented in the local administration reflects their point of view on health.

8.2 The politician responsible for $\square$ yes $\square$ no public health comes from a political party with wellformulated ideas on health issues.

8.3 If so (8.2), this politician has $\square$ yes 7 no made an issue of health in the coalescing negotiations after elections in 2002.

9.1 Public health officers take a broad view of their policymaking task.

9.2 Public health officers do not work in isolation but have an! internal and/or external reference group.

10:1 Other departments than the health department mention health in their policies.

11.1 Stakeholders give information.

11.2The information given by stakeholders is reflected in the policy.

12.1 A diwision of tasks among stakeholders in relation to the described objectives is included in the memorandum.

13.1 Stakeholders (in particular professionals) consider the policy process an occasion to reformulate and propose their favourite solutions as policy proposals.

13.2 Stakeholders perceive their influence as positive.

\section{Check list Weert}

$\square$ yes $\square$ no

not observable in long range plan

$\square$ formal view $\square$ plus

$D$ solely 1 internal

Dexternal
Qyes $\square$ no

Wyes ano

J yes 9 no

intention to form working groups
Myes $\square$ somehow $\square$ no especially for professionals 
Check list Roermond

$\square$ yes $\square$ no

$\square$ yes $\square$ no alderman changed after half a year in the town council

$\square$ yes $\square$ no not observable in long range plan

$\square$ formal view $\square$ plus

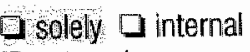

axternal

\section{Check list Roggel\&Neer}

0 yes no

$\square$ yes $\square$ no

$\square$ yes $\square$ no

not observable in long range plan

\section{Check list Roerdalen}

$\square$ yes $\square$ no

$\square$ yes $\square$ no

$\square$ yes 0 no

not observable in long range plan $\square$ formal view $\square$ plus

$\square$ solely $\square$ internal

$\square$ external $\square$ formal view $\square$ plus

Q solely $\square$ internal Gexternal temporarily $\square$ yes $\square$ no

$\square$ yes $\square$ no objectively: yes subjectively: opinions of stakeholders differ

\section{ayes Đno}

$\square$ yes $\square$ somehow no for professionals and non professionals

\section{Wyes $\square$ no}

$\square$ yes $\square$ no objectively yes, subjective experience is quite negative

$\square$ yes $\square$ no

an intermunicipal coordinative committee will be established to formulate and execute the policy plan

$\square$ yes घ somehow $\square$ no

๑yes 凹 somehow $\square$ no yes no

$\square$ yes $\square$ no

$\square$ yes $\square$ no some feel input is not recognised 


\section{Criteria}

14 The structure of the policy network at the municipal level influences the development of local health policy.

15 One of the stakeholders adopts an entrepreneurial position and attitude.

16 The RPHS is a policy entrepreneur.

17 Local health initiatives developed and managed by the RPHS" "Hartslag (Midden) Limburg' project create a favourable climate allowing municipal authorities to base their objectives and interventions on a community-based approach.
Indicator

14. 1 Central actors recognise their central role in the process.

14.2Peripheral actors recognise they have a minor role in the process.

15.1 Stakehalders identify one or more of them as a policy entrepreneur.

15.2This stakehoidder/entrepreneur takes a central position in the policy network.

16.1 Stakeholders identify the RPHS as a policy entrepreneur.

16.2 The RPHS considers the entrepreneurial rolle appropriate for its participation in local health policy-making.

17.1 Local health initiatives are implemented in consultation with municipal authorities and public health officers.

\section{Check list Weert}

$\square$ yes $\square$ na

$\square$ yes $\square$ no

$\square$ yes $\square$ no

$50 \%$ identify the mun. adm

$\square$ yes $\square$ no

$\square$ yes $\square$ no

$\square$ pro-active $\square$ reactive

RPHS considered as executive body and formal advisor

$1]$ information

$\square$ facilitation

budget available, no activities

$\square$ active role

Dother actors 


\section{Check list Roermond}

$\square$ yes $\square$ no

Dyes a no

opinions vary which actors are most important

Dyes Dno

ayes $\square$ no

\section{$\square$ yes $\square$ no}

$\square$ pro-active Dreactive practical task in policy-making process

\section{D information}

facilitation

finacement of number of activities

$\square$ active role

$\square$ other actors

\section{Check list Roggel\&Neer}

$\square$ yes $\square$ no

$\square$ yes $\square$ no

stakeholders find all participants equally important

ayes ano a few refer to the municipality

$\square$ yes $\square$ no

$\square$ yes 9 no

a pro-active D reactive

Ginformation

$\square$ facilitation

$\square$ active role

$\square$ other actors

\section{Check list Roerdalen}

$\square$ yes $\square$ no

a yes 0 no

$\square$ yes $\square$ no

Dyes a no

Qyes $\mathbf{Q}$ no

a pro-active a reactive
Dinformation

G facilitation money available, did nôt want to participate in health committee

$\square$ active role

$\square$ other actors 


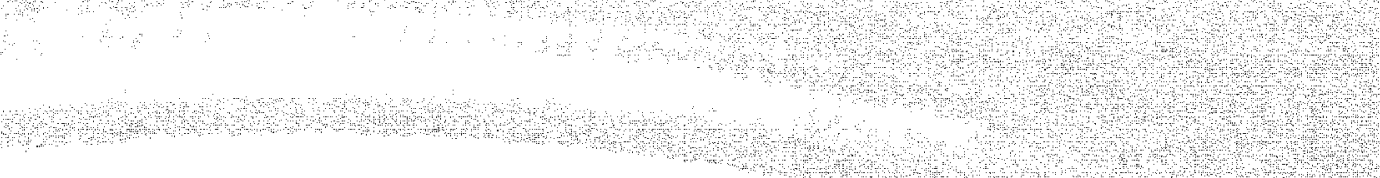

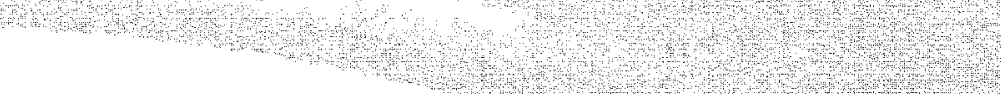

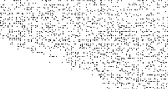

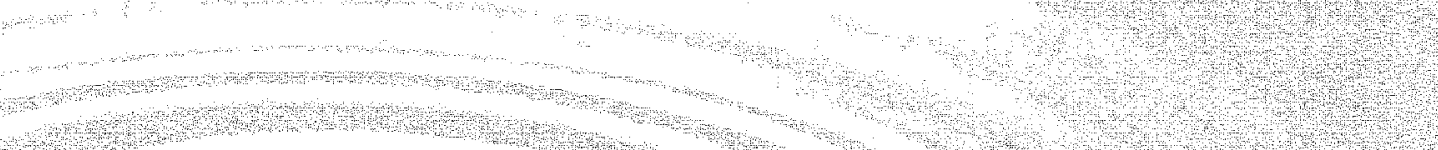

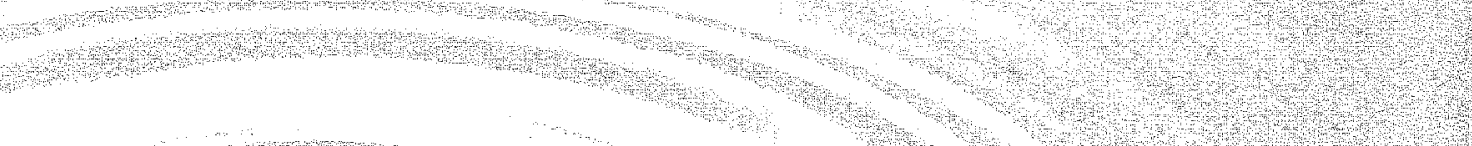

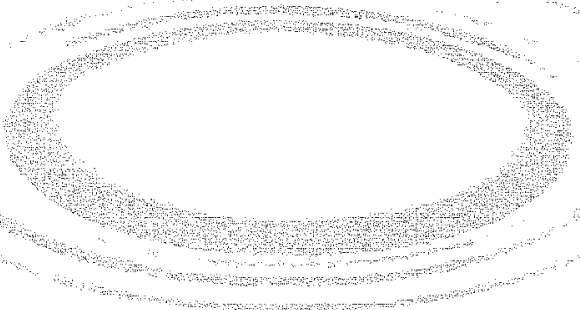

Sal W.1.

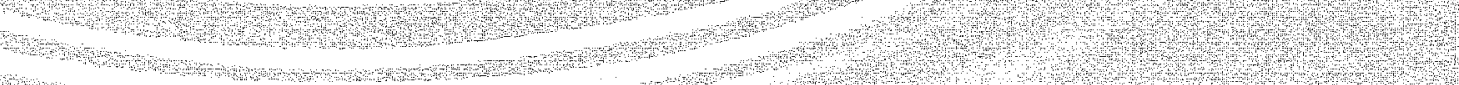
T.

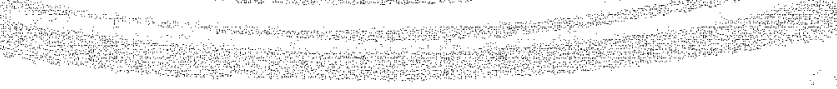

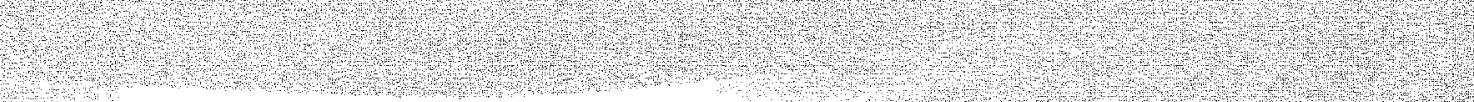

\section{6} Pln 


\section{DANK JE WEL}

Nu het grote werk gedaan is en de tijd aanbreekt voor een nieuwe uitdaging wil ik eerst een aantal mensen bedanken.

Om te beginnen bedank $\mathrm{ik}$ alle respondenten die hun medewerking hebben verleend aan dit onderzoek, in het bijzonder de portefeuillehouders en beleidsmedewerkers volksgezondheid, welzijn en zorg van de veertien gemeenten in Midden Limburg. lk was ook blij met de hulp van dhr. Arie Stas en mevr. Cecile Peeters van de gemeente Horst aan de Maas en mijn oud collega uit de zorg dhr. Hans Vestjens die me geholpen hebben met de jaarlijkse pre-testen. Verder een dankjewel voor de mensen die hand- en spandiensten voor me hebben verricht: Afra Hopman, Hélène van den Nieuwenhoff, Davy Cuppens, Ciska Hiemstra, Marieke Sijbers en Stefan Sels.

Dan bedanik ik mijn collega's. Allereerst de collega's aan de capaciteitsgroep GVO, jullie waren ondanks mijn geringe aanwezigheid een stimulans voor me. André Meijer van de capaciteitsgroep BEOZ bedank ik hartelijk voor alle afspraken in zijn balboekje. Vervolgens bedank ik de mensen van de afdeling gezondheidsbevordering aan de GGD-NML. Jullie gaven me het gevoel ook bij het team te horen. Dat was zeker in de eerste jaren van het onderzoek erg belangrijk voor me. Ik dank heel in het bijzonder Angélique van de Kar die aan de wieg stond van dit onderzoek en die me tot aan het einde toe heeft gesteund.

Een héél groot dankjewel is bestemd voor miln promotores. $1 \mathrm{k}$ was gezegend met drie promotores die me ieder op hun heel eigen wijze hebben geïnspireerd. Nanne, je noemt jezelf 'een harde jongen in de wetenschap, een positivistische empirist'. Bij de start gaf je me het voordeel van de twijfel omdat je nieuwsgierig was naar de betekenis van dit type onderzoek voor gezondheidsbevordering. Na het vertrek van Evelyne uit Maastricht werd ons contact intensiever en volgde een lange rij gesprekken met kritische reflecties, goede raad en vertrouwen. Je bleek zo hard niet te zijn. Evelyne, jij was degene die me van meet af aan inspireerde met je visie op en ideeën over gezondheidsbevordering in de breedst mogelijke betekenis. De bezoeken met Ellis aan de grote werktafel in je huiskamer in Denemarken waren een groot genot, niet in het minst om de vurige gesprekken over 'de wetesjap' en ál zijn wetenswaardigheden. Patrick, jij kwam halverwege de rit bij het team. Je maakte me wegwijs in de netwerkanalyse en wist bovendien juist die vragen te stellen die het onderzoek nog meer richting gaven. De vleug Belgische hartelijkheid was daarbij zeer aangenaam.

Hoewel niet erg gebruikelijk in de familie is een diep gemeend dankjewel gericht aan mijn ouders. Jullie stimuleerden me als klein kind om 'te leren' en later om gewoon stug door te werken. Verder ben ik blij met mijn centrale positie in het familienetwerk.

Tenslotte voor mijn mannen Peter, Gydo en Nieis. Jullie lieten me gelukkig afstand nemen van studie en onderzoek. Ik dank jullie uit de grond van mijn hart, jullie halen het beste in me boven.

Marjan 
as

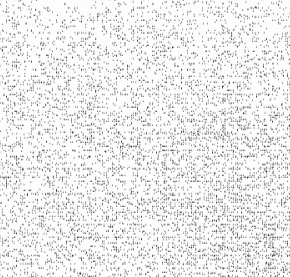

Pै।

$+3$

404

$4+2+?+?+?$

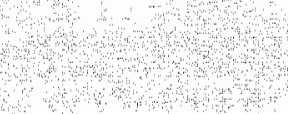

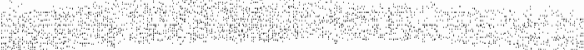

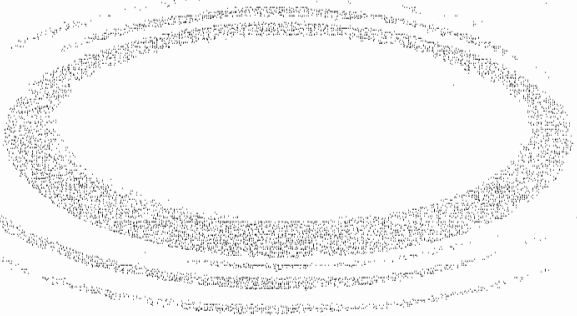

Ant

a

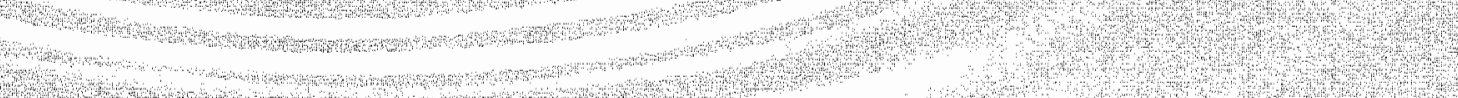

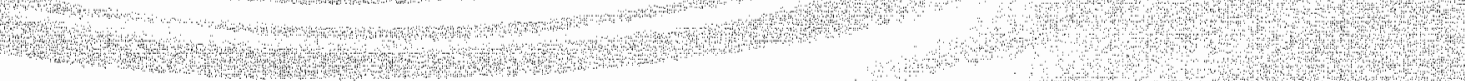

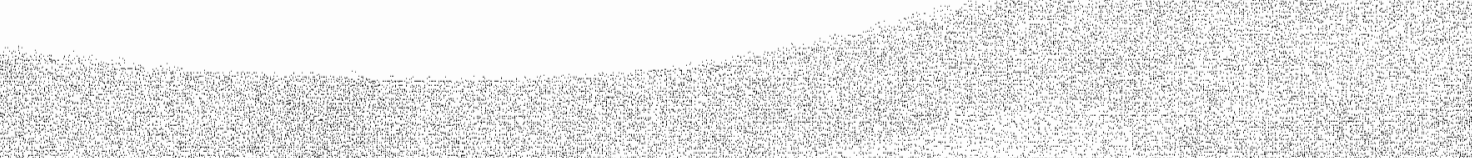

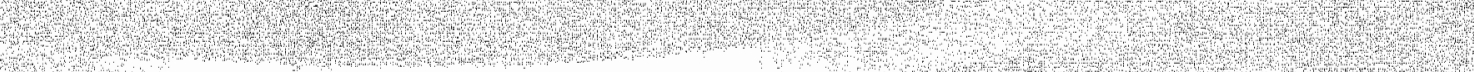

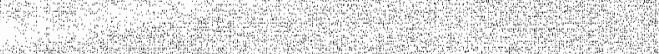




\section{ABOUT THE AUTHOR}

Marjan Hoeijmakers was bom on May 15, 1960 in the village of Horst, in the Dutch province of Limburg. In 1978 she received her secondary school diploma at the Boschveld College in Venray. That same year, she started her higher professional training in nursing at the Gezondheidszorg Academie in Sittard, where she graduated in 1982. Immediately after graduation, she started working as a community and home care nurse in three villages in the northern part of Limburg, where she remained until 1986. She continued this wide-ranging work for another two years in the area around the town of Maastricht. After intensive preparations, Marjan started to work in the tropics in 1988. For three years, she was a technical assistant for SNV (Netherlands Development Organisation] in Burkina Faso, at the department of mother and child care of the Direction. Provinciale de la Santé de la Sissili. From 1992 to early 1995, she was back in the Netherlands and enjoyed motherhood in combination with some activities in the care and development sector. Then the family moved to Uganda. Besides caring for her family and teaching her oldest son she became involved in the care for AIDS patients and health education. She became coordinator of a small AIDS programme at the Kasese Diocese, until she was forced to leave the country due to rebel activities. This abrupt change in September 1997 brought her to the Faculty of Health Sciences at Maastricht University, where she enrolled in the programme called Health Education and Health Promotion. During her studies, she worked as a hame care nurse in the night care for chronically and terminally ill patients. She graduated in 2000 and continued right away with the PhD project described in this thesis, at the department of Heaith Education and Health Promotion of Maastricht University. 
In network analysis, the circles represent the centrality of actors in a network.

In addition, the circles symbolise what you see when you throw a stone into a quiet pond - in this case by introducing local health policy. At the time of the action, it is impossible to predict the scope of the effect.

What we tried to identify in the four municipalities we investigated was the driving force behind the development of local health policy; this is symbolised in this figure by the vortex.

In netwerkanalyse geven kringen de centraliteit van de actoren in het netwerk aan.

Tevens symboliseren de kringen het effect dat optreedt als je een voorwerp in stil water laat vallen ... de introductie van lokaal gezondheidsbeleid ... De reikwijdte van dit effect is op dat zelfde moment nog onbekend.

In de onderzochte gemeenten waren we op zoek naar de stuwende kracht in de vorming van lokaal gezondheidsbeleid. Dit wordt gesymbollseerd door de draaikolk. 